\title{
MIGRATION CONTROL AND ACCESS TO WELFARE
}

THE PRECARIOUS INCLUSION OF IRREGULAR MIGRANTS IN NORWAY

Marry-Anne Karlsen
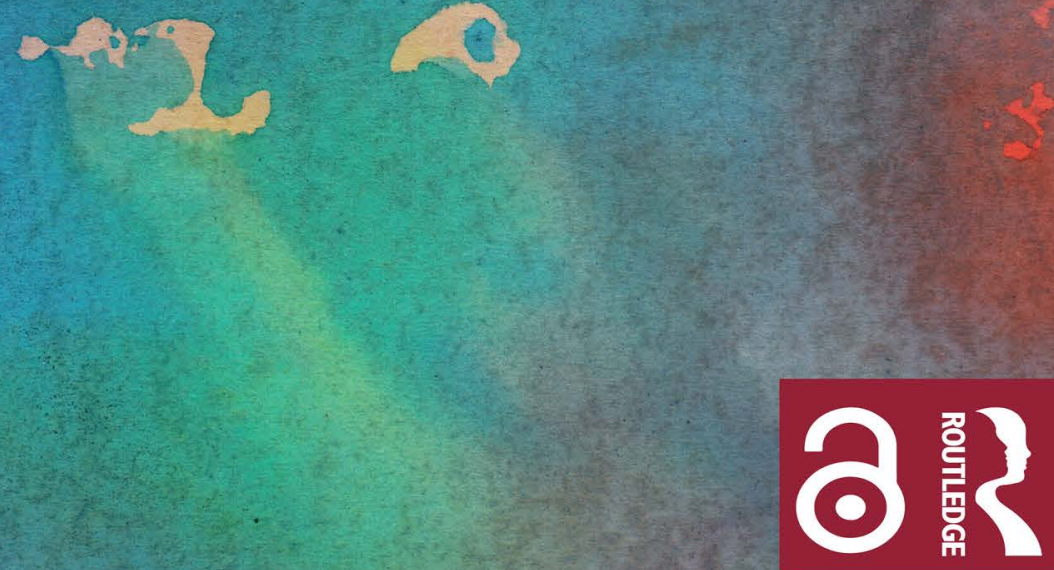


\section{Migration Control and Access to Welfare}

Over the past decades, European states have increasingly limited irregular migrants' access to welfare services as a tool for migration control. Still, irregular migrants tend to have access to certain basic services, although frequently of a subordinate, arbitrary, and unstable kind. Drawing on in-depth ethnographic fieldwork conducted in Norway, this book sheds light on ambiguities in the state's response to irregular migration that simultaneously cut through law, policy, and practice. Carefully examining the complex interplay between the geopolitical management of territory and the biopolitical management of populations, the book argues that irregularised migrants should be understood as precariously included in the welfare state rather than simply excluded. The notion of precarious inclusion highlights the insecure and unpredictable nature of the inclusive practises, underscoring how limited access to welfare does not necessarily contradict restrictive migration policies. Taking the situated encounters between irregularised migrants and service providers as its starting point for exploring broader questions of state sovereignty, biopolitics, and borders, Migration Control and Access to Welfare offers insightful analyses of the role of life, territory, and temporality in contemporary politics. As such, it will appeal to scholars of migration and border studies, gender research, social anthropology, geography, and sociology.

Marry-Anne Karlsen is Researcher at the Centre for Women's and Gender Research, University of Bergen, Norway. 


\section{On Edge: Ethnographies and Theories of Threshold Phenomena}

Series Editors:

Mark Graham is Head of the Department of Social Anthropology at the University of Stockholm, Sweden. He is the author of Anthropological Explorations in Queer Theory.

Elisabeth Lund Engebretsen is Senior Lecturer at the Centre for Gender Research, University of Oslo, Norway. She is the author of Queer Women in Urban China: An Ethnography and co-editor of Queer/Tongzhi China: New Perspectives on Research, Activism and Media Cultures.

This series seeks to explore the circumstances that compel subjects, life-forms, and material things to reimagine, redefine and reorder their existence at the edge of experience and social orders. Concerned with the ever-present but often unarticulated doubt embedded in everyday life and based on a metaphysics of emergence, novelty and creativity as forces in their own right, it welcomes anthropological and trans-disciplinary studies of transformations and threshold phenomena, such as crises, disasters and catastrophes, deaths and births, sexualities, rituals of transition, and social movements.

With attention to phenomena that lie beyond the reach of everyday experience, whether these be life forms such as bacteria, material processes such as rusting, or the uncanny dimensions of the cultural and social, On Edge: Ethnographies and Theories of Threshold Phenomena encourages studies that develop innovative methodologies, including those informed by post-humanist perspectives, and seeks to make space for inventive and experimental projects.

Titles in the Series:

\section{Impossible Refuge}

The Control and Constraint of Refugee Futures

Georgina Ramsay

\section{Migration Control and Access to Welfare}

The Precarious Inclusion of Irregular Migrants in Norway

Marry-Anne Karlsen

For more information about this series, please visit: www.routledge.com/ On-Edge-Ethnographies-and-Theories-of-Threshold-Phenomena/book-series/ ASHSER 1447 


\section{Migration Control and Access to Welfare}

The Precarious Inclusion of Irregular Migrants in Norway

\section{Marry-Anne Karlsen}

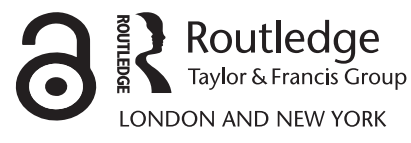


First published 2021

by Routledge

2 Park Square, Milton Park, Abingdon, Oxon OX14 4RN

and by Routledge

605 Third Avenue, New York, NY 10158

Routledge is an imprint of the Taylor \& Francis Group, an informa business

(C) 2021 Marry-Anne Karlsen

The right of Marry-Anne Karlsen to be identified as author of this work has been asserted by her in accordance with sections 77 and 78 of the Copyright, Designs and Patents Act 1988.

The Open Access version of this book, available at www.taylorfrancis. com, has been made available under a Creative Commons Attribution-Non Commercial-No Derivatives 4.0 license.

Trademark notice: Product or corporate names may be trademarks or registered trademarks, and are used only for identification and explanation without intent to infringe.

British Library Cataloguing-in-Publication Data

A catalogue record for this book is available from the British Library

Library of Congress Cataloging-in-Publication Data

Names: Karlsen, Marry-Anne, author.

Title: Migration control and access to welfare : the precarious inclusion of irregular migrants in Norway / Marry-Anne Karlsen.

Description: 1 Edition. | New York : Routledge, 2021. | Series: On edge: ethnographies and theories of threshold phenomena | Includes bibliographical references and index.

Identifiers: LCCN 2021008577 (print) | LCCN 2021008578 (ebook) | ISBN 9780367742133 (hardback) | ISBN 9780367742164 (paperback)| ISBN 9781003156598 (ebook)

Subjects: LCSH: Illegal aliens_-Government policy—Norway. | Norway-Emigration and immigration - Government policy. | Norway-Social policy_21st century. | Public welfare-Norway. | Welfare recipients-Norway.

Classification: LCC JV8252 .K37 2021 (print) | LCC JV8252 (ebook) | DDC 362.89/912056109481—dc23

LC record available at https://lccn.loc.gov/2021008577

LC ebook record available at https://lccn.loc.gov/2021008578

ISBN: 978-0-367-74213-3 (hbk)

ISBN: 978-0-367-74216-4 (pbk)

ISBN: 978-1-003-15659-8 (ebk)

DOI: $10.4324 / 9781003156598$

Typeset in Times New Roman by Apex CoVantage, LLC 


\section{Contents}

Acknowledgements vi

Introduction 1

\section{PART I}

Producing precarity

1 Exceptional care 25

2 Moral bordering 48

PART II

$\begin{array}{ll}\text { Blurred borders } & 67\end{array}$

3 Healthcare providers as petty sovereigns 69

4 Materialising and negotiating borders through administrative practices

\section{PART III}

Temporal tensions

5 Healthcare through the temporal lens of migration control

References 


\section{Acknowledgements}

This book was made possible by the support of a number of people to whom I will be forever grateful. Most of all, I would like to thank the people who shared their time and experiences with me during fieldwork. Thank you for your willingness to speak with me and help me learn, and to those of you I came to know over time, for letting me into your lives. I also want to thank the healthcare centre for undocumented migrants in Oslo, the Robin Hood house in Bergen, and Mennesker i Limbo in Oslo, for welcoming me when I did important parts of my fieldwork.

The book builds mainly on my doctoral research, which was part of the interdisciplinary research project Provision of Welfare to Irregular Migrants (PROVIR). It also draws on insight from my postdoctoral research conducted as part of the multidisciplinary project Waiting for an Uncertain Future: The Temporalities of Irregular Migration (WAIT), which provided me with the opportunity to revisit the field and extend my ethnographic research amongst irregularised migrants in Norway. Both projects were generously funded by the Research Council of Norway (RCN) through the programmes VAM (PROVIR) and SAMKUL (WAIT). I thank the RCN and the University of Bergen (UiB) for supporting my research and for providing financial support to make this book open access.

I am profoundly grateful to Christine M. Jacobsen, my supervisor, mentor, and project leader of both PROVIR and WAIT. Your always critical eye, constructive comments, encouragements, and guidance in the academic world have been invaluable. Thanks also go to Knut Hidle, my co-supervisor, for your generous support and enthusiasm.

It has been a privilege to be part of two highly intellectually stimulating interdisciplinary projects. I particularly want to acknowledge the contributions of the core group of researchers in PROVIR in developing my main argument on precarious inclusion, which, in addition to Jacobsen, consisted of Karl Harald Søvig, Synnøve Bendixsen, Andrea Süssman, and Njål Wang Andersen. I would also like to thank the master's-level students who were part of the project: Regine Karlsen, Faustin Gasana, Silje Thowsen, Laila Dawn Ljosdal, and Siri Knapskog, and all the network partners and others who generously provided input and engaged in discussions on irregularised migrants and welfare in a series of seminars, workshops, and conferences organised by the project. I want to thank in particular Nicholas De Genova, Heide Castañeda, Andrew Lattas, Shahram Khosravi, 
Bridget Anderson, Mette Anderson, Henriette Sinding Aasen, Milena Chimienti, Ursula Karl-Trummer, Gregor Noll, Sébastien Chauvin, Nando Sigona, Elaine Chase, Miriam Ticktin, and Linda Bosniak. I would also like to express my gratitude to Christina Brux Mburu for our many conversations during fieldwork and Halvar A. Kjærre for inspiring discussions and helpful comments during the final stages of my PhD thesis. Particularly heartfelt thanks to Kari Anne Drangsland for your encouragement, conversations, and comments throughout the process of writing the $\mathrm{PhD}$ thesis and the book.

This research has also benefitted from the support I have received from the different institutions and academic communities I have been affiliated with during this process: Uni Research Rokkansenteret (now NORCE), Bergen International Migration And Ethnic Relations Research Unit (IMER Bergen), and the Department of Social Anthropology at the University of Bergen, each of which provided me with a generous and stimulating academic environment during my $\mathrm{PhD}$ career, and the Centre for Women's and Gender Research at the University of Bergen, where I have been fortunate to be a postdoctoral fellow. During my PhD training, I also had the opportunity to spend five months at the Centre on Migration, Policy and Society (COMPAS), Oxford University. A special thanks to Bridget Anderson, Sarah Spencer, and Jonathan Price for good discussions and for coorganising a workshop at COMPAS on precarious migrants and access to welfare.

Furthermore, I received valuable feedback on a shortened version of the main argument during an invited seminar I gave at the Center for Race \& Gender, University of California, Berkeley (2018). Warm thanks to Leti Volpp, who invited me, and Cybelle Fox, my discussant, for engaged and inspiring discussions. Early ideas and different portions of the manuscript were presented at EASA workshop 'At Risk in Europe: Irregular Migrants Facing and Circumventing Uncertainty', Nanterre University (2012); the conference 'Illegality Regimes. Mapping the Law of Irregular Migration', VU University of Amsterdam (2013); Nordic Migration Research Conference workshops: Precariat, Contestation and Agency, Copenhagen University (2014); and Configurations of Migration Control, University of Oslo (2016), and at the Conference on Migration, Irregularisation and Activism: Challenging Contemporary Border Regimes, Racism and Subordination, Malmö University (2016). I thank the organisers and participants of these events for engaged discussions and particularly Sébastien Chauvin and Blanca GarcésMascareñas for being constructive discussants to my paper in Amsterdam, and Ruben Anderson in Oslo. Chapter 3 draws on material also published in Karlsen, M-A (2016), 'Migration control and migrant children's access to healthcare' in Thomas, F. (ed.) Handbook of Migration and Health. Edward Elgar Publishing Ltd, pp. 134-157. Portions of Chapters 1 and 2 appear in Karlsen, M-A (2018) 'The limits of egalitarianism: Irregular migration and the Norwegian welfare state', in Bendixsen, S, Bringslid, M.B., and Vike, H, (eds.) Egalitarianism in Scandinavia. Historical and Contemporary Perspectives, pp. 223-243. Palgrave Macmillan, Cham.

I am grateful to the series editors, Elisabeth Lund Engebretsen and Mark Graham, for seeing the potential of this book; the anonymous reviewer for thoughtful 
comments; and to Neil Jordan and Alice Salt at Routledge for seeing the book through.

I am also deeply indebted to my friends for teaching me the value of critical thinking and political activism together; my housemates for their encouragement and patience; and last, but not least, I want to thank my family, and particularly my parents, Åge and Britt, for always being loving and supportive. 


\section{Introduction}

\section{Setting the stage}

In December 2014 the Norwegian Broadcasting Corporation (NRK) told the story of Louila Tuban, a 31-one-year-old woman originally from the Philippines who came to Norway in 2010 as an au pair. Shortly after arrival, she suffered from acute renal failure. She received lifesaving treatment at a local hospital. However, no longer able to work as an au pair, she lost the grounds for her legal stay, but remained in the country. In Norway, patients with the same condition as Louila would normally be scheduled for a kidney transplant with a median waiting time of 40 days. Louila, however, was only offered dialysis, up to five times a week. This kept her alive, but after nearly five years on dialysis treatment, her doctors began to worry that her heart could not take the tough treatment anymore. Based on these medical considerations, she was granted a temporary residence permit of one year to receive a transplant. When it expired, she would again be required to leave the country. Yet, according to the transplant-performing hospital's internal guidelines, only patients with a permanent residence permit would be eligible on the grounds that a transplant would require lifelong medication and follow-up. Shortly after Louila's story was broadcasted, the hospital nevertheless decided to depart from these guidelines to allow her a kidney transplant, choosing to believe that the 'immigration authorities would listen to a reasonable medical argument' and grant her permanent residence (Nilsen et al., 2014). In February 2015, Louila had the kidney transplant. By then her temporary permit had expired and her future status remained uncertain.

I first became aware of Louila Tuban's case when I was asked by NRK to comment on it in one of their follow-up pieces. Her case aptly highlighted many of the themes emerging in my research on the provision of welfare to the so-called irregular migrants in Norway. For instance, her case clearly showed the ethical and practical dilemmas service providers face when the criterion of inclusion becomes legal status rather than need of treatment. Her case also draws attention to ambiguities in the state's response to irregular migration, arising from the interaction and tension between welfare policy and entry control. More fundamentally, though, Louila Tuban's case raises a series of urgent and troubling questions about state sovereignty and the valorisation of life in times of migration: To what 


\section{Introduction}

extent can those excluded from membership in the nation-state, but who are still present within its territorial borders, be lives to be cared for? How is the decision to care for certain lives made? What role do frontline service providers play in (re) producing, defining, and negotiating state borders?

In this book, I will address these questions through an ethnographic exploration of the Norwegian welfare state's attempts to deal with irregularised migrants' basic needs for food, shelter, and healthcare. Norway, with its specific combination of a comprehensive and ambitious welfare state, humanitarian image, and rather strict immigration policies, provides a particularly interesting, although not unique, context for examining the interplay between the geopolitical management of territory and the biopolitical management of populations.

\section{Bordering care}

The term 'irregular migrant' generally refers to migrants who enter or dwell on state territory without formal authorisation. Within the global system of territorially sovereign states, the irregular migrant has become an increasingly problematic figure as $\mathrm{s} /$ he ruptures the neat connections between territory and sovereignty, presence and membership, outside and inside, upon which this system rests. This rupture is very much evident in recent state efforts in Norway to distinguish between those lives, within state borders, that qualify for care and those that do not. This rupture also makes irregular migration an interesting lens through which to explore questions of state sovereignty and practices of care.

According to the Universal Declaration of Human Rights of 1948, everyone has the right to 'a standard of living adequate for the health and well-being of himself and of his family, including food, clothing, housing and medical care and necessary social services'. Yet, in today's globalised world, the system of sovereign nation-states and the sovereign prerogative of denying membership still plays a key role in determining how basic social protection is distributed. As the present system of nation-states, and international law, builds on the idea that everyone should belong to a particular state, it follows that a person's basic rights should be guaranteed by that state. In this sense, the system exempts states from the responsibility of caring for those not deemed to belong because their right to be protected and cared for lies 'somewhere else' irrespective of the major inequalities that exist between states in terms of wealth and stability. Although certain concessions are made through international conventions for asylum seekers and those deemed to fulfil the requirements for refugee status, states' right to control admission to state territory, including which and how many of the refugees are to be accepted, is generally recognised.

The question of what obligations states owe to those whose presence is not legally accepted is more controversial (Bosniak, 2006). While irregular migrants are theoretically entitled to internationally guaranteed standards of treatment with respect to human rights, their formal entitlements and effective access to basic social services have been shown to vary between different receiving states, and 
in many cases entitlements have been severely restricted (Karl-Trummer et al., 2009). Over the past decades, several European countries, including Norway, have implemented measures that limit irregular migrants' access to services as a way of compelling them to leave on their own. In the process, 'illegal migrants' as a category have increasingly been legally and discursively demarcated from asylum seekers and 'legal' migrants, as well as formal citizens. Nevertheless, irregular migrants still tend to have access to certain basic welfare provisions. These include, to various degrees, access to healthcare, shelter, education, and workplace protection. These services may be provided by state institutions, municipalities, or NGOs sanctioned or even funded by the state. State approaches to its irregular population are as such often more ambivalent than commonly assumed. The aim of this book is to explore what is at stake in these limited practices of inclusion.

\section{The trouble with inclusion}

So far, most research on irregular migration has focused on the problem of exclusion, highlighting repressive control practices. Indeed, much scholarship on irregular migration builds on the assumption that irregular migrants by definition are excluded members of society (De Graauw, 2014). For example, many studies have been influenced by Hannah Arendt's (1968) famous notion of 'the right to have rights', understood as the right to membership in a political community. As irregular migrants are deprived of this fundamental right, they are understood as 'absolutely rightless' even though they may have access to some civic and social rights (Parekh, 2004). Another and more recent source of inspiration is the work of Giorgio Agamben (1998) on sovereignty and bare life. Agamben locates sovereignty, not in the rule of law in a territory, as it has been understood traditionally, but in a decision on the (non-)value of life. Drawing on his work, several studies have approached irregular migrants as a modern example of a bare life unprotected by law and exposed to arbitrary state violence (Rajaram and Grundy-Warr, 2004; Darling, 2009; Kjærre, 2010).

In this theoretical context, it may seem counterintuitive to explore practices of inclusion oriented towards irregular migrants. However, scholars have begun increasingly to challenge the focus on irregular migrants as simply a figure of the excluded, instead emphasising the conditionality of legal status and social and institutional processes of boundary making (Goldring and Landolt, 2012; Gonzales and Sigona, 2017). Stressing the multiple dimensions of the institutions of citizenship, scholars have for example suggested that irregular migrants can develop other, more informal, forms of membership in the communities in which they live (Coutin, 2000) and challenge their political exclusion by acting as citizens (Isin and Nielsen, 2008). Studies on the so-called bureaucratic incorporation have also pointed to professional and moral concerns of street-level bureaucrats to explain irregular migrants' inclusion in a wide range of institutional arenas, including healthcare (Marrow, 2012; Van der Leun, 2006). While this literature has tended to focus on informal mechanisms of inclusion, there are also scholars who have 


\section{Introduction}

started to examine more formal circuits of incorporation that stem from a tension between immigration law and other areas of law such as labour and welfare laws (Gleeson, 2016; Chauvin and Garcés-Mascareñas, 2012; Abrego, 2011; Gonzales, 2011).

In this book, I seek to further nuance discussions and understandings of irregular migrants' inclusion/exclusion by interrogating the complex interplay between welfare policy and migration control in Norway. While the various explorations of irregular migrants' exclusion and limited inclusion mentioned so far have been highly perceptive, there is often an underlying assumption that inclusion is a straightforward solution to the injustice caused by exclusion. As such, they openly or implicitly evoke the progressivist assumptions embedded in the notion of citizenship and rights, thus risking to underplay the power relations associated with it. For example, while social participation and informal inclusion may importantly challenge migrants' political exclusion, political exclusion still shapes their inclusion. As cautioned by De Genova (2013), incorporation in the labour market tends to take the form of 'inclusion through illegalisation'. It is the migrants' illegality that makes them desirable as cheap and flexible labour. Formal inclusion through granting social rights to the politically excluded also has it limits as irregular migrants still risk deportation when exercising these rights (Noll, 2010).

My contention is that irregular migrants' exclusion/inclusion from welfare should not necessarily be understood as contradictory processes, nor just in terms of a continuum, or a hierarchy. It is the simultaneity of practices of inclusion/exclusion that produces irregular migrants' precarious position in society. The stakes are both analytical and theoretical, which I aim to unpack throughout this book. Yet, the stakes are also ethical and political, and it is necessary to reflect on this before continuing. Critically analysing current inclusive practices towards irregular migrants is, as importantly noted by Ticktin (2011), not without its own dangers as it may risk undermining the limited support structures available to them. This is particularly so in a time characterised by a gradual hardening of the political discourse about migration. For many of the irregular migrants in my study, the limited and substandard access to services that they received was of vital importance, and the significance of this should not be underestimated. Nevertheless, I agree with researchers such as Fassin (2012) and Ticktin (2011), who have insisted on the importance of scrutinising what is at stake in inclusive practices, particularly if current practices are complicit in furthering structural inequalities. Moreover, I believe that it is critical that neither the social scientific gaze nor our political imagination is constrained by the apparent naturalness and givenness of a world divided into nation-states. Irregular migration is a product of the nation-state system, global inequality, and increasingly strict immigration law. While regularisation, deportation, and rights without status are pragmatic approaches within the existing political and economic order to the presence of irregular migrants, they do not constitute a solution as they do not challenge or end the socio-legal production of migrant illegality. My concern in this book, though, is not the normative ought to-question, of how irregular migration should be dealt with, but the how of the ways state sovereignty operates. 


\section{Precarious inclusion as strategy of government}

In the book, I propose that irregularised migrants in Norway should be understood as precariously included in the welfare state, rather than simply excluded. The notion of precarious inclusion is an attempt to capture what I see as a complex interplay between irregular migrants' formal exclusion from the nation-state and their (limited) access to certain services aimed at ensuring their bodily survival. The term refers, on the one hand, to how the limited inclusive practices address the precariousness of migrants' life through a minimalist management of survival and, on the other hand, to how the inclusion itself is precarious, that is, insecure and unpredictable. The inclusive practices thus protect exposed life and expose it at the same time.

I understand precarious inclusion furthermore as a strategy of government in a Foucauldian sense, that is, as both intentional and non-subjective. According to Foucault (1979, 94-95), a strategy of government is intentional because no power is exercised without a series of aims and objectives. These are often highly explicit at the local level. Yet, it is also non-subjective because the overall outcome cannot be understood as resulting from the choice or decision of an individual or a group. Subsequently, the strategy can only be known through the realm of its effects (Dean, 2010, 269). As a strategy of government, precarious inclusion cannot therefore simply be read out of law, government policy documents, or statements but involves an exploration of practices and effects.

The notion of precarious inclusion stems in part from field observations. In Norway, irregular migrants were not completely excluded from access to welfare, yet they were neither included on equal grounds nor did they receive the same standard of welfare. The care offered tended to be of an arbitrary and unstable kind, as I will detail in depth in the following ethnographic chapters. The notion is also informed by a particular theoretical discussion about sovereignty and biopolitics inspired by the work of Agamben in his Homo Sacer-project. ${ }^{1}$ This work by Agamben, as previously mentioned, has become a touchstone of many of the current discussions on irregular migration and their relation to the state in which they live. Yet the complexities and subtleness of his arguments are often not fully recognised. Particularly his concept of bare life has been rather simplistically reduced to a mere figure of abject exclusion (De Genova, 2012). A major strength of Agamben's work, as I see it, is that it encourages a questioning of the concepts that are so often taken for granted in contemporary politics, such as national sovereignty, rule of law, and human rights. Furthermore, of importance for this book, his perspective intersects juridical power with biopolitics in a way that offers ways of rethinking what and where state borders are, and as such the ways in which the regulation of the population and that of state territory are intimately connected.

Although Agamben's work serves as a point of departure, my interest is notably different. Agamben offers a compelling metaphysical critique of the Western political tradition and its core concepts, whereas I hope to show how state sovereignty as a practice in everyday situations involves complex and simultaneous 


\section{Introduction}

processes of inclusion and exclusion. In exploring the interplay between practices of care and the production and maintenance of state borders, I critically engage Agamben's retheorisation of sovereignty to see how it can inform an ethnographic enquiry of state sovereignty, as well as how the knowledge produced by ethnography might advance and nuance the discussions. The notion of precarious inclusion is, in this sense, an attempt to move on, conceptually, from Agamben's inclusive exclusion through which irregular migrants can be analysed as the state's constitutive outside, to address how states try to govern irregular migration through the intersection of exceptional measures and the normal workings of state institutions. As such, I am concerned with less spectacular expression of sovereign exceptionalism than those generally explored in the literature inspired by Agamben.

Before introducing the study and the Norwegian context, I will give a brief outline of the theoretical discussions that guide the analysis in the subsequent chapters and how they inform my understanding and usage of the notion of precarious inclusion. My aim is not to give a full overview or try to overcome all the theoretical contradictions that exist in these theoretical discussions, but to highlight some analytical perspectives and tensions that contribute to the following analyses. There are particularly three interrelated themes in the discussions that I focus on, and which lie in the background for the argument developed, and which structure the book. These are the role of life, territory, and temporality in contemporary politics.

\section{The place of life in contemporary configurations of power}

One of the main questions explored in this book, as previously stated, is the extent to which, and the ways in which, people excluded from membership in the nation-state, but who are still present within its territorial borders, are lives to be cared for. This question raises other related issues such as: What is life? What does it mean to care for lives? The answers to these questions are not necessarily straightforward. In the case of Louila Tuban, for example, it is possible to see how her physical body was kept alive through dialysis, although she was not initially healed, nor was she allowed to work, study, or marry. The irregularised migrants that I met during fieldwork frequently used the disparity between being 'alive' and 'living' to explain their experiences. By this, they were referring to the state of biological survival while at the same time they were not allowed to fulfil their potential in ways they found meaningful.

The question 'what is life' and the place life holds in contemporary politics have been the subject of considerable academic discussions. One of the main influences has been the work of Foucault on biopolitics (Foucault et al., 2003; Foucault et al., 2007). To Foucault, biopolitics emerged in Western societies in the 18th century, representing a shift whereby the modern state started to gain its legitimacy from the protection of life (biopower) rather than the threat of death (sovereign power). Although this shift involved increasing state intervention in human life, it also resulted, according to Foucault, in life itself becoming the locus of right claims in liberal societies (Foucault, 1998, 144). With the notion 
of biopolitics, Foucault thus identifies the emergence of a contemporary rights discourse centred on claims about the right to health, happiness, and satisfaction of needs rather than protection from the sovereign (Wells, 2011). Such rights claims are articulated both in the UN declaration of Human Rights and the welfare states' expansions of social rights. Hence, the life that came to be cared for in the biopolitical welfare states that developed during the 20th century, including the Norwegian welfare state, was the rights-bearing subject.

The question of whether irregular migrants can be understood, and cared for, as rights-bearing subjects has been a central, and contested, topic in the literature on irregular migrants (Bosniak, 2007; Carens, 2008). Yet, in a Foucauldian perspective, rights are not a simple benefit, but also function as an administrative and regulatory tool. The lives that are cared for are therefore also lives that are governed. This perspective opens for the possibility of analysing the relation of irregular migrants to the state in which they live, not only in terms of inclusion or exclusion from rights but also according to how access to welfare is selectively applied as a regulating mechanism.

Agamben in his work on bare life draws on and reformulates Foucault's concept of biopolitics, focusing primarily on its relation to sovereignty. To Agamben (1998), biopolitics is not a distinctively modern form of power, or a separate entity from sovereign power, because sovereign power constitutes and is constituted by a decision on life from the very beginning. Agamben thus argues that Western politics, including its emancipatory resources such as rule of law, and human and citizens' rights, have been flawed since Aristotle because they are predicated on dividing the human into bios (the manner in which life is lived) and $z o \bar{e}$ (the simple fact of life common to all living beings) (Whyte, 2013). In the Greek polis, for example, one needed to be qualified beyond simply being alive to participate in political life. Conversely, what Agamben sees as characteristic of modern rule is how supposedly natural life begins to coincide with the political realm, producing a zone of indistinction between bios and zoē, law and life, inclusion and exclusion. What emerges in this zone of indistinction is what Agamben calls bare life, a life that is included in bios through an act of exclusion. Bare life is thus importantly not a category of ontic politics but a product of this abstract division between bios and zoē in Western political thought (Abbott, 2012). Yet, the key political problem of modernity is, according to Agamben $(1998,11)$, how bare life has become both the subject and object of political power, both the place for the organisation of state power and emancipation from it.

As I try to show here, Agamben provides a very distinct lens by which to examine the bodily protection of irregular migrants in Western welfare states from those who would frame it in terms of a (limited) success or failure of human rights, humanitarian values, or ideas of equality and human dignity inherent to the welfare state project. By entwining sovereignty with the state's new role of fostering life, Agamben draws attention to how state violence and care of life are intimately related. Moreover, to structure politics around the demand that the state protect bare life means to Agamben, as Whyte phrases it, 'to sacrifice the possibility that life could be something other than survival' $(2013,71)$. Agamben's identification 
of the fracture between 'natural' and 'political' life in Western political thought, thus, offers an entry point for analysing how provision of basic care to irregular migrants becomes entwined with a form of violence that reduces the value of life to mere subsistence, rather than the killing of life as such.

This perspective also draws attention to the role of practices directed at caring for the survivability of the body in governing irregular migrants. Insightful writing in anthropology on the topic of biopolitics that engages Agamben's work has for example highlighted how humanitarian reason has become an important force in contemporary European politics with particular significance for governing migration. The works of Ticktin $(2011,2016)$ and Fassin $(2012)$ on humanitarian government in France are particularly perceptive. They understand humanitarianism not only as a social field of action defined and administered by NGOs but rather as a moral principle that grants human life absolute priority. Hence, while social welfare fosters citizens of nation-states, humanitarian government targets a universal humanity perceived and united in its suffering or 'bareness' (Ticktin, 2011). Still, as Ticktin (2011) found, even the suffering body, while purportedly universal, requires certain political, historical, and cultural attributes to render it visible and worthy of care. The 'bare' lives that are cared for in humanitarian government are thus those recognised as 'victims' rather than bearers of rights.

Although Agamben's work offers a compelling lens, it also has its limits, as Ticktin's point shows. If biopolitics increasingly means reducing human life to a question of survival and necessities, how is it possible to explain the gradation of care offered to various lives on state territory, and how does this enable or inhibit different life projects? My central interest in this book is not simply to explore how irregular migrants are left legally unprotected but how and in what ways their bodily needs are still addressed by the welfare state despite their exclusion from the nation-state. How is it that an irregular migrant like Louila Tuban is kept alive (but not allowed to study, work, marry, etc.)?

One of the main criticisms of Agamben's work, particularly from black and feminist studies, is that it does not account for how power functions differentially (Butler, 2004; Weheliye, 2014). These scholars highlight the social and historical differentials of gender, race, and class, and their prominence in distinguishing between different values of life. Their critique is an important warning to those who interpret and apply Agamben's work within critical border and migration research. While Agamben's theory may enable evocative descriptions of the violence made possible by a particular legal experience, it does not allow for analysis of how and why certain lives are more exposed to this violence (Whitley, 2017). Also, as Ong (2006) has argued, Agamben's distinction between the protected life of the citizen and the expandable bare life can easily provide a too rigid and simple binary framework for research within the social sciences. Agamben's migration research followers thus risk portraying irregular migrants as a monolithic category that is excluded and outside the law, even when analysed and understood through their inclusive exclusion (i.e. as the state and citizens' constitutive outside or 'other'). 


\section{Governing territory and population}

The precarity of irregular migrants, such as Louila Tuban, not simply is a consequence of the limited support and recognition that they receive but also stems from the fact that their continuing presence on state territory is constantly under threat. Exploring irregular migrants' access to welfare thus also involves addressing the role of territory in contemporary government, and particularly the role the notion of territory plays in valorising and distinguishing between lives.

Control over people's movement across state borders has generally been considered an integral part of state's sovereignty. However, in migration and border studies, scholars have increasingly argued that migration control practices have shifted from more traditional forms of territorial control at the outer edges of the state to a more spatially mobile 'management of populations', focusing on the bodies of people on the move as a site of border policing. According to Coleman $(2012,403)$, the law, or more precisely, the production of legal disenfranchisement, is crucial to this shift from territory to population.

Coleman's point resonates with Foucault's (2003) famous argument that the emergence of biopolitics represented a shift from a 'territorial state' to a 'population state', that is from sovereignty to biopower. Sovereignty is here understood conventionally as the use of law to rule a specific territory. Territory, in this sense, is the foundation of the sovereign authority of the state. Yet, as argued for instance by Gupta (2012), the biopolitical concern with the people generally also presumes a territorial unit whose population is the object of either care or exclusion. Critical geographers engaging with Foucault's work have further criticised the way territory is uncritically understood as a bounded space, arguing instead that it should be approached as the site, medium, and outcome of statecraft (Brenner and Elden, 2009). Territory is, in this sense, a political technology for standardising, homogenising, and disciplining social and material reality, as well as an achievement that requires ongoing work. Territory is, in the context of this book, importantly a mechanism through which someone is customarily recognised as an insider or an outsider (Brighenti, 2010). One central aspect of the increasing misalignment of territorial and legal borders, illustrated by Louila Tuban's case, is, for example, that territorial presence no longer triggers access to legal rights or services typically envisioned as territorially distributed, such as healthcare. When migration control is emergent within states in the form of exclusion from welfare benefits, it tends to be justified in terms of the state's right to regulate entry into its territory (Bosniak, 1991). Hence, territory as an imaginary and legal mechanism distinguishing between insider and outsider marked Louila as an intruder. In Louila's case, healthcare providers' decisions on treatment thus became conditioned by the state's attempt to maintain territorial sovereignty.

The traditional geopolitical imagination of 'container-borders' has, even more than the concept of territory, been subject to re-examination in recent years. Etienne Balibar, for example, has argued that the meaning of the term 'border' is changing profoundly as attempts to preserve the sovereignty of the state are 'dispersed a 
little everywhere' $(2002,71)$. Hence, within border studies, there has been a shift in attention from studying the material and physical dimensionality of borders towards highlighting borders as socio-spatial constructions (Van Houtum et al., 2005), and borders as performed by and through the encounter between various actors (Salter, 2008). In this perspective, restricting access to welfare services is not only a substitute for exclusion at the border but is in itself a border(ing) practice.

Agamben's retheorisation of sovereignty offers further ways to rethink the relations between territory and borders, as far more complex and differentiated than what is portrayed by more traditional notions of sovereignty. For example, his work draws attention to how state sovereign borders are about not only territorial ordering but also biopolitical ordering (Vaughan-Williams, 2009). By reconceptualising the limits of sovereign power in terms of a decision about the (non-)value of life, state sovereign borders are linked to biopolitical decisions pertaining to who belongs to the population to be cared for rather than being understood as continuous linear structures enclosing a political territory. As such, the geographical expansion of borders does not mean that it necessarily materialises everywhere for everyone at all times, but that the attempt to preserve the function of state sovereignty involves a more dynamic delineation on state territory in terms of those who belong and those who do not belong (Weber, 2006). Moreover, this perspective suggests that state borders not only are delocalised but also potentially blurred, as biopolitical and territorial borders are not necessarily coterminous.

\section{The temporalities of power relations}

The importance of temporality to sovereignty and biopolitics has been less explored than the spatial dimensions. Yet, Louila Tuban's case, and the way it developed, clearly illustrates how time matters. For example, as time passed, it became more difficult for the doctors to justify denying her a new kidney and after nearly five years on dialysis, she received the transplant even though her legal situation had not become more predictable. In the following years, she would only receive temporary permits of one year, spaced by intervals without permits. Thus, she continued to live with the uncertainty of whether, and how long, she would be able to remain and receive the vital medical follow-up, as well as restrictions on what she could do while in Norway. Despite her difficult situation, Louila was still, in some ways, fortunate compared to many of the irregularised migrants I met during fieldwork. She had a local support network and a Norwegian fiancé, who was a well-known local musician with a broad network. In the summer of 2017, she finally got the permit that allowed her to settle in Norway.

Louila's case, however, not only illustrates how situations may change over time but also draws attention to the temporalities involved in governing irregular migration. Temporalities are integral to power relations, yet not always in the same ways or with the same implications. I use temporalities in the plural to highlight precisely how different temporalities, and the tension between them, are central to governing irregular migration. Biopolitics, for example, is temporal in that it targets the biological processes of man-as-species. The model of the welfare state 
contributed to structuring and standardising a 'normal' life cycle through attaching formal rules, rights, and obligations to chronological and biological life stages (Pinto, 2016). Yet, it is not simply the individual human taken care of from beginning to end that is the concern of biopolitics but the population over time, within which individual life is just a transitory moment (Braun, 2007). It is the future well-being of the collective social body of the nation-state that is the main concern. Hence, care of life is based or distributed on the basis of not just 'past rights' won but future potentiality (Povinelli, 2011). Concern for the future well-being of the collective body thus contains a mechanism for distinguishing between which lives should be invested in and which lives can be neglected.

Sovereignty as a decision on the exception is temporal, I suggest, in that it imposes a particular temporality, one that accentuates uncertainty and unpredictability for certain lives. While the state of exception has mostly been explored in spatial terms, as 'a piece of territory that is placed outside the normal juridical order' to use Agamben's words (2000b, 40), it can also be approached as a temporal structure of indefinite temporariness, as what was supposed to be a temporary state of emergency is normalised. A state of exception designates further a state of uncertainty in which activities of ordinary life become subsumed with concerns about immediate survival. This provides a particular temporal frame for the administration of care. As noted by Brun (2016), 'there is no future in humanitarianism', referring to how humanitarian action primarily aims for temporary solutions even in protracted situations.

For irregular migrants, time is often conceptualised as indefinite temporariness through concepts such as 'limbo' and 'liminality'. Migrants' lives as such are seen to unfold within a 'timeless present' or 'suspended time' (Griffiths, 2014). As 'normal' rhythms of time and life cycle become disturbed, migrants are thereby no longer seen as 'in-time with others' (Khosravi, 2014). Ramsay (2017, 2019), however, has criticised the tendency within migration scholarship to exceptionalise migrants' time through concepts such as liminality. To place migrants in a different temporal reality from non-migrants, she argues, ignores the ways in which migrants share particular temporal rhythms with other people, and rests on assumptions that the 'normal' life of citizens is necessarily secure and stable. It further embeds an assumption of linearity onto the experiences of migrants' life and implies that the condition of indefinite indeterminacy can be solved by the conferral of legal status. Ramsay (2019) proposes instead a focus on the shared uncertainty of migrants and citizens due to global capitalism and neoliberal restructurings. While I agree with her on the need to challenge simple binaries between migrants and citizens, and how certain frameworks normalise a particular temporal order, I also believe it is imperative to understand how state and market produce uneven temporal relations.

Temporalities are in many ways central to the making of the difference between the state categories of 'migrant' and 'citizen'. Cohen (2015), for example, has shown how citizenship is patrolled through temporal formulas that confer various rights. This importantly shapes migrants' relationship to the state, to the labour market, and to citizens in different ways. Moreover, as argued by Sharma (2014), a differential relationship to time organises and perpetuates inequalities and 


\section{Introduction}

allows for certain forms of interventions into people's life. In Norway, I suggest, the notion that irregularised migrants are only temporarily present is central to the administration of care for this population. Temporalities do play an important role in differentiating within citizenship as well (Anderson, 2019). Similarly, precarious inclusion as a strategy of government is not necessarily exclusive to irregular migrants, although the mechanism of inclusion/exclusion within citizenship may be slightly different from for those excluded from citizenship.

\section{Exploring sovereign practices ethnographically}

The theoretical discussions outlined so far serve as a point of departure to critically examine practices of care, and how they relate to the valorisation of life, social rights, and the inside/outside of the state. An ethnographic approach in this context offers a way to investigate the conditional nature of sovereign practices by providing a disaggregated view of the state. According to Gupta (2012), a disaggregated view makes it possible to understand how unintended outcomes are systematically produced by the friction between branches and levels that make up the state. Norway, which has tended to be characterised as having a strong statist tradition with a consensus-oriented, political-administrative system, also has an administrative system combining partly conflicting principles, values, and mixtures of different control devices, sometimes even located within the same institutions (Lægreid, 2003). As such, ethnography is particularly useful to shed light on how contradicting norms, knowledges, practices, and values assigned to various human categories can produce a range of contingent and ambiguous outcomes through which different degrees of care can be negotiated for the politically excluded. Yet, conducting such research has its own challenges. The following example from my fieldwork illustrates some of these.

Early in my fieldwork, I was conducting an interview with a doctor with whom one of my interlocutors had been in contact. After introducing my study and asking my opening questions, the doctor turned the tables on me by asking, 'How do you know if a person is illegal?' Doctor Lars had been late for our appointment because, as he explained, he had been contacted by another doctor about a patient he had referred and who turned out to be 'illegal'. Doctor Lars, therefore, hoped I could help him clarify this question. ${ }^{2}$ In Doctor Lars' documents, the patient was registered with a regular Norwegian personal identification number. However, the patient, in one of his first appointments with the doctor at the specialist clinic, revealed that he did not have legal residence. As such, he was not entitled to this type of medical care. However, terminating treatment that had already begun could do more damage and could conflict with professional ethical codes and knowledge concerning safe medical conduct. Doctor Lars and the other doctor were therefore in doubt about what they should do. I learned later from Doctor Lars that they eventually decided to end treatment in this case because the information came up in an early session. Had it come up later, the outcome might have been different. ${ }^{3}$

Like Louila Tuban's case, this example touches on many of the central topics in this book: how healthcare providers, whether they like it or not, are becoming 
implicated in migration control; how the configuration and enactment of the border not only is becoming a question of law but is also entangled with professional ethics and medical knowledge; and how irregular migrants' access to healthcare is becoming insecure and negotiated. I bring this episode in here, however, because it also brings up some key methodological and ethical dilemmas when exploring sovereignty ethnographically.

First, it draws attention to the difficulties of doing research involving an elusive and mobile population engaged in behaviour that is illegal from the point of view of the state. Irregular migrants are not easily identifiable to healthcare providers and researchers alike. This was not the only time during my fieldwork that healthcare providers with whom I came into contact asked me this question, and they were often unsure whether they had treated patients that were 'illegal'.

Second, the episode evokes the risk of reifying the category of 'illegals' and thus contributing to the surveillance of already stigmatised individuals when engaging in this type of research. As De Genova has importantly pointed out, 'by constituting undocumented migrants (the people) as an epistemological and ethnographic "object" of study, social scientists, however unwittingly, become agents in an aspect of the everyday production of those migrants' "illegality" - in effect, accomplices to the discursive power of immigration law' $(2002,423)$.

Research on irregular migration is a politically charged field, illustrated by the contested nature of the labels used to describe the migrants. Is the migrant illegal, irregular, undocumented, unauthorised, or something else? The different adjectives used tend to be associated with different political perspectives in polarised debates. 'Irregular' is the term often used in European academic literature because it is seen as more neutral. In approaching Doctor Lars, I did not use the term 'illegal' (ulovlig), but 'irregular' (irregulaer), with 'also referred to as undocumented (papirløs) ${ }^{4}$ and people without legal residence (personer uten lovlig opphold)' in brackets, as 'irregular migrant' was not a known concept in Norway. This episode, however, may serve to illustrate that irrespective of the label used, it remains essentially a legal classification and carries the norm associated with immigration law.

However, De Genova's point just referred to goes beyond terminology. He sees it as 'a central epistemological and conceptual problem, with significant methodological ramifications, ethical implications, and political repercussions' (2002, 423). De Genova thus calls for a shift in attention away from concrete categories of 'illegal' migrants and towards a critical examination of how migrant 'illegality' is legally and politically produced in various contexts and over time. Here, he cites Susan B. Coutin's research on Salvadoran immigrants' legalisation struggles as a model. She describes her approach as 'an ethnography of a legal process rather than of a particular group of people' $(2003,23)$. Along the same line, this book is not an exploration of a marginalised and excluded group but an anthropological exploration of state sovereignty. Nevertheless, the ethical dilemmas of representation are still heavily present as it engages with a politically controversial topic. Even by questioning and denaturalising the state's production of illegality, when conducting ethnography, one is confronted with choices about what to reveal in terms of behaviour, practices, and actions that are controversial or even 


\section{Introduction}

illegal, and one risks producing knowledge that the state can use to make the lives of those categorised as irregular migrants even more difficult.

\section{Introducing the study}

With the aforementioned dilemmas in mind, the book builds on ethnographic fieldwork of various intensities carried out in Bergen and Oslo, the two largest cities in Norway, between 2011 and 2018. The major part of the research was conducted between October 2011 and October 2013 for my PhD, which was part of a larger umbrella project on the provision of welfare to irregular migrants (PROVIR). I also draw on insights from five months of intensive fieldwork in Oslo in the autumn of 2017 related to a new multidisciplinary project on the temporalities of irregular migration (WAIT).

Although my aim was not to study irregular migrants per se, recruiting them as participants and following them in their daily activities was a key approach to shedding light on state bordering practices and observing what service providers and institutions 'do', and not only what they 'say'. During my fieldwork, I spoke and interacted with more than 100 migrants living irregularly in Norway. However, the main source of data for this book comes from a core group of 15 with whom I remained in contact over time, some of them for a period of several years. During this time, I followed them, in the sense of having multiple encounters and conversations, accompanying them in their various daily activities, including on a few occasions to appointments to doctors and lawyers, getting access to their medical journals, and interviewing the service providers with whom they had been in contact. The group of 15 was highly varied; it included families with children as well as single adults, both male and female. They were predominantly from sub-Saharan Africa and the Middle East. While in the larger set of interlocutors, there were people with various pathways into irregularity, within the core set, all had at some time applied for asylum in Norway. Their time in Norway varied from 2 to 20 years. Contacts with irregular migrants were made in various ways: through the healthcare centre for undocumented migrants in Oslo, through NGOs and activists, gatekeepers in ethnic communities, and at public events organised for and by irregular migrants. I volunteered once a week for three months in 2012 at Robin Hood-huset, a meeting place for those facing financial difficulties in Bergen, and I was present in the opening hours of the volunteer-run healthcare centre for undocumented migrants in Oslo once a week for six weeks in 2012 and four months in 2017.

Throughout the fieldwork, I also conducted interviews and had conversations with approximately $15 \mathrm{NGO}$ employees and 50 public care providers, including nurses, doctors, social workers, and administrative personnel. Although, participant observation and interviews are considered the core of ethnographic research, it is increasingly recognised as insufficient for capturing the complexities of social relations, especially when one conducts ethnographic research among loosely connected actors who may not even know one another (Feldman, 2011). Thus, in addition to following migrants in their various activities and encounters with those who came to represent the state in daily situations, I also followed the topics that emerged in various texts, including news articles and official documents (laws and 
regulations, consultation papers and guidelines, government press releases, commissioned reports, etc.). Conducting my research as part of an interdisciplinary research project comprising legal scholars and social anthropologists (PROVIR) was a great advantage when navigating and unfolding the implications of law in this study. Still, I treat the legal sources above all as ethnographic. Here, I follow Coutin and Fortin, in conceiving of ethnography as more than a research method, and instead as 'a way of seeing, or a type of account dedicated to representing and explicating social and cultural realities that may be encountered in multiple ways' $(2015,71)$. The approach of following people and the topics emerging in these encounters, in various texts with an aim to explicate state policies, is reflected in the structure of several of the ethnographic chapters.

\section{The 'good' welfare state as a context}

The Norwegian welfare state offers a particular context for understanding how and to what extent irregularised migrants' lives are cared for. Norway, along with its Nordic neighbours, has been the object of significant interest both among academics and in international political circles for its combination of economic success and a comprehensive welfare system (Andersen et al., 2016). Repeatedly topping international rankings of quality of life and happiness, the Nordic welfare states have been considered as successful and inclusive projects, creating conditions for equality and material security found hardly anywhere else in the world (Brochmann and Hagelund, 2012; Vike, 2004). The comparatively high standard of welfare and care offered to the general population, though, has not been extended to include irregularised migrants. In fact, the Norwegian welfare state does not necessarily stand out as particularly generous or caring towards irregularised migrants. For example, countries such as France, Belgium, and the Netherlands grant more extensive rights to healthcare to irregularised migrants than Norway does (Melberg et al., 2018).

Researchers examining how migrant 'illegality' has been experienced in Sweden have suggested that in strong welfare states where large parts of social life are regulated through the state, migrant 'illegality' means an even harsher everyday life than in countries with weaker welfare systems (Khosravi, 2010; Sigvardsdotter, 2013). Here, they refer in particular to the strict control systems represented by the use of a personal identification number supported by a central population register. In the Nordic countries, this number is required for most administrative purposes (tax, health and social services, passport, driver's licenses, etc.). It is also needed in contact with many private actors, such as banks and insurance companies.

Another aspect mentioned in the academic literature is the comparatively regulated labour market and small informal sector (Düvell, 2010, 4). While deregulations and a rise in subcontracting have contributed to the growth of the informal sector in certain areas (cleaning, construction, restaurants), the assumption has been that this sector to a larger extent employs migrants from the European Economic Area (EEA) (PU, 2017). Although Norway is not a member of the European Union, it is part of the common European labour market, in which all EEA citizens can exercise their right to free movement in order to work in other member 
states. The EU enlargement to the east in 2004 thus gave Norwegian employers access to a large reservoir of labourers who came from countries with wages that were considerably lower than Norwegian wages. While intra-EEA migrants may also find themselves in an irregular situation due to insecure employment and income (Misje, 2020; Thorbjørnsen, 2020), irregular migration to Norway has generally been associated with migration from non-European countries. As such, it has been linked to asylum migration and refusal rates rather than demand for (precarious) labour. The geographical location of the Nordic region in relation to the main migration flows into Europe has therefore also been used, together with the relative high levels of regulation of welfare and labour, to explain the comparatively low numbers of irregular migrants, and relatively late political and academic interest in the issue (Jørgensen and Meret, 2012).

Estimations of the size of the irregular population are difficult to make and tend to be unreliable, with different estimates often used to support or challenge particular political frames (Stenum, 2012; Koser, 2010). In Norway, estimated figures of non-EU migrants living irregularly have ranged between 5,000 to 56,000, although the lower range of these estimates $(10,000-20,000)$ seems to have most support both from NGOs in the field and the police (Zhang, 2008; Mohn et al., 2014; PU, 2017). While the numerical significance of irregular migrants cannot be said to be great, even in a country of slightly more than 5 million inhabitants, political attention has been substantial during the past two decades. Issues related to irregular migration have featured prominently in the media and have been subject to several policy initiatives and changes (Ihlen and Thorbjørnsrud, 2014; Johansen et al., 2013). In this regard, it is relevant to consider not only how the particular arrangements and institutions of the welfare state affect irregular migration but also how the particular norms and values considered to underpin the Nordic model, and as such the national self-image, affect the states' treatment of irregular migrants.

In the Nordic context, the welfare state is generally seen as constituting an important component of national identity (Vike, 2004) and as somewhat of a brand positioning the Nordics in the world (Marklund, 2017). The 'Nordic model' in this context is seen as an expression of a particular approach to welfare defined in terms of the broader objectives or norms that inform policies, rather than as a fixed set of policies or institutions (Kuhnle and Kildal, 2005). The key norms are a commitment to social and economic equality through an equitable distribution of material resources, rather than simply alleviation of poverty, and universal standards of entitlement, rather than means-tested benefits. Entitlements thus tend to be institutionalised via social rights and financed by progressive taxation. As the strong commitment to equality in the Nordic countries has been considered as to equality of outcomes or condition, and not only equality of opportunity or status (Lister, 2009), poverty has tended to be seen as deeply disturbing (Barker, 2017; Engebrigtsen, 2015). Furthermore, the commitment to equality has been associated with a disapproval of differentiated rights regimes (Nielsen, 2016).

Public responsibility for welfare is also considered a key characteristic of the Nordic welfare model as the state is seen as the guarantor of equal distribution of 
welfare, and a way to enable individual autonomy and independence. The Nordic countries have thus often been characterised as 'state friendly', with research continuing to show a very high degree of trust in the capacity and the desirability of the state to solve problems (Wollebæk et al., 2012; Henriksen et al., 2018). Hence, in comparison to other welfare states, the Norwegian state tends to play a larger role as a provider of welfare in contrast to more informal arrangements through family, private organisations, or the market (Jacobsen, 2015).

Research has, of course, complicated and nuanced this picture of the Nordic countries. Anthropologists, for example, have long problematised exclusivist aspects of Nordic egalitarianism evident in the way these countries have dealt with cultural difference, suggesting that the strong commitment to equality in these countries comes with a demand for 'sameness' or cultural conformity (Gullestad, 2002). Nordic integration policy and discourse, for example, has increasingly come to emphasise the ability to conform to 'Nordic' social norms and cultural values (Olwig, 2011). Migrants are thus problematised in a particular way that produces and reinforces an asymmetrical relationship between majoritised and minoritised populations (Rytter, 2019). Other researchers have cautioned against what they see as neoliberal welfare policy trends that modify the basic principles of the Nordic model. For example, by strengthening the link between contributions and benefits, the so-called workfare policies are understood to strengthen 'the norms of reciprocity at the cost of the principle of universalism' (Kuhnle and Kildal, 2005, 28). The countries are also experiencing increasing social inequality (Øverbye, 2017). Most welfare state research, though, still considers egalitarian norms to be relevant markers of the Nordic welfare states. Although the norms are not fully achieved or expressed in all policies, they are seen to inform national policy and identity (Pedersen and Kuhnle, 2017; Barker, 2017).

Historically, the universalistic welfare approach has implied that migrants should have the same formal rights to welfare as every other citizen. The criterion to qualify for different kinds of rights is usually residence, rather than citizenship. ${ }^{5}$ In this sense, the Norwegian welfare state has largely operated with a territorially based conception of membership, rather than a status-based one (Bosniak, 2007). Brochmann and Hagelund (2012) has argued that this approach rests not only on egalitarian norms but also on the social consideration that 'good welfare states' cannot function properly if a large part of its population is marginalised and socially excluded. However, this consideration has also motivated an assumption that the universally oriented Norwegian welfare model is particularly vulnerable to high level of migration (NOU, 2011, 7; NOU, 2017, 2). Restrictive admission has thus been seen, according to Brochmann and Hagelund (2011), as a prerequisite for the sustenance of the system as such. Hence, Norwegian policies have generally come to follow what Bosniak (2006) has called 'the hard on the outside and soft on the inside' model of citizenship.

Initially, the 'hard' outside involved a so-called ban on labour migration implemented in the early 1970s. Although there were some exceptions for certain types of skills, this ban made immigration essentially possible only through family reunification or the conferral of refugee status or forms of subsidiary protection (NOU 211). 
The ban on labour migration was partly liberalised when Norway became a member of the European Economic Area in 1994. This membership committed Norway to accept the free movement of workers from EEA-countries and created a distinction between intra- and extra-EEA migrants (Olsen, 2018). This distinction is not only in terms of law and policy. Intra- and extra-EEA migration have come to be viewed very differently in terms of their presumed 'utility' or 'risk' to the sustainability of the welfare state (Andreasen, 2019; Guðjónsdóttir and Loftsdóttir, 2017). Hence, in contrast to the liberalisation of intra-EEA labour migration, different Norwegian governments have imposed, over the past two decades, a series of restrictive policies with regard to both asylum and family migration, making these pathways to legal migration more difficult for extra-EEA migrants (NOU, 2011, 7, 2017, 2). These restrictive policies have been largely motivated by pointing to the need to limit new arrivals of asylum seekers (Grønningsæter and Brekke, 2017). For example, in 2008 the government increased the subsistence requirement and implemented a four-year residency requirement for family reunification for those not granted a refugee status (Staver, 2015), lowering the threshold for applying the 'internal protection alternative' (IPA) as a basis for denying refugee claims, including departing from the 'reasonableness' criteria set out by UNHCR (Schultz, 2019), granting only temporary permission until the age of 18 years to unaccompanied minors who do not meet the criteria for either asylum or residence permit on humanitarian grounds (Liden et al., 2017), and raising the threshold for obtaining residence permit on humanitarian grounds (NOAS, 2013). ${ }^{6}$ Deportations of irregular migrants have also been a higher priority in Norway compared to many other countries (Weber, 2015), underlining how the nations' commitment to equality also fosters exclusion through coercive tools to respond to mass mobility (Barker, 2018). These policy trends were further reinforced in the wake of the so-called 'refugee crisis' in 2015.

Growing concerns over the potential impact of increased international migration on the future sustainability of the Norwegian welfare state have also put the 'softer inside' under pressure (Hernes, 2018). Denmark, for example, saw an emerging break with the universal principle of the Nordic model already at the turn of the century, as conditions for receiving social benefits were tightened for immigrants (Jønsson and Petersen, 2012). The issue of differential or gradated rights has also been repeatedly raised in Norway, including in two Official Norwegian Reports on the relationship between international migration and sustainability of the Norwegian welfare state (NOU, 2011, 7; NOU, 2017, 2). While the reports noted that the idea that access to rights should in some way be 'earned' was gaining traction in Norway, the main recommendations were still to continue the universal approach for migrants with a legal residence status. ${ }^{7}$ Irregular migration, though, poses a particular challenge to the 'hard outside-soft inside' model of citizenship, as it exposes the unsustainability of a notion of a territorially bounded space that underpins this dual logic. The challenge facing policymakers with regard to irregular migrants thus becomes: Should the welfare state approach to territorially present, but politically excluded, migrants be guided by the 'hard' threshold norms or the 'soft' interior ones? 


\section{Overview}

The book consists of seven chapters, including an introduction and a conclusion. The five ethnographic chapters are further divided into three parts, reflective of the three themes that inform the main argument developed, that is, the role of life, territory, and temporality in contemporary politics. Although, all three themes are always present, there is a different emphasis analytically in each part.

In Part I of this book, I explore how care for irregular migrants has been politically and legally structured as well as legitimised in the Norwegian welfare state. In Chapter 1, I examine how irregular migrants' access to basic care such as shelter and economic support has been (re)structured in Norway, and to what effect, by situating some of the stories of the irregular migrants followed in the study within a broader account of shifts in Norwegian welfare policies and laws. These shifts include rejected asylum seekers changing access to work permits, shelter and economic support through the asylum reception system, access to support from the social services, as well as the emerging new role of NGOs in providing care for irregular migrants. One of my main arguments in this part is that during the past decades, there has been a dual process whereby irregular migrants were increasingly demarcated legally outside the scope of welfare legislation, while at the same time humanitarian exceptions were built into the system to relieve some of the tension between the welfare state's commitment to basic security and the exclusionary practices of migration control. The chapter is structured around the accounts of three different persons who had lived irregularly in Norway for more than ten years, showing how the limited inclusive practices contributed to their precarious circumstances of living.

In Chapter 2, I focus on the norms which govern irregular migrants' access to welfare services and explore how these reflect wider societal values regarding the legitimate and illegitimate, and not only legal and illegal. I analyse and show how different and competing conceptualisations of irregular migrants in public policies and discourses construct this migrant category as more or less worthy of compassion and care, focusing specifically on how irregular migrants are conceptualised in public texts (e.g. laws and regulations, background material for the laws and regulations (e.g. Official Norwegian Reports (NOU), consultation papers and guidelines), government press releases and public statements by government representatives, Parliamentarian initiatives and debates, etc.). I also examine what conceptions of the nation are installed in practices of care for the politically excluded. By addressing the moral bordering and ordering of various lives, I show how the exceptionalism surrounding the care for irregular migrants not only is legal in form and effect but also represents a broader departure from the norms of equality and universalism that have traditionally been considered core values shaping Norwegian welfare policies in general.

In Part II, I turn to the specific context of healthcare to explore how state borders are reproduced, negotiated, and tested in and through situated encounters between service providers and irregularised migrants. As such, the two chapters 
seek to address the role of territory in contemporary government, particularly the changing meaning and location of state borders and the role of territory in valorising and distinguishing between lives. Chapter 3 uses an ethnographic account of a medical appointment as a starting point to investigate the role of discretionary decision-making in (re)producing or challenging state borders in the medical encounter. Understanding these decisions as a form of sovereign decision on the exception or (non-)value of life, I seek to contextualise sovereignty as a practice within mundane institutional practices and expert knowledge. The ethnographic focus in this chapter thus brings forth the multiple and dispersed, as well as negotiated quality of the sovereign decision and hence the border in everyday practices and situations. It also shows how ambiguous outcomes were produced, by the friction not only between 'decisions' at different branches and levels that make up the state but also between different normalising frames informing those tasked with translating state policy into practice.

In Chapter 4, I shift the focus from the role of discretionary/professional decision-making in (re)producing or challenging state borders to how the border becomes materialised through administrative practices and routines, including the general practitioner scheme, the use of personal identification numbers, and the issue of payment. I show how these practices were not necessarily linked explicitly to migration and border control but linked to forms of control of the population in general. As such, they were not primarily about the detection of irregular migrants for deportation but excluded irregular migrants in more subtle ways, including deterring them from exercising the limited rights that they actually had. In the chapter, I also explore how healthcare providers navigate bureaucratic structures in their situated responses to the ethical and practical dilemmas raised in their encounter with irregular migrants. These situated responses did not necessarily pit formal law against informal inclusion but could be seen to operate in a grey zone opened up by ambiguities and tensions that simultaneously cut through law, policy, and practice.

In Part III, I move from an analysis of spatiality (the changing location of state borders) to the temporal implication of migration control, examining what happens when control of the patient's time in the medical encounter is challenged by the unpredictability and temporariness produced by migration law and enforcement. How does the temporal lens of migration control frame and condition the medical gaze, and hence the medical care offered irregular migrants? In Chapter 5, I start by unfolding an ethnographic example where the different temporalities involved in medical practice and migration control, and the tension between them, come to the fore. Following the patient over time, I show his continuous negotiation over time with healthcare providers and the immigration authorities. I also show how the threat of deportation and the emergency frame of the Healthcare Regulation concerning the right to health and care services to people without ordinary residence in the country (2011) had a disciplinary effect in the sense that it oriented the medical gaze to the temporal present. Consequently, care came repeatedly in the form of short-term solutions, rather than offering a cure. 


\section{Notes}

1 Agamben's Homo Sacer series consists of several books. My engagement draws primarily on Homo Sacer: Sovereign Power and Bare Life (1998), State of Exception (2005), Kingdom and Glory: For a Theological Genealogy of Economy and Government (2011), and Remnants of Auschwitz: The Witness and the Archive (2002a), as well as his more political work Means without end: Notes on politics (2000b).

2 All the names are pseudonyms. Due to strong privacy concerns when doing research with irregular migrants, I have also chosen to alter what I considered non-essential information (i.e. number of children, gender, age, years in the country, etc.). What I considered non-essential varied from case to case.

3 Unless otherwise noted, all translations of Norwegian sources (whether written or oral) are mine.

4 'Papirløs' is the main term used by NGOs in Norway for irregularised migrants from non-EU countries. The direct translation is 'paperless' or 'without paper'; however, in the book I will mainly translate the term to 'undocumented', as this is more commonly used in English.

5 Citizens from the European Economic Area (EEA) and their family members are entitled to equal treatment as Norwegian citizens if the reference person has legal work. EEA citizens who come to the country to seek employment under the EU mobility regime do not have access to social benefits and only limited access to healthcare.

6 Although the effect of these changes on the arrival of asylum seekers to Norway has been questioned (Brekke \& Aarset, 2009), they had an impact on my field. For example, one of the changes was that a stay granted on humanitarian grounds should be based on an individual treatment of each case and not a group assessment in relation to a particular geographical area. Until 2009, Palestinians had been one of the largest groups of asylum seekers arriving in Norway, and all Palestinians who could document that they were from the West Bank or Gaza had been granted residence. After the change in policy, acceptance fell to 24 per cent (NOAS, 2011). When I started fieldwork, Palestinians were among the most prominent groups of irregular migrants that I met, organising, among other things, a one-year-long protest camp outside a church in Oslo.

7 One minor change, though, was agreed in April 2017: introducing a five-year residence requirement for parents to receive cash benefits for their 1-2-year-olds (Kontantstøtten). Norway has also introduced new civic requirements for restricting access to permanent residence and citizenship (Hernes, 2018). 
$\because$ Taylor \& Francis

Taylor \& Francis Group

http://taylorandfrancis.com 


\section{Part I}

\section{Producing precarity}


$\because$ Taylor \& Francis

Taylor \& Francis Group

http://taylorandfrancis.com 


\section{Exceptional care}

\section{Eba}

'They gave me the rejection and the work permit together', Eba explained, laughing at the irony. Eba was a 42-year-old man originally from Ethiopia whom I met for the first time in the early spring of 2012. In our conversations, he explained how he had initially applied for asylum in 2003, a time when it was easier for asylum seekers to receive a work permit while their cases were being processed. At the same time as his first asylum application was rejected, Eba received a work permit. At that time, he was living in an asylum reception centre in a small community in the Western part of Norway with few job opportunities. When he received the second negative answer to his asylum application, the so-called 'final rejection', he left the reception centre and moved to Bergen, the second largest city in Norway. With a valid tax card, he was able to find work in a Chinese restaurant three days a week, earning wages below tariff, on which he paid taxes. He supplemented his income by working as many hours as he could as a temp in the food industry in the district surrounding Bergen. Though the hours varied, he made a decent living. At best, he declared, he had an annual gross salary of 470,000 Norwegian kroner.

At one point, Eba learned that his wife Kija, and their ten-year-old son, Demeke, were in Norway looking for him. For a year, they had been living in a reception centre in another part of the country. Having already received their first rejection, Kija and Demeke joined Eba in Bergen, where they lived in a small studio apartment close to the city centre, for which Eba paid 4,000 kroner a month. 'It was a small place', Eba stressed. 'There was only one room where we ate, slept, and did everything'. Eba smiled when remembering the paucity of those days. For Eba, this was a time when he 'lived' because he could work. Demeke was enrolled in school and he and Kija had a second child. When recounting his story to me in 2012, though, Eba was sitting in a much larger three-room apartment supplied by the Norwegian state in a decentralised asylum reception centre, living on a modest subsidy from the state.

Although Eba saw some material advantages, particularly for his children (e.g. access to kindergarten for the youngest), he considered life in the reception centre as 'mental torture'. As he elaborated, 'I tell you, at that time when I could work, 
I didn't think too much. I worked, I had money, I could go any place, I relaxed. I didn't just sit around. I didn't think about my case. But . . .' 'But now?' I asked. 'Yeah, now I don't work. I always sit at home. I always think about my situation. Later, little by little, maybe I'll get sick. I know many people now that are sick.'

For Eba, as the quote illustrates, losing work meant more than losing a source of income. In his view, work protected him against the stress of being an irregular migrant. So how did Eba end up back in the asylum reception system?

In this chapter, I explore how irregular migrants' access to basic care has been (re)structured in Norway and to what effect. I am particularly interested in how shifting welfare laws and policies (re)produce state borders by distinguishing between the lives on state territory that should be cared for and those that should not. However, as I will show, the question is not only whether a life is cared for, but what kind of life, and how.

The period during which Eba has lived in Norway has seen increasing attention and effort on the part of the state to come to terms with irregular migration, constantly changing and restructuring migrants' survival options. My own entry into the field in the autumn of 2011 happened shortly after one such significant change, which greatly affected several of my interlocutors, including Eba. This involved changes in practices related to the issuance of tax cards. In 2010, a cleanup in the Norwegian Tax Administration revealed that many rejected asylum seekers had kept receiving tax cards even though they did not have residence permits. These were asylum seekers who, like Eba, had received a temporary work permit while their asylum applications were being processed. The duration of these permits was set for six months or until a final decision was made in their case. The permits were renewable as long as the conditions continued to be met. Such renewals were common when the Norwegian Directorate of Immigration (UDI) needed more time to examine the application. However, when the permit expired, neither the tax authorities nor the employers were informed, and until 2011, tax cards were issued automatically to previous tax card holders.

Although employers were required to check that people had valid work and residence permits, there was a widespread misunderstanding that a person's tax card was sufficient evidence. ${ }^{1}$ However, from 2010 onwards, the government began to issue tax cards with a text explicitly stating that the card was not proof of a right to work or of legal residence. This policy was tightened even further in 2011 as it became mandatory for people without a standard Norwegian personal identification number to personally visit a tax office to receive the card. After the new procedures were introduced, several people were exposed as working in both private and public sectors without valid residence permits. Subsequently, as new tax cards were not issued automatically, Eba and others in his situation lost their jobs. Unable to find an employer who would hire him without a tax card, Eba and his family contacted the Directorate of Immigration and 'moved back into the system', as Eba called it. However, to Eba, this policy did not make much sense. As he put it,

I don't want the government to pay me. Why do they pay me to sit instead of letting me work? I can work. Yeah, really. Even if they don't pay for my 
family, I can work, I can help my family. Before it was like that. Why won't the government allow me to work?

While Eba's story is particular, it was not unique in Norway. During my fieldwork, I met many with similar stories in both Oslo and Bergen, particularly among Ethiopian and Eritrean migrants. In February 2011, around 100 Ethiopians responded to the tax administration's new practice with a hunger strike in Oslo Cathedral, highlighting their contribution to the Norwegian welfare system and their current suffering with the slogan 'We were taxpayers, but now on the street' (Bendixsen, 2017). While many of those affected by the new immigration controls implemented by the Norwegian Tax Administration, like Eba and his family, did eventually register for accommodation with the UDI, some did not, including Aster.

\section{$\ldots$ and Aster}

I first met Aster, a 45-year-old Eritrean woman, at the volunteer-run healthcare centre for undocumented migrants in Oslo in the autumn of 2012. She was there at the insistence of her friend Mehret, who was worried about Aster's lack of initiative. 'She doesn't understand why this is happening to her', Mehret explained to me, shaking her head. 'She just sits at home'. Aster struggled with headaches and muscular pain. At the healthcare centre, she was attended by both a doctor and a physiotherapist. However, as Aster later admitted to me, it did not help. She went occasionally at Mehret's insistence but, as Aster stressed, her problem was not really the headaches.

Aster, at the time we met, had been 'illegal' for 22 years. First, she recounted, she lived and worked cleaning private houses in Saudi Arabia before coming to Norway and applying for asylum in 2000. Initially, she was sent to a reception centre in the Northern part of the country. After about eight months, however, her application was rejected. By then, like Eba, she had already received a work permit, and she left for Oslo. There she spent about five months looking for work, while earning enough to survive by looking after children. Eventually she was hired by a cleaning company, and for the next nine years she cleaned private and public buildings in Oslo, paying tax and saving money to enable her one day to buy an apartment. She managed to save enough to meet the bank's requirement for a co-payment, and she explained that she even had meetings with them about getting a loan. However, everything changed when the tax card stopped being renewed. As in Eba's case, Aster's employer reluctantly let her go. For four months, he let her stay on without a tax card, withholding an obligatory 50 per cent tax on her salary. He also wrote a letter on her behalf to the UDI.

Aster was very proud of her time working. Both she and Mehret repeatedly told me she was a 'good worker' and that her employer was very pleased with her and would take her back if she could get a work permit. Although she was 'illegal', the period she worked represented, as in Eba's case, a happier time. It was also a time when she had her own place to live. After losing her income, Aster moved around, living with friends. Sometimes she would go to another city to relieve her 
network in Oslo, visiting friends from her time in the reception centre who now had received legal permits and with whom she had remained in contact. Often, though, she would live with Mehret, who shared a small council flat with her two minor sons. Mehret and Aster became friends shortly after Aster arrived in Oslo. Mehret, however, had received a residence permit 'on the third attempt', as she put it, shaking her head over why it proved to be so much more difficult for her friend.

As I learned of Aster's struggles to get by, I was curious as to why she did not move into an asylum reception centre, as many of the others that I encountered at that time eventually did. When I asked her whether she had considered moving back into a reception centre, she responded with a very sceptical 'no', indicating that this would be a last resort. The main reason she gave was that she would then have to leave Oslo. Asylum reception centres in Norway are geographically dispersed throughout the country, located in both small and large communities. Asylum seekers, rejected or not, have little say in where they are placed. Rejected asylum seekers who re-enter the system are sent back to the same region where they were initially placed. In Aster's case, it was the northern region of Norway, a place where she had stayed eight months, compared to the nearly 11 years she spent in Oslo.

Most of the rejected asylum seekers I met during my fieldwork who were living outside the reception centre system told of very harsh living conditions, relying on the help from friends and at times having nowhere to stay. Nevertheless, they expressed a strong resistance to moving back into 'the system'. The reasons given were not necessarily fear of detection and deportation, as one might have expected, but very often that, like Aster, they did not want to leave Oslo and their social network there. Next to geographical location, the most frequent answer I received as to why they did not want to live in asylum reception centres was the experience of undignified living conditions and the negative health effects they associated with it. Life in asylum reception centres has frequently been associated with a particular kind of social suffering in Norway. The literature has particularly stressed passivity and the absence of a normal everyday life as factors that negatively affect residents' health (Kjærre, 2015; Gasana, 2012; Hjelde, 2010). Several of my interlocutors, like Eba, regarded life in a reception centre as 'mental torture'.

\section{An unstable and exceptional landscape of care}

Most of the stories I collected during fieldwork, like Eba and Aster's, were accounts of increased hardship, stress, and anxieties. As such, they importantly illustrate some of the experiences migrants have as a result of government policies. In the following, I seek to situate these accounts within a broader context of shifts in Norwegian policies and laws to shed further light on the forces that shape the migrants' life, particularly how the limited inclusive practices contribute to producing migrants' precarity. In its broadest form, the concept of precarity can be defined as referring to life worlds characterised by unpredictability and insecurity. 
Most commonly, the precarity literature refers to particular experiences of insecurity deriving from neoliberal labour markets in contrast to the 'certainties' of welfare state labour markets and social arrangements (Waite, 2009). Here, though, I draw primarily on Butler (2004, 2009), who distinguishes between 'precariousness' as a shared human condition, exposing our interdependency, and 'precarity' as a politically created condition through which precariousness is maximised for some and minimised for others. Precarity thus concerns the dimension of politics that addresses the organisation and protection of bodily needs, drawing attention to the imposition of vulnerability that derives from different political decisions, social practices, and social norms (Butler in Puar, 2012).

The relevant policy shifts I trace in this chapter include rejected asylum seekers changing access to work permits, shelter, and economic support through the asylum reception system, access to support from the social services, and the role of NGOs in providing care for irregular migrants. The picture that emerge, I suggest, is more complex than irregular migrants simply being excluded from welfare services. Instead, it shows a continuing and complex negotiating of administrative practices and regulations at the national level. Here, the oscillation of policies between the perceived interests of immigration control and humanitarian concerns has produced a constantly changing landscape regarding how and to what extent irregular migrants' basic needs should be addressed by the state. This changing landscape in itself, I suggest, reinforces migrants' precarity. Another key characteristic was that while irregular migrants were increasingly excluded from the regular system, special measures were implemented that made it possible to address some of the most pressing bodily needs of this population.

In Norway, membership in the National Insurance Scheme (Folketrygden, literally 'people's insurance') is the key to eligibility for rights to various welfare services. Membership in the National Insurance Scheme is mandatory and is based on residence rather than formal citizenship. However, in order for someone to be considered a resident in Norway, their stay must last, or be intended to last, for at least 12 months, and the stay must be legal. If these requirements are met, membership starts from the date of entry into the country. Asylum seekers whose applications are under review are not full members of the National Insurance Scheme. While they have, at least in theory, the same rights as the general population to public services such as healthcare and education, an important exception was made regarding rights under the Social legislation in 1988 when the asylum reception system was established. This exception produced a two-tier system as asylum seekers did not receive access to any of the social benefits administered by the Norwegian Labour and Welfare Administration (NAV), but were guaranteed housing and financial support based on distinctly separate regulations and lower standards through the Directorate of Immigration.

Rejected asylum seekers generally received the same treatment as asylum seekers awaiting an answer to their application until 2002, when the government began to reduce financial support to rejected asylum seekers, and then removed it completely effective 1 January 2004. Parallel with reducing the economic benefits, the government decided, also in effect as of 1 January 2004, that the right to 
accommodation in asylum reception centres would be cancelled for rejected asylum seekers. The new measures, as argued by the government at that time, were put in place to prevent reception centres from being used as refuge for people who had no need for asylum or other forms of protection. The stated purpose of the new policies was further to force the migrants to cooperate on the procedure of their own return (Brekke and Søholt, 2005). It was in this climate that Eba 'chose' to leave the reception centre in the spring of 2004 after receiving a note of eviction. However, as seen, he did not leave the country.

The so-called withdrawal scheme (bortfallsordningen) regarding rejected asylum seekers' access to accommodation in reception centres was highly controversial. Using the words of Brekke and Søholt, who evaluated the policy changes in a report commissioned by the Ministry of Local Government and Regional Development in 2005, it turned out to be a minefield in the junction between the welfare state, local solidarity, and asylum policy goals. One of the main reasons for the controversies was that the policy challenged the established division of labour between state and municipalities. While rejected asylum seekers had previously been the state's responsibility through the asylum reception system, municipalities were now faced with the dilemma of how to deal with their social needs. Many of those who lost the right to accommodation were difficult to deport, partly due to lack of identity papers and partly due to political reluctance and unstable conditions in the countries of origin (Brekke and Søholt, 2005).

The controversy over the withdrawal scheme led to a series of adjustments in the course of the subsequent years. The first one came already in November 2004, only 11 months after the new tougher line had been introduced and before any residents had actually been forcibly evicted from reception centres. A proposal in Parliament from the Socialist Left Party (SV) to create special reception centres that would offer rejected asylum seekers simple board and lodging pending departure received bipartisan support, including support from the centre-right government parties behind the withdrawal scheme (Document No. 8:26 (2004-2005)). This proposal placed the responsibility for rejected asylum seekers' well-being again clearly at the national level yet maintained the distinction between rejected asylum seekers and asylum seekers awaiting a decision.

However, the new centres, which came to be called 'waiting centres' (ventemottak), quickly became controversial as well. According to an external evaluation commissioned by the Ministry of Justice and the Police in 2010 (Valenta et al., 2010), the centres were characterised by passivity, frustration, antisocial behaviour and substance abuse among residents, and a growing number of conflicts. In the period they operated, only two centres were actually established, hosting only a limited number of rejected asylum seekers. In June 2010, riots erupted among residents of both centres, and they were subsequently closed due to extensive fire damage. In September 2011, the government dropped the idea of special centres for rejected asylum seekers and announced that rejected asylum seekers again would be offered accommodation in ordinary reception centres.

Although, this development may look like a return to the situation before 2004, eight years of experimentation had led to a greater willingness to differentiate 
within the system based on legal status (Thorshaug and Valenta, 2012). For example, although rejected asylum seekers in reception centres would again receive economic support from the state, it was at a lower level than the support received by asylum seekers awaiting a decision and also significantly lower than what was considered the appropriate minimum for legal residents.

Figure 1.1 shows standard rates of economic support for rejected asylum seekers in state accommodation compared to asylum seekers (RS, 2008-0, 35V1; Seeberg, 2017) and state guidelines for social benefits (RS I-34/2001; RS A-2/2011; RS A-2/2015) for 2001, 2012, and 2016. The monthly amounts should cover all normal expenses except housing costs. As the figure shows, rejected asylum seekers (single adults) received almost 70 per cent of what the state guidelines stipulated for those receiving social benefits in 2001. The support was reduced to approximately 36 per cent of the amount stipulated in the state guidelines in 2012 and 30 per cent in 2016. In 2001, they received the same amount as asylum seekers awaiting a decision. After they were allowed back into the asylum reception centres in 2011, they would receive only about 60 per cent of what asylum seekers got. The difference between the two categories decreased in 2016 as the support to asylum seekers was reduced more than the support to rejected asylum seekers in the wake of the so-called refugee crisis in 2015.

During the main part of my fieldwork (2011-2013), some 5,000 to 6,000 persons with a so-called 'duty to leave' (utreiseplikt) lived in reception centres. This constituted about one-third of all residents. In 2017, this number had dropped

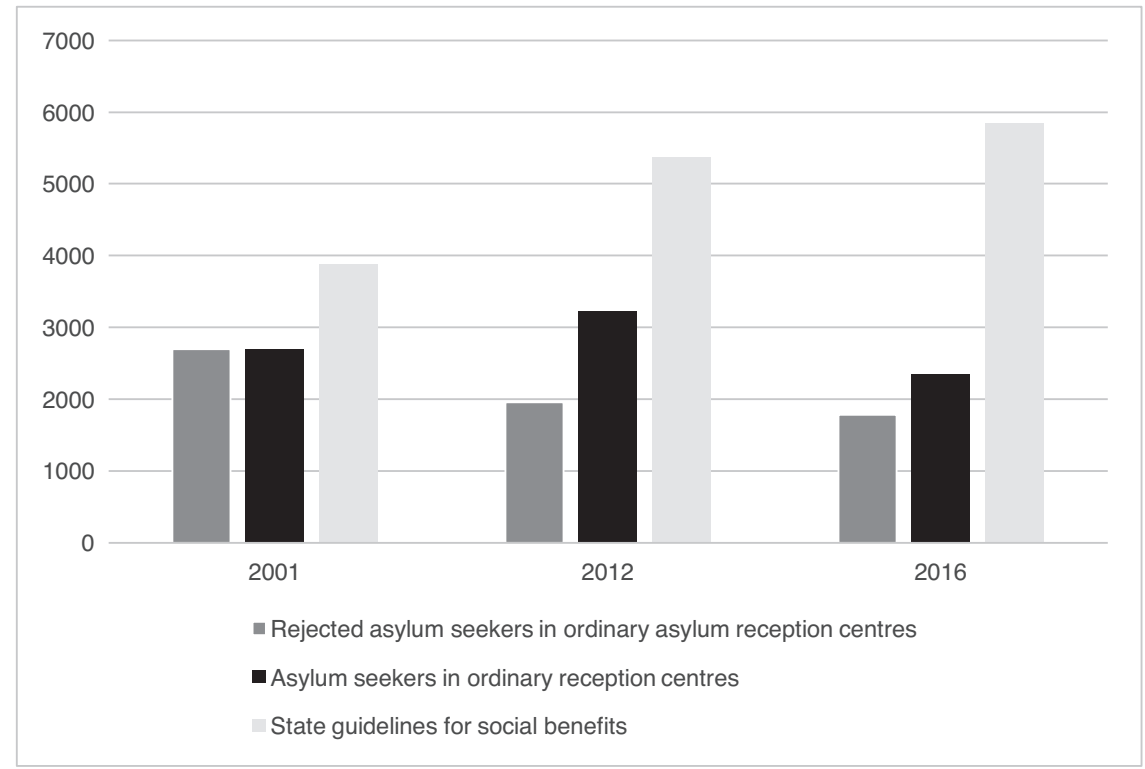

Figure 1.1 Economic support to rejected asylum seekers in state accommodation compared to asylum seekers and state guidelines for social benefits, 2001, 2012, and 2016 (NOK pr. month, single adult). 
to 1,421 persons (which still constituted about 28 per cent of all residents, UDI (2011-2017)). While the Norwegian state intensified its efforts to deport irregular migrants in this period, many also went 'missing'. The majority were assumed to have gone to other European countries, with a smaller number going to the major cities in Norway (PU, 2017).

It was not possible for me to detect any changes in terms of the size of the irregular population during the time I spent in the field. However, there was one noticeable change in my conversations with my interlocutors. While the question of moving back into the asylum centres was a key topic in 2011-2013, moving out was a more pressing concern in 2017. During my fieldwork in Oslo in 2017, I met several rejected asylum seekers who had stayed in Norway for years that had either just moved out of a reception centre or were considering it. One of them was Eshe, a woman in her forties originally from Ethiopia. Unlike Eba and Aster, she had stayed continuously in an asylum centre during the eight years she had lived in Norway. When I met her, she had just recently left the centre and moved to Oslo. With a limited social network in the city, she struggled to get by. She received some help from women at a mosque she went to, but she could not always find a place to stay or money for essentials. In our conversations, she spoke tearfully of the fear she felt having to spend some nights outside. Although living in a reception centre for years had been difficult, Eshe spoke warmly of the staff and the local community where the centre was located. Fear of deportations was the main reason she gave when I asked why she decided to leave the centre. The year 2017 was the first year the Norwegian state carried out deportations to Ethiopia. Ethiopians at that time constituted the major group with 'a duty to leave' in the asylum reception centres. However, Eshe and others also mentioned deteriorating conditions at the centres as a reason for leaving. These conditions included constant relocations as centres were closed due to low numbers of new arrivals and the low benefit level that was experienced as insufficient to survive on. A study carried out during the spring of 2017 on food insecurity among asylum seekers living in eight different reception centres in Norway also found a high prevalence of food insecurity among adults and children (Henjum et al., 2019).

\section{Make survive}

The changing landscape of care, I suggest, shows how the state in its distribution of care increasingly came to operate with a differentiated 'threshold possibility of life' (Redfield, 2005, 330). Another policy trend illustrated by the accounts I collected during fieldwork was how care to irregular migrants was reduced to subsistence, or what Agamben (1998) would call 'make survive'. Eba and Aster's cases, for example, show how policy changed from giving rejected asylum seekers work permits so that they could take care of themselves to granting humanitarian relief through the asylum system. This exceptional care, though, came at the price of heightened visibility, state surveillance, and greater susceptibility to deportation (Kjærre, 2015). 
When Eba and Aster applied for asylum, there was a consensus across party lines that temporary work permits for asylum seekers were a constructive initiative (Innst. O. nr. 54 (1995-1996), Innst. O. nr. 24 (1996-1997), Innst. O. nr. 66 (1999-2000) [The Parliament committee's recommendations on legislative decisions to the Odelsting/Parliament]). It was considered to have a positive effect on asylum seekers' mental health by combatting passivity and clientification, as well as making the asylum process more humane and cost effective, as the asylum seekers would be able to provide for themselves and even pay taxes. The goal was therefore that as many as possible should get work permits. In 2000, the Immigration Act and associated regulations were further amended to explicitly allow rejected asylum seekers to be granted temporary work permits until a 'departure could be effected' based on the same considerations (see Ot.prp. nr. 31 (1999-2000) [The government's Proposition to Odelsting/Parliament], and circular RS G-72/00). As such, it was not only a glitch that Eba and Aster received a work permit even though their asylum applications were rejected but part of an established practice at that time.

However, as authorities began to look for ways to limit the number of asylum seekers, temporary work permits came under scrutiny. The practice of granting work permits to rejected asylum seekers was cancelled through a circular issued by the Directorate of Immigration in 2003 (RS UDI, 2003-021). In 2009, a new Immigration Act came into force wherein the requirement for asylum seekers to prove identity to obtain work permits also became more stringent. The consequence of this change was that fewer asylum seekers were able to get work permits (Valenta and Thorshaug, 2011). This meant that Eba and Aster's mode of inclusion in Norwegian society as regularly employed taxpayers with fairly stable and decent employment became less of a possibility for newcomers.

Ironically, for Eba and Aster, paying tax and thereby contributing to financing welfare did not offer formal possibilities for claiming welfare benefits. Instead, access to welfare was primarily dependent on their status as 'rejected asylum seeker'. Although the asylum reception system represents a departure from the 'normal' frame of welfare provision through the Norwegian Labour and Welfare Administration (NAV), the centres could be considered to some extent a form of welfare state service specifically targeting this group. An Official Norwegian Report (NOU) on the asylum system published in 2011 noted, for example, that the reception of asylum seekers had primarily been guided by objectives and requirements characteristic of social and welfare policies rather than migration control (NOU, 2011, 10). However, the report acknowledged that the past decade had seen rising pressure to use reception centres as instruments for migration control. For instance, access to financial support as an asylum seeker (rejected or not) depends on people living in reception centres. Employees at these centres have increasingly been tasked with giving information to irregular migrants about voluntary return, and there have also been some amendments concerning the duty of confidentiality to make it easier for employees at the centres to share information with the Directorate of Immigration. ${ }^{2}$ Furthermore, asylum seekers' substitute for the right to assistance to housing and subsistence benefits was 
governed by the Immigration Act (2008) and not the welfare legislation. This act had been amended to state that while asylum seekers 'shall' be offered accommodation, rejected asylum seekers 'can' be offered accommodation pending departure. Also, the right under the Public Administration Act to file complaints about bureaucratic decisions, such as the allocation of accommodation, does not apply to the decisions of the immigration authorities (Søvig, 2013b; Ot.prp. nr. 112 (2004-2005)).

The cancellation of work permits, the 'can' in the Immigration Act, and the denial of the right to file complaints about bureaucratic decisions underscore, I suggest, how care for irregularised migrants was increasingly administered as exceptional government charity rather than as a social right. As such, it was not the life of a rights-bearing subject that was being cared for, as was the norm in the biopolitical welfare states that developed during the 20th century (Foucault, 1998; Wells, 2011), but instead a form of exceptional life the value of which was reduced to merely survivability.

This was evident, for example, in the negotiation between the state and the municipalities following the withdrawal scheme implemented in 2004. As previously mentioned, this scheme shifted the responsibility for rejected asylum seekers' welfare needs to the municipalities. The regulations and political signals regarding what this would entail, though, were vague. The new restrictive measures were neither provided in the form of laws nor even regulations, but in circulars and letters from various governmental departments. These specified that while individuals without legal residence were not entitled to financial support under the Social Services Act, 'no one should starve or freeze to death in Norway'. Instead, it was suggested that they could be entitled to emergency aid based on a so-called 'unwritten Act of Necessity'. Or, as the Ministry of Labour and Social Affairs clarified in a letter to all municipalities 19 December 2003:

[S]ociety as such has a general responsibility to provide urgent vital assistance in an emergency. This follows from general considerations of necessity. This means that a person may be entitled to assistance in the form of social services in particular emergencies regardless of whether the stay is legal.

(Ministry of Labour and Social Affairs, 2004)

The application of this 'unwritten Act of Necessity' was left to the discretion of each municipality, and this varied significantly (Brekke and Søholt, 2005). The government was nevertheless reluctant to give specific guidelines, arguing that 'the duty to help people in need rests with us all' (letter from the Department of Labour and Social Affairs to Centre Against Ethnic Discrimination, quoted in Aarø and Wyller, 2005). The ministry did, however, eventually issue a new letter on 4 October 2004 that made clear the following:

The Ministry would like to emphasise that this [the quote above] means that no one shall starve or freeze to death, and that social services need to provide vital assistance in an acute crisis situation, also to people without 
legal residence. This is not regulated by law or regulations but follows from unwritten considerations of the duty to help people in need.

(Ministry of Labour and Social Affairs, 2004)

These unwritten legal considerations of necessity thus clearly reflect the humanitarian moral principle of granting human life absolute priority. It is the survivability of the body that becomes the grounds for compassionate attention.

\section{Zeki}

Not all irregularised migrants I met during fieldwork were eligible for accommodation and economic support through asylum reception centres. One of them was Zeki. When I met Zeki, he had been addicted to heroin for more than a decade. Zeki, originally from Eritrea, came to Norway as an unaccompanied minor in 1994, and after a brief stay in an asylum reception centre, he settled in Oslo. Talking about those first years, Zeki emphasised how he struggled at school, finding it difficult to concentrate. As he explained, 'I came from war. I had no family. That was my problem. I couldn't sit in the classroom, thinking about my problems and focusing on the school at the same time'. 'But,' he continued in the same sad quiet tone, 'When I quit school, I started to become a criminal.'

In our conversations, Zeki described his encounter with drugs as a combination of naivety and love: 'I was very young', he repeated to me several times and he continued, 'I tried because of love. With a Norwegian woman. She taught me. I did not know drugs when I came to Norway. But the cost of love was addiction. My girlfriend died, and I still suffer today.' However, Zeki was increasingly feeling his age. As he elaborated: 'I am older now. I am an adult. I know what I am doing. I grew up, but I'm sinking.' Explaining how his life in Norway was, he said, 'I live just like a worthless human being. Imagine; I wake up every day not knowing where to sleep or where I will wake up tomorrow, where I will go to eat or change my clothes. My life is just exhausting.' He later added,

Every day is difficult. Every day I worry about the same things; where can I eat, where can I sleep. What shall I do today? I try to avoid doing crime. I don't like to do it. Sometimes I feel they [the authorities] force me to do it.

After Zeki came of age, he continued initially to live in a council flat. However, going in and out of prisons due to drug-related offenses, he was eventually stripped of his residence permit and was formally expelled from Norway in 2008. However, he could not be deported as there was no return agreement with Eritrea. Expelled, he also lost his council flat, and for the next five years, he was homeless, sleeping on the streets or with friends from the city's drug scene.

Describing his life of crime, Zeki was keen to underline that he was not violent, and he only committed petty crimes because he had no other choice: 'Sometimes I commit small crimes', he explained. 'And then I have to go to prison. In and out. In and out. But I'm getting older. I can't take it anymore. But I have no choice. 
I have no home to go to.' He felt harassed by the police, commenting cynically that he thought they just 'liked to put him in prison'. 'Sometimes I walk all night', explaining what he did when he could not stay with friends. 'But the police think I'm having fun and put me in prison. They are good at that. ... But I don't commit serious offenses so they can't put me away for a long time.'

In the autumn of 2011, Zeki, with the help of a community outreach worker, applied for assistance from a local Labour and Welfare Administration office (NAV). He was initially denied assistance and referred to the Directorate of Immigration for accommodation in one of the so-called waiting centres. Ironically, though, Zeki received this letter over a year after the centres had been closed. Zeki was also unaware of the closure of these centres, and he was reluctant to request accommodation there because of the centres' bad reputation. Yet Zeki eventually applied, hoping his medical situation, that is to say his addiction, would allow him to receive other form of accommodation. However, UDI rejected his request.

According to UDI, their offer was only for (rejected) asylum seekers. Zeki, who initially had successfully been granted asylum and had formally been settled in a municipality, was still the responsibility of the municipality, in UDI's view, and not the immigration authorities. With this letter, Zeki again applied for support from the local NAV office, and in the winter of 2013, nearly two years after he first applied for 'emergency aid', he was granted economic support and accommodation assistance. NAV was not willing to grant him a council flat but eventually decided to pay for a room at a homeless shelter (hospits), as Zeki was not able to enter the private housing market. In addition, Zeki received about 3,000 kroner a month to cover his living expenses (about 2,000 Norwegian kroner less than standard minimum rate at that time, but still more than he would have received in state accommodation). When I spoke to Zeki shortly after he had received the positive answer from NAV, asking what this meant to him in his everyday life, he replied that while he previously had to do 'a little crime every day', this was no longer necessary. Still, he found life in a homeless shelter hard.

\section{Municipal emergency aid}

While the changing accommodation policies for rejected asylum seekers has been well documented through various commissioned reports (Brekke and Søholt, 2005; Valenta et al., 2010; Thorshaug and Valenta, 2012), the situation for those not entitled to state accommodation has received far less attention. There is very little information regarding irregular migrants' encounters with welfare offices. One of the main sources of information is two consultations conducted in 2011 and 2013 concerning the regulation of emergency aid to people without legal residence (hereafter the Social Services Regulation, 2011). The statements received during these consultations indicate that irregular migrants' access to social benefits from local welfare offices was difficult and that this option was rarely used as irregular migrants were reluctant to approach welfare offices (Red Cross, 2013). Aster is one of those who at one point after losing her job, at the insistence of 
Mehret, sought out the Red Cross, asking for help for her dire economic and housing situation. When they referred her to NAV, Aster did not even bother trying, she confessed to me, already convinced that they would not help her.

Between 2008 and 2010, the Norwegian Red Cross and Juss-Buss, a free legal aid service operated by law students in Oslo, cooperated on a campaign to inform people without legal residence in Oslo about their rights. They also assisted irregular migrants in applying for emergency aid. The campaign ended, according to Juss-Buss (2011), because none of their clients was granted social assistance. As Juss-Buss commented in their statement to the public consultation concerning the Social Services Regulation in 2011, 'We considered it unethical to spread information about a right that apparently was completely illusory'. In their experience, either irregular migrants were barred from applying for assistance at welfare offices in Oslo or their applications were systematically rejected. They also pointed out that many caseworkers had little or no knowledge of the right to emergency aid (Juss-Buss, 2011). Statements from NAV offices, municipalities, and the county administrations $(2011,2013)$ also suggested that the number of applications from irregular migrants had been limited. ${ }^{3}$ However, the feedback from the local level indicated that though the cases were few, they were experienced as particularly burdensome due to their complexities. This was further reinforced by what the local authorities and welfare offices perceived as 'legal ambiguities'.

Irregularised migrants such as Zeki were eligible, in theory, for support from municipal welfare offices through the 'unwritten Act of Necessity'. As described earlier, this 'Act' was first referred to as an option in circulars and letters from the Ministry of Labour and Social Affairs to municipalities during the 2004 experiment during which rejected asylum seekers lost the right to accommodation in asylum reception centres. The Act of Necessity was eventually formalised through a new regulation that came into force on 1 January 2012 (the Social Services Regulation, 2011). This new regulation made it mandatory for municipalities to help people in 'dire need' with financial support and assistance in finding temporary accommodation. However, the support was supposed to be limited to the time required to obtain the necessary travel documents and availability of transportation out of the country - either to their country of origin or to another country (Ministry of Health and Care Services, 2010). Those who were eligible for state accommodation, that is rejected asylum seekers, were not entitled to this support.

While the regulation specified a right to social benefits for irregular migrants, the Act of Necessity from a legal point of view still maintained much of the same vagueness as the unwritten Act and also contained contradictory elements (Andersen, 2014). For instance, it defined irregular migrants' assistance in terms of both 'dire need' (akutt nød) and 'necessary care' (nødvendig omsorg), which could have different implications. The consultation paper (Ministry of Labour and Social Affairs, 2011) also specified that caseworkers should make individual assessments concerning when the migrant 'in practice' could leave the country. This illustrates how such case assessments were being tied to migration control that required knowledge about immigration policies that the social services did not necessarily have (i.e. knowledge about countries, return agreements, etc.). As 
Zeki's case illustrates, case assessments also required knowledge about how to distinguish between irregularised migrants. For example, it was not obvious why Eba received state accommodation and Zeki did not, and why Zeki received support from the municipality and Aster did not.

\section{The significance of necessity}

To understand the unstable landscape of care, and the changing and differentiated threshold of survival, I suggest, it is necessary to look at the form the policy changes have taken, particularly the legal instruments used. Irregular migrants' entitlements can be explicitly or implicitly stated in law; that is, they are not excluded from an inclusive entitlement to use the service. In Norway, welfare provisions have generally been provided through legal regulation characterised by broad object clauses and legal standards determining societal objectives and the general principles of the regulation (Aasen et al., 2014). For instance, the purpose of the Social Services Act (2010) is 'to improve the living conditions of disadvantaged persons, to promote financial and social security, including contributing to giving individuals opportunities to live and reside independently, and to promote the transition to employment, social inclusion and active participation in society'. Furthermore, the main body of Norwegian welfare laws concerning health and social security does not distinguish between 'legal' and 'illegal' residents. Both the Social Services Act (2010) and the Patients' Rights Act (1999) use the phrase 'everyone residing in the Realm' when defining the scope of the law. ${ }^{4}$ As such, there was a certain indecision for a time concerning the extent to which irregular migrants were entitled to services.

However, the acts allow for exceptions as ' $[t]$ he King can issue regulations limiting the application of the act in respect of persons who are not Norwegian nationals, or who do not have a place of residence in the Realm'. ${ }^{5}$ This formed the legal basis for various government ministries to issue regulations and circulars limiting irregular migrants' access to various services, a tendency that has increased over the past two decades. Although these new regulations and circulars still accorded irregular migrants a certain access, the explicit recognition of irregular migrants through these legal instruments primarily served to circumvent their access to services. As restrictions on irregular migrants' access to welfare were mainly governed through regulations, circulars, and letters issued by ministries and other governmental agencies, there was no comprehensive national or parliamentary debate on how irregular migrants' access to welfare benefits should be governed (Søvig, 2013b, 2015). As such, the regulations were issued piecemeal and by sector.

Scholars have questioned the legal basis for the welfare restrictions in relation to both due process and human rights obligations (Andersen, 2014; Süssmann, 2015). Here, I wish to draw attention to another aspect, namely how the legal instruments used contributed to the production of migrants' precarity by making access to welfare insecure and unpredictable. Administrative issued decrees, for example, are far easier to change than laws. More substantially, they could be understood as exceptional measures in an Agambenian framework. 
While Agamben's work on sovereignty has inspired interest in exceptional politics across disciplines, there are different ways of approaching and understanding what constitutes exceptions. Some key questions concern how the relation between exceptions and exceptional circumstances (emergencies or crisis) and the relation between exceptions, law, and practices of government are conceptualised. In exploring the ways and the extent to which irregular migrants are subject to exceptional measures, and what constitutes the exceptions in these cases, I follow Agamben in that designating policies as exceptional is as much a result of the theoretical lens as of the empirical designation of policies as such. Hence, the choice of the term implies a position taken on both the nature of the phenomenon under investigation and the logic most useful for understanding it (Agamben, 2005, 4).

Agamben's understanding of the state of exception as a 'technique of government', for example, importantly highlights how social issues are increasingly framed as exceptions and emergencies to justify a departure from legal standards. As such, his work draws attention to how the production and manipulation of a sense of emergency is used as a tool of socio-political regulation (McLoughlin, 2014). Migration has increasingly been framed as crisis that needs to be addressed through the adoption of exceptional measures (De Genova et al., 2018). In Norway, increased arrivals during the so-called 'refugee crisis' in 2015 , for example, was framed first as a current humanitarian crisis, and then increasingly as a (future) threat to the welfare state, the latter justifying a range of new emergency measures, including reducing financial support for rejected asylum seekers in reception centres (Bygnes and Karlsen, 2017). Yet, the language of exception, emergency, and crisis was not necessarily proliferating prior to 2015 in the discussions and policies concerning whether irregular migrants should be denied access to basic care (see Søvig, 2013b). Instead, many of the important changes came about in an unspectacular manner, as a clarification of present praxis. I am therefore concerned more with how the juridical practices of the state of exception coincide with and have been integrated into the normal workings of state institutions. To Agamben $(2005,2011)$, as I read him, law-making by administrative decree is not a practice associated simply with an extraordinary departure from the rule of law but with the rise of the regulatory or administrative role of the state. The legal structures of the regulatory state are thus 'exceptional' not simply because they first emerged in the context of crisis 'but because they have been thoroughly 'governmentalised', as argued by McLoughlin (2014, 701). As such, they represent a form of law based not upon generality and order but upon the singularity of particular circumstances.

Here, I follow attempts to read Agamben's account of sovereign exceptionalism in the context of, rather than in opposition to, Foucault's concept of governmentality. Thus, to understand how exceptionalism is related to government practices, it is necessary to recognise two different conceptions of law at work: that is, the distinction between law as an autonomous and legitimating discourse of rights and law as an administrative and regulatory tool. In the latter, law is not constituted with respect to a set of universal principles but has become subordinated to the logic of government and deployed as a tactic in the administration 
of the relationship between men and things (Foucault, 2007, 96). The problem with this, according to Agamben, is that ' $[\mathrm{t}]$ he normative aspect of law can thus be obliterated and contradicted with impunity by a governmental violence that while ignoring international law externally and producing a permanent state of exception internally - nevertheless still claims to be applying the law' $(2005,87)$.

This perspective, I suggest, provides an entry point to understand why none of the markedly different approaches necessitated a change of law by Parliament but were regulated through changing regulations and circulars issued by ministries and directorates. While these administrative decrees facilitated an exceptional departure from the universal principles that supposedly characterise Norwegian welfare provisions, they were generally seen as part of the normal workings of law.

This perspective also offers a way to explore the use and function of the emergency provision (e.g. the written and unwritten Act of Necessity) by taking necessity out of spectacular and exceptionalist settings and placing it in the context of mundane governing. To understand necessity as a legal concept, legal theory generally refers to the Latin maxim necessitas legem non habet, 'necessity has no law', variously understood as 'necessity does not recognise any law' and 'necessity creates its own law' (Agamben, 2005, 24). As such, necessity is understood as having the power to render the 'illicit licit'. To Agamben (2005), necessity can therefore be seen as a foundation for the state of exception. What it importantly does, he suggests, is that the perceived state of emergency allows for administrative decisions without challenging the rule of law, thus 'creating a zone in which application is suspended, but the law, as such, remains in force' (Agamben, 2005, 31). In this sense, necessity acts to justify a single, specific case of transgression by means of an exception. Or as Agamben puts it: 'Necessity is not a source of law, nor does it properly suspend the law; it merely releases a particular case from the literal application of the norm' $(2005,25)$.

The institution of necessity can be found in constitutions, as in a state of emergency, as well as in criminal and civil law. Here, necessity justifies a wide variety of actions that would be legally prohibited during periods of normalcy. The institution of necessity can also importantly be found, as in the case explored here, as a legal basis for decisions by public administration (Andorsen, 1999; Hovde, 2006). In relation to irregular migrants' access to welfare in Norway, necessity could be deployed both to include and to exclude. As shown previously, the casebased suspension of the law through the Act of Necessity allowed welfare offices to grant financial assistance to irregular migrants, while the law that excluded irregular migrants from social welfare (and the state) remained in force. The Act of Necessity, in both its written and unwritten form, is in this context less spectacular than a state of emergency, but it still poses a challenge to the classic liberal idea of the rule of law that emphasises order, regularity, and certainty, as opposed to the arbitrariness of royal rule. Thus, what is at stake is not only the question of universal versus particular law but the passage from general law to concrete case, and the role of professional discretionary judgements in this passage, which I will return to more extensively in Chapter 3. The point I wish to make here is that 
again we see that it is the exceptional life, rather than the right-bearing subject, that is being cared for.

\section{Care beyond the state?}

So far, I have explored access to care administrated by the state, either at national or municipal level. Many irregularised migrants, though, do not seek public assistance and rely on support within their own networks and from NGOs. Aster, for example, relied primarily on female friends in her ethnic and religious community. However, as the years went by, she, and others I met during fieldwork, experienced increasing strain on these networks. Tactics they would develop to deal with this involved rotating places to sleep, as well as constantly acquiring new friends.

In this section, I will explore the role of NGOs in providing care and support to irregular migrants. NGOs have been seen as an important source of basic support for irregular migrants in many contexts (Darling, 2009; Castañeda, 2011; Van der Leun and Bouter, 2015). An important characteristic of the Nordic welfare model, though, is precisely the key role the state has as provider of welfare, compared to more informal arrangements through family, private organisations, or the market (2015). Hence, in this context, it is interesting to see how and where civil society comes to play a role as the provider of care for irregular migrants and particularly how national policies constrain or enable assistance from NGOs or individuals. Allowing or funding NGOs can be seen as another example of an exceptional measure built into the system to alleviate some of the tension between border enforcement and humanitarian concerns, contributing to irregular migrants' precarious inclusion.

In the same period as irregular migrants' access to public services has become circumscribed, there have been attempts to define more restrictively the legal borders of a humanitarian space in which NGOs and individuals can provide irregular migrants with basic care. When the Immigration Act was adopted in 1988, it contained only a penal provision concerning the facilitation of entry into the country. This activity had to be 'organised' and made with 'the purpose of gain' to be illegal. With the entry into the Schengen agreement in 2001, Norway was required to make certain revisions to the act, including sanctioning those who assisted foreigners in staying illegally. In the initial revisions, this act also had to involve financial or material gain to be illegal. When revising the Immigration Act in 2008, however, the government went even further, proposing instead that anyone who 'wilfully (forsettlig) helps a foreign national to stay illegally' (Ot. prp. nr. 75 (2006-2007), 479, my emphasis [Proposals from the government to the Parliament that contain concrete proposals for decisions]) could be punished with a fine or imprisonment for a term not exceeding three years. ${ }^{6}$ Hence, the new proposal replaced the requirement of gain with one of merely intent that could potentially affect non-profit humanitarian assistance.

The proposal was strongly criticised by several NGOs, including the Norwegian Red Cross, which petitioned Parliament to explicitly clarify that humanitarian assistance to irregular migrants was not in conflict with Norwegian law. When 
the bill eventually came to Parliament, a broad cross-party majority of members expressed scepticism toward the provision in line with the Red Cross' reservations. However, they approved the proposed act without amendments but urged the ministry to later specify the boundary 'between legal humanitarian assistance to foreigners with illegal residence and what can be considered criminal complicity' (Prop. 141 L (2010-2011)). The Immigration Act was subsequently amended in January 2012 to this effect. The new provision $(\$ 108)$ read as follow:

A person who provides humanitarian assistance to a foreign national staying illegally in the realm shall not be liable to a penalty for aiding and abetting the illegal stay unless (a) the person in question has had the intention of helping the foreign national to evade the obligation to leave the realm, and (b) the assistance has made it more difficult for the authorities to implement removal of the foreign national.

This paragraph thus clarifies that it is allowed to give humanitarian assistance as long as it is not intended to help the migrant evade government control and efforts to deport the migrant in question. As examples of what the provision precludes criminal liability for, the ministry explicitly mentions humanitarian organisations that openly offer humanitarian assistance to people with unlawful presence, for example in the form of an offer of housing that is known to the authorities, food, medical care, etc.' (Prop. 141 L (2010-2011), 22). Søvig (2013a) points to shelter as the potentially most legally ambiguous form of assistance. To what extent does sheltering an irregular migrant constitute hiding the migrant? Could, for instance, Mehret, as a private person, be punished for housing Aster? This is unclear, but as Søvig (2013a) notes in his legal review, the wording of the provision does not require that the offer of shelter be announced or in any way communicated to the authorities. The attempt to legally demarcate a space for humanitarian assistance thus illustrates the tension, but also the merging of pity and control in the policies towards irregular migrants.

During the main part of my fieldwork, the volunteer-run healthcare centre in Oslo where I met Aster was the only NGO-run service explicitly targeting irregular migrants in Norway. This centre was established in 2009 and was run as a cooperation between the Norwegian Red Cross, its Oslo branch, and the Church City Mission. In October 2013, a similar centre was established in Bergen. This was a smaller operation run by activists after the local branches of the Red Cross and the Church City Mission initially decided against such a project. In 2018, however, the two organisations agreed to take over the administration of the already established volunteer-run centre. While these centres were not only service providers but also important advocates for irregular migrants' right to healthcare, they were caught in a double bind of having to interact with the state while simultaneously trying to remain critical of its policies (Castañeda, 2011).

Critical literature on humanitarianism has cautioned that focusing merely on humanitarian aid may, willingly or not, help build legitimacy for states' exclusionary policies and their retreat from responsibility for service provision to irregular 
migrants (Ticktin, 2011). These were dilemmas the centres were well aware of and struggled to deal with on a daily basis (see Chapters 4 and 5). An explicit aim of the healthcare centres from the beginning was to make the government take responsibility for irregular migrants' healthcare needs. In this respect, the centres followed a 'traditional' approach of Norwegian NGOs, in which they act as initiators of activities to be taken over by the public sector (Sivesind et al., 2002). ${ }^{7}$ A continuing challenge, though, was that while the humanitarian moral principle of securing biological life secured a space for care of irregular migrants, the care became premised on not challenging state sovereignty in determining membership. For example, when Trygve Nordby, the then secretary general of the Norwegian Red Cross, launched the initiative to provide healthcare services to irregular migrants he stated: "We do not dispute the sovereign prerogative to decide who should have legal residence in a country. This is only a matter of safeguarding basic needs and basic rights' (Norwegian Red Cross, 2007, 6). This argument was used repeatedly to justify and defuse criticism against the centre and as such maintain a space for humanitarian assistance. Yet, as Agamben's critique of modern rule highlights, the separation between humanitarianism and politics is ultimately based on a faulty notion that it is possible to separate the biological or 'bare life' of the individual from wider political questions. Thus, by relying on the political/humanitarian divide, humanitarian actors entrench a state sovereignty that is responsible for the very social suffering that they aim to minimise, according to Agamben (1998).

Beyond healthcare, there were few other services for irregular migrants, and access to food and shelter came to rely primarily on previous organisational structures and the norms of care and deservingness that informed these. Emphasising the 'state-friendly' context in the Nordic countries, academic literature on 'civil society organisations' has tended to see these organisations not as occupying an oppositional position in relation to the state but as part of a particular division of labour (Wijkström and Zimmer, 2011; Henriksen et al., 2018). Although voluntary sector providers of welfare exist, they have been considered so closely integrated into the public system of finance and control that they hardly constitute alternative providers of welfare services.

This context has had some particular implications for irregular migrants' access to humanitarian assistance from non-profit non-governmental organisations. First, the close integration of NGOs' welfare services in the public system essentially meant that these services were not available for irregular migrants. ${ }^{8}$ For instance, while Zeki, received assistance from an NGO working with drug users both materially (food and money for health and dental care) and as mediator with the public system (applying for emergency aid, rehabilitation, appealing his expulsion), getting treatment in an NGO-run rehabilitation institution was not an option. This is because the institutional places run by NGOs were generally pre-bought and administered by the public healthcare system. However, one of the low-threshold services for drug users in Oslo reported that in a few cases, they had initiated Medically Assisted Treatment for substance abuse with irregular migrants that had family and access to stable housing in Norway. 
Second, in Norway, the NGO sector mainly plays an important role as a social service provider in some particular subfields, drug rehabilitation being the most prominent one, and (partly by extension) women in prostitution. Although clothes and food hand-outs by organisations expanded during the 2000s and were also increasingly directed towards those considered poor in general, most lowthreshold services were still primarily oriented towards these traditional areas of humanitarian assistance (Nuland, 2007). Hence, irregular migrants such as Aster who were not suffering addiction were not necessarily able to benefit from these services.

Most of the organisations providing basic material support (food, clothes) in both Oslo and Bergen during my fieldwork were Christian organisations (the Church City Mission, Blue Cross, and the Salvation Army). In addition, there were two non-religious self-help houses originally initiated by recipients of social benefits (Fattighuset in Oslo and Robin Hood-huset in Bergen). During my fieldwork, these low-threshold services experienced the growing presence of irregular migrants in dire situations as challenging, and the organisations varied in their responses, that is, in the extent to which they were willing or able to offer their services to irregular migrants. In interviews and conversations, the staff members of organisations with whom I spoke pointed out two main dilemmas. The first dilemma was one of helplessness. While the organisations could offer irregular migrants some basic and temporal care under unfavourable conditions, their ability to serve as an entrance to public services, which many of the organisations saw as an important part of their role, was very limited. This limitation made some individuals and organisations reluctant to get involved. Second, some organisations feared that irregular migrants as new users of their services would push out the traditional users that they considered their target group (i.e. drug users). This led some NGOs to close their services to irregular migrants, while others decided to adjust their services to accommodate new user groups, including rejected asylum seekers and poor jobseekers from the European Economic Area (EEA). ${ }^{9}$

In some cases, but not all, funding was an issue, as some relied on earmarked public support. The two main services targeting irregular migrants were explicitly funded by a combination of their own means, private funds and donations, and public support. The healthcare centre for undocumented migrants in Oslo was primarily financed by the Norwegian Red Cross and the Church City Mission, with only some minor earmarked funds directly from the Directorate of Health for projects considered important from a public health perspective. However, although the centre itself only received a small amount of public funding, the two organisations behind the centre received significant funding through various state and local mechanisms. The centre in Bergen, in contrast, received most of its funding directly from the municipality and some from the county and the Directorate of Health.

Access to shelter hardly existed in the two cities. When I started fieldwork, the only NGO-run shelters available in Oslo and Bergen were explicitly only for drug users and therefore were unavailable or considered inappropriate for irregular migrants. However, in Oslo, an emergency centre would open if the temperature 
fell below minus ten degree Celsius. In this sense, the shelter illustrated the construction of a particularly minimalist biopolitics ('no one should freeze') and the arbitrariness in defining this threshold. The limit of ten degrees below zero, for example, was set by the health authorities in Oslo, and according to them, it was based on a 'professional medical evaluation' regarding when the weather conditions would constitute a danger to life and health (Vedeler et al., 2014). The shelters were, as such, regarded as acute medical care. However, in the winter of 2014, the municipality was criticised for its strict interpretation. In response, the municipality adjusted its criteria to 'perceived' or 'effective' minus ten degrees rather than the exact temperature showed by the thermometer. In comparison, Trondheim tried out a similar offer in 2013 and 2014, where the criterion was first set at minus ten, then changed to zero, before it was changed again to minus five degrees Celsius (Gullestad, 2013; Kilnes, 2013).

In Oslo, the emergency shelter was run by the Salvation Army, financed in cooperation with the municipality, and access was administered by the municipality through an after-hours social service office located at the main primary emergency care centre. To gain access, one had to register at the municipal office. The service considered its target groups primarily to be drug users and increasingly 'Roma-beggars' and expressed scepticism to irregular migrants filling up the available space (Drabløs and Holden, 2012). Hence, information about this possibility was not actively distributed among irregular migrants.

No equivalent formalised offer existed in Bergen. However, in the spring of 2013, the government launched a subsidy scheme for emergency services targeting 'foreign beggars'. The bulk of the money went to shelters organised by the Church City Mission and the Red Cross in Oslo and Bergen. However, a requirement for funding was that these shelters were to be reserved for 'travelling EEAcitizens'. However, the shelters did not check ID and thereby made it possible for irregular migrants to gain access. People from countries outside the EEA, however, constituted generally a very small percentage of the reported guests at the shelters.

\section{Universalism and particularism}

Linda Bosniak $(2006,31)$ has argued that universalism is the prevailing ethic within a political community whose boundaries and identity are taken for given. Likewise, the main characteristics of the Norwegian welfare state are thought to have developed prior to immigration becoming a politicised issue (Brochmann, 2017). In this sense, irregular migration has brought to the fore the limits and territorial boundedness of the Nordic welfare model's inclusionary ambitions.

It should be noted here, though, that the Nordic countries have not necessarily followed the same approach. At the turn of the millennium, when the debate over irregular migrants took off in Sweden, the migrants were defined as being outside the rights-bearing community of the welfare state. Since then, there has been a successive expansion of the scope of rights granted to irregular migrants. Most notably, two new laws were implemented in 2013, through which irregular 
migrants were explicitly granted certain rights to subsidised healthcare beyond emergency care, although not equal to that offered legal residents, and irregular children access to schooling and healthcare. Hence, Swedish policy, previously often singled out as one of the most restrictive in Europe, has been revised in a more inclusionary direction (Nielsen, 2016). However, these inclusive changes did not include access to social services, although these are provided by some municipalities (Nordling, 2017).

In Norway, irregular migrants' position with regard to welfare rights was more inclusive to begin with. For example, in 1993, when several hundred rejected asylum seekers from the Balkans, particularly Kosovo, sought sanctuary in Norwegian churches, the Norwegian health authorities issued a letter that clarified that the Municipal Health Services Act (1982) did not distinguish between legal and illegal residence. Therefore, the municipality's health services, which cover all primary healthcare, should include those that had sought church asylum (Mathiesen, 2002). Irregular migrants are also still considered to be equally included by the scope of important welfare statutes such as the Child Welfare Act (1992), the Education Act (1998), and the Act on Crisis Shelters (2009) (Søvig, 2013b). Irregular migrants' access to welfare, particularly to healthcare and social support, though, has become increasingly limited. A common trait emerging from these accounts, is that although irregular migrants were not included in the regular system of social support, there were certain exceptional measures that made it possible to compensate for the harshest consequences of their lack of legal status. In this sense, it was not the absence of state support per se but substandard and exceptional care arrangements that produced migrants' precarity.

\section{Notes}

1 This practice was recognised by the courts in 2013 when Gulating lagmannsrett (appeal court) acquitted a company of criminal enterprises for having employed an asylum seeker without a valid work permit in 2009 and 2010. The court noted that the company had built on a widespread misconception that a person's tax card was sufficient evidence for a work permit. This judgement is final as the Supreme Court rejected the state's appeal (UDI, 2013).

2 Employees at private and NGO-run centres can share information concerning residents with the UDI. This is part of their tender agreement through a clause used since 2003. However, employees at municipally run centres, as public employees, were bound by a stricter code of confidentiality and therefore could not legally share information with the UDI (NOU, 2011: 10, p. 10).

3 Local authorities were explicitly encouraged to give feedback on this issue in the consultation round of 2013. Few did, which could be an indication that there were few experiences or that knowledge was limited.

4 It should be noted that while social assistance can be considered universal in the sense that the circle of people who can apply for such support is very broad, it is not so universal in the sense that it is awarded on assessment, and the amounts conferred can vary (Brochmann and Hagelund, 2012).

5 This affirmation of sovereign prerogative in the welfare legislation was implemented in the Social Services Act first in 1991. Also, whereas the Patients' Rights Act of 2001 states that the King may 'grant exemption' for persons who are not Norwegian nationals 
or who do not reside permanently in the realm, the Social Services Act of 2010 uses 'limiting'. See Andersen (2014) for a discussion of possible implications of this distinction. For instance, from a legal perspective, Anderson criticises the government ministries for going too far in restricting irregular migrants' access to social benefits in relation to this opening given by the law.

6 The current provision in the Immigration Act concerning humanitarian aid was a preliminary end product of a series of amendments of a fairly technical nature. For a more detailed review, see Søvig (2013a).

7 Trygve G. Nordby, the then secretary general of the Norwegian Red Cross, stressed this point at the inauguration conference by comparing the healthcare centre to the Women's crisis shelter movement. Women's crisis shelter is a case in point in Norway exemplifying activities that originally were initiated by voluntary associations, then becoming almost totally financed by public sources, before becoming an obligatory municipal task, often run by the municipalities themselves (Sivesind et al., 2002).

8 There were some variations. For instance, the healthcare centres in Oslo and Bergen were able to make deals with the diaconal hospitals in the cities for access to certain types of healthcare (see Chapter 4). These hospitals were independent diaconal institutions within the Church of Norway. Both also function as local hospitals for Bergen and Oslo under contract with the regional health enterprises through which they receive the majority of their funding.

9 Irregular migrants here were just one category of a broader group of new users. Socalled 'Euro refugees' and 'Roma-beggars' generally constituted a larger presence. 'Euro refugees' was a term frequently used in the media during my fieldwork in 20112013 primarily to denote an influx of people coming from Spain to seek work due to the financial crisis and who found themselves in a precarious situation in Norway without shelter. 'Roma-beggars' and 'Euro refugees' seeking employment, whom these shelters were supposed to be for, often found themselves in a form of irregular situation as they did not necessarily conform to the requirements of self-sufficiency stipulated for free movement within the EEA. Nevertheless, as Europeans, they were constructed as a different problem field than non-EEA travellers (or irregulars). However, how this worked out for each category is ambiguous. EEA-citizens would not have access to the safety net of reception centres. 


\section{Moral bordering}

In February 2013, only a year after it went into force, the emergency aid provision that granted Zeki economic assistance from local welfare offices came under attack. Several Norwegian newspapers reported that a man from the Middle East, convicted of attempted rape in Sweden and expelled from Schengen, had been granted social assistance and housing benefits from the Norwegian Welfare Administration (NAV). Like Zeki, this man had initially come to Norway as an unaccompanied minor, before moving to Sweden in 2010. On his return, as the media account reported, the local office in the city of Skien first granted the man emergency aid for ten days during the summer of 2012. Later that year, the man applied for regular social support, which he was denied. However, the man appealed to the county governor, who concluded that he indeed was entitled to financial support and temporary accommodation until he 'in practice could leave the country', a phrase used in the regulation of the so-called emergency aid provision (the Social Services Regulation, 2011).

In response to the media coverage of the case, several prominent politicians reacted with strong condemnation. Torbjørn Røe Isaksen, a prominent conservative Member of Parliament, exclaimed that this gave anyone staying 'illegally' in Norway a 'carte blanche' to get money from the welfare administration. The Progress Party's Robert Eriksson, who 8 months later would become the Minister of Labour and Social Inclusion, claimed that 'we now find ourselves in the insane situation that we have become the social welfare office for the entire world' (Hegvik et al., 2013). The Minister of Labour and Social Inclusion at the time, Anniken Huitfeldt (the Labour Party), was also quick to declare that granting benefits to this man was contrary to her opinion about who should receive welfare benefits. However, while the opposition seemed to protest giving support to people staying 'illegally' in general, the Minister focused on this man's criminal background. In a statement quoted in VG, the largest Norwegian newspaper, she said, 'If the current emergency provision has such unreasonable effects, I will change it. I want to make sure that it is not abused by persons who have committed crimes and who have been expelled from the country' (Hegvik, 2013a). Five months later, the Minister, on the basis of this particular case, initiated a consultation on changing the regulation. As the regulation was only a year old, it became the second consultation on the so-called emergency provision in less than two years (Ministry of Labour and Social Affairs, 2011, 2013).

DOI: $10.4324 / 9781003156598-3$ 
Thus far, I have explored how irregular migrants' limited access to basic services is legally and administratively structured in Norway. But how is it legitimised? While the opening case underscores the instability of the care granted to irregular migrants as shown in the previous chapter, it also draws attention to how this relates to moral judgements and discourses about deservingness surrounding irregular migrants. In this chapter, I am interested in understanding how the norms that govern irregular migrants' access to welfare services reflect wider societal values and norms regarding the legitimate and illegitimate, and not only the legal and illegal, and how these norms can contribute to irregular migrants' precarious inclusion. Under what conditions does it become easier or more difficult to deny irregular migrants basic support such as food, shelter, and healthcare? Or more specifically in the context of Norway: How could the exclusion of irregular migrants from regular welfare be justified within a system supposedly based on equality?

Judith Butler $(2009,25)$ has argued that precarity, that is the differential distribution of precariousness, should be understood at once as a material and perceptual issue, as those not regarded as valuable are made to bear the burden of starvation, underemployment, legal disenfranchisement, and so on. Hence, to Butler, a central question when exploring the conditions under which certain human lives acquires a right to protection, and under what conditions they do not is what makes for a grievable life. For example, people who are deemed responsible for the ills that have befallen them or those that are considered dangerous to the community are generally less likely to be mourned or pitied and thus protected and cared for.

The persons who are cast as a threat or responsible for their own ills varies between societies and must be studied in a historical and socio-spatial context. In the Nordic context, structural explanations for deprivation and poverty, rather than individual blame, have been thought to have stronger support than in countries with other welfare regimes. With its normative basis, Nordic political culture has therefore been considered a least-likely case for a deservingness frame to be effective regarding policy design (Van Der Waal et al., 2013; Larsen, 2008). Nevertheless, in the Nordic countries, a 'deservingness rank order' similar to other European countries has been indicated, following to varying degrees criteria such as blame/innocence, 'us'/'them', and future/past reciprocity (Van Oorschot, 2007). A central stake regarding irregular migrants' access to welfare, as illustrated in the opening case, is whether all irregular migrants are undeserving, or are there some who are more (or less) worthy of compassion and care?

The moral economy of a society is also not only related to how the 'we' construct 'the Other' but also to how the 'we' perceives itself in relation to 'the Other'. Welfare is not simply about particular institutional arrangements but must also be approached as expressions of norms, values, and social goals having a significance as to how problems are understood and responded to (Kuhnle and Kildal, 2005). Such an understanding of welfare draws attention to the kinds of conceptions of the nation are installed and enacted in the institutions of welfare and how the basic cultural norms and values that underpin different welfare regimes may inform possible state action towards 'the Other'. Moreover, a focus 
on moral bordering practices can shed light on how care for irregular migrants is both moulded by and helps mould transformation in the welfare state. In the following, I will therefore first investigate how irregular migrants are constructed as deserving or undeserving in state policies and discourse before exploring how these constructions relate to national self-perception, and norms and values embedded in the welfare state.

\section{Between blame and pity}

The way irregular migrants are increasingly cast as 'undeserving', and not merely 'unwanted', in public discourse is widely commented upon within migration literature. In particular, the 'culture of disbelief' surrounding the category of asylum seekers in Europe, and the distinction increasingly made between legitimate and deserving refugees and bogus asylum seekers, has been seen to justify harsher policies, including restricted access to basic service provisions for those deemed undeserving. In this context, terms like 'asylum seeker' and 'irregular migrant' become not simply descriptions of legal status but value-laden and negative (Anderson, 2013). Constructed as undeserving and denied a political voice, irregular migrants are excluded not only from the political community but also, Willen argues, from 'the moral community of people whose lives, bodies, illnesses, and injuries are deemed worthy of attention, investment, or concern' (Willen, 2012b, 806). The question of deservingness as such becomes central to the way migrants' civic value is defined, measured, and translated into care.

Despite the fact that irregular migrants are surrounded by discourses portraying them as a threat to society, research has shown that humanitarian discourses also portray them as human beings variously in need and deserving of care. Which particular suffering is recognised in the public domain, however, is a question of struggle and construction and not of inherent 'merit', as argued by Ticktin (2011). Moreover, as suggested by Fassin (2012), the flip side of a politics of compassion that emphasises deservingness is that policies become more vulnerable to moral panic. This introduces both instabilities and an ambivalence in regard to how irregular migrants are perceived and managed. It also contributes to an increased differentiation and hierarchisation as certain categories of irregularised migrants evoke more or less compassion. The literature on the role of humanitarianism in governing migration in Europe has particularly highlighted the importance of the sick body (Fassin, 2012), but also how humanitarian exceptions are shaped by classed, racialised, and gendered notions of innocence and dangerousness (Aradau, 2004; Ticktin, 2016). Here, foreign women in prostitution are a prime example, as various mechanisms have been introduced in many countries to distinguish between women who are deserving and innocent victims of trafficking or undeserving and criminal irregular migrants (Plambech, 2014). Much of this literature has focused on the significance of humanitarianism for protection in the form of residence. However, many of the central characteristics identified can also be seen operating in regard to questions of what kind of care should be available to whom as long as they remain irregular. Cultural understandings and 
recognition of need, vulnerability, and deservingness produce further differentiated access to services.

In Norway, parallel to the changing social policies, there has been a growing state effort to distinguish discursively between the migrants who are 'worthy' and 'unworthy' receivers of welfare state benefits, I propose. As irregular migration is largely associated with the asylum system in Norway, this in particular has been pursued by an increasing tendency to distinguish the rejected asylum seeker from the asylum seeker, both in terms of welfare entitlements, as shown in the previous chapter, but also in terms of labelling. The term 'asylum seeker' has not necessarily had a negative connotation in Norway and was the term most often used by my interlocutors. To explore the moral ambiguity surrounding irregular migrants, I will first look at how irregular migrants' deservingness is expressed in various labels used within Norwegian public discourse, before examining how deservingness is used to differentiate between irregular migrants.

\section{Whose responsibility?}

The central contested issue that is expressed in the various labels used to describe irregular migrants in Norway, I suggest, is who is to be held morally responsible for their precarious situation - the migrants themselves or the state that fails to deport them. What is at stake in the labels is thus the question of individualversus-social responsibility for suffering. In 2004, the term ureturnerbar (unreturnable) was a prominent label introduced in the discussions surrounding the withdrawal scheme implemented in 2004 regarding rejected asylum seekers' access to state accommodation. The term was widely used among academics, politicians, and bureaucrats, and it contributed towards enlisting public sympathy (see for instance Brekke and Søholt, 2005; Aarø and Wyller, 2005). Many of those who lost access to state accommodation at that time were difficult to deport, either because the country of origin did not accept deportees or because identity was not established. However, since 2004 the government has made several attempts to define and delimit to whom the term 'unreturnable' should refer.

In a bill presented to the Parliament, the following definition was introduced:

Only when the person respects the rejection [of his/her asylum claim] by actively cooperating in his/her return to the country of origin, but still is prevented from returning by the home country's authorities, can he or she be referred to as a 'genuine' unreturnable.

(Ot.prp. nr. 112 [2004-2005])

In 2007, this definition formed the basis for changes in the Immigration Act, making it possible for the immigration authorities to grant work and residence permits as a last resort when there were 'practical obstacles for return'. Although 'genuine' here seems to signal that many of those who currently fell under the label 'unreturnable' were not so in the view of the state, the provision can be seen as a state acknowledgement of the category. When I started my fieldwork in 2011, 
however, the official view became categorical, namely that no one was 'unreturnable'; there were only 'return refusers' (returnektere).

The labelling of irregular migrants as 'return refusers' can be seen as an active attempt by the authorities to contradict the more established terms of ureturnerbare and papirløse ('undocumented', or more literally translated, 'paperless') and also to question the victim-status that these terms implied. The 'return refuser' label was first introduced by State Secretary (junior minister) Pål K. Lønseth, who acted as the government spokesperson on asylum issues between 2009 and 2013, in a newspaper comment in October 2011 (Lønseth, 2011). This comment was a response to concerns raised by several municipalities, including some of the largest cities in Norway, about irregular migrants' living conditions. These concerns were again spurred by various political mobilisations on the part of irregular migrants, including an asylum march from Oslo to Trondheim in August 2011 and a hunger strike in Bergen in October 2011, leading to a number of city councils adopting resolutions urging the government to re-evaluate current policies concerning work permits, healthcare, and regularisation. In continuation, two members of Parliament representing the Liberal Party (Venstre) submitted a proposal to the Parliament to ask the government, among other things, to 'ensure that undocumented ('papirløse') immigrants receive necessary physical and mental healthcare' and 'create conditions to ensure that undocumented immigrants can work legally and pay taxes until known departure date' (Innst. 199 S (2011-2012)).

In her written response to the Parliamentarian committee considering the proposal (Parliament's Standing Committee on Local Government and Public Administration), the Minister of Justice and the Police Grete Faremo responded by first 'clarifying the terms':

Initially, I find it appropriate to have a conceptual clarification. The term 'undocumented' ('papirløse') is unfortunate as it can be misunderstood to mean that the person in question does not have identity documents or written decision from the Norwegian immigration authorities. I assume that 'undocumented' here refers to people without legal residence in Norway. A more appropriate term, which I will use in what follows is 'return refusers'.

(Innst. 199 S (2011-2012), my emphasis)

'Person without legal residence' is the official term used in public documents and regulations. Therefore, it might seem strange that 'return refuser' should be 'a more appropriate term' in this context. The different labels preferred by the MPs and the minister, however, have significantly different connotations regarding responsibility, morale, and agency and, as such, represent different ways of framing the problem and the solutions. In the dominant Western model of personhood, the individual is generally characterised as rational, autonomous, and unitary. Notions of agency therefore become central to attributing responsibility and accountability (Jacobsen and Skilbrei, 2010). 'Unreturnable' and to an extent 'undocumented' assign the migrant a passive subject-position and signals a failure on the part of the state to act, whereas 'return refuser' puts the agency 
and the moral responsibility of not returning clearly on the migrant. It also makes the migrant, and not the state, responsible for their own and their children's living conditions while they are irregular. It is the migrants themselves that hold the solution to their problems. As then State Secretary Pål K. Lønseth put it, 'They are themselves responsible for putting their own and their children's lives on hold by refusing to return' (Lønseth, 2011). This was followed by similar statements made by the Minister of Justice and Police Grete Faremo. In a newspaper comment regarding children of irregular migrants, with the telling title 'Parental responsibility', she writes, 'The important thing to remember is that the state is responsible for the [asylum] procedure and the time this takes. Everything happening after the final decision is the asylum seekers' own responsibility' (Faremo, 2012). Faremo, by 'clarifying the terms' in her letter to the Parliamentarian Committee, could thus be said to place the blame for the difficult situation on the migrants themselves, justifying the state's lack of compassion. Her response to the concerns raised by the two members of Parliament and the municipalities of Trondheim, Bergen, Stavanger, Sandnes, and Kragerø was, not surprisingly, that there was no need for the government to soften their current policies.

\section{Mismanaged life and humanitarian exceptions}

Several scholars have commented upon the trend within neoliberal governmentality to place the moral blame on individuals for their own predicament, rather than pointing to structures of inequality based on class, race, and gender. Accordingly, a 'mismanaged' life becomes evidence of and grounds for (an Agambenian form of) abandonment (Pratt, 2005). It becomes a 'banishment by choice' (Mitchell, $2006,103)$. This is clearly implied in the term 'return refuser', as, in the view of the Norwegian government, they were themselves responsible for putting their lives 'on hold' by refusing to return to their country of origin. Nevertheless, as shown in the previous chapter, irregular migrants were (and still are) entitled to certain benefits. Throughout the past decade of changing policies, certain groups have been continuously singled out for special care. For example, families with children and individuals with health problems could remain in ordinary state accommodation during the period the withdrawal scheme was in effect. This draws attention to how recognition of vulnerability and perceived blame were used to distinguish between irregular migrants deemed to be more or less deserving of care. In this case, there seem to be two different mechanisms operating. The first mechanism relates to the distinction between the 'good' and 'bad illegal migrant' as illustrated in the opening passage. Here, the minister singled out 'convicted criminals' as those who should be excluded from services that other irregularised migrants receive. In this sense, these are lives that are seen as 'extra mismanaged' or 'ungrievable' as they are perceived to have failed in some important moral ways and therefore do not deserve even humanitarian compassion. The second category is the so-called 'humanitarian exceptions' based on particular notions of suffering and vulnerability through which certain individuals and categories of irregular migrants become eligible for particular forms of care. 
Several scholars have pointed out how the deservingness discourse constructs particular subject-positions for the irregular migrant. For example, while the focus on irregular migrants as 'bogus refugees' or 'criminals' has helped construct the category of the 'bad illegal', irregular migrants are also encouraged to make themselves 'good illegals' to counter these associations in an attempt to gain both moral and legal acceptance (Coutin, 2003; Khosravi, 2010: Anderson, 2013). According to Chauvin and Garcés-Mascareñas (2012), the good character of irregular migrants in various EU countries and in the USA has been increasingly defined in terms of noncriminal conduct, economic reliability, fiscal contribution, identity stability, and bureaucratic traceability. As such, irregular migrants can make themselves 'less illegal' and more deserving by working and avoiding crime. Through their exploration of 'the moral economy of illegality' in France, Spain, the Netherlands, and the USA, Chauvin and Garcés-Mascareñas (2012) suggest that work participation in the workforce is an important currency in the moral economy in these countries. Work, as they point out, is both a major pathway towards legal recognition and an area where irregular migrants can access formal rights. In most European countries, labour law formally protects all workers irrespective of their legal status. In France, the Code du Travail specifically states that illegally employed workers are entitled to the same guarantees as the regularly employed, including the calculation of pay based on seniority.

Whereas wage labour is a key marker of inclusion in most countries, including Norway, Eba and Aster's cases in the previous chapter illustrate how, for legal and political reasons, they were not considered, or not allowed to be considered, as 'contributing members of society'. However, through their protests in Oslo Cathedral following the loss of the tax card, the Ethiopians still attempted to inscribe themselves in what Anderson (2013) calls 'the community of values' by emphasising their deservingness as taxpayers (Bendixsen, 2013). Moreover, as shown in the previous chapter, Eba and Aster stressed their attributes as 'good workers' in their conversations with me, referring to the recommendations they had received from previous employers. Scholars have pointed out that such statements must not be understood just as conveying an aspect of their identities but also as challenging the discursively and institutionally produced positionality of the 'unproductive Other' (Haas, 2012, 253; Bendixsen, 2013). Nonetheless, labels may mould in subtle ways the identities of those who are consigned to a label (Dauvergne, 2005). For instance, when I asked Aster if she had tried to look for informal work, she replied that she had thought about it. She had considered knocking on doors in her neighbourhood and asking if people needed domestic help. 'But you know', she explained, 'I didn't do it because I'm ashamed. Ashamed that I am illegal.'

In Norway, being good workers and taxpayers neither created formal possibilities for gaining access to welfare for Eba and Aster nor did it lead to becoming regularised. Consequently, it could be argued that their moral capital as workers did not translate into rights, but rather worked to document their lengthy breach of immigration law, thus making it a more serious offense in the view of the immigration authorities. Chauvin and Garcés-Mascareñas $(2012,253)$ also acknowledge the temporal double bind that places 'deserving' irregular migrants 
at constant risk of being framed as 'more illegal' for the same economic features assumed to increase their civic capital.

When it comes to questions of deservingness and humanitarian exceptions, Norway's moral economy resembles to a large extent that of various other European countries, where children and women in certain circumstances are considered particularly vulnerable and have been targeted in policies. Based on her research on irregular migration in France and the USA, Ticktin (2016) has argued that perceived innocence is important for suffering to become recognised. As she writes, 'The quintessential humanitarian victims bear no responsibility for their suffering. ... As innocents, they are pure, without guile, and without intent - they are seemingly outside politics and certainly outside blame for their misfortune' (p. 257). With innocence increasingly being required in order to designate the sufferer as worthy, 'blameless children' become in theory the ideal recipients of humanitarian care, she suggests.

In Norway, the so-called 'long-staying asylum children', a term that generally refers to children who have lived in asylum reception centres for more than three years and whose families' asylum cases have been rejected, have received significant attention in the media and at the government level. This category has been the main subject of Norway's limited regularisation schemes, through which children's 'affiliation to the Realm' has become a key issue in evaluating whether a family should get residence on humanitarian grounds (Meld. St. 27 [2011-2012]). Children are also granted the right to education and to most healthcare services. However, caught in the tension between states' commitments to protecting children and their governments' desire to limit unwanted migration, asylum children's position has increasingly become ambivalent (Vitus and Lidén, 2010). For example, Norwegian policies have adopted a distinction between children under or above the age of 15 . Unaccompanied minors younger than 15 years, since 2008, are entitled to live in special care centres administered by the Child Welfare Services to ensure that they are entitled to the same standards of care and support as were the children in child protection institutions. Minors aged 16-18, however, are placed in asylum centres for unaccompanied minors under the jurisdiction of the Directorate of Immigration. Since 2009, unaccompanied minors over the age of 16 at the time of the decision may also be given only temporary permission to stay until they reach the age of 18 (Lidén et al., 2017).

Women in prostitution are also an ambiguous category in terms of innocence. In Norway, irregular migrants suspected of being the victims of human trafficking have the right to temporary residence by entering the so-called reflection period. In this six-month period, they are granted the right to accommodation, financial support, and healthcare services. However, without being recognised as a victim or witness whose presence is necessary for an investigation and prosecution, these women lose the residence status and the rights that accompany it (Jacobsen and Skilbrei, 2010; Jahnsen, 2014). As irregular migrants, they have very limited access to healthcare, but both Bergen and Oslo municipalities have particular healthcare arrangements for women in prostitution in general that also extend to irregular women in this situation. The state also funds activities by NGOs directed 
at women in prostitution that include irregular women. However, the care services these can offer are very restricted and do not involve access to shelter or money. As such, NGOs I spoke with would sometimes assist women with applications for asylum as a way of temporarily regularising their stay and gaining access to housing in asylum reception centres for certain periods of time.

However, what appeared as the clearest and most particular example of humanitarian exception in the Norwegian context was rejected asylum seekers' access to state accommodation and economic benefits through the asylum reception system and the Act of Necessity that I described in detail in the previous chapter. While it is difficult to say whether the distinction between rejected asylum seekers and other irregularised migrants was based on some moral judgement of deservingness due to an attachment to the asylum system or based on pragmatic concerns, both systems could be said to be grounded in what Fassin (2009) has called 'biolegitimacy', as they primarily were premised on the basic survivability of the body. However, in contrast to Fassin's (2012) France, it was not the sick body that was the primary object of compassion but the starving and freezing body. Thus, while inclusion in healthcare services was a more prominent feature of precarious inclusion in France, state accommodation in asylum reception centres became, I suggest, a more central characteristic in Norway. This relates in part, I believe, to how visible poverty has been seen as deeply disturbing in the Nordic countries (Barker, 2017) and thus the manner in which it touches on questions of national identity.

\section{National identity and care for the excluded}

Humanitarianism as a form of government rationality not only makes a distinction between the deserving and undeserving 'Other' but could also be said to say something about national identity. Catherine Dauvergne (2005), for example, makes this argument. By examining the role of humanitarianism in Australian and Canadian immigration law, she notes that humanitarianism defines national identity not only through creating 'the other' who is the target of 'our' generosity but also by presenting a mirror in which the nation seeks a reflection of its benevolence. As she writes, 'The need that is met by humanitarianism is the need to define and understand the nation as compassionate and caring' $(2005,75)$.

Norway and the Nordic countries are not alone in sustaining a self-image as good and moral states. Fassin (2005) and Ticktin (2011), for example, observe how France's self-image as the 'homeland of human rights' contributed to a particular humanitarian government of migration in which the 'suffering' body, rather than the political or labouring migrant body, gained recognition. In a similar vein, Norway, together with its Nordic neighbours, has long fostered a selfperception and image as exceptionally compassionate and good nations through its commitments to welfare both domestically and internationally (Lawler, 2013). Domestically, the comprehensive welfare system, and high degree of social levelling, has been highlighted. Internationally, the countries have defined themselves through such things as a strong commitment to an UN-centred world order, the promotion of mediation-based conflict resolution, and, perhaps most distinctively, 
the provision of overseas development assistance. As pointed out by Trägårdh 'many countries engage in foreign aid, but outside the Nordic region few have been as vocal in proclaiming as their national mission such a strong commitment to foreign aid efforts and human rights ideals' $(2018,94)$. Particularly, Norway and Sweden have promoted an image as 'moral' or 'humanitarian great-powers' (NOU, 2003, 19; Fuglerud, 2005; Marklund, 2017). In much scholarly literature, the Nordic brand of 'normative internationalism' has been closely linked to the countries' domestic political cultures in which the values of solidarity, equality, and social justice are emphasised (Bergman, 2007; Witoszek and Midttun, 2018). In this sense, a commitment to solidarity and equality at home and human rights and development aid abroad are seen as two integrated aspects of 'the Nordic model' (Trägårdh, 2018). Although the thesis of Nordic exceptionalism and solidarity is somewhat overstated, it has undoubtedly been influential in shaping the nations' self-perception and has enjoyed considerable popular legitimacy.

The Nordic countries initially pursued a liberal asylum and refugee policy in line with their commitment to internationalism (Gammeltoft-Hansen, 2017). However, this has been changing over the past decades as the Nordic countries have imposed a series of restrictive policies with regard to both asylum and family migration (Staver, 2015; Liden et al., 2017; Brekke et al., 2020). The restrictive changes have come in different degrees and paces in the various countries, with Norway generally placing itself somewhere between Denmark, which has tended to take the lead in the turn towards restrictive policies, and Sweden, generally considered the most liberal of the Nordic countries (Brochmann and Hagelund, 2012; Hagelund, 2020). In all countries, and particularly after the increase in the numbers of asylum seekers in 2015 , these restrictive policies have increasingly included what Gammeltoft-Hansen (2017) calls indirect deterrence. Unlike direct deterrence, these policies do not physically or legally restrict access to seek and obtain asylum but include measures designed to discourage applications for asylum or divert them to other countries by making conditions for asylum-seekers and recognised refugees appear as unattractive as possible. Gammeltoft-Hansen (2017) sees these policies as a form of 'negative nation branding' that could potentially create dilemmas with regard to the wider 'branding' of the nation, as well as the country's self-image.

In the following, I will explore the role played by notions of goodness as part of national identity in relation to care for irregular migrants in Norway. Two aspects emerge as particularly significant. The first aspect relates to the tension between the 'goodness' implied in humanitarianism and in the universal welfare state. The second is the ambiguous role public discussions of goodness have had in terms of justifying more restrictive policies towards irregular migrants.

\section{Welfare nationalism and humanitarianism}

Exploring how the Norwegian welfare state embodies a form of community that is emotional and moral, anthropologist Halvard Vike (2004) has suggested that there is a form of 'welfare state nationalism' in Norway, where suffering is rarely 
considered solely the sufferer's own problem. Instead, he argues, suffering is a kind of stain that testifies to an incomplete and somewhat immoral society. ${ }^{1}$ In this regard, safeguarding and providing care to groups defined as weak is important to maintaining the welfare state's legitimacy and, as Rugkåsa (2010) suggests, citizens' identity as citizens in an inclusive society. This creates a strong normative pressure or expectation on the part of the state to address suffering of different kinds and to ensure that no one lives under conditions defined as undignified. Vike (2004) has characterised the Norwegian welfare state as ambitious and virtually limitless in the way it assumes responsibility for citizens' needs.

It is, however, unclear whether this kind of welfare nationalism could extend to those who are not deemed to belong, politically or morally, in the state or the nation. A basic premise in the Nordic model, for example, is that welfare policy should be universal and not limited to certain social groups, such as workers or the poor (Rugkåsa, 2010). Yet, as argued by Gullestad (2002), there is also an ethnically defined nationalism embedded in the seemingly egalitarian rhetoric in that equality is conceived as 'sameness'. This could potentially be used to discriminate. In Norway, scholars have further shown how the politics of migrant admission and incorporation is increasingly shaped by gendered, ethnicised, and classed notions of deservingness and desirability (Guðjónsdóttir and Loftsdóttir, 2017; Staver, 2015). Moreover, as previously noted, the welfare state's idea of distributive justice is often seen to presuppose a bounded world within which distribution takes place, a view inherent in the hard-on-the-outside soft-on-the-inside approach to migration (Bosniak, 2006; Brochmann and Hagelund, 2012). Irregular migrants represent in this context a tricky problem for welfare states by putting core welfare and national norms at odds. On the one hand, there is the bounded notion of membership represented by citizenship. On the other hand, there is the egalitarian notion of justice, redistribution, and equality.

The Norwegian form of welfare state nationalism to which Vike (2004) points can thus be said to include grounds for both inclusion in and exclusion from welfare for irregular migrants. The argument that suffering not only is the sufferer's own problem but testifies to a somewhat immoral society was definitely present within debates about irregular migrants and welfare, and it could be seen as creating a bottom line to what 'illegal residents' are allowed to suffer. For example, Brekke, who conducted the commissioned evaluation of the withdrawal scheme in 2004, has linked irregular migrants' continued access to food and shelter despite political efforts to remove it to core values underpinning the welfare system. As he argues in relation to the unwritten Act of Necessity:

[T] he debate over the rights of these people showed that at rock-bottom there is a limit to what people can be allowed to suffer, which is frost and starvation. On the basis of the legislation prevailing in 2005, rejected persons can be pressured thus far, but not beyond that limit. The norm that provides emergency aid in such extreme cases is not a formal obligation of the welfare state and was not based on any formal entitlement. These softer norms that call for provision of help can possibly be seen as a side effect of a long-term 
tradition of provision of welfare, or even more possibly as the result of basic humanitarian concerns and ideas of equality, which have served as the basis for the establishment of the welfare state.

(Brekke, 2008, 21, my emphasis)

During my fieldwork, prominent voices supporting a more 'humane' approach to irregular migrants, including bishops, politicians from different political parties, humanitarian organisations, and local activists, similarly referred to irregular migrants' dismal situation as a 'disgrace to the welfare state' or even characterised the policies as 'un-Norwegian'. Human suffering as a disgrace to the welfare state can be seen in this sense to play a similar role as the alternative 'homeland of human rights' rhetoric Fassin observed in France (2005) in appealing to a national identity as good and compassionate to justify access to basic care for irregular migrants.

In Norway, scholars have linked the discourse of national goodness, and its political legitimacy, with its success in being able to combine the solidarity concept of the labour movement and the Christian concept of compassion (Loga, 2002; Gripsrud, 2018). While the interconnection between these concepts is seen as important for understanding Norwegian history and political culture, they also represent different and diverging commitments and projects, a fact often underappreciated in academic and public discussions of Norwegian 'goodness'. Importantly in this context, there is a difference between welfare based on notions of social rights and redistribution, and on compassion and charity. In the Nordic model, these different welfare commitments have largely been projected onto two separate stages - humanitarianism internationally and universality domestically. The interesting question here becomes: What happens when the principles of humanitarianism are not only applied to a geographically distant stranger but applied in the domestic field in regard to irregular migrants?

Scholars of humanitarianism in the field of migration have tended to emphasise three particular characteristics of humanitarian care. First, humanitarianism is about feelings rather than entitlements. Actions are based on compassion and benevolence and oriented towards 'victims' rather than bearers of rights (Fassin, 2012). Second, humanitarian discourse and practice rest on a distinction between 'us' and 'them' and are grounded in a specific type of difference created by material inequality (Dauvergne, 2005). Third, humanitarianism is oriented towards alleviating human suffering rather than fostering equality (Feldman and Ticktin, 2010). By focusing on individuals and not structural realities, humanitarianism includes a tendency to de-politicise and individualise suffering (Ticktin, 2014, 277-283). Humanitarianism as a moral principle guiding welfare policy has mainly been associated with support for more modest and means-tested measures directed at poverty relief (Feldman and Steenbergen, 2001).

As shown in the previous chapter, the basic safety net granted to irregular migrants resembles more a form of humanitarian exceptions than how the Norwegian welfare state traditionally frames and addresses suffering. Nilssen and Kildal describe this 'normal frame' as a 'social right' policy that satisfies basic needs 
and expresses 'a resource-based egalitarian notion of justice, including ideas of redistribution, equal opportunity and equal respect' $(2009,313) .^{2}$ Kuhnle and Kildal $(2005,23)$ further note that an essential historic reason for adopting the twin concepts of social rights and universalism in Norwegian welfare politics was to remove the humiliating loss of status, dignity, and self-respect that goes along with exclusion from programmes and entitlements. Human dignity, Kuhnle and Kildal (2005) argue, was a salient theme in the Norwegian socio-political debates, expressing first and foremost a deep dissatisfaction with the pre-World War II poor relief system. The legacy of this has been seen as a welfare state characterised by an aversion to differential treatment in the system. The emphasis on public responsibility for welfare has further meant that the tradition of philanthropy and charity has been comparatively weak in the Nordic countries (Henriksen et al., 2018). Yet, despite this political commitment, certain groups of citizens in Norway have had to rely on charity for their needs to be met (e.g. drug users, women in prostitution), as noted in Chapter 1.

My suggestion here is that the humanitarian exceptions through which irregular migrants gained access to basic care builds on and reinforces this tendency in the Norwegian welfare state to address the needs of certain populations that fall outside the norms of society through poor relief and charity. Moreover, the very modest and substandard humanitarian services given to irregular migrants served to some extent to protect the integrity of the welfare state by hiding poverty and social suffering. Hence, they allowed the Norwegian state to maintain a self-image of a compassionate and caring state while simultaneously departing from the core norms and values of security, solidarity, and equality assumed to underpin the welfare state. ${ }^{3}$

\section{A 'tyranny of goodness'?}

The perceived centrality of 'goodness' to Norwegianness, and its effect on policy, however, has increasingly been criticised, particularly in relation to migration. In November 2015, at the height of the so-called refugee crisis in 2015, Sylvi Listhaug, a government minister, launched a blistering attack on bishops of the Church of Norway, claiming they were part of a 'tyranny of goodness' haunting the Norwegian immigration debate. According to her, the church leaders labelled those who wanted stricter immigration policies as 'nasty people', thus reducing the complexities of immigration policies to a question of being good.

Listhaug belonged to the Progress Party (FrP), a right-wing populist party that has positioned itself as the most anti-immigration party in the Norwegian Parliament. Its history of dog-whistling contributed for a long time to other parties refusing to formally collaborate with them. Norwegian sociologist Anniken Hagelund, for example, argued in an article in 2003 that the distinction between the Progress Party and the remaining political parties in regard to immigration policies was often formulated in terms of decency (anstendighet in Norwegian), with the Progress Party constructed as the indecent part (Hagelund, 2003a). This outsider position, though, was one the Progress Party thrived in, and after the 
election in 2013, they joined a minority coalition government with the conservative party (Høyre), supported by the Liberal Party (Venstre) and the Christian Democratic Party (KrF). Listhaug, at the time of her critique of the Norwegian bishops, was the minister of agriculture and food. However, only six weeks later she was appointed to a newly created cabinet position of minister of immigration and integration, vowing that she would make Norway's asylum policies 'one of the strictest in Europe' (Elster, 2015).

By attacking the 'tyranny of goodness', Listhaug not only played on the outsider position that had proven popular among parts of the electorate but also contributed to a problematisation of 'goodness' as a positive national characteristic. Such problematisation was not new in the field of migration policies. Most notably there was the 'snillisme' debate, which began in the 1990s and has had a significant impact on Norwegian integration policies and practices (Hagelund, 2005). The term 'snillisme' is constructed by combining the Norwegian word for kind (snill) with the suffix '-ism' - kind-ism. Used by both right-wing populists and social democratic reformers, the term tried to capture what was seen as a misguided and counterproductive kindness and naivety shown by Norwegian politicians, policy-makers, and academics towards immigrants. This mistaken 'kindism' explained, according to the proponents of the term, why integration seemingly had failed.

Similar problematisations of the role of 'goodness' in the field of immigration were formulated by prominent Norwegian scholars. Social anthropologist Unni Wikan (2002) used the term 'generous betrayal' to describe how the state in its effort to be kind failed or ignored to address problematic cultural practices among immigrants. Sociologist Ottar Brox characterised already in 1991, in his book 'Jeg er ikke rasist, men ...' (I'm not a racist, but ...), the Norwegian immigration discussion as a moral championship where legitimate criticism of immigration was excluded (Midtbøen, 2017).

The 'tyranny of goodness' claim had also a scholarly corollary. In the public debate that followed Listhaug's criticism of the church leaders, Terje Tvedt, a professor in human geography, quickly claimed the term, referring to how he had coined this and the related term 'regime of goodness' in a report evaluating Norwegian foreign aid policy issued in 2003 (Tvedt, 2016). Tvedt claimed that these were analytical terms meant to uncover certain power mechanisms in society. 'The tyranny of goodness' was a technique of power that reduced complicated political questions to a simple moral dichotomy of good and evil, he argued. As such, it set a framework for what could legitimately be discussed and what was acceptable criticism. According to Tvedt, a particular elite had emerged in Norway who legitimised their power by staging themselves as the wardens of 'the good'. The central task of this 'regime of goodness' was to shape the nation in the image of a new humanitarian-political complex $(2017,271)$.

In 2017, Tvedt launched a book where he combined his initial analysis and critique of Norwegian foreign aid policy with a critique of Norwegian immigration and integration policy, arguing that both fields were dominated by the same humanitarian-political elite. The book received considerable attention both 
within and outside academia. One of the harshest criticisms of Tvedt's book came from Jostein Gripsrud, professor of media studies. He wrote a counter book as a response, criticising Tvedt's perspective on the role of goodness in Norwegian history and politics. In addition to accusing Tvedt of poor academic craftsmanship, including random use of sources and inaccurate and misleading language, Gripsrud criticised Tvedt for failing to recognise how immigration and integration have been highly contested issues in the public debate. He also criticised Tvedt for neglecting the deep historical roots of 'goodness' as part of Norwegian national identity and culture.

In this regard, it is interesting to observe how both seem to agree that notions of 'national goodness' importantly inform immigration policy debates and decisions. But how? While Listhaug, Tvedt, and Gripsrud, all seem to equate the 'goodness' discourse with a push for liberal policies in this field, Hagelund has shown how the establishment and implementation of a relatively strict immigration regime in Norway have actually taken place within a vocabulary of equality, humanity, social justice, and decency:

A whole rhetoric has evolved where immigration politics appears as a matter of decency, somehow apart from the more pragmatic tug-of-wars affecting other fields of politics. On the one hand, a 'restricted and controlled' immigration is necessary in order to protect certain moral qualities of Norwegian society. But on the other hand, immigration politics has also appeared as an indicator of the moral qualities of the Norwegian nation-state thus requiring 'decent policies' in order not to threaten the image of a nation embodying such moral qualities.

(Hagelund, 2003b, 177)

The arguments for restrictive immigration policies have thus been both to protect the state of equality in Norway and to be able to protect adequately 'those who really need it', in accordance with Norway's 'humanitarian traditions'.

It is possible to identify a similar discourse of decency used to justify restricting welfare services to irregular migrants, for instance by portraying irregular migrants as a potential threat to 'legitimate' refugees' well-being. As State Secretary Pål K. Lønseth (Labour Party), wrote in a commentary printed in several major newspapers, 'The Government will not agree to proposals that would undermine the work done to ensure return . . . . It would undermine confidence in the asylum system and our ability to take care of those who need it most - namely refugees' (Lønseth, 2011, my emphasis). This commentary was a response to the call mentioned earlier from several major cities in Norway for work permits and better healthcare for irregular migrants and was also significant as it marked the government's first official use of the term returnekter ('return refuser').

Listhaug's attack on the 'tyranny of goodness' as well as her vow to implement one of the strictest asylum policies in Europe was a break from the tendency identified by Hagelund (2003b) and can be seen as a deliberate attempt of re-branding Norway as a 'hard-line' country when it comes to asylum and 
immigration. According to Gammeltoft-Hansen (2017), such negative branding aims to achieve a 'beggar-thy-neighbour' effect by diverting flows to other countries but also largely serves symbolic or domestic political purposes. In the Norwegian case, it is interesting to observe how Listhaug's claims sparked an intense political discussion about asylum policy, rhetoric, national identity, and values, yet there was a broad political consensus regarding the actual restrictive policies implemented in the wake of the 2015 increase of asylum seekers in Norway. Also, interestingly, Listhaug and the Progress Party came increasingly to frame their restrictive policies within a vocabulary of decency by arguing that it was better for refugees to be helped in their geographical and cultural vicinity (Stokke, 2016). This underlines, I suggest, both the centrality of 'goodness' to national identity and the contradictory role it plays in relation to migration policy.

\section{Deservingness and discourses of rights and justice in the welfare state}

By returning to the debates surrounding the emergency aid provision in February 2013 , it is possible to see from the way it developed that it did not only become a question of migrants' deservingness but also about the nature and moral limit of the welfare state. For instance, the consultation paper issued by the Ministry of Labour and Social Affairs (2013) clearly shows a tension between social policy and immigration control concerns, and between politicians and bureaucracy, on these issues. Whereas the minister stated to the media that the changes she initiated were to prevent the system from 'being abused to enable illegal residence' (Hegvik, 2013b), particularly by perceived criminals, the consultation paper sent out by her department directly contradicted this objective. Instead, it stated that there was no evidence that the limited right to support from NAV offices was conducive to maintaining 'illegal residence'. Furthermore, it underlined that it was 'important that the welfare services were not attempted used as a tool for solving problems related to illegal immigration' (Ministry of Labour and Social Affairs, 2013). Moreover, in the public debates, the minister, as all previous ministers, still specified that no one should starve or freeze to death in the streets in Norway, regardless. As such, it became highly unclear what the suggested amendments were meant to achieve.

This case thus reveals some of the contradictions and tension that can exist within what is referred to as 'the state' and which can be the source of unintended outcomes (Gupta, 2012). In this case, the politicians' inability to remove a minimum of humanitarian aid for irregular migrants despite several efforts is perhaps a somewhat surprising outcome. The case also illustrates the difficulties arising when moral questions of deservingness intersect with juridical questions of rights. While moral assessments of deservingness are typically relational, the juridical discourse of rights presumes blindness to individual particularities. As Sarah Willen points out, 'Whereas rights claims are expressed in a formal juridical discourse that presumes universality and equality before the law, deservingness claims are articulated in a vernacular moral register that is situationally specific and often 
context-dependent' (Willen, 2012a, 813-814). However, as noted in the governmentality literature (Dean, 2010), as law assumes administrative functions, the distinction between law as an autonomous discourse and an administrative and regulatory control becomes blurred. I suggest that the attempts of moral bordering led to the right to emergency aid becoming governed by a flexible regulatory framework and one in which vagueness would mask disagreement and doubts about policy.

In the consultation paper, the Ministry of Labour and Social Affairs (2013) initially presented two options: going back to the system of granting assistance based on an unwritten Act of Necessity or explicitly specifying that the benefit could be tied to specific requirements pertaining to return efforts on behalf of the recipient. Neither of the two suggestions was considered to have any significant economic or administrative consequences for the welfare state. However, the suggestions would neither necessarily lead to a separate treatment of 'good illegals' and 'bad illegals', as the minister initially signalled the motive was, nor to deny emergency aid completely to '(bad) illegals'. In this sense, the debates were rather about the extent to which the provision of emergency aid should be formally regulated or not, not whether irregular migrants should have access to emergency aid. Still, a return to an unregulated state would potentially mean less security for the applicant as it would remove their right to appeal individual assessments of need.

In this regard, the response of the Welfare Administration to this consultation is interesting because the directorate declared strong support for the Social Services Regulation 'as it was' (NAV, 2013). In their opinion, the current regulation was sufficiently clear, and they found a return to a state of 'unauthorised granting of relief' particularly undesirable. Reports received from local NAV offices and county governors also made it clear that the problems they experienced differed from the ones raised by the consultation. As an example, they mentioned possible rights for the 'so-called unreturnables' not entitled to state accommodation (NAV, 2013). So, while the government's official view at the time was that no one was unreturnable, this was still experienced as a reality and concern for the bureaucrats in NAV who did not want the explicit responsibility of deciding on the exception.

In the end, few consultative bodies supported the amendments. In the midst of the consultation, there was a general election, and a new right-wing government coalition came to power. Erna Solberg, the minister who had initially been in charge of the tough 'withdrawal scheme' in relation to accommodation in 2004, became prime minister, and Robert Eriksson, who had strongly criticised the emergency aid to irregular migrants, became the minister of labour and social inclusion. In March 2014, Eriksson announced new amendments to the regulation concerning emergency aid to people without legal residence: aid should now primarily be offered as food stamps and as 'a bed to sleep in', rather than cash (Ministry of Labour and Social Affairs, 2014). Hence, even with the change of government, the bottom line still remained; that is, no one would be denied food and shelter. However, aid was to be given in a more stigmatising way. The actual 
amendments to the Social Services Regulation, however, were not as clear as Eriksson claimed. The amendments only specified that aid should be granted 'for a short period' and that NAV offices 'may' demand that the person contribute to his or her own departure, for example by obtaining travel documents (Regulation amending the social services regulation, 2014). Thus, for Zeki, a 'convicted and expelled criminal', these amendments had no practical significance as he continued to receive emergency assistance for years.

Time is here revealed to play an ambiguous role in terms of deservingness and welfare rights. While in some European countries, irregular migrants can receive access to certain services, for instance to healthcare in France or local social benefits in Spain, by documenting (length of) residence (Da Lomba, 2011; Burchianti, 2013), length of stay does not grant irregular migrants any formal benefits in Norway. Services, when authorised, are explicitly meant to have a short time frame. However, in practice this creates difficulties for service providers, which is illustrated in the opening case through the difficulties NAV Skien and the county governor had in determining what leaving the country 'in practice' meant. While NAV Skien found ten days of emergency aid sufficient, as 'emergency' generally implies a short time frame, the county governor instead tried to ascertain what 'in practice' realistically means. After learning from the International Organisation for Migration (IOM) that they used two to three months to process applications for assisted return, and that it was unclear whether a person expelled for crimes would be eligible for IOM support at all, the county governor concluded that NAV Skien had 'a duty to assist' as long as the person was actually in the country. Thus, in a sense, the county governor recognised emergency as an enduring aspect of an irregular migrant's life.

From a legal perspective, Andersen (2014) has criticised the Social Services Regulation (2011) for seemingly departing from the basic principle of social right that social benefits should be based purely on needs assessment and that it should be irrelevant whether the needy can be blamed for their situations. However, he also concedes that it is legally unclear whether this is the intention of the regulation, as it remains vague. Despite requests from the bureaucracy, the ministry was not willing to clarify whether this was their intent. Andersen (2014) also notes that municipalities still retained 'discretionary freedom' to grant social benefits to irregular migrants beyond legal rights. It could thus be argued that the difficulties of drawing a moral border primarily contributed to legal vagueness, and rather than a strict divide between included and excluded, inside and outside the state, an Agambenian zone of indistinction was produced.

\section{Notes}

1 Welfare nationalism in this sense should not be confused or equated with welfare chauvinism, i.e. that only national citizens should receive welfare. For example, in their comparative study of people's attitudes toward welfare for immigrants, Van Der Waal et al. (2013) found lower levels of welfare chauvinism in social-democratic regimes. Though welfare nationalism can be used to restrict assistance to foreigners, it can also be used to justify inclusion. 
2 It should be noted that although the norms of the welfare state arguably remain important for governing in Norway, Norwegian welfare researchers have cautioned against what they see as recent trends in the development of welfare policy that modify the basic principles of the welfare state, not least through new 'workfare approaches'. The movement from a policy of 'social rights' to a policy of 'rights and duties' represented by these policies implies, according to Nilssen and Kildal (2009), that the traditional egalitarian notion of justice is being replaced by an idea of 'justice as reciprocity'. In regard to the politically excluded, those not allowed to contribute, humanitarianism, I suggest, similarly dilutes the egalitarian notion of justice by building policy on notions of charity and poverty relief. Both 'justice as reciprocity' and charity can be said to emphasise and introduce different notions of deservingness into the welfare state.

3 It should also be acknowledged that care for the irregular population is justified not only by humanitarianism but also by more traditional biopolitical concerns of the welfare state related to public health and order. For instance, the image of 'ticking bombs' or 'pressure cookers' was present in discussions regarding medical care. Here, 'ticking bombs' generally refer to potentially contagious diseases spread by irregular migrants or mental problems that could lead to violence. Treatment for communicable diseases is one of the few services free of charge for irregular migrants. The Healthcare Regulation (2011) also states explicitly that mentally unstable persons, who may be a threat to themselves or to others' lives or health, have a right to psychiatric care. The rights to (free) healthcare for communicable diseases and psychiatric care for mentally unstable patients were, as the Ministry wrote in the consultation paper to the Healthcare Regulation, not only 'to help the patient, but also to ensure public interests' (Ministry of Health and Care Services, 2010, p. 14). Since 2013, the state, also funded, as shown in the previous chapter, NGO-run shelters in Oslo and Bergen as part of their programme to combat public begging and vagrancy. 


\section{Part II}

\section{Blurred borders}


$\because$ Taylor \& Francis

Taylor \& Francis Group

http://taylorandfrancis.com 


\section{Healthcare providers as petty sovereigns}

In this and the next chapter, my aim is to explore how state borders are reproduced, but also negotiated and tested in everyday encounters between service providers and irregularised migrants in the context of healthcare. How (and to what extent) are healthcare services becoming involved in migration control? What happens when frontline service providers translate migration control policies into daily, situated practice on the ground level?

Several scholars have drawn attention to how state borders are no longer only at the external territorial outer-limit of nation-states but spread out throughout the territory and are materialising wherever mobility exists and is controlled (Balibar, 2002; Vaughan-Williams, 2009). In this sense, state borders have come to follow irregularised migrants in their daily life (Bosniak, 1991; Coutin, 2003). However, there is still a need to better understand how these internal borders are materialised in different settings and contexts. For instance, territorial borders have often been imagined as walls or barriers, comprising watchtowers, fences, detection devices, and armed guards, emphasising surveillance and exclusion. Obviously, the reproduction of state borders in the context of healthcare provisions does not share such topographies or materiality. Nevertheless, there are practices that can be seen as reproducing state borders in daily situations and settings. Studies of the internalisation of borders have particularly emphasised the dividing lines drawn by and within the law itself in terms of rights (Bosniak, 2006), and the spread and decentralisation of surveillance and control measures aimed at detecting and exposing irregular migrants for deportation (e.g. police controls at workplaces, controls in the streets or on public transport) (Broeders and Engbersen, 2007). Importantly, the concept of internal borders has also drawn attention to the proliferation of new actors involved in migration control through the devolution of responsibilities to frontline public officials, non-profit organisations, and others who come into direct contact with migrants.

In this chapter, my aim is to investigate the role of discretionary decisionmaking in (re)producing or challenging state borders in the medical encounter by engaging Agamben's concept of sovereignty as a decision on the exception. I will begin the exploration of the relation between discretionary judgements and sovereign decisions on the exception within mundane institutional practices and 
expert knowledge with a short extract from a medical appointment, which I was allowed to attend.

\section{A medical encounter}

Hind was a young primary school girl living in an irregular situation whom I met early in my fieldwork. She needed extensive surgery. Children left untreated could survive into adulthood, but morbidity was severe, and the condition posed significant physical, functional, social, and psychological burdens on patients and families. It was also a condition that was challenging to manage for healthcare providers and in normal circumstances would be treated with surgery from a very early age, with lifelong follow-up care. Upon learning that she and her family's asylum application had been rejected, the surgeon who had initially examined her was not willing to carry out the complicated procedures.

Hind and her family had received the so-called 'final rejection' in 2009, and when I met them, their residence status was no longer considered legal. However, they had remained living in an asylum reception centre, working on various appeals and trying to get surgery for Hind. About a year after I first met her, Hind's condition started to worsen. She complained of pain, making it difficult for the parents to carry out the daily care necessary to keep her condition under control. After a while, her GP, not being able to help her, referred her to a paediatrician at a local hospital. This hospital, however, did not have the necessary technical competency to perform the surgery.

Doctor Olav, the paediatrician, had not met Hind before, but he was familiar with her situation through her patient journal and he had received the discharge summaries from the first hospital that had seen her. He was therefore well aware of Hind's medical situation, that surgery was necessary and that the main obstacle to surgery was her legal status. Inside the doctor's office, after we had all introduced ourselves, Doctor Olav started the appointment by trying to get a better understanding of the family's situation:

'Has anything changed regarding your social situation recently', he asked. After exchanging confused glances with her husband, the mother started explaining Hind's new symptoms. 'Yes, we will get to this part', Doctor Olav interrupted, 'but first I need to know if there is any new information about how long you can stay [in the country]'. The parents still looked confused and he tried to explain that if he were to convince the surgeon to start operating, it would help if he could say something new about this particular question. 'We have been here for many years now and he still won't start', the mother exclaimed. 'There is nothing new. There is no set date for us to leave'. She continued explaining that they had received two negative replies to their asylum application, but that they were still working on another appeal. The parents were getting agitated. Feeling that this might be their last chance to get a doctor to listen, they started unloading their frustration of years of rejections from immigration authorities and doctors. Doctor Olav dismissed this 
calmly, focusing only on the question that mattered to him in this case: 'But, you don't have any idea of how long you can stay?' He also added, 'It is not a doctor's job to find out about these things', referring to Hind's legal situation. 'A surgeon will not do this job, but I will try to see what I can do'.

Not satisfied with the parents reply, he then asked if there was a social worker or anyone else who knew their case that he could contact to get information. The parents seemed puzzled by the question but offered a name at the asylum reception centre where they were living. 'You can also contact the UDI [the Directorate of Immigration] if you want', the mother offered. 'Please do. We also told this to the surgeon, but he wouldn't. Sometimes I feel like we are trapped between doctors and the UDI. The UDI wants information from the doctors, which the doctors don't give, and the doctors won't do anything without answers from the UDI'. 'You know', Hind's uncle who was there as an interpreter intervened, 'if the surgeon would just start the operations, she would probably be allowed to stay at least until it is over'. To this Doctor Olav responded, 'It is not the doctor's job to decide your destiny', before he added, more consolatory, 'but I will see what I can do'. The consultation was drawing to an end and Doctor Olav moved on to ask briefly about the girl's new symptoms before he quickly examined her and scheduled a new appointment.

\section{Sovereign decisions and professional discretion}

Hind's medical appointment illustrates, I suggest, how border control in the context of healthcare not only has become about detecting and excluding migrants at the hospital's doorstep but draws the territorial rationality of migration control into the diagnostic act itself in terms of deciding a course of treatment. In this case, the whole medical consultation and the relationship between the involved parties were structured by the possibility of Hind's deportation. As shown, it became more important for Doctor Olav to assess her legal status and its temporal implications for treatment options than to address her new somatic symptoms. Hind's case thus draws attention to the role of professional discretion in the intersection of immigration law, expert knowledge, and professional integrity, and its significance for reproducing and contesting state bordering and ordering of life.

By exploring how the decision is made within a particular institutional framework, my aim in this chapter is to contextualise the sovereign decision. One of my arguments is that healthcare providers not simply are reconfigured as border guards patrolling the welfare state border but are also becoming petty sovereigns defining the threshold of exclusion in their everyday encounter with irregularised migrants. Petty sovereigns, according to Butler $(2004,65)$, are professionals who use discretionary power and who have an important say in matters of life and death. Yet, petty sovereigns are agents who often do not recognise the full impact of the work they do, 'but perform their acts unilaterally and with enormous consequence' (Butler, 2004, 65). 


\section{Blurred borders}

In the following, I will contextualise the sovereign decision within the context of healthcare by showing how the decision about whether or not Hind should get treatment involved (1) government decisions translated into law, (2) administrative decisions about the category in which she should be placed, (3) expert judgement on severity and treatment, and (4) managerial decisions about whether to proceed. Furthermore, all these decisions were conditioned by the immigration authority's decision not to grant Hind legal residence. However, before I proceed, it is necessary to address the question: How can professional decisions be understood as an expression of sovereignty?

To address this question, it is necessary to look more closely at the concept of sovereign decisionism and its relation to professional discretion within the medical context. In an Agambenian framework, sovereignty is not a pre-ordained power, identifiable through constitutions or laws, but instead rests on a concrete political fact - the decision that positions a certain individual or category of people outside the protection of the law. Agamben's (1998) concern is not who has power within the political order, but the role of sovereignty in constituting a threshold of the juridical-political order. Still, Agamben's concept allows us to think of the location of sovereignty beyond institutions such as the parliament, the president, or the government (Dean, 2007). Agamben for example proposes that modern biopolitics, which is characterised by the integration of medicine and politics, implies a displacement and gradual expansion of the sovereign decision on bare life beyond political life. The result, he suggests, is that the sovereign decision moves into a more ambiguous terrain in which 'the physician and the sovereign seem to exchange roles' $(1998,143)$.

The idea of doctors exercising a sovereign-based power over patients' bodies is not new. For instance, within what Lupton (2012) calls the political economy perspective within medical anthropology and sociology, medical sovereignty is tied to doctor's exclusive and legitimate right to define medical reality and claim authority over issues defined by them as medical (rather than caused, for example, by social inequalities). In this perspective, doctors have their professional position and authority achieved from their state-sanctioned, socially accepted, and ascribed exclusive knowledge and competence which gives them the right to make authoritative judgements about diagnosis and to prescribe treatments. However, this way of understanding medical dominance has been criticised from a more Foucauldian perspective as having a simplistic and negative understanding of power by emphasising professional exploitation of power instead of understanding power as what enables the doctor to act as situationally and institutionally competent (Måseide, 1991).

Agamben offers a different perspective on medical sovereignty through his focus on a particular type of decision that can be seen to operate within or alongside a biomedical concern with fostering life. This is both a decision about the (non-)value of life but also one that marks the passage of law - or (healthcare) rights - to fact. To Agamben (2005), the problem with law is first and foremost that it cannot recognise singularity, and because it cannot recognise singularities, he sees the sovereign suspension of law as inherent in any application of law to 
life. In this sense, the state of exception becomes the central device for articulating and holding together sovereignty and government, law and life. Thus, Agamben's argument goes further than only claiming that all law requires interpretation and the use of discretion.

Engaging Agamben's work, Dean (2007) offers a slightly different definition of sovereign decisions. To him, what makes certain decisions in the medical encounter sovereign, and not merely governmental or even 'biopolitical' choices, is that they concern matters of life and death. As such, he reserves it to cases such as euthanasia, abortion, genetic screening, the removal of life support systems for an individual in a coma, notions of brain death, and so on. These decisions are sovereign decisions in Dean's view:

because they involve not merely a matter of letting die but a form of killing without the commission of homicide. Or at least they involve a point at which it is difficult to know whether we are letting die or exercising a right of death.

Here, though, as my interest is in how healthcare services become involved in territorial border control, I will use an understanding of sovereign decisions in the medical encounter that differs somewhat from both Agamben's and Dean's definitions. In this chapter, I am concerned with decisions by healthcare providers on treatment that is not necessarily a question of biological life and death but that reanimates a sense of territorial state borders, or contests them, and thus irregularised migrants' political exclusion, which can be seen as a form of 'death'. The decisions by healthcare providers are sovereign decisions in the sense that they are still decisions on the (non-)value of life. The decisions can involve a withdrawal of assistance and thus a withdrawal of the means of life, but they can also grant treatment. However, these are ultimately in the case of irregularised migrants, as I will show, conditional decisions making healthcare providers not 'the ultimate' medical sovereign but rather petty sovereigns as the delegation of sovereignty is only partial. This highlights how discretionary decisions of healthcare providers in the case of irregular migrants are to some extent different from other areas where they decide on eligibility for services.

I will illustrate this point briefly by returning to the case of Louila Tuban (Chapter 1) and by comparing it to another case that received significant media attention in the same period. This was the case of Siv Tove Pedersen, a 40-year-old woman from Bergen, Norway, with chronic obstructive pulmonary disease (COPD) grade 4 , respiratory failure, and 12-per cent lung capacity who was denied access to being on a donor recipient list for lung transplantation. Siv Tove was a Norwegian citizen, and a lung transplant was considered medically necessary; however, she was denied access to the list because she was a patient who received methadone as Medically Assisted Treatment for substance abuse. According to the doctors who evaluated her case, daily methadone use constituted a disqualifying drug addiction even though it was given as treatment (Aarøy, 2013). Having been denied the 


\section{Blurred borders}

hope of a new lung, Siv Tove opted for assisted suicide in a clinic in Switzerland in January 2015 (Ryste et al., 2015).

Louila Tuban, as previously described, was initially denied a kidney transplant, first because she did not have legal residence and later because she could only get a temporary residence permit. However, in her case, the hospital decided, as her health was deteriorating, to depart from their internal guidelines, and a transplant was performed in February 2015. At that point, her temporary residence permit had expired, and her future legal status was still undecided.

In both cases, the doctors' decision on whether Louila and Siv Tove were eligible for transplants could be said to not only have rationed services but also, on some level, to have made an evaluation and decision on the value or quality of their lives. Siv Tove and Louila's cases are interesting to compare because they reveal some of the complexities of sovereign decisionism in every day medical situations and its intersections with state territorial jurisdiction. First, while the doctors in Louila's case decided to perform the transplant to save her life despite her precarious legal status, she still had to wait for the immigration authorities to make another decision on whether she could stay and get the vital follow-up she needed, as well as gain access to other means to sustain her life, such as social support, the legal employment market, education, and so on. Siv Tove, however, formally remained a citizen with access to other attributes of a so-called 'qualified life' but was denied the means to preserve her biological life. Hence, both Siv Tove and Louila's cases, I suggest, blur any clear distinction between qualified and bare life as sovereign decisions on life becomes multiple and dispersed. Second, both cases had territorial and biopolitical implications, but in different ways. Siv Tove, by travelling to Switzerland for assisted suicide, evaded and challenged both the doctors and the Norwegian state's jurisdiction over her life. In Louila's case, healthcare providers' decisions on treatment contested her exclusion, yet remained conditioned by the state's attempt to maintain territorial sovereignty by not granting her legal residence. In both cases, the doctors' power to deny treatment was absolute, but in Louila's case, their ability to grant treatment was circumscribed and conditioned by decisions made by the immigration authorities. It is this latter entanglement of territorial and biopolitical dimensions of sovereignty that is expressed in the doctors' decisions on whether irregular migrants should get treatment, and what type of treatment they should get. This is the issue I will explore now by turning to how different forms of 'decisions' framed Hind's access to healthcare.

\section{Legal bordering}

In Norway, over the past decades, welfare law has undergone several changes that can be seen as an attempt by the sovereign to withdraw protection from irregular migrants through administrative reinterpretation concerning the scope and content of existing laws (Chapter 2). Access to healthcare services is a prime example. While the laws governing healthcare have not been changed, the Ministry of Health and Care Services has amended the scope of these laws by administrative decree. ${ }^{1}$ 
In 2010, the ministry initiated a review of existing laws due to what they called 'continuing doubt and varying practices' regarding irregular migrants' access to healthcare. One of the major challenges, according to a consultation paper issued by the Ministry of Health and Care Services (2010), was precisely how to interpret the words 'all' (alle) in the Patients' Rights Act (1999), 'reside or temporally reside' (bor eller midlertidig oppholder seg) in the Municipal Health Services Act (1982) and 'permanent domicile or residence' (fast bopel eller oppholdssted) in the Specialised Health Services Act (1999). As the consultation paper argued:

The wording seems to imply that the scope of the [Patients' Rights] Act is very broad, see 'all', so that people residing illegally in the country are covered. However, it could be questioned whether it ought to be interpreted in a legality requirement, i.e., that lawful residence in the country should be a requirement although it is not directly stated in the text?

Also, in the Municipal Health Services Act and the Specialist Health Services Act, there were no explicit requirements that the residence had to be legal. Although, the ministry conceded that the wording seemed to imply that the scope of the acts covered people residing illegally, they eventually concluded that it would be reasonable 'to interpret into the law' a legality requirement so that 'one cannot be considered to be "a resident" when unlawfully staying in the country', referring to similar practice in other areas of the law, such as the National Insurance Act (1997).

In Agambenian terms, the sovereign could be seen here as making a decision on the exception under which the law's application is withdrawn through an administrative decree. However, the government not only decided to withdraw irregular migrants' access to healthcare but also specified certain rights in a new Healthcare regulation concerning the right to health and care services to people without ordinary residence in the country (hereafter the Healthcare Regulation, 2011). As argued in the consultation paper, the new regulation meant to clarify the law in a way that would both limit and extend rights in relation to current practice (Ministry of Health and Care Services, 2010). Thus, while irregular migrants were to be given some specified rights to specialist healthcare beyond emergency care, their access to primary healthcare was to be restricted. ${ }^{2}$ In this sense, irregular migrants, I suggest, were not only included through an exclusion (i.e. an inclusive exclusion) but precariously included, that is, a restricted and unstable inclusion based on the assurance of survival

The wording of the new regulation was further designed in a general way so that the rights specified for those residing illegally would apply to 'all persons staying in the Realm'. This was done, according to the consultation paper, to ensure that individuals staying legally in the country, for example tourists, should have at least the same rights to healthcare as people who were staying illegally. Irregular migrants and tourists thus came to form one common legal category, referred to in the regulation as 'persons without ordinary residence in the country' (Andersen, 2014). 
Their rights specified in the regulation applied primarily to emergency primary and specialist healthcare services. In addition, 'people without ordinary residence' were entitled to (1) health services which are absolutely necessary and cannot wait without the risk of imminent death, permanent and seriously reduced functionality, serious injury or severe pain; (2) necessary healthcare before and after birth; (3) termination of pregnancy under the provisions of the Abortion Act; (4) healthcare for communicable diseases; and (5) healthcare that cannot wait until deprivation of liberty is lifted (i.e. detention in remand, prison, an involuntary psychiatric ward or an institution for minors under the Norwegian Child Welfare Act). In contrast, citizens and legal residents were entitled to what is called 'necessary healthcare', a legal term introduced in the Patients' Rights Act in 1999. This right applies if (1) the condition is sufficiently severe, (2) the patient can be expected to benefit from the healthcare, and (3) the costs are reasonable in relation to the effect of the measure.

Children (i.e. persons under the age of 18) without a legal right to stay were entitled to necessary primary and specialist healthcare services but were not entitled to be part of the general practitioner scheme or receive support for transportation to treatment facilities. Furthermore, and of particular importance to Hind, the regulation states that these children have the right to necessary healthcare 'unless concern for the child dictates that assistance should not be provided'.

To understand how the regulation draws the territorial rationality of migration control into the medical evaluation, it is necessary to look more closely at the way 'concern for the child' and 'healthcare that cannot wait' were defined. At first glance, 'concern for the child' may look like a reference to the United Nations Convention on the Rights of the Child (UNCRC) specifying that 'the best interests of the child shall be a primary consideration'. However, as the background documents and guidelines to the healthcare regulation make clear, this was not what the clause referred to. Instead, the clause primarily stipulated that treatment should not interfere with state efforts to deport the child (Karlsen, 2015). As the circular issued by the Ministry of Health and Care Services clarified:

This [concern for the child] will be a professional evaluation, and may for example include cases where healthcare professionals have certain knowledge that the child is about to leave the country, and it would be irresponsible to start a treatment that cannot be completed.

(RS I-5/2011)

For adults, what was deemed 'healthcare that cannot wait' was also to be based on individual medical assessments. In the background documents and guidelines, the ministry gave a temporal guideline of two to three weeks, indicating that treatment that could wait beyond these weeks should not be initiated. This time frame of three weeks was not medically justified but was set according to what the Ministry of Health considered to be 'a reasonable time frame' for the irregular migrant to be able to leave the country. However, there are few conditions that 
are so standardised that they enable uniform guidelines to be established, thereby making it necessary for doctors to decide in each case.

As shown here, the territorial and political rationality of immigration control became part of the diagnostic act, while leaving the exact demarcation of the border (or the threshold of inclusion) to a certain extent to the discretionary judgement of the healthcare provider. As official government decisions that are translated into law or decisions that suspend the law constitute the most common way of understanding sovereign decisionism, the legal framework in itself could thus be understood as a decision. However, it can also be seen as a normalising frame for decisions by other agents. In this sense, the law does not act through coercively enforced constraints, but rather in more decentralised and diffused forms of power relations that regulate and discipline conduct (Rose and Valverde, 1998; Foucault, 2003). Hence, one of the main consequences of the healthcare regulation regulating irregular migrants' access to healthcare, as I see it, was that it established the person with legal residence as the norm and thus legal status as a criterion for judgement rather than simply prohibiting access to healthcare.

\section{Fuzzy categories}

To make a (sovereign) decision on whether or not law applies involves making a judgment on what categories in which to place individuals. As Agamben (1998) points out, law can only relate to life through juridico-political categories. In practice, categorisation is not necessarily a straightforward practice, as indicated in the following statement by Linda, an experienced nurse who had worked on and off in the reception centre at a primary emergency care centre for the past fifteen years.

I think it is very difficult to know whether they are undocumented ('papirløs') or not. Because it [the asylum system] is a jungle. It is difficult to know whether they're from the reception centre, and if they are from there, what kind of card they might have and so on. If they live at the reception centre, they're still kind of in the system. There are also some who choose to live with their families but are still here legally. Sometimes people forget their ID. Or they have overstayed. It's a jungle. So, you just have to kind of trust what they are saying. And I don't know all the rules about when they become [illegal]. ... And the rules keep changing. Also, [the authorities] don't tell us what kind of papers they should have.

Linda, nurse

As the quote illustrates, categorisation depends on the providers' knowledge. In this case, it particularly requires health personnel's familiarity with the asylum process and changing immigration policies as well as healthcare laws. How the patient categorises herself can also have an impact on how the healthcare providers perceive the patient. Patients do not generally fit into only one defined category. Hind for example was a child, an irregular migrant, and a person diagnosed 
with a severe condition. Which category would be most important in this case? More informal ways of categorising people, such as those implied in the moral economy of deservingness (Chapter 2), may also have an important impact on the process of categorisation.

In Norway, 'legal residence' is not a clearly defined category in immigration law and has been given a somewhat different content in different legal contexts (e.g. the Marriage Act and the Social Security Act, see Knapskog, 2013). When the Healthcare Regulation was implemented, there were no guidelines that clarified specifically who should be considered legal residents. The consultation paper (Ministry of Health and Care Services, 2010), however, mentioned that foreigners placed in Norwegian prisons, or similarly detained in the country by force, and persons falling under the Dublin agreement should be considered to be legal in terms of healthcare rights. Asylum seekers who had 'a final rejection' and had overstayed their departure date were explicitly mentioned as people not to be considered to have legal residence and should be assessed according to the new regulation. The paper further specified that patients who were in the course of treatment or regular follow-up care and had his/her formal residence status changed to 'illegal resident' were not automatically entitled to receive continued medical care that was planned or started.

Most of my interviews with healthcare providers were conducted one to two years after the implementation of the new Healthcare Regulation (2011). However, few that were not already involved in the volunteer-run clinic had heard of it and had even less knowledge of the content of the consultation paper. However, they did generally have an idea that irregular migrants were only entitled to emergency healthcare, at least when it came to specialist care, but did not necessarily know when people 'became illegal' or how to identify them.

The exchange between the doctor and the patient in the beginning of this chapter, where the doctor tried to get information about the patient's legal situation, can be seen as an attempt to categorise Hind and was not unique to this incident. Accompanying Hind to different doctors' appointments, I witnessed several attempts to clarify her legal status and the subsequent consequences for treatment. The healthcare providers' reception would vary to some extent depending on whether she was categorised as an 'asylum seeker' or as 'rejected'/'illegal'. In the following, I will reproduce two brief field note excerpts from Hind's medical appointments, this time with Doctor Knut, to illustrate the difficulties as well as the negotiated process of categorisation.

Field note excerpt:

This time we were met by a younger doctor. He had seen Hind before (although a while ago). He starts the appointment by expressing sympathy, saying that he thinks it is regrettable that nothing has been done yet. He sits at the end of his desk with a piece of paper and pen and looks at the mother. 'Can you say something about your situation?' He asks. The mother is unsure of what he means by this. Doctor Knut notices her hesitation and tries to rephrase the question in an easier way; 'Are you still asylum seekers?' The 
mother smiles relieved and answers 'ah, yes'. The doctor makes a note of this on his piece of paper. He explains that he and the hospital are not able to perform the major surgery she needs, but they will try to do what they can to help her as Hind clearly needs medical care. He listens to the mother describing the symptoms, asks various questions, and expresses that he finds the symptoms and the situation serious.

After checking Hind and asking a number of questions about her somatic symptoms, Knut starts asking questions about Hind's social situation (school, friends, etc.) to find out how her condition affects her in her everyday activities. Hind's mother answers these, but also starts to explain in more detail their legal situation (two negatives, but no exit dates or plans) to make sure he understands their difficult situation. Both she and her husband also explain how they feel trapped between doctors and the UDI and how they are continuing to appeal their case. Doctor Knut looks more confused, however, and Hind's mother asks if I can help explain in Norwegian. I do, but neither Hind's mother nor I use the term 'illegal' or 'final rejection', just 'two negatives'. The explanations do not seem to affect Doctor Knut's opinion about what to do next.

In this case, it was a deliberate choice on my part to use the same terminology as Hind's parents used. Although I knew that they did not try to capitalise on the confusion regarding categories and terminology, the situation presented the dilemma of whether or not I as a researcher would reproduce state-defined categories, thus contributing to the everyday production of certain migrants' 'illegality'. In the Norwegian system, the Directorate of Immigration makes the initial decision in asylum cases. In case the UDI rejects an application, it can be appealed to an independent Immigration Appeals Board (UNE). If UNE rejects the appeal, it is referred to as 'the final decision'. If the rejected asylum seeker fails to leave before the departure date set for him/her, his/her stay is generally no longer considered legal and thus formally demarcates the border between 'legal' asylum seeker and 'person without legal residence'. However, rejected asylum seekers, as shown in previous chapters, were still allowed to stay in asylum reception centres and receive a small subsidy from the state. It was also still possible to request a 'renewed consideration' (omgjøringsbegjcering) from UNE numerous times. However, filing such a request would not change their (il)legal status and they could still be deported at any time.

The irregularised migrants I met during fieldwork categorised themselves in various ways. For instance, Aster, and even Eba (Chapter 2), would sometimes refer to themselves as 'paperless' (papirløs) and even 'illegal'. However, they would often reject the latter label as something the state had imposed on them. Hind's family, and most of the migrants I met, however, still primarily considered themselves asylum seekers as they continued to work on their appeals. They would not refer to the second rejection as 'the final rejection', but instead as 'the second negative'. Some would even say that they had three or four 'negatives', not necessarily seeing any one as final, as they would refer to people they knew 
who got 'a positive' after several 'negatives'. For instance, Mehret, Aster's friend, got one, as she said, 'on the third attempt'. In the public discourse the categories of refugees, asylum seeker, and undocumented/illegal migrant are also often interchangeable, and children such as Hind were almost always referred to as long-staying asylum children (lengevoerende asylbarn), even by public officials.

When asked, Hind's parents would always carefully explain their situation to the various doctors: that they had applied for asylum and that they had received two 'negatives' but were appealing. As such, they did not try to hide their status. However, being unfamiliar with the asylum procedure, the doctors did not necessarily recognise the significance of the second rejection and were unsure how to categorise them. This was not limited to Hind's case, but a general uncertainty I met among healthcare providers. For instance, when I asked a GP, who had many asylum seekers on her patient list, whether she had many patients without legal residence, she was aware of only two. One had told her in an appointment and the other's referral to a specialist had been denied because of his (lack of) legal status. When I asked the doctor how many of her patients had two or more negatives, she estimated about 25 . This illustrates that although the categories of asylum seeker and person without legal residence have been more clearly demarcated legally, the discursive and practical border between them in Norway remained blurry.

A point that further illustrates this was that while residents at asylum reception centres were not legally entitled to more healthcare than those living outside of the centres, they often had better access in practice. This was often due to a combination of the efforts and facilitation on the part of centre staff, and doctors' unawareness of immigration law, or that they considered it unethical to end a doctor-patient relationship already established. Reception centres would also at times assist their residents financially with medical expenses. This was done either by giving residents loans, which they would then deduct directly from the financial support the migrants received from the state every two weeks, or by assisting them in applying to the UDI for extra support. For instance, for Eba, who had type 2 diabetes, paying for medicine became a serious concern after losing his job. By moving back into 'the system', he received support to cover his medical expenses. The centre also arranged for the family to get a regular GP even though they were not entitled to it. As an employee at the reception centre explained, she had a list of sympathetic GPs who would accept rejected asylum seekers if she called.

Access to specialist healthcare seemed to vary more even for rejected asylum seekers staying in reception centres. Some of my interlocutors continued to receive regular treatment by specialists and were never charged more than regular user fees. Hind, however, was not so fortunate. Friends of the family had at one point contacted the specialists to explain the gravity of their situation, that is, that they could be deported anytime, in the hopes that it would speed up the process for setting a date for surgery. With this information, the surgeon and his superiors instead backtracked on the possibility of surgery.

Hind's (lack of) legal status, though, was never written in her medical journal. Over the following years, as Hind was not deported, and her condition was still 
serious and worsening, her GP continued to refer her to specialist care. The next time Hind met Doctor Knut, she received a different reception:

We were sitting in the consultation room when the doctor arrived. It was Doctor Knut again. Walking across the room towards his chair, he began to explain that he had been informed by his colleague that they had received a final rejection. When this did not seem to make an impression on the parents, he asked if it was not correct that they had talked to his colleague. The parents responded that they did not recognise the name, but that she might have talked to someone from the reception centre.

The doctor's attitude was now clearly different from the last appointment. He appeared very uncomfortable throughout the meeting (perhaps reinforced by my presence. He often looked at me this time). He explained that there was no more they could do for Hind when the other hospital would not accept her and the surgeons at this hospital said they did not have the necessary expertise. 'I cannot tell the other hospital what to do,' he said. He did not seem to want to be further involved. The parents asked him (as they did all doctors they met) if he could write a report to the UDI about Hind's medical situation. To this, he replied that he did not have the necessary expertise and that they would have to ask the surgeon. The parents explained that they had repeatedly and unsuccessfully tried to contact the surgeon. Doctor Knut gave only brief answers. He listened to the parents' frustration but looked mostly away or down and offered little solace or understanding. Upset with the doctors' refusals, the father asked in frustration, 'What should we do? Should we pay someone to smuggle us to France?' Doctor Knut just apologised again and said he could not help, and he did not know what they should do. It was a short session, with no examination. At the end, the doctor got up and said goodbye, patted Hind on the head and washed his hands before leaving the room. Having observed Hind and her family's struggle for medical care and residence for over a year now, I found the symbolism of the doctor's routine action painful to watch.

In this case, it seemed, having been informed that Hind and her family had a 'final rejection' and not merely 'a second negative' had a negative impact on Doctor Knut's willingness to help and promote Hind's case within the healthcare system. This, of course, raises the obvious point of a possible moral economy at work, where asylum seekers and irregular migrants' legitimacy and deservingness are valued differently (even for children). In this case, though, it should also be noted that Doctor Knut was a junior doctor in a hierarchical structure. His uneasiness could thus be related to a sense of helplessness confronting a particularly difficult case for which he did not personally have a solution and to which he responded with evasion and inaction. This was a response I encountered in other cases (see Chapter 4). It also became clear later that there was another (incorrect) assumption in circulation that affected the doctors' decisions, namely that a final rejection actually meant an impending departure. Hind's continuing presence years 
after she was supposed to have left the country became a headache not only for the immigration authorities but increasingly so for the healthcare system as well. While the surgeon and Doctor Knut, in the second field note extract, might have acted in accordance with the letter and intention of the Healthcare Regulation for 'persons without ordinary residence in the country', it became increasingly more difficult to defend as a medical decision. Nonetheless, the two fieldwork extracts illustrate both the difficulties and relative importance of the administrative decision on category.

\section{Expert decisions in the intersection between law, politics, and medicine}

So, how does the Healthcare Regulation (2011) become mediated through the judgements of disciplinary experts? Sovereign decisions on the exception, as noted by Dean (2007), are always made within various normalising frames. These do not necessarily derive solely from law but also from more general social norms about gender, class, race, and so on. In this study, professional codes of ethics and expert knowledge represented important normalising frames that clashed with 'the law', represented by the Healthcare Regulation (2011), complicating the decision on the exception. For example, both the Norwegian Medical Association (2010) and the Norwegian Nurses Organisation (2010) have clearly stated that the Healthcare Regulation was, in their view, in conflict with the general ethical guidelines to which health professionals should relate. This was also a view shared by most of the healthcare providers whom I met during fieldwork. The requirement to take migration concerns into consideration was predominantly experienced as a political interference in medical practice (see Chapter 4). Moreover, it frequently challenged established understandings of what clinical knowledge is (or should be) and particularly what factors should be deemed medically significant and relevant information. Thus, for most, the regulation was seen as putting them in an 'impossible situation' since they felt called upon to make judgements based on non-medical criteria or knowledge they did not have or were not qualified to evaluate (i.e. the extent to which departure was likely or whether adequate medical follow-up or treatment would be available if sent out). Still, the regulation can be seen as having a disciplinary function on healthcare providers by discouraging them from providing healthcare services for fear of acting against the law, while at the same time delegating to them the responsibility for the decision that marks the exact threshold of exclusion.

A good example that may illustrate the dilemmas and conditional character of the decision-making process is the case of Adam Dzortov, a case that has many similarities, but also important differences, with Hind's case. Adam was a nineyear-old boy, originally from Ingusjetia in Russia, who needed extensive surgery. Adam had a crooked spine and spinal pressures on his lungs made it difficult for him to breathe. According to Adam's doctors, his spine was so curved that it could not be corrected in a single operation. This meant that he would need follow-up, in the form of regular operations as long as he was growing. Without the operations, 
he would become disabled and most likely die young. However, as in Hind's case, surgery was initially denied by the hospital.

In June 2014, his doctors, relieved of their doctor-patient confidentiality by Adam's parents, were interviewed by the Christian-oriented newspaper Vårt land. In this interview, one of his doctors, Arild Egge, chief surgeon at the neurosurgical department at Oslo University Hospital (OUS), was quoted as saying, 'If law can trump medicine in this case, it is shocking.' He continued,

As doctors, it is our duty to save lives and health. Adam's condition is lifethreatening. Here we see that the system is speaking with two tongues. Had we failed to treat another patient in this way, we would have been held legally responsible for not doing anything.

(Huseby, 2014a)

Egge's statement was followed up on by Adam's attending doctor, Rolf Riise:

Adam's critical condition puts us as doctors in a huge ethical dilemma. On the one hand, we have a duty to help - and we fully have the opportunity to treat him. On the other hand, we are not allowed to operate on him now because of his unresolved asylum-seeker status.

(Huseby, 2014a)

As the quotes clearly illustrate, the doctors saw the law as preventing them from doing what they thought was medically right, that is to operate on Adam.

Adam's story was quickly picked up by most of the major media in Norway through an article by the news agency NTB with the headline: 'Terminally ill nine-year old denied help because of his asylum seeker status' (NTB, 2014). Many news channels followed up immediately with different individual articles published online. Svein Aarseth, head of the Council for Medical Ethics in the Medical Association, was one of those interviewed. He stated that the doctors would not be doing anything 'illegal' if they chose to operate on Adam because, as he specified, 'it is still not illegal to help anyone in Norway - fortunately' (Huseby, 2014b). Within hours of the story breaking in the media, the hospital retracted their decision, and the following statement was made by Olav Røise, head of the Clinic for Surgery and Neuroscience (OUS):

We see now that we have interpreted the regulation too strictly. Our original decision was based on the fact that the patient's future possibility to obtain follow-up with us had not been resolved. However, since the patient is under 18 years of age, he is entitled to treatment on a par with other patients who are presently in Norway. We find, therefore, that our responsibility is to provide healthcare to the patient.

(Huseby, 2014c)

Fifteen days later, Adam had his first surgery. Røise, who was the one ultimately responsible for both decisions in Adam's case (first refusing, then allowing 
surgery), explained in a later interview that it was the last sentence of the Healthcare Regulation (2011) that had been difficult to interpret. 'The sentence can be understood as both a "yes" and a "no" to healthcare', Røise added, referring to the exception implied in the sentence "unless concern for the child dictates that assistance should not be provided' (Huseby, 2014d).

Røise's comment - that the clause in the Healthcare Regulation could be understood as both a 'yes' and a 'no' to healthcare - seems to point to an experience of legal indeterminacy. As Hind and Adam's cases showed, both denying and granting treatment at various stages in their contact with healthcare providers did not contradict 'the law'. In this sense, it resonates with Agamben's observation that one of the paradoxes of the exception as a technique of government lies in the fact that it becomes impossible to distinguish transgression of the law from execution of the law $(1998,57)$. Hence, the issue is not only that law is suspended but that fact and law are completely confused.

While the doctors felt restrained by law from acting, as seen in Adam's case, representatives of the government confronted by the media with difficult cases could, and would, refer to it as being the healthcare providers' decision. This, for example, was the political response in Adam's case. After his story received broad media coverage, the Minister of Health and Care Services Bent Høie specified that the government's position was that all children residing in Norway, 'as a general rule', should be entitled to necessary healthcare and that children's best interests should be a 'primary consideration'. As he elaborated further: 'Current regulations do not prevent children who are in the situation that was featured in Vårt Land on June 10, from getting the help that doctors deem necessary' (Bjåen, 2014). Yet, what the minister actually clarified, in line with the regulation, is that the decision to deny or grant treatment is deferred to the doctors' discretionary judgement. So, whereas the media coverage in Adam's case may have contributed to getting him surgery, no actual changes were made to the regulation. One practical consequence of delegating the decision to expert discretion thus seemed to be to obscure responsibility and controversy in official policy.

While Adam's doctors, as soon as it was clarified that the law was no obstacle to surgery, made no reservation to the treatment they provided him, this was not the case with Hind. The difference in approach occurred even though the question of what was considered medically essential follow-up care remained uncertain in both cases and would remain so as long as the children continued to be deportable. In Hind's case, the surgeon seemed aware from the beginning that it was ultimately his decision, and he did not base his rejection on the regulation directly, but on the professional evaluation of what was 'medically safe'. In his view, as long as Hind was deportable and necessary medical follow-up was not guaranteed, it could be deemed 'irresponsible to start a treatment that [could] not be completed', as the circular specified (RS I-5/2011).

Over the years that I followed Hind and her family, Doctor Johan, the surgeon, had in many ways become the villain in this story, and the parents directed a lot of their anger for being rejected, both by the immigration authorities and by the hospital, at the surgeon. As the parents saw it, he was the main obstacle to both 
Hind's medical treatment and to their aspirations of approved residence, as they believed Doctor Johan had not adequately explained Hind's medical situation in the report sent to the UNE, the appeal board.

Doctor Johan, however, when I finally met him, was clearly uncomfortable with being the villain. He tried to explain to Hind's parents in an appointment to which I accompanied them that it was not a case of not wanting to help them. He sympathised much with their situation, he said, and he 'was not judging them' for trying to stay in the country. His main dilemma, as he laid it out, was that the best medical option for Hind depended upon whether she would be deported or was allowed to stay. If he performed the same surgery as he would for legal residents, and Hind was deported and left without proper medical follow-up, her situation could become fatal. Doctor Johan could perform another type of surgery which would be less risky in case of deportation, but which would have a less satisfactory result in terms of life quality for Hind, and could entail more rounds of surgery to rectify this, if she were allowed to stay. Doctor Johan found this to be a very difficult decision to make, and one that was also difficult for the parents to respond to. Doctor Johan had thus appealed to his superiors who initially, in agreement with Doctor Johan, decided not to do anything as they believed Hind, as Doctor Johan explained, would shortly be leaving the country, having received a 'final decision'. Two years later, with no change in Hind's legal situation, still rejected but not deported, and with her health situation worsening, the doctors decided they had to do something. Again, Dr Johan appealed to his superiors to make what he found to be a very difficult medical decision. In the end, they decided to go for the safer surgical option in case of deportation.

\section{'Managerialisation' of healthcare and the clinical gaze}

I believe that the more bureaucrats are employed in an institution to ensure that the rules are followed, the harder it is to help people who do not fit into the box. [. . .] There are lots of people in Norway who work in the healthcare services to prevent people from being treated outside of the rules. And at the major hospitals, this group of people is very big, which makes it much harder to find some kind of arrangement where one, based on ordinary humane considerations, may overlook some things that concern the government.

Doctor Lena, GP

The last point I will address in this chapter is how doctors' decisions in the medical encounter were framed or conditioned by hospital structures and management forms. Besides 'the law', management and the relation, or relative power, between the administration and the professional expert were mentioned by the healthcare providers I interviewed as factors that impacted the decisions made. Doctor Lena was thus not alone in the viewpoints expressed in the previous quote. Also, in Hind's case, those who had the difficult task of explaining to Hind's frustrated parents why she did not get help pointed to the management. As one doctor put it, 
after a particularly heated exchange with Hind's father, 'all the doctors and nurses here want to help you, but our bosses won't let us'.

The differences between administrative managers and frontline workers have been pointed out in the literature on irregular migrants' limited incorporation in service provision, also called 'bureaucratic incorporation' (Lewis and Ramakrishnan, 2007). For instance, Marrow (2009) found that service providers in the USA, like schools and hospitals, aim to serve and help by ignoring, circumventing, or protesting barriers, while regulators and enforcers tend to 'go by the book' and minimise exceptions. Van der Leun (2006), exploring internal border control in public services in the Netherlands, also suggests that the tendency to be more lenient towards irregular migrants appears to be correlated with a high degree of face-to-face contact with clients on a more personal basis.

Like other bureaucratic organisations, hospitals have a hierarchy. Decisions are therefore not necessarily only up to the autonomous professional's sole discretion. However, while I believe many of the service providers that I met, including Hind's doctors, sincerely felt, and were at times demonstrably restricted by hospital bureaucracy, it is worth noting that managerial decisions could potentially be used by frontline service providers as an excuse to relieve themselves of a difficult responsibility. In Hind and Adam's cases, the managers were also doctors.

In this case, it can therefore be useful to look at how governmentality-inspired literature on hospital reform has drawn attention to the more complex ways 'managerialism', implying an increased emphasis on management techniques and rationalities, has affected hospital practices and decisions and also what is understood by expert knowledge (Harrison, 2002; Teig, 2012). In Norway, as in many other welfare states, reforms inspired by a market ideology that strengthens the administrative logic have been implemented. With the introduction of the so-called New Public Management (NPM) in the hospital sector in Norway, health professionals are frequently regarded as having lost much of their previous independence, because they have been enlisted into new professional roles and subjected to increased indirect control, where professional standards are not necessarily the determining principle anymore (Teig, 2012).

While these reforms are seen as strengthening and creating new hierarchical administrative relations, they also blur managerial and professional jurisdictions (Waring and Currie, 2009). This process of blurring jurisdictions is often described as involving 're-stratification', the drawing of professional elites into bureaucratic roles and 'bureaucratisation', the standardisation of work operating procedures. For instance, Harrison (2002) describes the New Public Management modernisation agenda as signalling a shift from reflective clinical practice to scientific-bureaucratic medicine as medical knowledge, whereby medical practice becomes rationalised and standardised. This has raised the question of the extent to which managerialist and accounting values are colonising the medical profession, thus leading to the hybridisation of medical expertise. It is also seen as reconstructing the professional role itself by drawing management duties into professional work (Waring and Currie, 2009). Ong, in her work on refugee medicine in the USA, describes this reconstruction of professional roles by noting how 
clinicians, constrained by a market-driven healthcare system, have 'their gaze on their patients distracted by an eye on the bottom line' (Ong, 2003, 92).

In Norway, the legal term 'necessary healthcare', introduced in The Patients' Rights Act in 1999, can be seen as part of the process of drawing management duties into professional work because the term can be read as an attempt to merge medical prioritisation theory and practice with economic concerns by directly linking rights to priority level (Halvorsen, 2004). In this sense, the right to healthcare applies, as previously noted, if (1) the patient can be expected to benefit from the healthcare; and (2) the costs are reasonable in relation to the effect of the measure. This means that the question is no longer merely what is medically feasible and sensible but also what the best cost-benefit ratio of treatment is.

As with the cost-benefit perspective introduced through the legal concept of 'necessary care', taking migration control concerns into consideration before initiating treatment is becoming part of the discussion of what should count as medically significant and relevant information informing medical decisions. Regarding Hind and Adam's cases, medical treatment would be accorded to legal residents in similar situations based on established scientific-bureaucratic routines. As such, it is treatment the patient is normally expected to benefit from with costs considered reasonable in relation to the effect of the measure. However, with the new Healthcare Regulation, healthcare professionals are expected to prioritise not only based on a cost-benefit perspective but also according to legal status. To paraphrase Ong (2003), their gaze on their patients was now also distracted by an eye on the territorial border. However, while hospitals have acquired financial expertise in management, they still do not have 'expertise' in evaluating migration concerns (e.g. means of acquiring necessary information about healthcare availability in other countries, etc.).

The ground on which to prioritise is a question not only of expert knowledge but also of the way the professionals see and understand themselves and their roles. Health professionals are generally socialised to see themselves as beneficial helpers and not as powerful gatekeepers or controllers (Grimen, 2009). Nonetheless, they are both. Even according to their professional codes of ethics, healthcare professionals are even expected to balance patients' interests against the assumed interests of the society. Hence, setting a 'medical purist' stance aside, healthcare professionals are directly and indirectly in charge of public resources and to varying degrees experience this as a responsibility. One doctor explained this dilemma to me as the duality he felt between doing what was right for the patient and his loyalty to 'the publicly financed healthcare system that pays my salary and paid for my education'.

Doctor Johan, in Hind's case, clearly felt this conflicting responsibility, and in conversation with Hind's family and me, brought up, in addition to his 'purely' medical doubts about the best course of medical action, issues such as the danger of 'medical migration', not as a current problem but as a possible future challenge if access to healthcare were to be liberally granted. Though he did not accuse Hind's family directly of medical migration, he elaborated examples of cases he had heard, seeing these as valid concerns the government had and that he felt 
obliged to take into consideration. In the discussion, he also brought up Hind's country of origin. The medical care Hind needed existed in theory there, as far as Doctor Johan knew, so the question was to a larger extent if it would actually be available to her for economic reasons. To Johan, this seemed to complicate the question of deservingness, as he suggested that the decision would have been easier to make if she had been from a country 'such as Somalia or Afghanistan', where it was clear that such medical expertise did not exist at all. Hind's case, in this sense, points out the manner in which what has been called a 'culture of disbelief' (Watters, 2007) surrounding the category of asylum-seekers in Europe also becomes part of the medical encounter and how the ways to determine which individuals are worthy subjects of compassion are classed, racialised, and gendered.

In contrast to Doctor Johan, Adam's doctors not only provided medical care but also actively supported him in his asylum appeal. They were convinced that adequate medical help would not be available to him in Russia, despite the immigration authorities' assurances that it was, and they even testified as expert witnesses in a court case for Adam. The different approaches by Hind and Adam's doctors thus illustrate the blurriness of the borderline not only between managerialism and expert knowledge but also between medical views and the prevailing political and moral views on immigration and deservingness.

\section{Muddled and entangled decisions}

While my focus in this chapter has been on the sovereign decision within the specific context of healthcare institutions, the cases explored also illustrate the dilemma arising from the medical decision being separate from the decision on legal residence. In Norway, there is no formal system for how medical claims in asylum cases should be assessed. Reports are generally written by regular healthcare professionals requested by the patients themselves and not by some specially appointed experts who issue medical statements in immigration cases. In this respect, Norway differs, for instance, from France, where specific state-appointed healthcare professionals are involved in assessing cases, writing country of origin reports, and categorising illnesses that can provide the basis for temporary or permanent residence permits (Ticktin, 2011). In my study, healthcare providers frequently expressed the complaint that their expert views were being ignored by the immigration authorities, questioning the authorities' competence in doing so (Chapter 5).

Nonetheless, as suggested by Hind's uncle, doctors could still potentially exercise a form of sovereign power by simply commencing treatment. For example, when the doctors attending Adam initiated surgery, they arguably bound him to a healthcare system of a certain type and standard. This surgery involved the insertion of extendable rods along his spine that needed to be lengthened every six months to keep up with Adam's growth. He would also need close and continuous follow-up in the event of complications, which in these cases is not uncommon. Yet, what may become a sovereign decision cannot necessarily be known in advance, and in these cases the outcome often remains uncertain. A year after 
surgery, Adam's fate was still undecided. When Adam appealed his case to the immigration appeal board (UNE) after surgery, he was only given a temporary and conditional permit of one year to receive treatment. Although this could be renewed, it still meant that Adam and his doctors would have to cope with uncertainty. Hind, on the other hand, was granted legal residence shortly after surgery. The permit, however, was not granted for medical reasons but because Hind's 'affiliation to the Realm' was seen to outweigh migration concerns, as she had lived in Norway for six years. This was in line with political signals in a new White Paper that made children's integration into Norwegian society a key issue in evaluating residence on humanitarian grounds (Meld. St. 27 (2011-2012)).

\section{Notes}

1 This was initially done as amendments to the so-called Priority Regulation (2000) implemented in June 2011 and continued in a new regulation implemented in January 2012 called 'Regulation concerning the right to health and care services to people without ordinary residence in the country'.

2 While irregular migrants were generally seen to only have the right to emergency specialist healthcare, there appear to have been some ambiguities and diverging views on the extent to which they also had a right to necessary, not only emergency, healthcare from municipalities (Aarø and Wyller, 2005, Andenæs and Bayegan, 2009, Hjelde, 2010). 


\section{Materialising and negotiating borders through administrative practices}

We do not experience many requests from undocumented migrants because we do not know who is undocumented and who is not. If they don't tell us themselves that they are undocumented, then we don't know.

Doctor Lena, GP

During fieldwork, when I asked healthcare providers how they knew their patients' legal status, most would answer like Doctor Lena, that they did not know as long as their patients themselves did not tell them. In Lena's case, she also added, 'And we don't care'.

In this chapter, I shift the focus from the role of professional decision-making in (re)producing or challenging state borders to how the border becomes materialised through administrative practices and routines that contributed to deterring and excluding irregular migrants, even in cases where they were entitled to healthcare. Recognising the situated, material dimensions of bureaucratic knowledge, as argued by Colin Hoag (2011), may help us attend to bureaucratic practice without fetishising the bureaucratic (or sovereign) decision. In the first part, I will look at how certain technologies came to mediate social interaction and knowledge production in the encounter between healthcare providers and irregular migrants. For example, the problems of categorisation described in Chapter 3 were somewhat related to the limited ways of identifying irregular migrants. This provided healthcare providers with both challenges and opportunities in regard to treating irregular migrants. In the second part, I explore healthcare providers' situated responses to the ethical and practical dilemmas raised in their encounter with irregular migrants. How did healthcare providers navigate bureaucratic structures, contradictory demands, and ambiguous expectations of how they should treat irregular migrants?

\section{Detection and deterrence}

Detection, detention, and deportation are perhaps the most visible forms of internal border control, and scholars have explored how welfare services have become involved in this control through surveillance being delegated to service providers

DOI: 10.4324/9781003156598-5 
and institutions. Broeders and Engbersen, for example, have argued that as part of the internal border 'the state raises a protective wall of legal and documentary requirements around the key institutions of the welfare state and "patrols" it with advanced identification and control systems' (2007, 1595). The aim, they suggest, is to discipline the institutions and social networks irregular migrants use and need for their daily lives: 'It is a strategy of exclusion through the delegitimisation and criminalisation of all those who may be employing, housing, and aiding irregular migrants' $(2007,1596)$.

In the context of Norway, the legal exclusion of irregular migrants from healthcare was not followed up with specific control systems through which irregular migrants could be identified. Due to doctor-patient confidentiality, the only way to know a patient's legal status was if the patient themselves disclosed this information (Søvig, 2015). There was also no sharing of information between healthcare institution and immigration authorities and the police. Importantly, it was not illegal to give medical assistance to irregular migrants (Søvig, 2013a). It was just that they had limited rights to it. Nonetheless, the healthcare services did comprise various administrative practices and technologies through which the state border materialised for irregularised migrants. In Norway, what emerged as particularly important was the extensive use of personal identification numbers and the financial framework. These practices were not necessarily linked explicitly to migration and border control, but to forms of control of the population in general. Hence, as I will show in the following, 'the protective wall' of documentary requirements was not principally about detection of irregular migrants for deportation but excluded and deterred them in more subtle ways.

\section{The personal identification number as bordering practice}

The extensive use of the same personal identification number (PIN) supported by a central population register is a particular characteristic of the Nordic countries. The fødselsnummer, which it is called, has been in use in Norway since 1964 and is well integrated into all administrative routines and allows for a comprehensive and detailed record of the population. ${ }^{1}$ This PIN is perhaps the most significant biopolitical technology for controlling the population in general.

Within literature on irregular migration, the extensive use of personal identification numbers to identify inhabitants has been seen as a factor that makes irregular living particularly difficult in the Nordic countries (Sigvardsdotter, 2012; Khosravi, 2010). For example, the fødselsnummer is among the first things all persons will be asked about when attempting to access healthcare. The number can be used to distinguish individuals from one another but cannot be used to authenticate that a person is who she claims she is. Hence, the PIN is not an ID, though it is sometimes used and experienced as such in the Nordic countries. This makes it an ambiguous bureaucratic tool for identifying and excluding irregular migrants from healthcare. ${ }^{2}$

In Norway, the responsibilities for healthcare services are divided between state and municipal levels. Primary healthcare (including general practitioners 
and nursing care) is a municipal responsibility and is based on a list system with regular general practitioners (GP). Everyone who is registered in the population register as a resident in a municipality is entitled to be registered as a patient with a GP. As GPs are responsible for all initial assessment, investigation, and treatment of patients, they play a key role in the healthcare system. Access to secondary care is based on referral by a GP.

The introduction of the general practitioner scheme in Norway made it more difficult to seek out a GP without already being associated with the doctor as a list patient. This has become a particular challenge for irregular migrants, including the children, as they are not entitled to be registered as list patients. However, all municipalities are required to have a primary emergency care service. In the larger cities, these are drop-in centres open 24/7. Formally, these have become irregular migrants' main access point to healthcare.

Even though 'all persons staying in the Realm' have a right to emergency care, the primary emergency care centres routinely ask for the fødselsnummer, and increasingly an ID, when people come to register. In the healthcare system, the PIN is mainly used as a unique identification of patients in different treatmentoriented information systems such as the electronic medical record and patient administration systems. The PIN's primary purpose is thus to facilitate the recording and exchange of medical information.

When I interviewed employees at the primary emergency care centres in Oslo and Bergen, they stated very clearly that they did not reject people for lacking a fødselsnummer or ID. As Linda, an experienced emergency nurse, explained:

'We don't differentiate based on whether people have papers or not. If they need help, we register them. Where would we refer them otherwise? We are not supposed to reject people. We never reject them. We sometimes refer them [for example, to their regular GP]. But then you have to be sure [they have one], right?' And she added later: 'I don't know what happens further on in the system, but for the care we give, it does not matter [whether they have a PIN or not]'.

Part of Linda's job was registering patients who arrived at the primary emergency care centre. As such, she performed an important gatekeeping function. If prospective patients were not able to provide the PIN, Linda, or other nurses on duty, could register the patient using a support number. Hence, lack of ID and personal identification numbers was not necessarily a physical barrier to primary emergency healthcare. The lack of a PIN, paired with the increasingly computerised registration and record keeping, however, caused administrative complications for registering irregular migrants as patients, and required separate routines, and often complex instructions. ${ }^{3}$

In Norway, most public healthcare services are connected to a database containing information from the national population register based on the personal identification number. The healthcare provider is thus automatically able to check whether a PIN is valid and if an individual is a resident of the municipality. Yet, 
there are irregularities and delays in the system, and people are forgetful, as Linda pointed out. Establishing identity nonetheless remained an important part of the registration process. As Linda explained:

We have many who come in without a personal identification number, but whether they are undocumented or have just forgotten, we don't know. We try to search for them in the system [with their PIN]. But if even one digit is wrong, we can't find them. Then we try to search using their names, but it's difficult, because many foreigners have very many names. We ask for the surname and the first name. But then we might misunderstand and search using the first name and not the surname.

And she added later:

We do try to find them [in the national population register], and we take time trying. Because it is important that we know that they are not in the population register before we make a separate patient journal. So, we search and ask many times. Are you sure this is your date of birth? Could you write it down? What is your name? What is your first name? What is your surname?

Linda explained that she sometimes became suspicious if people could not provide a personal identification number, and she then engaged in these kinds of interrogations 'in order to do her job'. Nevertheless, she concluded, 'but I don't know, so I have to believe them. And it could be true.'

For Linda, the attempt to establish whether the person had an existing PIN was primarily about administrative procedures for establishing a patient journal as one unique medical document. For irregular migrants, though, always being asked about their PIN in their interaction with healthcare constituted a potentially dangerous moment of visibility. It created what Khosravi (2006) has called 'everyday irregularity'. As Khosravi explains:

The landlord, the employer, the subway ticket controller, the nurse at the healthcare institution, and everyone else that demands documents proving one's legal status, contributes to the construction of everyday irregularity. [. . . This everyday irregularity results in a constant feeling of vulnerability and surveillance that functions as a disciplinary mechanism.

(Khosravi, 2006, 295-296, my translation)

In this sense, the routine of asking for a PIN can create an environment of suspicion and mistrust that might deter some irregular migrants from exercising the limited rights they actually have. Bendixsen $(2015,2018)$, exploring irregular migrants' experiences of their rights and their capacity to manoeuvre in the healthcare system in Norway, found that migrants frequently viewed their encounters with healthcare providers as uncomfortable, risky, and potentially humiliating. 


\section{Blurred borders}

She observed that there was a general feeling of being rejected by healthcare providers, which appeared to come both from personal experience and from rumours about other migrants' encounters with healthcare providers. Irregular migrants that I met during fieldwork would also refer explicitly to the lack of a PIN as a barrier for gaining access to healthcare.

Lack of knowledge about their rights and the healthcare system, fear of being reported to the police, poor language skills, and arbitrariness in healthcare professionals' attitudes and knowledge have been cited in the academic literature as important barriers to access to healthcare that goes beyond policy and law (Biswas et al., 2011). These are also factors that can help explain the experience of rejection recounted by irregular migrants in Norway. Another possible explanation, suggested by nurses and doctors at the primary emergency care centres with whom I spoke, was disagreement regarding the urgency of the situation. Though the primary emergency care centres said that they practiced a liberal understanding of emergency to some degree both for irregular migrants and legal residents, they also recognised that diverging understandings of emergency could be experienced as discrimination. As Lena, the doctor at the primary emergency centre, explained:

I can tell you, it's incredibly difficult to explain to someone who has grown up in Norway with college degrees that this is a condition that can wait a few days and that they could get an appointment with their regular GP. . . . People perceive themselves as much sicker than we in the healthcare system believe that they are, in terms of urgency. And to explain it to a patient who does not speak Norwegian, who was not born and raised in Norway, who has a completely different understanding of the world than we do, is extra challenging. I can understand how misunderstandings occur and that they may feel rejected. And many of these people [irregular migrants] are paranoid for good reasons, and sometimes that paranoia takes over. But for us, it largely falls under 'business as usual'.

Paradoxically, the quest for establishing identity for medical purposes created its own problem as people with legal residence would share their PIN with irregular migrants. As Doctor Lena explained:

Now and then we notice that someone comes in with a history that does not quite fit with what they told us previously. We know of course that people share PINs and come on behalf of one another and so on, but it makes it particularly challenging to treat them medically.

For doctors, having access to information regarding allergies, medications, medical conditions, test results, and so on is important in order to provide the best possible healthcare. Wrong information may occur if more than one person is registered under the same PIN and can have serious consequences. To exemplify, Doctor Lena recalled the following episode: 
Last year I had this couple from Somalia; I don't know if they were sisters or friends, but they would switch off coming in and they used the same personal identification number and the same credit card as ID, probably because one had legal residence and the other one did not. Anyway, one of them had a pretty serious condition and the other one was completely healthy. And they looked similar. Therefore, it was very challenging for us to know whether it was the one with the serious condition that came in. If so, we needed to take several precautionary measures, treating the sick one in a completely different way medically than the healthy one with whom we did not need to take any precautions. There was one time where 'the healthy one' was put on our observational post for blood tests and treatment and stuff, and then it turned out it was not the healthy one after all, but the sick one. That was challenging!

This example illustrates how the reliance on fødselnummer can pose specific challenges for healthcare institutions interaction with irregular migrants.

\section{Rights for a price}

I can recall that we have had patients who did not want to be admitted, saying they were afraid, that they could not pay and such. But I could see that they were too sick not to be admitted. In those cases, we have said, forget about the money and so on. We will help you.

Hedda, gynaecologist

I've told them - you'll get a bill, but it rarely becomes a big issue if you cannot pay. I've said that to some, so that they would not be afraid that there would be a lot of trouble.

Kari, midwife

The issue of payment emerged as the second main area of bureaucratic practices through which state borders materialised, as indicated by these quotes. In Norway, the healthcare sector remains largely publicly financed and the government still plays a major role in the provision and distribution of healthcare services. Nevertheless, the healthcare sector is one of the main areas where market-orientated management systems have been introduced in the past decades as part of a search for greater efficiency and accountability in service production. These changes have involved a gradual move towards more individualistic and right-oriented legislation, followed by a more comprehensive control system and financing based on quasi-markets and performance measurement models (Teig, 2012; Magnussen and Nilssen, 2013). Since 2002, hospitals in Norway have been organised into five regional health enterprises owned by the state. These enterprises provide decentralised management and delegation of financial responsibility, while at the same time the minister of health, in theory, can instruct the regional health authorities and overturn board decisions in all cases (Lægreid et al., 2005). These regional health enterprises primarily have a provider responsibility that involves 
a commitment to providing specialist services to the population within a specific geographic area. The actual performance of services may be carried out by both public and private hospitals.

Similarly, most GPs in Norway are self-employed, but part of the regular GP scheme. Accordingly, their financing comes in three parts: (1) basic funding from the municipality, (2) activity-based funding such as refunds from the national government, and (3) user fees from patients. Primary emergency centres are similarly financed. The regional health enterprises are financed by the state through basic funding and activity-based funding. The activity-based funding is based both on number of patients and on type of treatment based on the diagnosis-related groups (DRG) classification system (Byrkjeflot, 2005).

The issue of compensation from the state is one of the reasons why it is important for healthcare institutions to verify the personal identification numbers of patients. In Norway, governmental reimbursement schemes require the registration of these numbers. The issue of compensation was also one of the reasons why it became tricky for healthcare institutions to treat irregular migrants. Unlike legal residents, irregular migrants are expected to carry the full cost of treatment, even in cases where they are legally entitled to care, such as emergency care, neonatal care, childbirth, and abortion.

The rules regarding payment of expenses for patients who 'do not have ordinary residence in the realm' are specified in the Specialist Health Service Act (1999, § 5-3). This act states that if the patient cannot cover the expenses, costs should be covered by the respective health institution or service provider (RS $\mathrm{I}-2 / 2008)$. In this way, the act places the ultimate responsibility for covering the expenses on the individual healthcare institutions, by either pursuing the patient for the amount due or covering it themselves through their own budgets. The circular issued by the Ministry of Health and Care Services regarding the new Healthcare Regulation in 2011 specified further that it would not be possible for the healthcare institutions to demand prepayment for emergency care and specialist healthcare services 'that cannot wait'.

During fieldwork, it became clear that the ways in which healthcare institutions dealt with the issue of payment varied. There were cases, for example, where patients would receive large bills for treatment they were entitled to, while others received treatment that did not conform to the letter of the law and did not receive bills or were charged only user fees. Healthcare providers, to varying degrees, would also inform patients beforehand that they were required to pay the full price after receiving services. The difference in practice could be due partially to different policies, routines, and practices between hospitals but was also, as indicated by my interlocutors, due to a certain use of discretion in different cases within the same hospital. For some institutions, the small likelihood of retrieving the money meant that it was not worth the effort of trying to collect it.

The issue of payment, nonetheless, exacerbated the environment of suspicion and mistrust that discouraged irregular migrants from approaching healthcare services. Irregular migrants I met, for instance, reported having been confronted with unpaid bills when they sought treatment in primary emergency care centres, and 
healthcare providers I spoke with told of experiences with patients wanting to leave hospitals before the doctors thought it was safe or meeting women reluctant to give birth at hospitals after being informed that they were required to pay for it afterwards.

Shortly after the new Healthcare Regulation came into force in June 2011, there were also a couple of cases that emerged in the public media that challenged, and ultimately limited, healthcare institutions' ability to pursue patients for payment. These cases concerned specifically women's right to healthcare in relation to birth and abortion, both explicitly mentioned as rights in the Healthcare Regulation (2011).

In the first case, a woman was refused abortion services at a hospital in Oslo as she could not pay for it in advance. According to a statement by the hospital, this was standard procedure as abortion was not considered an emergency situation. However, in the patient journal it was noted that the patient should contact Pro Sentret to get financial support for an abortion. Pro Sentret is the City of Oslo's service for women and men who sell sex and is financed jointly by the central government and the city. At that time, the centre had a budget post in the amount of 100,000 NOK allocated for women using their services who needed abortions, earmarked by the Directorate of Health. However, this support was not necessarily available for women not selling sex. This illustrates how irregular migrants' access to care largely relied on previous organisational structures in the NGO sector and the norms of care and deservingness that informed these (Chapter 1).

Although the woman in this case was ultimately able to have the abortion at another hospital without paying, the case was brought before the Board of Health Supervision by the volunteer-run healthcare centre for undocumented migrants in Oslo. In its verdict, the board concluded that the hospital had not fulfilled its obligation. Since the woman's pregnancy was considered to be in week $8+4$, and an abortion must be carried out before week 12 according to the Abortion Act (1975), the board considered it to be a case of 'healthcare that cannot wait' and for which healthcare providers cannot demand prepayment (the Board of Health Supervision in Oslo and Akershus, 2011). Although the verdict technically could be said to allow the demand of prepayment at an earlier stage of pregnancy, the outcome was that the hospital changed its procedure and stopped asking for prepayment in all cases.

The second case concerned the hospital in Kristiansand that billed women for giving birth at the hospital. While one woman had been invoiced for 18,000 NOK in 2011, another woman had received a bill in 2009 for more than 80,000 kroner that was subsequently sent to debt collection in 2011 (Larsen and Eie, 2011; Nilsen and Eie, 2011). This prompted a MP of the Liberal Party to address a written question to the minister of health and care services in November 2011 to clarify policy. In her response, the minister at the time, Anne-Grete Strøm-Erichsen (Labour Party), specified that although patients were supposed to cover the treatment themselves, the law required hospitals to cover it if the patient was not able to pay (Document No. 15:286 (2011-2012)). The initial interpretation of this was that hospitals could send bills but could not send unpaid bills to debt collection, a 
practice some of the institutions that I spoke with already practiced. The hospital in Kristiansand consequently withdrew the debt collection claim shortly afterwards. However, in February 2015, a new case emerged. This time, a woman had received a bill of 52,000 kroner from Levanger Hospital after a birth involving a caesarean section. In his response, then Minister Høie (The Conservative Party) went further, stating to the media that

no pregnant woman should be worried [. . . ] it is up to the hospital to make an individual assessment on whether the woman can pay for what the birth costs. If the woman cannot pay, the hospital must not send a bill.

(Dommerud, 2015, see also Document no. 15:502 (2014-2015))

These cases illustrate the dilemmas the separation of rights from financial support posed for healthcare institutions. Since many irregular migrants were unable to pay, healthcare institutions and providers, in most cases, would have to shoulder the cost within their own budgets. For most providers, this was not necessarily an economic challenge, as the numbers were quite low. Although some individual specialist cases could be expensive, irregular migrants overall were not seen as a strain on hospital budgets. ${ }^{4}$ Not even the primary emergency care centres in Oslo and Bergen, which one can assume experienced the highest demand, reported treatment of irregular migrants as a financial burden. Nevertheless, the risk of not getting compensation for treatment carried out made an irregular migrant an undesirable patient, as Doctor Susanne, a hospital specialist and volunteer at the healthcare centre for undocumented migrants in Oslo, suggests in the following quote.

If an undocumented had, let's say, cancer, I do believe he would get treatment, and it would not be a huge problem arranging it. However, the money problem is still there. The person would be getting treatment without the hospital being compensated. And that's a problem. It makes the hospitals less inclined to take on this type of patient. [.. . It's bad business for the hospitals.

Susanne's comment should be seen in relation to the NPM-inspired financing system in which hospitals partly receive activity-based funding based on both the number of patients and the type of treatment. This makes some patients more desirable than others. As irregular migrants do not have valid PINs, they will not be counted as patients in this system and the hospital will not be compensated. Susanne had experienced complaints about this in her hospital ward and had therefore become more reluctant to assist irregular migrants there, as she had previously. Instead, she preferred to help them at the volunteer-run centre. Hence, I suggest that the main function of the financial framework in regard to irregular migrants should not be understood in economic terms, but as a disciplinary tool informing healthcare providers' decisions, for example, by encouraging a restrictive interpretation of 'healthcare that cannot wait'. It also discouraged extending 
care beyond formal rights. As noted earlier, it is not illegal for healthcare institutions and providers to treat irregular migrants.

The disciplinary function of the financial framework was a decisive factor in Zeki's case (Chapter 1). At one point, Zeki was granted the right to drug rehabilitation in an institution. A GP had sent a referral on his behalf, and after a multidisciplinary assessment of his health situation, he was found to fulfil the strict requirements and was granted the so-called right to necessary healthcare. The referral was open about Zeki's legal situation and his history: expelled, but 'unreturnable'. However, as one of those reviewing his case explained, there had been others before in similar situations who had been granted treatment; therefore they had not given his legal status much weight. 'The right', though, was withdrawn a month later by management before Zeki was summoned to start his treatment. In the refusal letter, the manager stated both that Zeki was not legally entitled to it because he did not have legal residence status and also that they were not allowed to perform services that their 'owner did not permit'. The 'owner' in this case, was a state-owned health enterprise. What also emerged when I spoke with different actors involved in the decision was that during the administrative preparation for Zeki's medical summon, the institution where Zeki was to be treated had raised the issue of financial compensation. Who was going to pay for his treatment? In this case, the public health enterprise was not prepared to shoulder the cost and neither was the individual private institution to which treatment was being outsourced. Zeki's case thus illustrates how the decision on treatment was framed by financial concerns. The negotiation concerning threshold for payments that takes place in the cases discussed earlier is also an indicator of the controversy and ambiguity that characterises policy towards irregular migrants. The financial framework, similar to the regulation, obscures the responsibility for the decision of excluding irregular migrants.

\section{Managing ambiguities and contradictions}

I can certainly understand that they [the government] are afraid of this kind of situation [health migration]. . . . But the question is: can we defend refusing treatment to all irregular migrants based on some individual examples? I believe that this is tricky. . . . It can't be up to the healthcare services to get them [irregular migrants] out. Why should the doctor be put in this situation? It is the immigration authorities that must take care of it.

Doctor Hans, paediatrician

So, to what extent were healthcare providers willing and able to engage in the control-based activities prescribed in policy? Although, healthcare providers to some extent have always had a role in controlling the borders of welfare through rationing eligibility for services, they are also generally perceived, and see themselves, as having a commitment to relieve suffering and maximise the quality of life for service users (Grimen, 2009). In the following, I am interested in exploring 
how healthcare providers respond when this commitment becomes circumscribed to the extent that it is in relation to irregular migrants. I am particularly interested in how they navigate bureaucratic structures in their situated responses to the ethical and practical dilemmas raised in their encounter with irregular migrants.

All of the healthcare providers I met during fieldwork expressed more or less similar sentiments as those voiced in the opening quote regarding the new regulations and the idea that healthcare somehow should be involved in migration control. For most, the regulation was regarded as putting them in an 'impossible situation' as they felt called upon to make judgements based on non-medical criteria or knowledge they did not have or were not qualified to evaluate (i.e. to what extent departure was likely or whether adequate medical follow up or treatment would be available if sent out). Taking immigration concerns into consideration before initiating treatment further challenged established understandings of what clinical knowledge and professional ethics were (or should be) and particularly what should constitute medically significant and relevant information. Doctor Lena expressed her frustration with the new terms:

They use healthcare as a means of coercion in immigration policy. And it is absolutely unforgivable. There is no one in the healthcare service that uses the term 'healthcare that cannot wait'. It's a kind of bureaucratic expression that some bureaucrat invented, probably a lawyer. It's just nonsense.

What made the term so frustrating to Lena was the impossibility of deciding if treatment could wait three weeks if she did not know if treatment would be available for the patient after these weeks. As she explained:

As a doctor in Norway, I cannot find out whether people can get vital treatment in rural Afghanistan or Somalia or wherever. It is absolutely impossible for me to do that. And even if I checked, I would probably conclude that the right thing to do would be to treat the person here in Norway to ensure that he gets proper treatment.

The regulation said nothing about the realism of departure within three weeks or whether or how doctors should know if treatment actually would be available to the patient later on. More often, the medical results would be better if treatment were started sooner rather than later.

The Medical Association (2010) and the Nurses Organisation (2010) in Norway have also stated that the new Healthcare Regulation (2011), in their view, was in conflict with the general ethical guidelines to which health professionals should relate. The Healthcare Regulation and professional codes of conduct could thus be said to place contradictory demands on healthcare providers regarding how they should treat irregular migrants. The main response from the healthcare providers in my study and the Norwegian Medical Association (2010) to the dilemmas raised by the regulation was to call for a regulation that clearly separated what they saw as 'politics' from 'medicine'. This, they believed, would 
enable them to make decisions solely on medical grounds, a task they felt trained and competent to do.

The position of calling for a clear distinction between the right to healthcare and the right to legal residence has been a central tactic employed by healthcare providers challenging the state's attempts to manage and control unwanted migration through welfare restrictions in different contexts (Castañeda, 2013; Gottlieb et al., 2012). However, the problem with this approach, as appropriately remarked by Ticktin $(2011,123)$, is that the proposition that irregular migrants could exist outside politics is impossible, as the classification of 'undocumented' or 'illegal' is political in the first place.

The literature on the so-called bureaucratic incorporation of irregular migrants tends to emphasise further themes of social dissent, discursive resistance, and informal practices on the part of service providers. Particularly, a local level in charge of providing welfare and workers placing professional ethics ahead of restrictive definitions of their legitimate constituency is seen as an opening for local advocates to protect irregular migrants' access to welfare services (Van der Leun, 2006; Marrow, 2012; Laubenthal, 2011; Cuadra and Staaf, 2012; Villegas, 2013). For example Castañeda (2013), through her exploration of doctors' organised efforts to provide medical aid to irregular migrants within Germany's strict policy environment, has argued that the distinctive ethics associated with providing medical care has the ability to disrupt the scaling of citizenship by the state by treating noncitizens ostensibly as citizens. She suggests that consequently the provision of medical care becomes a protest against citizenship as an exclusive organising principle of German society.

Some of my interlocutors, primarily those in primary healthcare, similarly expressed that they were not overly concerned with the regulation and that they would treat irregular migrants that they came into contact with 'the same as other patients', regardless. As one GP, Doctor Ingrid, explained, 'I think the regulation applies more to specialists. When it comes to us, we follow the rules, but not always [laughs]. Anyone who needs help gets it. That's my rule.' I also observed different acts of individual support, such as treating irregular migrants pro bono, providing them with free medical supplies, and so on.

However, as I observed during my fieldwork, although the conflicting demands between law and ethics could be used as a basis for health professionals to stretch the limits of the regulation to provide irregular migrants with extended care, it could also create uncertainty and reluctance to act. For instance, Hind's case (Chapter 3 ) illustrates that professional ethics and knowledge did not always lead to access for irregular migrants but could reinforce the policy of exclusion. In Hind's case, her condition was complex and rare, requiring specialist medical knowledge, which was a dilemma for many of the doctors and nurses further down in the hospital hierarchy who were often the ones confronted by Hind and had to explain to her face-to-face that she would not receive treatment. However, what surprised me was that although many of the healthcare providers expressed sincere sympathy in their meetings with her, seeing the situation as grave and wrong, they were not necessarily willing to follow up on her case within the healthcare 


\section{2}

system, in the media, or by writing reports to the UDI/UNE. The response was generally that they felt they lacked the necessary expertise, and it had to be the surgeon, whom the parents were unable to reach on their own. Evasion, reluctance to get involved and/or act, and keeping to a narrow biomedical framework, ignoring circumstance, were approaches taken by healthcare providers that I observed during fieldwork that could be said to reinforce exclusion.

There were also those who did try to help Hind and who eventually got her the necessary surgery. Hence, during fieldwork I observed various practices employed by service providers to manage contradictions and ambiguities encountered when translating policy into practice in various situations that challenged irregular migrants' exclusion. I would not go so far as to say that they disrupted the scaling of citizenship, as Castañeda (2013) stated. Instead, they contributed to what I have called precarious inclusion. These practices did not necessarily pit formal law against informal inclusion but could be seen to operate in a grey zone opened up by ambiguities and tensions that simultaneously cut through law, policy, and practice.

In the following, I will explore in particular the potential and limits of challenging the border inherent in two common tactics encountered in the field: the productive uses of ignorance and structural compensation. I do not necessarily frame these 'tactics' by service providers as acts of resistance or compliance. Instead, I see them primarily as embedded and situated responses or actions that contribute to the precarious inclusion of irregular migrants. In this sense, they are manoeuvres or ways of coping within the constraints of a landscape of strategic power (de Certeau, 1984).

\section{Engaging, coping, and evading through ignorance}

I am sure that I have treated many who have been undocumented and who have not had personal identification numbers. I haven't asked why they don't have the PIN. I've just looked through my fingers and written the birthdate.

Doctor Grete, private practice gynaecologist

Ignorance should not be understood simply as lack or absence of knowledge but involves deflecting or obscuring inconvenient or unsettling knowledge (McGoey (2012). As a bureaucratic tactic, it allows actors to maintain a selective understanding of their own competences and responsibilities. It is a way of managing tasks by simplifying and reducing the emotional labour of complex encounters, but it may also open a space for actors to act in accordance with their principles and values (Borrelli, 2018). In this sense, it may help both to maintain and to disrupt social and political orders.

In the context of healthcare, this tactic involves ignoring or overlooking the question of legal status and/or the existence of the Healthcare Regulation (2011). Healthcare providers may ask, but not prioritise, investigating legal status in cases where people fail to provide a valid ID or a PIN, do not follow up on unpaid bills, 
or fail to communicate questions of legal status. Doctor Grete, as she mentions in the previous quote, would 'look through her fingers' regarding their lack of a PIN and treat them as other patients, which also meant charging them regular user fees.

Unlike the 'don't ask don't tell' approach adopted by some sanctuary cities in the United States (Nyers, 2011), ignoring legal status is not an official policy in Norway, but it can be seen as a response by individual healthcare providers. It can also be practiced more or less informally at an institutional level. Tina, a social worker working in a hospital ward, described the practice at her workplace: 'I'm a bit like this: If I do not know if it is allowed, I leave it until I find out. Here though [her ward], we do it until we find out it is not allowed.' In her experience, the doctors were generally not that interested in finding out what the law said, thus doing what they saw fit until they got caught.

Also, Doctor Lena, in the introductory quote of this chapter, noted that they generally did not know who was irregular at her primary emergency care centre, but they nevertheless 'did not care'. When Lena started working at the centre, she had asked her superior about what happened with irregular migrants. Her superior just answered, as Lena quoted, "'Shh. They just come like everyone else. It's nothing to worry about. They get help like everyone else",.

As emergency care patients, irregular migrants have the right to treatment on an equal footing with other patients. Nevertheless, the healthcare providers at these centres still met several specific obstacles in treating irregular migrants, compared with other patients. For example, in non-urgent cases and in regard to patients with a chronic condition, they were not able to refer them to follow-ups with a regular GP. Should they, then, treat these conditions or wait until they become acute? The centres have few possibilities for following up patients and giving continuous care. Referral to a specialist may also pose challenges. In light of this, Lena's statement that they 'do not care' about the patient's legal status is interesting.

For Lena, 'not caring' meant, for example, to 'deliberately under-communicate ambiguities regarding legal status' in referrals to specialists. It also meant practising a generous understanding of the emergency care concept as far as capacity allowed and downplaying the issue of payment. As she explained:

We are concerned with finding pragmatic solutions for patients. And when people who do not have money come in, we find a way to help them one way or another. And when we know the chances of getting payment are zero, there is an understanding, at least in the medical group, that we treat the patient and they do not pay. It is not our business. We ensure that they receive treatment, and the rest is up to the finance department. A bill is sent if they provide a home address, but most have understood that they can provide a false home address and that this is okay.

Nevertheless, there is sometimes a very fine line between ignorance which facilitates irregular migrants' precarious inclusion and ignorance which reinforces the policy of exclusion. Many of the doctors I spoke with, like Lena, emphasised that 
they treated all patients the same way and did not take legal status into consideration. However, they were less concerned with, or conscious about, the challenges the patient might encounter in actually getting as far as the doctor's office or the discomfort that followed registering without a PIN and being billed. In this sense, doctors' abilities to ignore legal status relied on a division of labour and was a tactic not as easily available to gatekeepers, such as Linda, whose work it was to register patients.

Ignorance of the patient's legal status also presented healthcare providers with some particular challenges. In some cases, ignorance of the migrant's status ran the risk of exposing the patient to the authorities. A couple of my interlocutors recounted episodes where they had thought the patient was an asylum seeker and had, without thinking about it, contacted the UDI to sort out the practical information. As Tina recalled:

'I had one experience that was not okay, to put it mildly. I think I was lucky to get away with it. I had spoken with him [the patient] and everything seemed fine. And then I needed some information for a report, and I called [the UDI] without thinking.' She continued, 'The man who answered said, "He has disappeared". "Okay. Is there any possibility that you can forget that I have called?" I asked.'

In this case, it went well, and the man was treated without being apprehended. However, it illustrates a key ethical challenge for healthcare providers, namely that irregular migrants are not protected from deportation when accessing healthcare. Gregor Noll (2010) refers to this as 'the bundling effect of jurisdiction', that is, that welfare jurisdiction still comes with immigration jurisdiction within a defined territory.

Failure by healthcare providers to recognise irregular migrants' legal status could also compromise patients' health. Doctor Siv, a primary emergency care doctor, recounted an episode that illustrated this particular challenge. The patient was a woman who, according to Siv, had been irregular for ten years, but who still had been able to work and pay taxes most of the time, cleaning, among other things, government-owned premises.

'I met her at the primary emergency care centre the first time,' Siv began. 'She had a condition that is quite common. She had myoma in the uterus.' Siv continued to explain that this is a common condition that many women have, which causes constant vaginal bleeding, making patients anaemic, 'and when they finally don't have enough blood, they die,' she clarified. When recounting this specific case, Siv elaborated,

It is a condition that we don't normally see this advanced in Norway anymore ... . She came in and had an $\mathrm{Hb}$ (haemoglobin level) of 2.9. This is so low that no one could believe it. She was almost out of blood. She looked like a vampire. Her gums, the membrane behind her eyelids, and her hands were completely white. 
Though myomas are common, they are normally dealt with at an early stage. The surgery is advanced, Siv explained, but at the same time very easy and routine for gynaecologists. What particularly upset Siv was that this condition had been discovered by doctors five years before when the woman was admitted to a hospital and received a blood transfusion. Siv continued:

The doctors who discharged her were not aware that she did not have legal rights, that she did not have a regular GP. So, they discharged her with an epicrisis (discharge report) that read, 'Recommend that the patient be referred for a hysterectomy within the next few months'.

This, Siv emphasised, would be a 'perfectly safe and reasonably treatment' in most cases. However, since this patient did not have a GP who could refer her for surgery, she had continued to bleed for the next five years, fainting several times. When she came to the emergency centre, she had very low blood pressure, a dropping pulse, and she was about to go into circulatory shock. In addition, the patient expressed fear of accessing healthcare, begging Siv not to report her to the police when she finally came. To Siv, this episode had been a real wake-up call. As she explained:

Meeting this woman, who had lost all that blood because of a simple gynaecological condition, I was so angry and embarrassed by the Norwegian healthcare system. She almost died needlessly from a completely banal thing and the entire time she had cleaned our dirt and paid her taxes. And then she experienced the Norwegian healthcare system as so dismissive that she didn't dare come in until she was absolutely sure that she would die. And she was right. With an $\mathrm{Hb}$ of 2.9 and still bleeding, you won't live very long.

Doctor Siv's case brings out how lack of trust and knowledge can cause treatment delays regardless of the regulation. Moreover, it shows how failure by healthcare providers to recognise irregular migrants' precarity can compromise patients' health. Within literature on irregular migrants' access to health, delayed treatment is often referred to as one of the main impediments to individuals' ability to receive adequate medical attention (Magalhaes et al., 2010; Biswas et al., 2011). Delayed treatment frequently leads to late diagnosis and to the illness or disease becoming more severe and more difficult to treat. In some cases, there may be permanent damage that could have been avoided.

In the literature, delayed treatment is often attributed to irregular migrants' fear of deportation or fear of rejection by healthcare providers, as well as bureaucratic barriers (Castañeda, 2009; Larchanché, 2012; Bendixsen, 2015). In this case, delayed treatment was partly because the initial doctors treated the irregular migrant according to established routines and did not know or take her legal status into consideration. This raises the following question: Could better or more timely healthcare be ensured if irregular migrants were more easily identified within the 
healthcare system or if they were allowed to remain anonymous and 'treated as everyone else'?

The answer to this is not obvious. In France, for example, a parallel administrative system has been created specifically for irregular migrants. The system, called 'State Medical Assistance' (Aide Médicale de l'Etat - AME), allows undocumented migrants and their dependents to access publicly subsidised healthcare. In practice, AME is a certificate granted for a period of one year that must be shown to care providers. In this sense, the AME certificate allows irregular migrants to access healthcare without some of the problems I have identified in this chapter; it also provides them with an identity within healthcare for patient security. However, to obtain the AME certificate, irregular migrants have to present a valid identification document, evidence of an address and uninterrupted residence in France for three months, and proof that over the last 12 months their financial status has remained below a certain economic threshold. As the process to obtain the AME certificate involves cooperation and communication with the authorities and many difficult requirements, the bureaucratic system in itself may become a serious obstacle for irregular migrants' access to healthcare (Larchanché, 2012; Da Lomba, 2011). Another dilemma for healthcare providers is how knowing the patients' status might not always make it possible for healthcare providers to help as long as the broader circumstances for treatment are unfavourable.

\section{The dilemmas of structural compensation}

Structural compensation as a tactic involves implementing alternative structures to compensate for the exclusion of irregular migrants from mainstream services (Karl-Trummer et al., 2009). NGO or volunteer-run healthcare centres for irregular migrants, which now exist in many European cities, are important examples.

The healthcare centre for undocumented migrants in Oslo, which was an important site during my fieldwork, was initially open for four hours, two days a week for walk-in consultations but had to extend their offer over the years to include an additional day for planned consultations. The centre had 3 to 4 employed positions and more than 150 active volunteers. The volunteers consisted of doctors (including GPs, gynaecologists, psychiatrists, and neurologists), psychologists, nurses, physiotherapists, midwives, laboratory technicians, pharmacists, dentists, social workers, and telephone interpreters. The centre was also equipped with a medical laboratory, two ultrasound machines, one EKG machine, a basic stock of medications, and six treatment rooms for patients. Since 2010, the centre has had a cooperative agreement with Diakonhjemmet Hospital, which welcomed patients for medical, surgical, radiological, and rheumatology treatment upon referral from the centre.

The centre in Bergen was a smaller operation, having 1 employed position and about 100 volunteers. It was open for three hours one day a week for walk-in consultations with doctors, psychologists, and nurses, and one day second each week for consultations with a gynaecologist. They also had arrangements with three GPs to whom they could refer patients in need of treatment continuity and 
a dentist office where patients could get urgent pain-relief treatment. The centre also has an agreement with Haraldsplass Deaconess Hospital to perform tests. ${ }^{5}$

Many of the volunteers with whom I spoke said that these centres provided them with an opportunity to provide care and circumvent the limitations they experienced working in the mainstream health service. While ignorance or individual acts of support to some extent mitigated the dilemmas they experienced in their encounter with irregular migrants, most expressed that they still felt limited in terms of providing necessary care within the mainstream healthcare system. For instance, although a GP could follow up a patient in his or her private practice, there would be problems if the patient needed tests or needed to be examined by a specialist. In contrast, these centres gave healthcare providers an environment in which they could volunteer and provide care based on medical considerations. Several of the volunteers at the centre in Oslo also emphasised the advantages of the close cooperation and co-location between different medical specialities for treatment.

However, these centres were not without their own dilemmas. Ticktin (2011) and Fassin (2012) have powerfully problematised the idea of humanitarian assistance as it produces victim-subjects in contrast to rights-bearing individuals. Another challenge that the volunteer-run healthcare centres faced daily was that they risked glossing over the ethical and political dilemmas of irregular migrants in need of healthcare, making it possible to ignore the problem both at the policy level and within the mainstream healthcare system.

One key dilemma for the centres was the compensatory role they acquired in what they described as 'a broken chain of treatment' (Ottesen et al., 2015). This meant, for instance, taking on special responsibility for preventive measures as well as monitoring and rehabilitation after treatment, or healthcare excluded by the temporal frame of the Healthcare Regulation (2011). In the Oslo centre's experience, hospitals would refrain from carrying out interventions that were considered necessary because there were no rehabilitation services willing to accept the patient. Hence, by providing such services, the patient could get the required treatment within the mainstream health institutions. Some of the patients I met at the volunteer centre were also able to use the mainstream healthcare services, for instance for check-ups during pregnancy, but still had to rely on the volunteer run centre for access to free medication. Yet, by providing such services, the centres risked becoming a convenient pressure-relief valve for the mainstream health services. For example, it gave the primary emergency care centre an alternative place where they could refer irregular migrants rather than treat them themselves.

A key quotidian dilemma described to me by one of the employees of the healthcare centre in Oslo was, in individual cases, whether to test the system or just provide the healthcare themselves. While their main operation consisted of providing in-house care, they tried to refer patients to mainstream healthcare when necessary or when it was clearly in line with the regulation (i.e. children and pregnant woman). In most cases, they succeeded. The main challenge they experienced concerned referrals to mental healthcare. Together with the Norwegian Red Cross' legal team and the Medical Association, the centre actively tried to bring 
cases, such as the abortion case mentioned previously, to the Board of Health Supervision in a deliberate attempt to expand mainstream services' accountability.

The healthcare centre also sent patients they did not have time for during their short hours to the primary emergency care centres. In some rare cases, this resulted in a sort of stand-off between the two care providers. In one case I observed during fieldwork, a man arrived at the volunteer-run centre with a potentially broken bone. He had initially gone to the primary emergency care centre where he had been told he would have to pay. When he explained that he was unable to pay, the nurse told him about the healthcare centre for undocumented migrants. However, upon arrival there, he was sent back to the primary emergency care centre accompanied by one of the volunteer nurses and a note from the centre for undocumented migrants clarifying what they perceived as the primary emergency care centre's responsibility in this case. The primary emergency care centre eventually treated the man.

The Covid-19 pandemic that struck the world in 2020 highlighted further the precariousness of relying on alternative structures to compensate for the exclusion of irregular migrants from mainstream services (Drangsland et al., 2020; Thorbjørnsen, 2020). The volunteer-run healthcare centres for undocumented migrants in Oslo and Bergen had initially to stop their regular services, because the healthcare providers that usually volunteered were no longer able to do so. Many of the volunteers at the centres were retired and age-defined as a risk group for Covid-19 infections. Other volunteers, who were still working in the public healthcare system, were restricted from working elsewhere. Both centres managed after a short period to provide a limited service (the centre in Oslo, for example, opened an outdoor clinic in their back yard for simple consultations), and both the municipalities in Bergen and Oslo eventually assigned a GP, who would see patients referred by the centres one day a week. Although the centres as such succeeded in making the local authoritites somewhat more accountable for this patient group under the pandemic, access to care still relied on a limited supplementary arrangement.

\section{Borders as ambiguous thresholds}

Anthropological research on borders has often highlighted how borders can represent both dividing lines and thresholds of passage (Wilson and Donnan, 2012). As such, they can be alternately permeable or extremely solid. Accordingly, the border can be understood not only as a tool for exclusion but also as an instrument for producing differentiated forms of access and 'rights'.

In this chapter, I have explored administrative practices and routines affecting irregular migrants' access to healthcare and how healthcare providers navigate bureaucratic structures in their situated responses to contradictory demands and ambiguous expectations. Both are factors that can help explain the ambiguous or contradictory outcomes observed in many cases regarding irregular migrants' encounter with 'the state' in the context of healthcare. Hence, 'the border' appears both as more flexible and negotiated than perhaps initially implied in Agamben's notion of sovereign decisionism and exceptionalism and as much of the 
governmentality-inspired research on the so-called 'internal border control' that has tended to emphasise the importance and prevalence of surveillance technologies and exclusion.

Nevertheless, as shown in this chapter, health services do comprise various administrative practices and technologies that can be explored as practices of border control, where identification was used not primarily to detect but to exclude and deter irregular migrants in more subtle ways. There is little to suggest that this contributes in any significant way to the expulsion of irregular migrants from state territory. My argument is thus that the increasing intersection between migration control and healthcare access first and foremost contributes to regulate and discipline the conduct of irregular migrants and the healthcare providers they come into contact with by normalising the excluded status of irregular migrants. The Norwegian case thus highlights how current configurations of migration control do not necessarily produce a clear-cut division between included or excluded but reinforce a blurring of inside and outside. Furthermore, the border control is not only located where one enters but at multiple points during the medical encounter. The dispersed border is, as I will turn to in the next chapter, not also only materialised through practices of surveillance and decisions on life but by the imposition of a temporality that accentuates temporariness and unpredictability.

\section{Notes}

1 The personal identification number (called fødselsnummer) consists of 11 digits divided into 2 main parts: date of birth (six digits) and a social security number (called personnummer, five digits). The first three figures of the social security number are called individual digits and indicate century of birth with the third digit indicating gender (even number for females and an uneven number for males). The last two figures of the social security number are called control numbers and are calculated from the preceding figures (calculated by modulus 11). Although fødselsnummer is the formal term for the entire number, the term personnummer is commonly used colloquially.

2 While the social security numbers of other states are approximate equivalents to the personal identification numbers in Nordic countries, there are a couple of important differences. First, the fødselsnummer is obtained automatically at birth and is not tied to employment or insurance and is assumed to be universal. Second, the number, which includes sex and date of birth and follows you throughout your life, is supported by a central population register. Third, it is required for most administrative purposes (tax, health and social services, passport, elections, legal proceedings, driver's licenses, etc.). It is also needed in contact with many private actors, such as banks and insurance companies. Unlike in many other countries (e.g. the United Kingdom, the United States, or Spain), it is not possible in Norway to provide pieces of mail as proof of address to get a bank account. Asylum seekers and foreign nationals who come to Norway to work for less than six months are given a D-number that serves many of the same purposes. D-numbers are constructed in the same manner as the standard identification numbers except that the birth date is modified by adding 4 to the first digit. This makes it distinguishable from a regular fødselsnummer.

3 Healthcare providers have the option of registering patients under the so-called support number (also called an emergency number, H-number, or FH-number). Although the procedure has become increasingly standardised and possible within the electronic 


\section{Blurred borders}

systems in use, my interlocutors also reported several different ad hoc ways of registering patients without fødselsnummer or 'D-nummer', including using hard copies.

4 For instance, Diakonhjemmet hospital in Oslo was the only hospital that explicitly accepted cases pro bono from the volunteer-run healthcare centre. As such, they received most of the referrals from this centre for specialist healthcare within the specialities they had. They reported to me in interviews, however, that they experienced the economic burden to be limited.

5 Both Diakonhjemmet and Haraldsplass are independent diaconal institutions within the Church of Norway. Both also function as local hospitals for Bergen and Oslo under contract with the regional health enterprises through which they receive the majority of their fundings. 


\section{Part III}

\section{Temporal tensions}


$\because$ Taylor \& Francis

Taylor \& Francis Group

http://taylorandfrancis.com 


\section{Healthcare through the temporal lens of migration control}

In his book Pascalian Meditations, Pierre Bourdieu argues that absolute power is the power 'to make oneself unpredictable and deny other people any reasonable anticipation, to place them in total uncertainty by offering no scope to their capacity to predict' $(2000,228)$. This highlights how time is an integral part of the exercise of power. In recent years, there has been an increased scholarly attention to how temporal techniques are central to governing migration (Jacobsen et al., 2021; Drangsland, 2020; McNevin and Missbach, 2018; Andersson, 2014). This literature has underlined the imposition of a temporality marked by temporal suspension and stagnation, uncertainty, and unpredictability in the governing of migrants. The socio-legal condition of migrant illegality and deportability has frequently been described as an ongoing state of temporariness and uncertainty, where the migrant learns to live, or rather survive, in the here and now (De Genova, 2002). In this chapter, I aim to explore how the temporal imperatives of migration control frame and condition the medical encounter between irregular migrants and service providers. I ask: How does unpredictability and temporariness shape the medical gaze as well as medical judgements and practices?

Hind's case (Chapter 3) illustrates how both the territorial and temporal rationality of migration control are drawn into the diagnostic act itself. As the whole medical consultation and the relationship between the involved parties became structured by the possibility of deportation, it became more important for Doctor Olav to assess Hind's legal situation and its temporal implications than her new somatic symptoms. However, the case also illustrates how Hind's continued presence became a headache not only for the immigration authorities but also for the healthcare system. As time passed, it became more difficult for the doctors to justify the lack of treatment, and eventually the doctors performed surgery even though her legal status had not become any more secure. In the following, to explore how the medical encounter is framed by the temporal lens of migration control, I will start by unfolding another case I came across during fieldwork that brought this tension to the fore.

\section{Timing}

I met Roland quite early in my fieldwork, and for a long time, I thought he was going to be my 'happy case', in many ways in contrast to that of Hind. Like Hind, 


\section{Temporal tensions}

Roland needed surgery, but as an adult, his legal right to healthcare services was more limited. Still, Roland had not experienced any difficulties accessing both specialist and continuous healthcare treatments up until the time I met him.

As a child in the Democratic Republic of Congo, Roland was diagnosed with a chronic condition that restricted his mobility and for which he would require lifelong medication. In 2008, at the age of 32, he came to Norway and applied for asylum. By the time I met him he had received, as he put it, his 'fourth negative'. However, he was relentlessly optimistic, insisting that it was only a matter of time before he would get 'a positive'. When I would ask him if he feared deportation, he would dismiss it as a possibility. Initially, he would claim, 'They are not stupid in Norway. They know exactly what's happening in my country.' Later, after a friend and fellow countryman left on the so-called assisted return-agreement, his emphasis would change to his health, 'They can't, you know. Because of my medical condition', he would say.

After having arrived in Norway, Roland was diagnosed with a second condition, one that, in normal situations, could easily be treated with outpatient surgery. However, in Roland's case, due to his chronic condition, surgery would have been quite complicated, and it could have risked escalating his physical disability. The same outcome was likely without surgery. As the surgery was not yet urgent and Roland was considered a high-risk patient, the doctors initially decided to wait and instead regularly monitored the progression of his condition. Surgery was still likely to become necessary at a certain stage, that is, when the condition started to hinder him from performing daily tasks. Hence, it became a matter of continuously weighing the risk and finding 'the right time' for the proposed procedure. In the meantime, he was followed up closely by a specialist.

When I met with Roland, he rarely complained. Instead, he always tried to make the best of every situation. He also always expressed complete confidence in his doctors' judgements and satisfaction with the way they treated him. He dismissed having had any problems receiving medical treatment or having experienced being treated differently both prior to and after his second negative. Not being treated differently also meant that he had to pay the regular user fees for medical appointments and for medicine. However, as these costs were quite high in total, the UDI had agreed to reimburse them, along with covering his transportation to medical appointments. He had told his GP and his regular specialist about his 'negatives' since he had also asked them for medical reports for his appeals. It had not been, as he could recall, a topic of discussion in his appointments with specialists at the hospital. However, as with Hind's family, Roland never considered himself irregular, illegal, or undocumented, but as an asylum seeker. His lack of a personal identification number only became a problem in relation to e-prescriptions, but he could always get a hard copy prescription to bring to the pharmacy.

Although Roland expressed absolute confidence in his doctors, he still feared becoming more severely disabled, and it was a constant worry. Several times during my fieldwork, Roland believed the surgery was about to be scheduled. However, it usually turned out that he just underwent more examinations conducted 
by various specialists at the hospital. On these occasions, Roland talked about his worries, as illustrated here in one of my field note passages:

When I arrive, he is listening to the radio, a French channel reporting news from Africa. There has been an incident in the Ivory Coast, which he tells me about. We try to speak in Norwegian this time, he speaks quite well, but he says he finds my dialect difficult to understand, so we often slip into English. As usual when I come, he is very cheerful. He had told me on the phone earlier that he had received a notice from the hospital, and he thought it meant that he was scheduled for surgery. He tells me again excitedly that he is to see the 'chief surgeon' this time and not his normal doctor. This doctor has to check that it is time for the operation. I ask if he is nervous about surgery. 'Ah, Saturday was bad, you know. Really bad', he replies shaking his head, explaining that he had been thinking of his mother, his legal situation, and the operation. All together it had been too much. This is the first time he has expressed his worries about his legal situation to me. Normally he talks about his health problems, his worries about becoming more physically disabled, everyday events, and his plans for when he gets his papers. I ask if there is anything new, but he says it's just that five years have passed now without a 'proper answer'. He had not thought it would take this long. But, he continues more optimistically, 'perhaps when I have the operation something will happen'. He continues to tell me (again) how important the operation is to him, going through the details of the procedure with me once more.

As with several of the other irregular migrants in my study, 'the anniversary' of their arrival in Norway was, for Roland, a particularly difficult time, marking the passage of yet another year 'stuck'. This passage also displays how waiting for surgery and waiting for papers became entwined in Roland's life.

After Roland had waited anxiously for five years for surgery, a date was finally set. However, upon examination on the day of Roland's admittance to the hospital, the 'chief surgeon' decided that Roland's condition was still too good to risk surgery. When I spoke with Roland afterwards, he claimed not to be disappointed, rather a little relieved. Though he knew he would need it one day, he was nervous about the risks, as he said. At this stage, he was also convinced there would be (another) time.

A few weeks later, on one of our last meetings, Roland told me he expected good news soon. At least that was what his lawyer had told him, he said. He had just been to see him before meeting me in a city park. They had sent another request for renewed consideration (omgjøringsbegjcering), and UNE had asked for updated information about his medical situation. Roland had received a discharge summary from the doctors that the lawyer was now going to send in. And, as Roland told me, his lawyer was very optimistic. I asked Roland if he too was optimistic. Again, he displayed one of his rare moments of doubt, saying he would believe it when he saw it. I tried to ask him if he was worried that he might be deported, having not had the surgery, as it was now postponed again for 
an unspecified period. However, he dismissed this more confidently with, 'They can't, because of my medical condition.' A few months later, while I was abroad, I learnt that Roland had been apprehended and deported.

\section{Treating deportable bodies}

Within medical anthropology and sociology, control of patient time (and space) has been conceptualised as a central aspect of the power asymmetry between health professionals and patients and, as such, of medical sovereignty. In his influential article "YYour Time or Mine": temporal contradictions of biomedical medicine', Ronald Frankenberg (1992) suggests that differences in the value of patients' and doctors' time are reflected in how time is enacted as a symbol of power and status. Patients and their relatives are made to wait, perpetuating uncertainty and dependence on doctors, while 'the sacred, inviolable time of the qualified physician' (Frankenberg, 1992, 1) is protected and parcelled out by his or her supporters. This protection and value placed on doctors' time was something I came to experience during fieldwork as access to doctors turned out to be more difficult than access to the so-called hidden population of irregularised migrants partly due to the strict parcelling of their time by their gatekeepers.

However, control of time in the medical encounter is not simply an expression of repressive power. From a more Foucauldian perspective, control of time can be understood as a productive form of power. In the patient-doctor relationship, power enables doctors to act in the competent role demanded of them by most patients and which is legally and professionally prescribed. As such, doctors do not necessarily behave in such a way as to deliberately oppress their patients and subordinate staff; instead, they behave in a way that is expected of them by their co-workers and their patients, and they cannot easily 'decide to break the frame of their professional game’ (Måseide, 1991, 552). Or as Deborah Lupton puts it:

Doctors themselves are subject to the field of power that constitutes institutionalised norms of behaviour in medical practice, while patients expect such behaviour as necessary and rational. From the moment the patient walks into the waiting room or hospital, it is up to the medical staff to take control. As the 'experts' in the medical encounter, doctors and other health professionals must advise patients how to behave in the encounter, direct their bodily movements in clinical examinations, prepare them for surgical procedures and advise them on behaviours relating to their health problem and treatment regimes, for as 'non-experts' the majority of lay people simply do not know what to expect or do.

What is notable in both the case of Hind and Roland is how medical practice, depending on doctors' control of patients' time and space, was challenged by their bodies being deportable. In Hind's case, it made doctors reluctant to initiate surgery, while in Roland's case, ongoing treatment was interrupted by his actual 
deportation. These cases thus indicate an inherent tension between the temporalities of medicine and migration control.

Several scholars have critically examined deportation as something more than an inevitable conclusion to various 'failed' migrant and refugee aspirations. Many of these have come to consider deportation as a disciplinary practice and an instrument of state sovereignty that renders certain populations deportable, regardless of their ties to the 'host' society (Peutz and De Genova, 2010; Nijhawan, 2005). Deportation, in most cases, is time-consuming, expensive and is only applicable in some cases. De Genova (2002) has therefore argued that it is deportability, or the protracted possibility of being deported, that is the real effect of these policies and practices. It is, as he and Peutz put it:

[t]he grim spectacle of the deportation of even just a few, coupled with the enduring everyday deportability of countless others ... that produces and maintains migrant 'illegality' as not merely an anomalous juridical status but also a practical, materially consequential, and deeply interiorised mode of being - and of being out of place.

(Peutz and De Genova, 2010, 14)

In Hind's case, the disciplinary effect of deportability, along with its practical and material consequences, is clearly visible in that she initially did not get surgery. The complex and contradictory temporalities and the unpredictability that permeate threats of deportation not only affected Hind and her family's mode of being but also, importantly, had a disciplinary effect on the healthcare providers with whom they came into contact. In Roland's case, the question of deportation worked slightly differently. I did not ask Roland's doctors directly to what extent they had been aware of, or took into consideration, the possibility of Roland's deportation when performing the 'individual professional evaluation' (i.e. deciding to postpone surgery). However, the indication I received (mainly from Roland himself and his patient journal) was that they had not and did not, though it might not have made any difference. Also, Roland's access to specialist healthcare suggests that his doctors either did not know about his legal situation or ignored it, making their decision within established biomedical knowledge and routines 'like for any other patient'. Nevertheless, both Hind and Roland's cases illustrate in different ways the challenges and dilemmas that possible deportation raises for healthcare providers. Should they or should they not take this possibility into consideration when deciding course of treatment?

In France, and to a lesser degree Germany, mechanisms have been established to address this dilemma by temporally suspending deportation in certain cases to allow treatment. This has been related to the way the suffering body gains a particular salience for understandings of deservingness and the right to stay in these countries (Fassin, 2012; Ticktin, 2011). The illness clause is a humanitarian provision in French law that gives people with serious illnesses the right to stay in France and receive treatment if they are declared unable to receive proper treatment in their own countries. To benefit from an illness permit, one has to get an 


\section{Temporal tensions}

official medical certificate saying that one is sick and that one's pathology should be taken into consideration as the basis for granting residence permits. This claim is then examined by a state doctor at the state medical office who issues an opinion about whether the patient needs papers and for how long. This is sent to the immigration office that puts it into practice. In Germany, the system, officially called Duldung (literally 'toleration'), plays a similar, but more restricted role (Castañeda, 2010). The Duldung is not a residence permit, but a temporary suspension of deportation that can be issued to pregnant women (six weeks before and eight weeks after birth) and people suffering severe illnesses (either if the person is too ill to travel or if a person is in 'mortal danger' and treatment is not available or too expensive in the country of origin), among others. However, both Ticktin (France) and Castañeda (Germany) maintain that although these exceptions are framed as examples of benevolence on the part of the host society, they serve the interest of a restrictive policy, leaving the benefiters either more visible and in danger of deportation or in a protracted state of deportability.

In Norway, the system is not as formalised as in France and Germany, but there are some mechanisms that can be used to suspend deportation for treatment purposes. UNE, for instance, can grant temporary residence on humanitarian grounds. This has been granted in a limited number of cases based on conditions related to health, as in the cases of Adam Dzortov (Chapter 3) and Louila Tuban (Introduction). Most of these permits were granted in cases where the patient was already in treatment or undergoing assessment, or there were specific plans for this, at the time of decision (UNE, 2009, 2020). There were also examples of temporary permits being issued when the forecast for the current diagnosis suggested that the need was temporary. UNE also has the opportunity, when issuing the 'final decision', to extend the deadline for departure (utvidet utreisefrist) in cases where the person is already under medical evaluation and/or temporal treatment for a serious condition that should not be interrupted. However, the extended deadline for leaving must not exceed three months. An exception is made for persons under investigation or receiving treatment for tuberculosis. As a general rule, they are not ordered to leave the country before suspected tuberculosis is disproved or treatment is completed. In addition, UNE can issue the so-called deferred implementation (utsatt iverksetting). This is not issued for medical treatment, but in cases where a person is appealing the final decision, either in court, to the Parliamentary Ombudsman, or to UNE. Deferred implementation is not automatically granted in appeal cases but is based on a specific assessment in each case. Also, deferred implementation does not make the stay legal but only temporarily removes the threat of deportation. Common to the different measures mentioned is that they may suspend the immediate but not the long-term threat of deportation. Hence, similarly to the French illness clause and the German Duldung, they maintained a sense of temporariness and unpredictability.

Neither Hind and her family nor Roland were granted any of these options. However, they did engage in more informal practices in order to become 'less deportable'. Chauvin and Garcés-Mascareñas (2014) and others investigating migrant illegality have noted how good conduct has become a tactic employed by 
irregular migrants to make them either less detectable or less prioritised for deportation. Such tactics include not committing petty crimes, such as public transportation fraud, avoiding interaction with the police, and not committing serious crimes to avoid becoming a priority for removal programmes. Tactics also include paying taxes and keeping the same constructed identity over time so as to build a consistent trail for legalisation. By living a transparent, above-board quotidian existence, they situate themselves in the domain of the licit (Coutin, 2005). Hind and Roland, living at addresses known to the state and avoiding crime, tried to decrease the likelihood of deportation by keeping their reception centre and UNE informed about scheduled medical appointments and treatments. At times, they also requested renewed considerations and registered with IOM in hopes it would keep the police away for a time. For instance, Hind's family registered with IOM when Reema, Hind's mother, became pregnant, primarily to feel safe from the police during the pregnancy, but also following a cycle of ups and downs where they had serious discussions about returning. Their resolution frequently changed.

UNE on occasion also requested updated information about their medical treatment while evaluating their requests, as I described earlier in the case of Roland. Shortly before his scheduled surgery, Roland had filed a new request for reversal in his asylum case, submitting the information about the upcoming surgery. At UNE's request, Roland sent an updated medical report after surgery was cancelled. This was not a specific report written for UNE, but a standard discharge summary and as such principally written for other healthcare providers. Roland did not know exactly what it said but believed it still clearly stated his need for surgery. However, the report was much vaguer, stating that the hospital would continue to monitor him and that the need for surgery would be re-evaluated if his condition progressed. Having this dialogue with UNE gave Roland a sense of security. Still, by the time Roland's last request was denied he had already been deported.

\section{Healthcare as urgent and temporary measures}

While the illness clause in France described earlier can be seen as an attempt to deal with the tension between the temporalities of medicine and border control by giving some precedence to medicine, the Norwegian response was primarily to limit access to healthcare and to impose a particular temporal frame on medical assessments and treatments which made urgent and deferred treatment the norm.

Since 2004, it has been an official aim that all contacts between public institutions and the individual irregularised migrant should signal a sense of temporariness so as to indicate that their time in Norway has come to an end (Brekke, 2008). In the Healthcare Regulation (2011) this was clearly evoked by limiting healthcare services in most cases to 'emergencies' and 'healthcare that cannot wait'. In the circular and consultation paper to the Healthcare Regulation, the Ministry of Health and Care Services indicated that treatment that could wait more than two to three weeks should not be initiated (Ministry of Health and Care Services, 2010; RS 1-5/2011). The consultation paper also showed that the time 
frame of three weeks was not medically justified but was set according to what the Ministry of Health considered to be 'a reasonable time frame' for the irregular migrant to be able to leave the country. Hence, the Ministry of Health and Care Services presupposed that people without legal residence should (and could) 'go home' within three weeks and receive the healthcare they needed. The evaluation of what conditions cannot wait was still to be made on individual medical grounds. However, some examples were included as guidelines (see Table 5.1).

For children, temporariness was evoked in the Healthcare Regulation (2011) through the sentence 'unless concern for the child dictates that assistance should not be provided'. This sentence did not, as previously noted, refer to 'the best interests of the child' in line with the UN Convention on the Rights of the Child

Table 5.1 Examples of conditions that fall under the concept 'healthcare that cannot wait' according to the circular issued by the Ministry of Health and Care Services (RS $1-5 / 2011$, under remarks to the regulation).

\begin{tabular}{|c|c|c|c|c|}
\hline Condition & $\begin{array}{l}\text { Potential } \\
\text { treatment }\end{array}$ & Severity & $\begin{array}{l}\text { Period of time } \\
\text { the treatment } \\
\text { is assumed to } \\
\text { be able to wait }\end{array}$ & $\begin{array}{l}\text { Outcome if } \\
\text { untreated }\end{array}$ \\
\hline $\begin{array}{l}\text { TIA - warning of } \\
\text { an approaching } \\
\text { stroke }\end{array}$ & $\begin{array}{l}\text { Assessment } \\
\text { prophylaxis }\end{array}$ & $\begin{array}{l}\text { Potentially } \\
\text { severe }\end{array}$ & $0-3$ weeks & $\begin{array}{l}\text { Risk of developing } \\
\text { a stroke }\end{array}$ \\
\hline $\begin{array}{l}\text { Threatening heart } \\
\text { attack }\end{array}$ & $\begin{array}{l}\text { Assessment, } \\
\text { possibly } \\
\text { blocking or } \\
\text { bypass surgery }\end{array}$ & $\begin{array}{l}\text { Potentially } \\
\text { severe/ } \\
\text { deadly }\end{array}$ & $0-2$ weeks & $\begin{array}{l}\text { Developing a heart } \\
\text { attack, death, } \\
\text { heart failure }\end{array}$ \\
\hline $\begin{array}{c}\text { Sciatica with } \\
\text { increasing } \\
\text { paralysis }\end{array}$ & $\begin{array}{l}\text { Assessment, } \\
\text { surgery }\end{array}$ & Severe & $2-3$ weeks & $\begin{array}{l}\text { Widespread } \\
\text { paralysis, } \\
\text { incontinence, } \\
\text { permanent } \\
\text { paralysis }\end{array}$ \\
\hline Gangrene wounds & Amputation & Severe & $1-2$ weeks & $\begin{array}{l}\text { General infection, } \\
\text { increasing } \\
\text { gangrene }\end{array}$ \\
\hline 3rd Degree Burn & Plastic surgery & Severe & 2 weeks & $\begin{array}{l}\text { Infection } \\
\text { spreading }\end{array}$ \\
\hline $\begin{array}{r}\text { Threatening } \\
\text { psychosis }\end{array}$ & Pharmacotherapy & Severe & Days & $\begin{array}{l}\text { Acute aggravation, } \\
\text { endangering } \\
\text { themselves and } \\
\text { others }\end{array}$ \\
\hline $\begin{array}{l}\text { Severe depression } \\
\text { with suicide risk }\end{array}$ & $\begin{array}{l}\text { Pharmacotherapy, } \\
\text { ECT }\end{array}$ & & Days & Suicide \\
\hline $\begin{array}{l}\text { Suspicion of very } \\
\text { serious cancer }\end{array}$ & $\begin{array}{l}\text { Pharmacotherapy/ } \\
\text { surgery/ } \\
\text { radiotherapy }\end{array}$ & Severe & Days & Imminent death \\
\hline $\begin{array}{l}\text { Cancer in the } \\
\text { terminal stage }\end{array}$ & Palliative care & Severe & 2 weeks & $\begin{array}{l}\text { Severe pain, } \\
\text { reduced quality } \\
\text { of life }\end{array}$ \\
\hline
\end{tabular}


but instead stipulated that treatment should not interfere with the state's attempt to deport the child (Chapter 3). In the case of children, neither the regulation nor the consultation paper or other guidelines indicate a 'reasonable time frame' for deportation to occur to defer treatment. It is thus unclear whether the doctors should consider a theoretical time frame for a possible departure, that is, two to three weeks as with adults, or if they should try to establish a realistic time frame (Karlsen, R., 2015).

One of the challenges from a medical perspective posed by the regulation was that it was not always clear what qualified as a severe and urgent condition worthy of exception. In a consultation statement to the Healthcare Regulation (2011), the Norwegian Medical Association (2010) pointed out several temporal paradoxes and ethical dilemmas that healthcare providers experienced when medicine was approached through the temporal lens of migration control. For instance, from a medical point of view, knowing that many irregular migrants would not leave after two to three weeks, waiting may conflict with professional ethics and expert knowledge on what would be the best medical option. As the Medical Association (2010) explained:

Untreated diseases will often worsen over time and will still end up as conditions that cannot wait while the prospect of treatment often becomes worse if you postpone treatment. . . . Considering that many, despite a decree to leave the country, will remain in Norway, it will become impossible for them to receive adequate healthcare. This would be contrary to accepted medical ethics, which states that everyone shall receive treatment regardless of social status, position, ethnicity, etc.

In their consultation statement, the Medical Association also protested the new distinction between 'healthcare that is absolutely necessary and cannot wait' and necessary medical care accorded to legal residents, arguing that that there are no medical grounds for this partition. According to the Medical Association, this distinction would be difficult to deal with in practice and assessments would necessarily be very subjective. Also, the Priority Regulation (2000) regulating what constitutes necessary healthcare for legal residents already stated that severity should be of primary importance when prioritising between patients, defining severity in terms of loss of functionality, pain, and discomfort.

How to prioritise within medicine has long been a controversial and contested issue as it ultimately reflects a valorisation of life and distinctions between different lives, undermining the idea of healthcare as a universal right. The question of organ transplantation in Siv Tove and Louila's cases (Chapter 3) clearly illustrates the dilemma of prioritising and how it merges medical and moral judgements on life. In these cases, it involved not only a judgement on their current life worth compared to drug-free and legal residents but also a judgement about their future life quality. Priority is thus not a simple question of 'objective' medical standards as medical severity can be understood in different ways. Priority decisions can therefore vary based on whether 'current', 'future', 'past', or 'lifetime' health is 
emphasised. Norway was the first country to attempt to implement an explicit priority setting system in 1987 (NOU, 1997, 7). Even so, priority levels have been an ongoing discussion. In 2009, 32 national task forces consisting of medical doctors and other healthcare providers from specialist healthcare, general practitioners, and patient representatives were established to define the concepts of severity, efficiency, and benefit of intervention within different specialised fields of medicine. These definitions were to provide the basis for guidelines meant to ensure that the law is practiced equally throughout Norway and to aid the clinicians responsible for evaluating referrals received from primary GPs (Hara and Borchgrevink, 2010). Still, there continued to be indications of divergent practices both between hospitals and between specialties and departments within the same hospital (Magnussen and Aasen, 2013), illustrating to some extent the continuing arbitrariness and difficulties of priority decision-making.

With respect to the discussions in Norway on formal prioritisation standards and values, 'healthcare that is absolutely necessary and cannot wait' could be said to make things more complicated by establishing a new and poorly defined priority level based on unfamiliar temporal considerations. In addition, the process of deciding and defining this term only took a few months and minimal involvement of healthcare providers. Not surprisingly, all the healthcare providers I interviewed found the term difficult to interpret. Furthermore, the doctors did not see the time frame of two to three weeks suggested by the ministry as a workable guideline for deciding whether or not to initiate treatment. The regulation says nothing about the realism of departure, or whether or how doctors should know if treatment actually would be available to the patient within this timespan. Having to assess the acuteness of treatment without having this information was regarded as putting the doctors in 'an impossible situation' (see Chapter 4).

Though many of those I interviewed were not familiar with the Healthcare Regulation beforehand, or with the Medical Association's statement, they conveyed much the same criticism. Some also pointed out that emergency care was already a very broad term. 'If you ask ten different doctors, you'll get ten different answers', one doctor explained to me. What constitutes an emergency, according to him, could change based on the patient's social status, insight into their illness, access to a general practitioner, access to caregivers who can look after them while they are sick, access to a good home, or circumstances at home that are constructive. This definition of emergency, which takes social inequalities into account, gives a more flexible temporal understanding of what emergency care is and could therefore provide doctors with professional grounds for extending emergency services to irregular migrants for conditions otherwise considered non-urgent.

Regardless of the ambiguities in the Healthcare Regulation (2011), it primarily framed healthcare to irregular migrants as temporary and urgent measures, and as indicated by the circular (Table 5.1) and the three weeks framework, it was the severity and immediacy of current illness and suffering that should guide access and not a consideration of future quality of life. As Table 5.1 shows, it was not cancer itself but suspicion of very serious cancer and cancer in the terminal stage that 
triggered the right to healthcare. Hence, a main challenge for healthcare providers became how to treat chronic patients such as Roland and Hind. According to the regulation, they should not receive care until the situation became acute. From a medical viewpoint, this contradicted established practice and knowledge that indicated that untreated illness and treatment prospects often worsened over time. Furthermore, chronic patients, in going untreated, could end up as intensive care patients. As such, they would be entitled to healthcare, but potentially at greater economic costs than if they had received adequate treatment at an earlier stage. Here, it is interesting to note that the Swedish legislation, which also uses the phrase 'healthcare that cannot wait' (vård som inte kan anstå'), defines the term differently. In Sweden, healthcare is given to irregular migrants if it can counteract a more serious illness or supplant the need for more comprehensive care and treatment (Ministry of Health and Social Affairs, Sweden, 2013). Hence, in Sweden, continuous treatment of chronic conditions can be interpreted as 'healthcare that cannot wait', while this does not hold true in Norway. This underscores again how the term is ultimately about establishing medical standards based on the temporal rationality of migration control and how these standards are linked to the way particular moral economies valorise life and define acceptable suffering.

\section{The 'here-and-now perspective'}

The temporal insecurity inscribed into the medical encounter by deportation practices and the temporal frame stipulated by the Healthcare Regulation (2011) result in not only interrupted and delayed treatment but what the healthcare providers in my study described as an orientation of medical practice to the 'here-andnow perspective'. This meant that they tried to address whatever health problem the patient brought into the medical appointment, within the allotted time of the appointment.

For the healthcare providers at the level of primary healthcare, this reorientation was not primarily due to the regulation but due to the possibility that patients might suddenly disappear and/or that the centre had limited or no means of contacting them. As such, it was framed by the wider social condition of migrant illegality and the difficulties in trying to deal with socio-political issues medically. Hind and Roland, with their complicated somatic conditions, represented in many ways distinct cases where the tension between the temporalities of medicine and migration control intensified. In most cases, the healthcare providers in my study stressed that the health issues they encountered tended to be 'lifestyle related' and of a kind that could be dealt with at the primary healthcare level. Still, many of the same dilemmas presented themselves. ${ }^{1}$

In particular, two obstacles for treating irregular migrants, as opposed to legal residents, came up repeatedly in interviews and conversations with healthcare providers. These were the difficulties of providing continuity of care and how to deal with cases that were seen as socially and legally caused and without clear medical solutions. In Norway, as long as primary emergency care centres were irregular migrants' main way to officially access healthcare, irregular migrants were forced 


\section{4}

to seek care from institutions that were not organised to provide continuous care and where it was difficult to a build a long-term relationship that fostered trust. Accordingly, the structure of available assistance accentuated care as temporary and urgent measures. Also, for irregular migrants, possible and optimal treatments for their medical conditions were often complicated by social realities caused by their legal status. These frequently included poor living and working conditions, limited social network, and a lack of knowledge concerning rights and services available, in addition to the insecurity and fear caused by deportability (Willen, 2012b; Quesada, 2012; Bendixsen, 2015).

For healthcare providers, though, the temporal challenges related to treating irregular migrants were not exclusively related to their difficult present situation. For example, when I asked Doctor Morten, a GP, what he found most challenging when treating irregular migrants, he did not answer the lack of rights in the Healthcare Regulation (2011) as I had somewhat expected. Instead, he pointed to the migrants' 'lack of a future'. This, in his mind, was what, more than anything else, separated his patients that were irregular from others in difficult life situations. As a doctor, he found this difficult to deal with. They represent a kind of helplessness I don't think doctors or others are comfortable with. I do not look forward to it when I see that they are on the list [of today's patients]. They make me feel hopeless', he explained.

Morten's comment is interesting as it brings forth how medical personnel's conceptions of time, hope, and future are challenged in the encounter with irregularised migrants. Petersen and Wilkinson (2014) note that in healthcare and medical practice, an 'attitude of hopefulness' is increasingly viewed as a valued aspect of personal wellbeing and deemed as having a therapeutic value. However, as they point out, the use of hope in the discourses and practices of medicine and healthcare tends to be associated with an increasing, constructed individual responsibilisation, linking hope to the exercise of choice, personal control, and empowerment in a way that overlooks the discursive and socio-political significance of 'hope'.

Doctor Morten's concern, however, refers more to what Ghassan Hage (2003) has called the unequal distribution of hope in society. While the term 'irregular migrant', as a legal category, is applied to individuals in vastly different circumstances who may have varying individual experiences of hope, Hage's observation draws attention to hope as not necessarily an inherent quality but as a product of social conditions. Hope, in this sense, refers to the way access to resources reduces or encourages perceptions of a better future. In the case of irregular migrants, the state, through border(ing) practices, circumscribes access to resources, and hence irregular migrants' experiences of a (better) future and the possibilities to plan for one. It is as such central to the production of their precarity.

In this context, Doctor Morten identified the absence of hope (i.e. lack of future) amongst his patients as a cause of ill health but also as an obstacle to treatment. The therapeutic method of 'instilling hope', empowering the patient, was revealed as inadequate. The challenge for frontline service providers identified by Doctor Morten was related to both the hopelessness experienced and expressed by the patients themselves and the hopelessness experienced by providers related 
to not being able to help in any meaningful way. This sense of hopelessness and helplessness was in many ways related to the very limited availability of assistance for irregular migrants as they are cut off from the normal channels of support, and it was also something that affected me as a researcher in this field (see also Brunovskis and Bjerkan, 2008). For Morten and other healthcare providers, their dilemma became both how to deal with this circumscription of the future in the medical encounter and how they become part of it through a reorientation of medicine towards temporary cures.

It was not only irregular migrants' lack of future prospects that presented a time-related dilemma for the healthcare providers treating them. How to deal with their past could also be challenging. As Liv, a psychologist working in a healthcare centre for children and families, explained:

'Many of them come with a history of traumas and things that one should address. But very much ends up being about the current situation because it is so uncertain. So, I think a lot of what I do is to try to find out how to live with this uncertainty. And is it possible to do something about it?' She also added, "To work with trauma issues and that sort of thing when the "now situation" is so uncertain ... [f]irstly, it is not wise. One is advised not to do so. And secondly, it is difficult because it is in a way not where their focus is'.

As implied here, a certain level of stability is usually understood as a professional and ethical requirement for initiating trauma treatment. This is difficult to achieve when faced with irregular migrants who find themselves in a continuous life crisis. What Liv often ended up doing with these patients instead was assisting them with practical issues, such as writing letters, calling the UDI, getting them in contact with a lawyer, and so on. In other words, she helped them to sort out their difficult legal 'now situation'. Hence, Liv moved beyond the medical frame in an attempt to help her patients. Also, Morten, in some cases, became personally involved in his patients' asylum cases and in helping them with practical issues such as shelter.

Morten and Liv worked as healthcare providers in Bergen before the volunteerrun centre was established there in March 2014, and that time they felt alone and unsure about how to deal with irregular migrants. One of the advantages of establishing volunteer-run centres was that it provided healthcare providers with an arena where the difficult issues could be discussed and addressed. In the following, I will therefore look at some of the ways the healthcare centre for undocumented migrants in Oslo tried to tackle insecurity and unpredictability when treating irregular migrants.

\section{'Doctors cannot write a prescription for residence'}

The title quote to this section is from a former director of the healthcare centre for undocumented migrants in Oslo and hints at the limitation and frustration faced by healthcare providers when cause and cure for ill health is not necessarily to 
be found within the biomedical perspective. Medical anthropologists have previously noted how medical technology may be effective in curing many acute biological pathologies but is often poorly designed to address the social structural problems that 'wreak havoc on the bodies of poor people' (Bourgois and Schonberg, 2009, 304). Medicine thus risks contributing to a 'medicalisation of suffering' by ignoring important political, socio-cultural, and moral dimensions of distress (Fassin and d'Halluin, 2007; Ticktin, 2011). For healthcare workers in my study, even when they were aware of the negative impact of illegality on their patients' health, they experienced limitations on what they could do as doctors, nurses, psychologists, and physiotherapists. Their encounters with irregularised migrants also often challenged established models of treatment.

The volunteer-run healthcare centre for undocumented migrants in Oslo, during my fieldwork, was the most stable and continuous place for care for irregular migrants in that area. Though their main activities were on-the-spot appointments for which patients would have to queue, they also at times scheduled follow-up appointments. The temporal orientation of the centre was not medical emergencies. Emergencies should still be handled by the public primary emergency care centres. Instead, the centre was equipped as, and saw its function to be, a regular GP office, but with some additional technology, including an ultrasound apparatus, electrocardiogram, a private laboratory, and a somewhat wider range of medicines in stock. In this sense, on a daily basis, the centre challenged the emergency frame behind the government's approach to irregular migrants, although in principle it remained within the biomedical frame. However, in so doing, the centre took on a compensatory role in what might be described as 'a broken chain of treatment' (Ottesen et al., 2015, chapter 4).

Nevertheless, continuity of care was challenging, on the one hand, because patients would disappear and, on the other hand, because of the changing rotation of volunteers. Most volunteers would only work once a month and were often unable to follow up the patients themselves. Many of them pointed out how they ended up reorienting their clinical focus to the here and now and to what could be addressed in the medical encounter without being able to rely on follow-up appointments. They stressed that in this regard, the centre provided an advantage over the mainstream healthcare services because of the multitude of providers and specialities represented by the volunteers working there. As such, a patient would be able to see a GP, a psychologist or psychiatrist, a physiotherapist, or even a gynaecologist or a neurologist on the same day without having to be on a waiting list. Changing the rotation of volunteers was a larger issue for the Tuesday evening roster. The volunteers on Thursday consisted to a larger extent of retired healthcare providers who volunteered more frequently; some were often present every week, and some were able to establish relationships of trust with their patients that resembled the patient-caregiver relationship of the regular GP scheme (Ottesen et al., 2015).

However, the question of 'regulars' was a debated topic at the healthcare centre. Some of the volunteers felt that frequent users took up time and space that could have benefited patients who needed it more. Tuesday evening could be 
particularly crowded and at times they had to turn people down. 'The regulars' were a mixed group but included those the healthcare providers saw as coming in for conditions that were not serious or for which the doctors could not do much. They were often perceived as either overly anxious about their health or coming for social contact rather than medical reasons, and volunteers discussed how far their responsibility in these situations should go. For instance, in one discussion, one of the physiotherapists took up the issue of 'big consumers' (storforbukere) she regarded as 'shopping around' at the centre. That day she had a patient who had already had more than 30 consultations. He had seen all the physiotherapists, and there was not much more they could do for him. He had been given exercises he needed to follow. The man, who had been coming there for years, also wanted to see a doctor for a 'dry throat'. Another doctor who was present mentioned that she had several patients coming in, asking for a prescription for a shampoo containing a fungal retardant, not because they needed it but because they were looking for free shampoo. These cases were not representative of the majority of patients, but since the centre had so far adopted a liberal view, seeing that their social role was medically important, concerns about having to prioritise were growing as the patient flow was increasing.

The discussion about 'regulars' also brought forth different understandings of biomedical cure versus care and the extent and purpose of medical humanitarianism, including questions of deservingness in medical assessments. Much of the anthropological literature on medical humanitarianism has highlighted its relation to crisis and emergency thinking, as it developed through particular international responses to certain situations of acute suffering (Redfield, 2005; Ticktin, 2011). Providing medical care to irregularised migrants involves to a larger extent dealing with 'ordinary' and less severe conditions, as well as with what Morten described as 'non-medical health issues'.

How to actually address the complex socio-political issues in the clinical encounter was as such a related and recurring issue. Bendixsen (2015), in her study of irregular migrants' experiences with healthcare in Norway, describes how her interlocutors felt their illnesses had not been taken seriously or treated sufficiently by healthcare providers. This was a dilemma also experienced by healthcare providers in my study and at the volunteer-run centre (see also Ottesen et al., 2015; Mburu et al., 2015), as they felt the tools they had available were inadequate, seeing the 'real cure' as a residence permit. Some of the healthcare providers saw the assistance they could give primarily as a form of 'reality orientation'. This involved, as my interlocutors explained, recognising the pain the patient felt as real but also helping them understand that the cause and solution was not medical. In the period from 2011 to 2014, the volunteer-run centre initiated a pilot project with group consultations that attempted to develop 'appropriate techniques for stabilisation of trauma symptoms and management of daily stress' for their patient group. The dilemma for this project, as Mburu et al. (2015) describe it, was how to establish a therapeutic dynamic that clarified what forms of assistance the centre could and could not offer and simultaneously recognise the socio-political dimensions of patients' mental and psychosocial problems. 
Mburu was a participant observer in these sessions, and the article describes how the more the group leaders tried to draw up boundaries for mental healthcare and the therapeutic purpose of the group, the more the participants opposed what they saw as a depolitisation of their suffering. The group leaders therefore ended up abandoning their attempts to establish clear boundaries. In addition to arranging the group-based treatment programmes, the centre also started facilitating venues for socialising and mutual support to address some of the issues that emerged, such as social isolation (Näsholm, 2014; Karlsen, 2021).

So far, in this section, I have described how healthcare providers, particularly the volunteer-run centre, dealt with the temporal constraints of migration control by focusing on the here and now. Through this, I have also shown the continuing tension and dilemmas experienced by healthcare providers because this temporal frame often only means relieving symptoms and fails to address the underlying issue of the patients' ill health or the main constraint on adequate and continuous healthcare, that is, the condition of illegality. On a final note, though, I would like to emphasise that healthcare providers are not the only ones trying to find alternative ways to deal with the way the condition of illegality affects migrants' health. Bendixsen (2015) describes different practices irregular migrants themselves employ, including forms of 'self-care', such as traditional medicine and praying. Some of the irregular migrants in my study also exercised self-care, but most often in addition to school medicine. Reema, Hind's mother, and Roland were among those who sought both school and alternative medicine in an attempt to deal with the stress of waiting and the uncertainty and unpredictability it entailed.

Reema, in a particularly tough period, had problems sleeping and remembering things. 'It's because there is something I do not want to remember', she explained to me, 'but my brain can't choose, so I am forgetting all kinds of things'. She would write down things she wanted to remember in a notebook, and when we were talking, she would often confer with her notebook. At one point, she sought help from her GP, who prescribed sleeping pills. Reema, though, was reluctant to take them and decided she would first try to come through it by praying regularly. As she explained, 'I sent Nadir [her husband] to the pharmacy and he returned with two packages. I looked at them, and I said "no" and put them in the cupboard. I told myself that I am stronger than the medicine. I will heal myself.' When I asked Reema how she would heal herself, she replied, 'I believe in God. I am a Muslim. I believe he will take care of me.' She added, 'He is the strongest. He can help me'. She explained how it helped her to pray, 'if only for a few minutes, three to five minutes. It is like yoga?' She asked, a bit unsure if she used the right word. I suggested meditation. 'Yes', she replied. 'I can sit like this and talk with my god. Like this, talking together helps.'

Reema explained to me that the reason she was hesitant to take pills was that she had two friends in the same situation who had been taking sleeping pills for years. They told her that they became tired from the tablets and had to sleep a lot. One of her friends, who had moved away, was no longer able to manage without them. She became nervous and itchy and just wanted to go home and take a tablet, Reema explained. Reema and some friends had tried to talk to her about it, telling 
her they would help her to quit, but she had not wanted to. Reema did not want to risk ending up in a similar situation.

Roland also suffered from trouble sleeping and stress that would erupt in itchy rash all over his body. To deal with stress and to keep his mind occupied, he tried to keep busy and participated in a number of voluntary, physical activities. His doctors also prescribed various crèmes and tablets for his rash. However, increasingly frustrated by the lack of success, Roland eventually asked for my help in finding a local healer through the internet. The recourse to alternative medicine, however, was not related to traditional beliefs, as Roland laughingly dismissed when I naively broached the topic. He was 'a city boy' who had always relied on school medicine and not 'country beliefs'. He got the idea from a friend who had watched a documentary about traditional Sami healers. Though there were no Sami healers around, we found some names for Roland to consider. When I later asked him if he ever contacted any of the healers, he said he had, but it had been too expensive for the meagre subsistence Roland received from the UDI. The price for a session was 800 NOK and Roland received 910 NOK every fortnight. By this time, his doctors had just suggested a new treatment, and though fairly expensive, the UDI had agreed to cover it. However, Roland commented, if this did not work, he would contact the healer again to see if they could make a downpayment agreement. By then, however, Roland was back in Congo.

The point I wish to make here is that all of the described situated responses on the part of both healthcare providers and irregular migrants, represented attempts to deal temporarily and medically with issues mainly caused by irregular migrants' legal situation. Though this provided limited relief from symptoms, it also reveals the limitations of a one-sided medical response. For instance, while healthcare providers were able, through the volunteer-run centre, to challenge some of the temporal limitations in the Healthcare Regulation (2011), the socio-political condition of illegality and deportability were not challenged because of the split between healthcare as humanitarian assistance and immigration policy. Ticktin, in her book Casualties of Care (2011), calls this a 'medicalisation of politics', where the temporality of medical emergencies are brought to social and political problems. With this in mind, I will turn to the role of health and healthcare providers in individual migrants' regularisation efforts through medical reports.

\section{A future through medical reports?}

While deportation might be one 'way out' of the situation irregular migrants find themselves in, regularisation is another. Writing about France, Fassin and d'Halluin argue that the medical certificate, 'a modest object in asylum policies', is far more than a mere expert's assessment. 'It is the tenuous thread on which hangs the entire existence - both physical and political - of the asylum seeker' (2005, 606). Fassin (2012) and Ticktin (2011) have documented that, in France, illness increasingly became a source of social and political recognition in the 1990s. There, as the number of permits granted under the title of refugee diminished significantly, the number of permits for medical reasons concurrently increased. 
Although, the opportunities have been restricted somewhat in later years, health remains an important pathway to regularisation. The reason for the legitimacy of health in France, Fassin (2012) suggests, is that illness is to a large extent devoid of the suspicion associated with economic migrants. Hence, with humanitarian reason as the driving logic, the sick body becomes the legitimate manifestation of a common humanity worthy of being acknowledged in the form of rights.

In Norway as well, healthcare is cited as the basis for legal residence in many cases (UNE, 2020). However, health and medical reports have not gained the same formal significance as in France. Moreover, illness is not devoid of suspicion in the view of Norwegian immigration authorities, as they worry about 'health migration'. This was clearly seen in Adam's case (Chapter 3). In their response to his appeal, UNE recognised the strong humanitarian concerns in Adam's case but insisted that the concern for 'health migration' weighed more than 'the best interest of the child'. According to them, 'it was clear' that the family's motive from the beginning was 'better and free healthcare', and as such it constituted 'an abuse of the asylum institute' (Jensen et al., 2014). This is as such an example of how the temporalities of biopolitics shape migration policy as it is the future well-being of the collective social body of the nation-state that becomes the main concern, and not individual life in the present.

Nonetheless, in my study, the irregular migrants regarded medical reports as highly valuable for the real or imagined authority they conveyed. However, obtaining these was not always easy. For their asylum application, Hind's family had initially submitted the discharge summary written by Norwegian surgeons following her first examination. Though these were quite detailed, they were also mainly technical medical documents. Their lawyer therefore recommended that they try and get 'a proper medical report' and gave them a list regarding what such a report should contain. He also stressed that it should be from 'the specialist'. However, Hind's parents, Reema and Nadir, were not able to get in contact with Doctor Johan by themselves, as his 'inviolable time' is strictly protected and parcelled out by various gatekeepers. As such they were not able to get a report. Disillusioned, Hind's parents' resentment and anger towards Doctor Johan grew because they felt that he held the key to both their residence permits and Hind's surgery. 'I want to write a letter to Dr. Johan, explaining him what he is doing to us', Reema, Hind's mother, told me angrily more than once. She also frequently expressed that she did not trust him, questioning his expertise, saying that she did not think he could do the surgery and was therefore 'hiding from them'.

For months, their sense of helplessness grew, as well as their stress and trouble sleeping. In my field notes during this period, I frequently noted how tired and depressed they seemed, and their friends also expressed worries to me, reacting to what they saw as their passivity towards their situation. However, Reema and Nadir eventually resolved to fight. Part of this resolution came after a family they knew with a sick child received a 'positive' on their 'fourth attempt'. Visiting Reema shortly after their friends had received the good news, she was both happy about it and upset, telling me about the celebration she and some other women had just organised for this family. Reema did not understand why her friends had 
received a 'positive' while they had not. I asked Reema if she had asked her friend if she knew why they were eventually granted residence permits. She had, and the friend told Reema that it was because 'they had worked hard with their case'. By this she meant that they had 'gathered reports from everyone they met'.

Soon after this, Reema asked me if I would come with her to see a lawyer. She and her husband had decided to appeal again. Though this lawyer refused their case, saying it would be a waste of their money, Reema and her husband did not give up and started actively pursuing every healthcare provider with whom they came in contact for reports, even if they had only seen Hind for five minutes. These were often quite awkward moments in the medical encounter. Agitated and nervous out of fear of losing the opportunity, and due to language barriers, their requests sometimes came across as quite aggressive. The healthcare providers did not necessarily dismiss their request right away but would say they were unsure what kind of report they wanted or questioned whether they were qualified to write it. Nevertheless, this mission gave Reema a sense of purpose and she did not give up, and within the next year, she and her husband were able to collect reports of various quality from their GP, a school nurse, a specialist nurse at the hospital, a paediatrician, a psychologist, and a surgeon (though not Doctor Johan).

In their study of irregular migrants in various EU countries and the USA, Chauvin and Garcés-Mascareñas note how 'an incipient moral economy' defining deservingness in terms of noncriminal conduct, economic reliability, fiscal contribution, identity stability, and bureaucratic traceability sees 'irregular migrants accumulating official and semi-official proofs of presence, certificates of reliable conduct and other formal emblems of good citizenship, whether in the name of civic honour, in the hope of lesser deportability, or in view of future legalisation' $(2012,242)$. In a similar sense, Reema and Nadir's collection of medical reports was an attempt to prove deservingness for regularisation purposes, though based on what Fassin (2009) calls biolegitimacy rather than 'good citizenship'. Reema and Nadir's story, though, came to illustrate two practical challenges for irregular migrants in this endeavour, namely (1) actually obtaining medical reports and (2) obtaining the right type of documents for regularisation purposes in line with the current moral economy.

Despite the fact that most healthcare providers in my study clearly supported the idea that irregular migrants' right to healthcare should be on a par with citizens, they expressed reluctance when it came to getting involved in their patients' regularisation efforts. Although there were some who combined a medical and political commitment and took on an advocacy role for their patients, most preferred to maintain a strict separation between what they saw as the medical domain and the political domain. Maintaining a strong separation between medicine and politics was, as previously noted, a source for resisting the new regulation that limited irregular migrants' access to healthcare and imposed a particular temporal frame on the treatment given. In these cases, however, this splitting approach seemed to limit healthcare providers' willingness to use the scientific legitimacy of medicine to intervene in the area of migration control. This was also the case 


\section{2}

for healthcare providers who would do voluntary work at the healthcare centre for undocumented migrants.

There seemed to be different reasons for this. For some it was a way of protecting oneself from becoming burnt out while making a contribution where they felt they had something to give (their medical expertise). Others were unfamiliar with the procedure and expressed hesitations regarding what was expected of them and what it would entail, as well as a dislike for the extra administration it would involve. Also, for the healthcare centre, capacity was an issue in their reluctance to write medical reports for their patients. The centre frequently received requests for such reports, and all of these were referred to the management. While they would give everyone a printed copy of their journal, they would only write separate reports after a careful assessment of the particular case.

Another theme that came up among the healthcare providers was the question of whether accountability to the patient and advocacy work on their behalf inherently challenged or contradicted their obligations to the state and society in general as impartial experts. While some saw advocacy for the patient as in line with professional ethics, others saw it as an ethical contravention. To some extent it was a matter of keeping things 'tidy', as one senior physician expressed it: 'It's great that doctors participate in campaigns and fight. But they should not do it as doctors, but as private persons. It is about keeping it tidy. If you are a doctor, you also need to maintain a certain objectivity.'

He found doctors' reluctance to write medical reports understandable but explained it in terms of a misunderstanding about what it entailed. As he explained:

There are some misunderstandings about what a medical report is. A medical report is simply that you write what the patient has and what the consequences are and that sort of thing. It is neutral. . . But some doctors believe that they're supposed to argue the patient's case. And that's not right. They're experts.

This has also been the UDI and UNE's position. UNE has previously criticised publicly the quality of medical reports they received, stating that these were often characterised by a strong commitment to the patient and included evaluations/ recommendations that often went beyond what the medical judgement warranted, in UNE's opinion. In Norway, there is no formal system for how medical claims in asylum cases should be assessed. Reports are thus generally written by regular healthcare professionals requested by the patients themselves and not by some specially appointed experts who issue medical statements in immigration cases. Norway differs from France in this respect. In France, specific state-appointed healthcare professionals are involved both in assessing cases and in writing country-of-origin reports and categorising illnesses that can provide the basis for permits (Ticktin, 2011).

Healthcare providers in my study, however, frequently asserted that their expert views were ignored by UNE and said they questioned UNE's competence. As doctor Morten expressed it: 
You develop strong sympathy for the patient, you get close to them, and there is trust. You feel you are the only one who can say anything sensible to the bureaucracy about this person, yet you are not believed. You become infuriated... There are many doctors who sit there and write statements and are certain that they are the one who knows best because they have talked more than anyone else with the patient. And then they do not get through because there are no official channels to use. [The statements] are considered only by ordinary bureaucrats who file them away as insignificant.

Doctors not only have traditionally been gatekeepers to the healthcare system but have frequently been called upon to make authoritative judgements for the legal system, employers, and other social authorities. As such, medical sovereignty has been about doctors' role as institutional expert in all matters related to health (Willis, 2006), or as Lupton describes it:

[Doctors] are able to dominate not only the medical encounter, but also are disproportionately powerful in broader society, in terms of being able to represent problems as medical issues (rather than caused, for example, by social inequalities) and claiming authority over these problems.

(Lupton, 2012, 111)

However, the medical profession has been gradually losing their privileged position since the 1980s in Norway (Byrkjeflot, 2005; Erichsen, 1995), and migration control has potentially made this trend more explicit and advanced it, as Doctor Morten's frustration illustrates. Nonetheless, in response to the criticism levelled at UNE's expertise when it came to evaluating medical claims, they established a trial arrangement in 2017 with a consultant who was a medical expert (a psychiatrist, UNE, 2016).

Still, for a migrant, the threshold for gaining residence on medical grounds remains high. In Hind's case, when the family eventually went to see a lawyer, taking with them all the medical reports they had gathered, the lawyer doubted the usefulness of the documents. As he saw it, UNE had already decided that Hind was out of reach of the threshold, and additional reports would not change this. The lawyer encouraged Reema and Nadir instead to start gathering reports from kindergarten, school, and after-school activities. It turned out, Reema and Nadir had worked hard on their case for a year but had gathered the wrong documents according to what was then Norway's current moral economy of legal deservingness.

In Norway, children's 'affiliation to the Realm' has become an important avenue for regularisation of families with children. ${ }^{2}$ The assessment of children's ties to the country should, according to the government, take into consideration aspects such as the child's age, whether the child has been in day-care or attended school, whether the child participates in extracurricular activities, and whether the child speaks Norwegian (Meld. St. 27 [2011-2012]). In practice, it is mainly children of school age, with more than one year of schooling and at least $4 \frac{1}{2}$ years of 


\section{Temporal tensions}

residence, that are considered to have sufficient affiliation for a residence permit on humanitarian grounds. However, children's affiliation, measured in years and age, is often weighed against what is perceived as the parents' 'lengthy breach of immigration law', including their lack of cooperation with regard to enabling return and clarifying identity (Ilstad, 2014). In this sense, it clearly illustrates what Coutin (2003) has called the temporal double bind of illegal time.

Though Reema asked me sarcastically why they were paying the lawyer, when actually they themselves did all the work gathering reports, she and her husband went ahead with the suggestion, approaching teachers and others for documents stating how well integrated they were, and Hind in particular. This time, as previously mentioned, their appeal was successful. On the plus side, their acceptance letter from UNE noted that their identity was substantiated and that they had not tried to evade deportation by staying in a reception centre. Hence, in this case, it turned out to be the well-integrated and innocent child with law-abiding parents, rather than the sick body, that became the grounds for legal deservingness.

\section{Short-term remedies and migratory trajectories}

In this chapter my aim has been to explore how the temporalities associated with bordering processes and practices frame the encounter between irregular migrants and service providers. While state borders have generally been thought of in spatial terms, they can also be approached as temporal strategies and practices (Mezzadra and Neilson, 2013). In this chapter, I have primarily been concerned with the temporalities of the border as a threshold where inclusion and exclusion occur simultaneously and where ordinary rhythms of time are disturbed and framed by a sense of temporariness. For irregular migrants, time is often conceptualised in terms of waiting, characterised, on the one hand, by stasis and, on the other hand, by uncertainty, unpredictability, and an enforced orientation to the present (De Genova, 2002; Jacobsen and Karlsen, 2021). These temporal characteristics, that is, temporariness, presentness, uncertainty and unpredictability, are central features of the process by which irregular migrants are precariously included.

In this chapter, I have been especially interested in examining what happens when control of the patient's time (and space) in the medical encounter is challenged by the unpredictability and temporariness implied in migration control, how it comes to frame medical practice, and how service providers and migrants attempt to deal with these temporal confines. As I have shown, the threat of deportation and the temporal frame of the Healthcare Regulation (2011) had a disciplinary effect in the sense that it oriented the medical gaze to the temporal present. It was also a factor in healthcare providers' reluctance to act and was instrumental in deferral or interruption of treatment. The healthcare providers' gaze was further obstructed or constrained by the split between politics and medicine implied in medical humanitarianism, which allowed them to attend to or ease the immediate suffering of their patients but not to address the underlying causes for the suffering found outside the medical domain. These practices (again) did not fundamentally challenge the state's exclusion of irregular migrants, but extended care to 
them in the immediate present. Consequently, care came repeatedly in the form of short-term solutions that never offered a cure. In this regard, I would like to conclude here by extending the focus somewhat by continuing from where I started this chapter, with Roland's case.

From the perspective of the migrant receiving state, and in most cases the healthcare providers, the removal of irregular migrants brings a certain closure to their cases, allowing for a general lack of interest in what happens to them as soon as they are outside its borders (Peutz, 2006). As such, there is little information about what happens with people in ill health who have been deported. In calling for 'an anthropology of removal', Peutz (2006) claims that while the deportation of an individual may take only a few days, 'the significance of this episode - replicating and engendering as it does histories of suffering and subjection - will continue to reverberate in the lives of the deportees and their kin' (2006, 217-218). Although Roland's life was not in immediate danger, his health problems and need for medication and surgery did not go away, and he continued to face the further loss of function of his body. A short time after his deportation, I managed to re-establish contact with Roland. For months, he remained shocked and bewildered by the process of removal, repeating that he had not thought they could do it. Roland wanted to get in touch with 'a human rights organisation' in Norway, as he believed it was a violation of human rights conventions to deport a person with a chronic condition. 'A friend of mine read it on the internet', he explained. 'And I am sure my lawyer told me that too', he continued.

Deportation subjected Roland to some very specific medical difficulties as well. When he was forcefully deported, he had been given only three months' worth of medicine to take with him. While he was dependent on this medicine, the particular type he used in Norway was not available in his country of origin. He was only able to get a type that was not as effective. This had been one of his main points of contestation with Norwegian immigration authorities. When his medication ran out and he switched to the other kind, he started feeling worse and experienced what he called 'a crisis' before his family in Europe were able to send him his standard medicine by express package delivery. However, this was an expensive solution, and he did not know how to solve this problem in the long run.

A greater concern for Roland, however, was that not only had he been deported from Norway but he had also been imposed a two-year expulsion from the entire Schengen area. As the necessary expertise for surgery was not available in Congo, Roland was convinced that he needed to get back to Europe. Speaking to him months after his deportation, his life still revolved around how to return to Europe to get surgery, contacting authorities to get his expulsion lifted. He put all his efforts into this, unable to think of his future in any other terms. As he explained to me, 'I did not come to Norway to be lazy. I came to study, to work. They destroyed all that. Here, people like me have no opportunity.' In this sense, Roland's case fits with what other ethnographies of removal suggest, that is, for deportees, deportation is not necessarily the end to their migratory trajectories or attempts (Peutz, 2006). 


\section{Temporal tensions}

\section{Notes}

1 According to the healthcare centre for undocumented migrants, most diagnoses there are related to the digestive system, whereas half are related to dental care, the muscular and skeletal system, mental health, skin, and the respiratory system. In terms of mental health, the six most common diagnoses were: feeling anxiety/nervous/tense, situational mental imbalance, emotional depression, sleep disorder, depressive disorder, and post-traumatic stress disorder. Poor mental health, they report, is seen mostly in patients who have been refused asylum, as opposed to those who have not registered in Norway (Healthcare centre for undocumented migrants, 2014).

2 In 2007, Norway implemented an ongoing regularization mechanism, which was further strengthened in 2013. Through this, children, and their families, can be granted a residence permit on the grounds of strong humanitarian consideration on a case-by-case basis. In the assessment, 'the child's affiliation to the realm shall have particular weight' (Ilstad, \& Bondevik, 2016). 


\section{Conclusion}

The main objective of this book has been to scrutinise what is at stake in the limited inclusive practices directed at irregular migrants. Scholars have addressed questions concerning what is or should be states' obligations towards unwanted migrants residing within their territory (Bosniak, 2006; Carens, 2008), as well as mapping and comparing states' actual policies regarding irregular migrants' access to healthcare and social benefits (Karl-Trummer et al., 2009; Spencer, 2018). Investigating the state's approaches to irregular migrants' welfare, however, can also be a fruitful point of departure to explore broader questions of state sovereignty, including the interplay between the biopolitical management of populations and the geopolitical management of territory and the changing meaning and location of state borders. This latter line of research has been the primary concern of this book.

The theoretical discussions spurred by Agamben's reconceptualisation of sovereignty has served as a point of departure to critically examine practices of care and how they relate to valorisation of life, social rights, and the inside/outside of the state. To Agamben, state power is ultimately founded on bare or biological life 'which is kept safe and protected to the degree to which it submits itself to the sovereign's (or the law's) right of life and death' (Agamben, 2000b, 5). By entwining sovereign exceptionalism with the state's role of fostering life, Agamben draws attention to the Janus-faced character of the state and to how state violence and care of life are intimately related. To Agamben, the problem with human and citizen rights is not only that they do not offer protection against sovereign violence but that they also ultimately presuppose the state and the relation of sovereignty and bare life and thus facilitate an infinite expansion of disciplinary coercion and biopolitical control (Agamben, 1998, 121 and 181). As he writes in Homo Sacer,

the spaces, the liberties, and the rights won by individuals in their conflicts with central powers always simultaneously prepared a tacit but increasing inscription of individuals' lives within the state order, thus offering a new and more dreadful foundation for the very sovereign power from which they wanted to liberate themselves. 
In this perspective, reform of existing institutions from human rights to the welfare state can only entrench rather than overcome the worst aspects of sovereignty and the system of nation-states (Whyte, 2013).

Agamben's work is often considered dystopic, presenting the state as a killing machine and the Nazi concentration camp as the nomos of the modern. This perspective might seem at great odds with the image of the Norwegian welfare state, generally perceived both as good and caring and as a particularly successful and stable state in today's world. Much of the initial work on the state of exception also largely examined paradigmatic examples such as the Guantanamo camp and other detention camps (e.g. Butler, 2004; Rajaram and Grundy-Warr, 2004; Aradau, 2007). In this book, I have been concerned with a less spectacular expression of sovereignty, addressing instead how sovereign exceptionalism operates and relates to practices of mundane government and particularly how the decision on the exception relates to professional and bureaucratic discretion. To Agamben $(2005,2011)$, as I read him, law-making by administrative decree is not a practice associated simply with a rupture to ordinary life under the rule of law but with the rise of the regulatory or administrative role of the state. One of Agamben's most central and controversial claims is that because life in modernity is increasingly placed at the centre of state politics, exceptional politics has become the rule $(1998,111)$.

The claim that we are all potentially 'homines sacri' $(1998,111)$, I find, is an important reminder that the (mis)treatment of irregular migrants is not necessarily as exceptional as it is often assumed but rather represents a paradigmatic site of modern techniques of what Foucault calls 'governmentality'. Still, this does not mean that all life is equally vulnerable to the operations of power within the nation-state. Similarly, precarious inclusion as a strategy of government is not necessarily exclusive to irregular migrants. Possessing status as a legal resident or citizen of a given nation-state does not always result in being considered a member of the political or moral community of that (nation-)state. For example, citizens who do not live up to society's ethnicised, gendered, or classed norms or ideals regarding behaviour may also experience simultaneous processes of exclusion and inclusion that make access to care insecure and limited. The case of Siv Tove Pedersen recounted in Chapter 3 is a forceful example. Recently, the practice of deregularisation (through which an individual gradually or suddenly lose her legal status as a resident or citizen) has also been revived in a number of liberal democratic states, including Norway, making migrants and their descendants holding presumably secure statuses more vulnerable to state's power to deport (Brekke et al., 2020; Gibney, 2020). Still, territorial presence on state territory for most citizens is not threatened the way it is for non-citizens.

The perspective pursued in this book has been one through which sovereign decisionism is not necessarily regarded as associated with 'the state', meaning government or parliament, or exceptional circumstances, but is instead found in mundane institutional practices and procedures in which the decision is devolved upon various agents, including service providers. As such, the decisions on the exception do not rest only on the normalising frame of law but also on social 
norms, professional codes and knowledge, institutional frameworks, and so on (Dean, 2007). An ethnographic approach, in this context, offers a way to investigate the conditional nature of sovereign practices by providing a disaggregated view of the state (Gupta, 2012; Ong, 2006). It can thus shed light on how contradicting norms, knowledges, practices, and values assigned to various human categories can produce a range of contingent and ambiguous outcomes through which forms of care can be negotiated for the politically excluded. For example, the ethnographic focus on how the sovereign decision is made within the context of healthcare has underscored the negotiated and conditional quality of these decisions and, hence, the border in everyday practices and situations. Moreover, it has revealed that there was no single critical decision that defined the border; instead, multiple and dispersed decisions on the exception or (non)value of life constituted a central aspect of migrants' precarious inclusion.

\section{The role of life, territory, and temporality in governing irregular migration}

An important aspect of this book involves the understanding that evaluations of irregular migrants' lives are incorporated in regimes of care and control and that different rationalities and technologies of care and control employed in governing irregular migrants may contribute to precarious inclusion. How irregular migrants are increasingly cast as 'undeserving' in public discourse is widely commented upon within migration literature. Scholarly work has also shown how such casting, as well as the politics of migrant admission and incorporation, is shaped by gendered, racialised, ethnicised, and classed notions of innocence, dangerousness, and economic desirability (Ticktin, 2016; Guðjónsdóttir and Loftsdóttir, 2017). In Norway, over the past decades there has been growing effort to legally and discursively demarcate and formalise the category of 'person without legal residence' in contrast to 'asylum seeker'. This has been related to significant changes in rejected asylum seekers' access to healthcare, state accommodation, and economic benefits. Not recognised as a worker, but rather cast as 'the unproductive other', the irregular migrant becomes a humanitarian concern, whereby survivability of the body becomes the grounds for compassion and care in the context of Norway. In humanitarian forms of reasoning, innocence and suffering is more highly valued than fiscal contributions. As such, humanitarianism projects on the migrants a life as victims, rather than as rights-bearing subjects. Yet, as Fassin (2012) has suggested, the increased emphasis on deservingness and moral worth associated with the politics of compassion represented by humanitarianism makes policies more vulnerable to moral panic.

In this book, I have suggested that the unstable, limited, and substandard care offered to irregular migrants maintains precarious life rather than enabling liveable life. It rests on a form of minimalist biopolitics (Redfield, 2005) that allows for life to be preserved, if never quite cured or fully cared for. Care is thus simply offered to regulate the worst consequences of their lack of legal status for determined periods of time. Hence, it is not the absence of state support per se 
but substandard and exceptional care arrangements that contribute to precarity in the life of irregular migrants. What is significant about this form of care is that it demarcates the acceptability of a 'lower threshold possibility of life' (Redfield, $2005,330)$ than what has been the norm in the Norwegian welfare state. The commitment to equality in Norway has traditionally included not merely equality of opportunity and status but what some would call 'equality of condition', an equitable distribution of material resources so as to promote well-being and enable all members to pursue their own life projects (Lister, 2009). When it comes to irregular migrants, care has come to entail a parallel system in which urgent and basic assistance is available only when their very survival is at stake. The supposedly universal welfare state, in its distribution of care, has thereby increasingly come to differentiate between lives. The centrality of humanitarian reason in governing migration has importantly served to reify the notion of the welfare state as compassionate and caring while simultaneously departing from the core norms and values of security, solidarity, and equality assumed to underpin the Nordic model of welfare.

Within this system ostensibly based on equality, the hierarchisation of care is largely made possible by the distinction territory, as an imaginary and legal mechanism, makes between lives. Even though irregular migrants are physically present on state territory, the spatial fixation of them as intruders has made them more socially legitimate to neglect. One of the main consequences of the Healthcare Regulation (2011) regulating irregular migrants' access to healthcare in Norway was that it established the person's legal status as a criterion for judgement rather than simply prohibiting access to healthcare. Border control in the context of healthcare thus not only became about detecting and excluding migrants at the hospital's doorstep but drew the territorial rationality of migration control into the diagnostic act itself in terms of deciding a course of treatment.

Moreover, my examination has shown that this exclusionary result was not necessarily a given. The Norwegian welfare state has largely operated with territorially based conceptions of membership, rather than a status-based one. Under the territorial conception of membership, rights are primarily determined by a person's territorial presence. In this sense, it repudiates the notion of differential levels of inclusion based on various formal statuses under the law (Bosniak, 2007). The main body of Norwegian welfare laws concerning health and social security uses the phrase 'everyone residing in the Realm' when defining the scope of the law. The actual laws do not distinguish between 'legal' and 'illegal' residents. The initial response to rejected asylum seekers and other irregularised migrants was thus more inclusive (Mathiesen, 2002), and they are still considered to be equally included by the scope of important welfare legislations such as the Child Welfare Act (1992), the Education Act (1998), and the Act on Crisis Shelters (2009) (Søvig, 2013b). Accordingly, while all irregular migrants are banned by law from residing in the country, other areas of welfare law still offer some protection to subcategories of irregular migrants.

Considering this, it is interesting to note how Norwegian authorities used a public perception of inconsistency as a reason for restricting irregular migrants' 
access to social benefits. Their rationale for this was that it would seem inconsistent if the state granted full social benefits to a person who was denied residence by the immigration authorities. However, as argued by Andersen (2014), this would not be inconsistent from a strictly legal perspective. Norwegian administrative law is based on the so-called sectorial principle. This means that each administrative agency only relates to, and realises, the control purposes set out in the particular legal framework for the specific, relevant sector. Granting full welfare rights to irregular migrants in accordance with the purpose of the Social Services Act (2010) would thus be in line with the legal and administrative principle of the welfare state, even if they contradict the Immigration Act (2008). In this sense, it can be argued that the inconsistency derived from the merging of these two legal and administrative fields. Nonetheless, problems would still emerge in practice, as both jurisdictions are exercised in and intimately tied to the same territory. This is what Noll (2010) has referred to as 'the bundling effect of jurisdiction', which means that irregular migrants cannot necessarily use welfare services without risking deportation.

The difficulties in separating the jurisdictional domains of entry and rights in practice produce a simultaneity of inclusion and exclusion that makes irregular migrants' access to care more precarious. This highlights how temporalities are integral to governing irregular migration. What emerged as particularly relevant in the Norwegian case were the ways in which limited inclusion contributed to the institutionalisation of insecurity and temporariness. Inclusive practices either were being administered for a short-term period, such as through the emergency aid provision, or were constantly changing, such as with access to accommodation and economic support through the asylum reception system. The temporal imperatives of migration control also served to orient the medical gaze and practice towards the immediate present. This temporal focus, as shown in Chapter 5, has significant consequences for the care offered to irregular migrants.

\section{Precariously included in the welfare state}

In this book, I have proposed to conceptualise irregular migrants as precariously included in the welfare state, rather than as simply excluded from it. I understand precarious inclusion as a feature of welfare states' governing of irregular migration and as related to the challenges such states face reconciling the tension between their commitment to people's basic security and the exclusionary practice of migration control.

The Norwegian welfare state provides a particular context for examining sovereign exceptionalism. As part of the family of liberal democratic states, the Nordic states have inclined more towards maximising equality than maximising liberty (Brown, 2005), emphasising universal rights more than limited rule as the pathway to freedom. Comparatively, they have been seen as more interventionist, where belief in social engineering and expert rule has played an important role in developing the strong welfare states (Slagstad, 2004). In Norway, research also continues to show a very high degree of trust in political institutions and in the 


\section{2}

capacity and the desirability of the state to solve problems (Fimreite et al., 2013). As such, Norwegian society has been characterised as 'state friendly', and to a greater extent than elsewhere in Europe outside Scandinavia, the state has been, and still is, seen as an extension of society rather than as an adversary or threat (Wollebæk et al., 2012). In this context, the welfare project's ideal of a public guaranteed justice has largely gone unquestioned across the political spectrum and within welfare state research (Vike, 2004; Slagstad, 2009; Holst, 2009). When it comes to irregular migrants, however, the Norwegian welfare state does not necessarily stand out as particularly generous or caring.

While the Norwegian welfare state has served as my focal point, I suggest that precarious inclusion as a strategy for governing irregular migration is not limited to the context of Norway. Everyday state practices that involve complementary and simultaneous processes of inclusion and exclusion can be found in many welfare states. In some countries such as France and Italy, irregular migrants are legally granted access to public services such as healthcare and education but experience administrative and bureaucratic obstacles to access them (Perna, 2019; Schweitzer, 2019; Geeraert, 2018). In countries where irregular migrants are excluded from regular social provisions, additional and inferior safety nets have often been developed (Spencer and Delvino, 2019). These services may be, as in the Netherlands, variously provided by state institutions, municipalities, or NGOs sanctioned or funded by the state (Leerkes, 2016; Van der Leun, 2015). While these practices provide vital services for irregular migrants, they also contribute towards normalising their precarity.

Precarious inclusion as a strategy of government may reconcile some of the tension between welfare states' commitment to basic security and migration control in current migration regimes, but it is uncertain how long such a strategy can effectively be maintained. While regularisation, deportation, and rights without status are pragmatic approaches to the presence of irregular migrants within the existing political and economic order, they do not constitute a long-term solution because they do not end the ongoing socio-legal production of migrant illegality. 


\section{References}

Aarø, A. H., and Wyller, H. (2005). Mat, tak over hodet og helsetjenester. Statens forpliktelser overfor personer uten lovlig opphold. Oslo, Senter mot etnisk diskriminering.

Aarøy, T. A. (2013). Føler meg rundlurt av legene. BT, [Online] 25 November. Available at: http://www.bt.no/nyheter/lokalt/--Foler-meg-rundlurt-av-legene-3012488.html [Accessed on 16.05.2015].

Aasen, H. S., Gloppen, S., Magnussen, A.-M., and Nilssen, E. (2014). Juridification and social citizenship: International law, democracy and professional discretion. In Aasen, H. S., Gloppen, S., Magnussen, A.-M., and Nilssen, E. (eds.) Juridification and Social Citizenship in the Welfare State. Cheltenham, Edward Elgar Publishing, pp. 277-299.

Abbott, M. (2012). No life is bare, the ordinary is exceptional: Giorgio Agamben and the question of political ontology. Parrhesia, 14, 23-36.

Abrego, L. J. (2011). Legal consciousness of undocumented Latinos: Fear and stigma as barriers to claims-making for first-and 1.5-generation immigrants. Law \& Society Review, 45(2), 337-370. https://doi.org/10.1111/j.1540-5893.2011.00435.x

Agamben, G. (1998). Homo Sacer: Sovereign Power and Bare Life. Stanford, CA, Stanford University Press.

Agamben, G. (2000a). Remnants of Auschwitz: The Witness and the Archive. New York, Zone Books.

Agamben, G. (2000b). Means Without End: Notes on Politics. Minneapolis, University of Minnesota Press.

Agamben, G. (2005). State of Exception. Chicago, University of Chicago Press.

Agamben, G. (2011). The Kingdom and the Glory: For a Theological Genealogy of Economy and Government. Stanford, CA, Stanford University Press.

Andenæs, K., and Bayegan, C. (2009). Rett til helsehjelp for personer uten lovlig opphold i Norge. Juristkontakt, 43(5), 55-57.

Andersen, N. W. (2014). Den nasjonale reguleringen av retten og plikten til å yte nødhjelp til personer med ulovlig opphold i Norge - analysert ut fra et rettssikkerhetsperspektiv. Nordisk socialrättslig tidskrift, 9, 31-77.

Andersen, T. M., Schjelderup, G., Roine, J., Bratsberg, B., Roed, K., Svarer, M., Rosholm, M., Takalo, T., Toivanen, O., and Johnsen, J. V. (2016). Nordic Economic Policy Review: Whither the Nordic Welfare Model? Copenhagen, Nordic Council of Ministers.

Anderson, B. (2013). Us and Them? The Dangerous Politics of Immigration Control, Oxford, Oxford University Press.

Anderson, B. (2019). New directions in migration studies: Towards methodological denationalism. Comparative Migration Studies, 7(1), 1-13. https://doi.org/10.1186/s40878019-0140-8 


\section{References}

Andersson, R. (2014). Time and the migrant other: European border controls and the temporal economics of illegality. American Anthropologist, 116(4), 795-809. https://doi. org/10.1111/aman.12148

Andorsen, K. V. (1999). Strafferettslig nødrett. Oslo, Universitetsforlaget.

Andreasen, S. M. (2019). The costly and demanding - Exploring solution-based othering of 'Non-European immigrants' in Norwegian policy recommendations. Nordlit, 42, 327-346. https://doi.org/10.7557/13.5018

Aradau, C. (2004). The perverse politics of four-letter words: Risk and pity in the securitisation of human trafficking. Millennium-Journal of International Studies, 33(2), 251277. https://doi.org/10.1177/03058298040330020101

Aradau, C. (2007). Law transformed: Guantánamo and the 'other' exception. Third World Quarterly, 28(3), 489-501. https://doi.org/10.1080/01436590701192298

Arendt, H. (1968). The Origins of Totalitarianism. New York, Harcourt, Brace \& World.

Balibar, E. (2002). World borders, political borders. Pmla-Publications of the Modern Language Association of America, 117(1), 71-78.

Barker, V. (2017). Nordic vagabonds: The Roma and the logic of benevolent violence in the Swedish welfare state. European Journal of Criminology, 14(1), 120-139. https:// doi.org/10.1177/1477370816640141

Barker, V. (2018). Nordic Nationalism and Penal Order: Walling the Welfare State. Abingdon, Routledge.

Bendixsen, S. (2013). Becoming members in the community of value: Ethiopian irregular migrants enacting citizenship in Norway. In Edelstein, A., and Dugan, M. (eds.) Migration Matters. Oxfordshire, Inter-Disciplinary Press, pp. 3-22.

Bendixsen, S. (2015). Vilkårlige rettigheter? Irregulære migranters tillit, sosiale kapital og kreative taktikker. In Bendixsen, S. K., Jacobsen, C. M., and Søvig, K. H. (eds.) Eksepsjonell velferd? Irregulcere migranter $i$ det norske velferdssamfunnet. Oslo, Gyldendal forlag, pp. 184-202.

Bendixsen, S. (2017). Voice matters: Calling for victimhood, shared humanity and citizenry of irregular migrants in Norway. In Gonzales, R. G., and Sigona, N. (eds.) Within and Beyond Citizenship: Borders, Membership and Belonging. London, Routledge, pp. 185-207.

Bendixsen, S. (2018). The politicized biology of irregular migrants: Micropractices of control, tactics of everyday life and access to health care. Nordic Journal of Migration Research, 8(4), 167-174. https://doi.org/10.2478/njmr-2018-0020

Bergman, A. (2007). Co-constitution of domestic and international welfare obligations: The case of Sweden's social democratically inspired internationalism. Cooperation and Conflict, 42(1), 73-99. https://doi.org/10.1177/0010836707073477

Biswas, D., Kristiansen, M., Krasnik, A., and Norredam, M. (2011). Access to healthcare and alternative health-seeking strategies among undocumented migrants in Denmark. BMC Public Health, 11(1), 1-11. https://doi.org/10.1186/1471-2458-11-560

Bjåen, B. K. (2014). Barn som oppholder seg ulovlig i Norge skal få helsehjelp. Vårt Land, [Online] 20 June. Available at: www.vl.no/barn-som-opp-holder-seg-ulovlig-i-norgeskal-f\%C3\%A5-helse-hjelp-1.85889 [Accessed on 20.06.2014].

Borrelli, L. M. (2018). Using ignorance as (Un)conscious bureaucratic strategy. Qualitative Studies, 5(2), 95-109. https://doi.org/10.7146/qs.v5i2.104421

Bosniak, L. (1991). Human rights, state sovereignty and the protection of undocumented migrants under the International Migrant Workers Convention. International Migration Review, 25(4), 737-770. https://doi.org/10.2307/2546843 
Bosniak, L. (2006). The Citizen and the Alien: Dilemmas of Contemporary Membership. Princeton, NJ, Princeton University Press.

Bosniak, L. (2007). Being here: Ethical territoriality and the rights of immigrants. Theoretical Inquiries in Law, 8(2), 389-410. https://doi.org/10.2202/1565-3404.1155

Bourdieu, P. (2000). Pascalian Meditations, Cambridge, Polity Press.

Bourgois, P. I., and Schonberg, J. (2009). Righteous Dopefiend. Berkeley, Berkeley University of California Press.

Braun, K. (2007). Biopolitics and temporality in Arendt and Foucault. Time \& Society, 16(1), 5-23. https://doi.org/10.1177/0961463X07074099

Brekke, J. P. (2008). Making the unreturnable return. The role of the welfare state in promoting return for rejected asylum seekers in Norway. ISF Paper 2008:1. Oslo, Institutt for Samfunnsforskning.

Brekke, J. P., and Aarset, M. F. (2009). Why Norway - Understanding Asylum Destinations. Oslo, Institute for Social Research.

Brekke, J. P., Birkvad, S. R., and Erdal, M. B. (2020). Losing the right to stay: Revocation of refugee permits in Norway. Journal of Refugee Studies, 0(0), 1-20. https://doi. org/10.1093/jrs/feaa006

Brekke, J. P., and Søholt, S. (2005). I velferdsstatens grenseland En evaluering av ordningen med bortfall av botilbud i mottak for personer med endelig avslag på asylsøknaden. ISF-Rapport 2005:5. Oslo, Institutt for Samfunnsforskning.

Brenner, N., and Elden, S. (2009). Henri Lefebvre on state, space, territory. International Political Sociology, 3(4), 353-377. https://doi.org/10.1111/j.1749-5687.2009.00081.x

Brighenti, A. M. (2010). On territorology: Towards a general science of territory. Theory, Culture \& Society, 27(1), 52-72. https://doi.org/10.1177/0263276409350357

Brochmann, G. (2017). Immigration policies of the Scandinavian countries. In Nedergaard, P., and Wivel, A. (eds.) The Routledge Handbook of Scandinavian Politics. London, Routledge, pp. 229-239.

Brochmann, G., and Hagelund, A. (2011). Migrants in the Scandinavian welfare state: The emergence of a social policy problem. Nordic Journal of Migration Research, 1(1), 13-24. https://doi.org/10.2478/v10202-011-0003-3

Brochmann, G., and Hagelund, A. (2012). Welfare state, nation and immigration. In Brochmann, G., and Hagelund, A. (eds.) Immigration Policy and the Scandinavian Welfare State 1945-2010. New York, Palgrave Macmillan, pp. 1-24.

Broeders, D., and Engbersen, G. (2007). The fight against illegal migration identification policies and immigrants' counterstrategies. American Behavioral Scientist, 50(12), 1592-1609. https://doi.org/10.1177/0002764207302470

Brown, W. (2005). Edgework: Critical Essays on Knowledge and Politics. Princeton, NJ, Princeton University Press.

Brun, C. (2016). There is no future in humanitarianism: Emergency, temporality and protracted displacement. History and Anthropology, 27(4), 393-410. https://doi.org/10.1080/ 02757206.2016.1207637

Brunovskis, A., and Bjerkan, L. (2008). Research with irregular migrants in Norway. Methodological and ethical challenges and emerging research agendas. FoU-report. Oslo, UDI.

Burchianti, F. (2013). Internal control and claims of rights: Undocumented immigrants and local politics. In Guillaume, X., and Huysmans, J. (eds.) Citizenship and Security: The Constitution of Political Being. London and New York, Routledge, pp. 128-144.

Butler, J. (2004). Precarious Life: The Powers of Mourning and Violence. London, Verso. 
Butler, J. (2009). Frames of War: When Is Life Grievable? London, Verso.

Bygnes, S., and Karlsen, M.-A. (2017). Krise og kontinuitet i mottak av flyktninger i Norden: Innledning til temanummeret. Tidsskrift for Velferdsforskning, 20(4), 260-267. https://doi.org/10.18261/issn.2464-3076-2017-04-01

Byrkjeflot, H. (2005). The rise of a healthcare state? Recent healthcare reforms in Norway. Working Paper 15. Bergen, Stein Rokkan Centre for Social Studies.

Carens, J. H. (2008). The rights of irregular migrants. Ethics \& International Affairs, 22(2), 163-186. https://doi.org/10.1111/j.1747-7093.2008.00141.x

Castañeda, H. (2009). Illegality as risk factor: A survey of unauthorized migrant patients in a Berlin clinic. Social Science \& Medicine, 68(8), 1552-1560. https://doi.org/10.1016/j. socscimed.2009.01.024

Castañeda, H. (2010). Deportation deferred: 'illegality', visibility, and recognition in contemporary Germany. In De Genova, N., and Peutz, N. M. (eds.) The Deportation Regime: Sovereignty, Space, and the Freedom of Movement. Durham, NC, Duke University Press, pp. 245-261.

Castañeda, H. (2011). Medical humanitarianism and physicians' organized efforts to provide aid to unauthorized migrants in Germany. Human Organization, 70(1), 1-10. https://doi.org/10.17730/humo.70.1.a16566172p238244

Castañeda, H. (2013). Medical aid as protest: Acts of citizenship for unauthorized im/ migrants and refugees. Citizenship Studies, 17(2), 227-240. https://doi.org/10.1080/13 621025.2013 .780744

Chauvin, S., and Garcés-Mascareñas, B. (2012). Beyond informal citizenship: The new moral economy of migrant illegality. International Political Sociology, 6(3), 241-259. https://doi.org/10.1111/j.1749-5687.2012.00162.x

Chauvin, S., and Garcés-Mascareñas, B. (2014). Becoming less illegal: Deservingness frames and undocumented migrant incorporation. Sociology Compass, 8(4), 422-432. https://doi.org/10.1111/soc4.12145

Cohen, E. F. (2015). The political economy of immigrant time: Rights, citizenship, and temporariness in the post-1965 era. Polity, 47(3), 337-351. https://doi.org/10.1057/ pol.2015.15

Coleman, M. (2012). Immigrant il-legality: Geopolitical and legal borders in the US, 1882 present. Geopolitics, 17(2), 402-422. https://doi.org/10.1080/14650045.2011.563155

Coutin, S. B. (2000). Denationalization, inclusion, and exclusion: Negotiating the boundaries of belonging. Indiana Journal of Global Legal Studies, 7, 585-595.

Coutin, S. B. (2003). Legalizing Moves: Salvadoran Immigrants'Struggle for U.S. Residency. Ann Arbor, University of Michigan Press.

Coutin, S. B. (2005). Contesting criminality: Illegal immigration and the spatialization of legality. TheoreticalCriminology,9(1),5-33.https://doi.org/10.1177/1362480605046658

Coutin, S. B., and Fortin, V. (2015). Legal ethnographies and ethnographic law. In Austin, S., and Ewick, P. (eds.) The Handbook of Law and Society. New York, John Wiley, pp. 71-84.

Cuadra, C. B., and Staaf, A. (2012). Public social services' encounters with irregular migrants in Sweden: Amid values of social work and control of migration. European Journal of Social Work, 17(1), 88-103. https://doi.org/10.1080/13691457.2012.739556

Da Lomba, S. (2011). Irregular migrants and the human right to health care: A case-study of health-care provision for irregular migrants in France and the UK. International Journal of Law in Context, 7(3), 357-374. https://doi.org/10.1017/S1744552311000188

Darling, J. (2009). Becoming bare life: Asylum, hospitality, and the politics of encampment. Environment and Planning D-Society \& Space, 27(4), 649-665. https://doi.org/ $10.1068 / \mathrm{d} 10307$ 
Dauvergne, C. (2005). Humanitarianism, Identity, and Nation: Migration Laws in Canada and Australia. Vancouver, University of British Columbia Press.

Dean, M. (2007). Governing Societies: Political Perspectives on Domestic and International Rule. Maidenhead, Open University Press.

Dean, M. (2010). Governmentality: Power and Rule in Modern Society. London, Sage.

de Certeau, M. (1984). The Practice of Everyday Life. Berkeley, University of California Press.

De Genova, N. (2002). Migrant 'illegality' and deportability in everyday life. Annual Review of Anthropology, 31(1), 419-447. https://doi.org/10.1146/annurev.anthro.31. 040402.085432

De Genova, N. (2012). Bare life, labor-power, mobility, and global space: Toward a marxian anthropology? CR: The New Centennial Review, 12(3), 129-151. https://doi. org/10.1353/ncr.2012.0062

De Genova, N. (2013). Spectacles of migrant 'illegality': The scene of exclusion, the obscene of inclusion. Ethnic and Racial Studies, 36(7), 1180-1198. https://doi.org/10.1 080/01419870.2013.783710

De Genova, N., Garelli, G., and Tazzioli, M. (2018). Autonomy of asylum?: The autonomy of migration undoing the refugee crisis script. South Atlantic Quarterly, 117(2), 239265. https://doi.org/10.1215/00382876-4374823

De Graauw, E. (2014). Municipal ID cards for undocumented immigrants: Local bureaucratic membership in a federal system. Politics \& Society, 42(3), 309-330. https://doi. org/10.1177/0032329214543256

Dommerud, T. (2015). - Sykehus kan ikke kreve betaling for fødsel. Aftenposten [Online], 3 February. Available at: www.aftenposten.no/helse/-Sykehus-kan-ikke-kreve-betalingfor-fodsel-7886863.html [Accessed on 16.05.2015].

Drabløs, M. B., and Holden, M. (2012). Har for få sengeplasser. NRK [Online], 3 December. Available at: www.nrk.no/ostlandssendingen/har-for-fa-sengeplasser-1.9250431 [Accessed on 28.05.2015].

Drangsland, K. A. (2020). Bordering through recalibration: Exploring the temporality of the German 'Ausbildungsduldung'. EPC: Politics and Space, 38(6), 1128-1145. https:// doi.org/10.1177/2399654420915611

Drangsland, K. A., Jacobsen, C. M., and Karlsen, M.-A. (2020). How is the Covid-19 pandemic affecting migrants with precarious legal status? Blogpost [Online], 16 April. Available at: www.uib.no/en/project/wait/135202/waiting-uncertain-futures-pandemictimes [Accessed on 21.09.2020].

Düvell, F. (2010). Foreword. In Thomsen, T. L., Jørgensen, M. B., Meret, S., Hviid, K., and Stenum, H. (eds.) Irregular Migration in a Scandinavian Perspective. Maastricht, Shaker, pp. 3-8.

Elster, K. (2015). Vi kommer til å få en asylpolitikk som er blant de strengeste i Europa. NRK [Online], 29 December. Available at: www.nrk.no/norge/_-vi-kommer-til-a-faen-asylpolitikk-som-er-blant-de-strengeste-i-europa-1.12724216 [Accessed on 16.12. 2019].

Engebrigtsen, A. (2015). Invading our homelands. New beggars in the streets of Oslo. In Johansson, M., Salonen, T., and Righard, E. (eds.) Social Transformation in Scandinavian Cities: Nordic Perspectives on Urban Marginalisation and Social Sustainability. Lund, Nordic Academic Press, pp. 143-161.

Erichsen, V. (1995). Health care reform in Norway: The end of the 'profession state'? Journal of Health Politics, Policy and Law, 20(3), 719-737. https://doi.org/10.1215/ 03616878-20-3-719 
Faremo, G. (2012). Foreldrenes ansvar. BT, kronikk. 10 April. Available at: https://www. regjeringen.no/nb/aktuelt/foreldrenes-ansvar/id677923/?regj_oss $=200$ [Accessed on 16.05.2015].

Fassin, D. (2005). Compassion and repression: The moral economy of immigration policies in France. Cultural Anthropology, 20(3), 362-387. https://doi.org/10.1525/ can.2005.20.3.362

Fassin, D. (2009). Another politics of life is possible. Theory Culture \& Society, 26(5), 44-60. https://doi.org/10.1177/0263276409106349

Fassin, D. (2012). Humanitarian Reason: A Moral History of the Present Times. Berkeley, University of California Press.

Fassin, D., and D'Halluin, E. (2005). The truth from the body: Medical certificates as ultimate evidence for asylum seekers. American Anthropologist, 107(4), 597-608. https:// doi.org/10.1525/aa.2005.107.4.597

Fassin, D., and D'Halluin, E. (2007). Critical evidence: The politics of trauma in French asylum policies. Ethos, 35(3), 300-329. https://doi.org/10.1525/eth.2007.35.3.300

Feldman, G. (2011). If ethnography is more than participant-observation, then relations are more than connections: The case for nonlocal ethnography in a world of apparatuses. Anthropological Theory, 11(4), 375-395. https://doi.org/10.1177/1463499611429904

Feldman, I., and Ticktin, M. (2010). Introduction: Government and humanity. In Feldman, I., and Ticktin, M. (eds.) In the Name of Humanity: The Government of Threat and Care. Durham and London, Duke University Press, pp. 1-26.

Feldman, S., and Steenbergen, M. R. (2001). The humanitarian foundation of public support for social welfare. American Journal of Political Science, 45(3), 658-677. https:// doi.org/10.2307/2669244

Fimreite, A. L., Lango, P., Lægreid, P., and Rykkja, L. H. (2013). After Oslo and Utoya: A shift in the balance between security and liberty in Norway? Studies in Conflict \& Terrorism, 36(10), 839-856. https://doi.org/10.1080/1057610X.2013.823754

Foucault, M. (1979). The History of Sexuality I: An Introduction. London, Allen Lane.

Foucault, M. (1998). The History of Sexuality: The Will to Knowledge, vol. 1. London, Penguin.

Foucault, M., et al. (2003). Society Must Be Defended: Lectures at the Collège de France, 1975-76. New York, Picador.

Foucault, M., et al. (2007). Security, Territory, Population: Lectures at the Collège de France, 1977-78. Basingstoke and New York, Palgrave Macmillan.

Frankenberg, R. (1992). 'Your time or mine': Temporal contradictions of biomedical medicine. In Frankenberg, R. (ed.) Time, Health and Medicine. London, Sage, pp. 1-30.

Fuglerud, Ø. (2005). Inside out: The re-organisation of national identity in Norway. In Hansen, T. B., and Stepputat, F. (eds.) Sovereign Bodies: Citizens, Migrants, and States in the Postcolonial World. Princeton, NJ and Oxford, Princeton University Press, pp. 291-311.

Gammeltoft-Hansen, T. (2017). Refugee policy as 'negative nation branding': The case of Denmark and the Nordics. In Fischer, K., and Mouritzen, H. (eds.) Danish Foreign Policy Yearbook 2017. Copenhagen, DIIS (Danish Institute for International Studies), pp. 99-125.

Gasana, F. (2012). Irregular migrants' structural vulnerability and survival strategies. A case study in the Bergen area. Report 5. Bergen, Uni Rokkansenteret.

Geeraert, J. (2018). Healthcare reforms and the creation of ex-/included categories of patients - 'Irregular migrants' and the 'undesirable' in the French healthcare system. International Migration, 56(2), 68-81. https://doi.org/10.1111/imig.12405 
Gibney, M. J. (2020). Denationalisation and discrimination. Journal of Ethnic and Migration Studies, 46(12), 2551-2568. https://doi.org/10.1080/1369183X.2018.1561065

Gleeson, S. M. (2016). Precarious Claims: The Promise and Failure of Workplace Protections in the United States. Oakland, CA, University of California Press.

Goldring, L., and Landolt, P. (eds.) (2012). Producing and Negotiating Non-Citizenship: Precarious Legal Status in Canada. Toronto, ON, University of Toronto Press.

Gonzales, R. G. (2011). Learning to be illegal: Undocumented youth and shifting legal contexts in the transition to adulthood. American Sociological Review, 76(4), 602-619. https://doi.org/10.1177/0003122411411901

Gonzales, R. G., and Sigona, N. (eds.) (2017). Within and Beyond Citizenship: Borders, Membership and Belonging. London and New York, Routledge.

Gottlieb, N., Filc, D., and Davidovitch, N. (2012). Medical humanitarianism, human rights and political advocacy: The case of the Israeli Open Clinic. Social Science \& Medicine, 74(6), 839-845. https://doi.org/10.1016/j.socscimed.2011.07.018

Griffiths, M. B. (2014). Out of time: The temporal uncertainties of refused asylum seekers and immigration detainees. Journal of Ethnic and Migration Studies, 40(12), 19912009. https://doi.org/10.1080/1369183X.2014.907737

Grimen, H. (2009). Power, trust, and risk. Medical Anthropology Quarterly, 23(1), 16-33. https://doi.org/10.1111/j.1548-1387.2009.01035.x

Gripsrud, J. (2018). Norsk hamskifte. En kritikk av Terje Tvedt, et betinget forsvar for godheten og en etterlysning av midtbanen i innvandringsdebatten. Oslo, Vigmostad \& Bjørke.

Grønningsæter, A. G., and Brekke, J. P. (2017). Family Reunification Regulation in Norway-A Summary. Oslo, Institutt for samfunnsforskning.

Gullestad, F. H. (2013). Uteliggere fryser mer i Oslo. Klassekampen, 12 December, page 10 , part 1.

Gullestad, M. (2002). Invisible fences: Egalitarianism, nationalism and racism. Journal of the Royal Anthropological Institute, 8(1), 45-63. https://doi.org/10.1111/1467-9655.00098

Guðjónsdóttir, G., and Loftsdóttir, K. (2017). Being a desirable migrant: Perception and racialisation of Icelandic migrants in Norway. Journal of Ethnic and Migration Studies, 43(5), 791-808. https://doi.org/10.1080/1369183X.2016.1199268

Gupta, A. (2012). Red Tape: Bureaucracy, Structural Violence, and Poverty in India. Durham, NC, Duke University Press.

Haas, B. M. (2012). Suffering and the Struggle for Recognition: Lived Experiences of the U.S. Political Asylum Process, PhD thesis, University of California, San Diego. Available at: http://escholarship.org/uc/item/7pd0w87k\#page-483

Hage, G. (2003). Against Paranoid Nationalism: Searching for Hope in a Shrinking Society. Annandale, NSW, Pluto Press.

Hagelund, A. (2003a). A matter of decency? The progress party in Norwegian immigration politics. Journal of Ethnic and Migration Studies, 29(1), 47-65. https://doi. org/10.1080/1369183032000076713

Hagelund, A. (2003b). The importance of being good: Power and morality in Norwegian immigration politics. In Brochmann, G. (ed.) The Multicultural Challenge. Amsterdam, Elsevier Science, pp. 177-203.

Hagelund, A. (2005). Why it is bad to be kind. Educating refugees to life in the welfare state: A case study from Norway. Social Policy \& Administration, 39(6), 669-683. https://doi.org/10.1111/j.1467-9515.2005.00463.x

Hagelund, A. (2020). After the refugee crisis: Public discourse and policy change in Denmark, Norway and Sweden. Comparative Migration Studies, 8(13), 1-17. https://doi. org/10.1186/s40878-019-0169-8 
Halvorsen, M. (2004). 'Nødvendig helsehjelp' som redskap for prioriteringer. Lov og Rett, 43(3), 143-156.

Hara, K. W., and Borchgrevink, P. (2010). National guidelines for evaluating pain Patients' legal right to prioritised health care at multidisciplinary pain clinics in Norway implemented 2009. Scandinavian Journal of Pain, 1(1), 60-63. https://doi.org/10.1016/j. sjpain.2009.10.002

Harrison, S. (2002). New Labour, modernisation and the medical labour process. Journal of Social Policy, 31(3), 465-485. https://doi.org/10.1017/S0047279402006694

Hegvik, G. K. (2013a). Huitfeldt: Utvist mann burde ikke fătt sosialhjelp. $V G$ [Online], 25 February. Available at: www.vg.no/nyheter/innenriks/arbeiderpartiet/huitfeldt-utvistmann-burde-ikke-faatt-sosialhjelp/a/10107872/ [Accessed on 16.05.2015].

Hegvik, G. K. (2013b). Huitfeldt strammer inn Nav-hjelp. VG [Online], 25 July. Available at: www.vg.no/nyheter/innenriks/arbeiderpartiet/huitfeldt-strammer-inn-nav-hjelp/ a/10112433/ [Accessed on 16.05.2015].

Hegvik, G. K., Skarvøy, L. K., and Beyer-Olsen, A. (2013). Dømt for voldtektsforsøk, utvist fra Norge, får sosialhjelp og bolig av Nav. $V G$ [Online], 25 February. Available at: www. vg.no/nyheter/innenriks/stoltenberg-regjeringen/doemt-for-voldtektsforsoek-utvist-franorge-faar-sosialhjelp-og-bolig-av-nav/a/10107772/ [Accessed on 16.05.2015].

Henjum, S., Morseth, M. S., Arnold, C. D., Mauno, D., and Terragni, L. (2019). 'I worry if I will have food tomorrow': A study on food insecurity among asylum seekers living in Norway. BMC Public Health, 19(592), 1-8. https://doi.org/10.1186/s12889-019-6827-9

Henriksen, L. S., Strømsnes, K., and Svedberg, L. (eds.) (2018). Civic Engagement in Scandinavia, Volunteering, Informal Help and Giving in Denmark, Norway and Sweden. Cham, Springer.

Hernes, V. (2018). Cross-national convergence in times of crisis? Integration policies before, during and after the refugee crisis. West European Politics, 41(6), 1305-1329. https://doi.org/10.1080/01402382.2018.1429748

Hjelde, K. H. (2010). 'Jeg er alltid bekymret'. Om udokumenterte migranter og deres forhold til helsetjenestene i Oslo. In NAKMIs skriftserie om minoriteter og helse. Oslo, NAKMI.

Hoag, C. (2011). Assembling partial perspectives: Thoughts on the anthropology of bureaucracy. PoLAR: Political and Legal Anthropology Review, 34(1), 81-94. https:// doi.org/10.1111/j.1555-2934.2011.01140.x

Holst, C. (2009). I beste mening. Opposisjonsvitenskapens fallgruver. In Tranøy, B. S., Christensen, J., and Nuland, B. R. (eds.) Hjernen er alene. Institusjonalisering, kvalitet og relevans i norsk velferdsforskning. Oslo, Universitetsforlaget, pp. 159-175.

Hovde, M. (2006). Nødrett som rettsgrunnlag for forvaltningens faktiske handlinger og rettslige beslutninger. Master, Universitetet i Tromsø.

Huseby, V. B. (2014a). Hvis jussen kan trumfe medisinen, er det sjokkerende. Vårt Land [Online], 10 June. Available at: www.vl.no/samfunn/hvis-jussen-kan-trumfemedisinener-det-sjokkerende-1.85289 [Accessed on 10.06.2014].

Huseby, V. B. (2014b). - Legene kunne operert Adam. Vårt Land [Online], 10 June. Available at: www.vl.no/samfunn/legene-kunne-operert-adam-1.85305 [Accessed on 10.06.2014].

Huseby, V. B. (2014c). Sykehuset snur - Adam får operasjon. Vårt Land [Online], 10 June. Available at: www.vl.no/samfunn/sykehuset-snur-adam-f\%C3\%A5r-operasjon-1.85316 [Accessed on 10.06.2014].

Huseby, V. B. (2014d). Vil fjerne all tvil om helsehjelp til personer uten lovlig opphold. Vårt Land [Online], 27 June. Available at: www.vl.no/mobile/samfunn/vil-fjerne-alltvil-om-helsehjelp-til-personer-uten-lovlig-opphold-1.86216 [Accessed on 27.06.2014]. 
Ihlen, Ø., and Thorbjørnsrud, K. (2014). Making news and influencing decisions: Three threshold cases concerning forced return of immigrants. European Journal of Communication, 29(2), 139-152. https://doi.org/10.1177/0267323114523149

Ilstad, J. T. (2014). Barnets tilknytning til riket: En analyse av juridisk argumentasjon i utlendingsforvaltningen. Kritisk Juss, 40(4), 141-164.

Ilstad, J. T., and Bondevik, H. (2016). Asylum-seeking children: Affiliation to Norway or the 'home country'. Nordic Journal of Human Rights, 34(2), 124-137. https://doi.org/10. 1080/18918131.2016.1208412

Isin, E. F., and Nielsen, G. M. (2008). Introduction: Acts of citizenship. In Isin, E. F., and Nielsen, G. M. (eds.) Acts of Citizenship. London, Zed Books, pp. 1-12.

Jacobsen, C. M. (2015). Begreper og perspektiver i forskningen omkring irregulær migrasjon og velferd. In Bendixsen, S. K., Jacobsen, C. M., and Søvig, K. H. (eds.) Eksepsjonell velferd? Irregulare migranter $i$ det norske velferdssamfunnet. Oslo, Gyldendal Norsk Forlag, pp. 25-46.

Jacobsen, C. M., and Karlsen, M.-A. (2021). Introduction: Unpacking the temporalities of irregular migration. In Jacobsen, C., Karlsen, M.-A., and Khosravi, S. (eds.) Waiting and the Temporalities of Irregular Migration. London and New York, Routledge.

Jacobsen, C. M., Karlsen, M.-A., and Khosravi, S. (eds.) (2021). Waiting and the Temporalities of Irregular Migration. London and New York, Routledge. https://doi.org/ $10.4324 / 9780429351730$

Jacobsen, C. M., and Skilbrei, M.-L. (2010). 'Reproachable victims'? Representations and self-representations of Russian women involved in transnational prostitution. Ethnos, 75(2), 190-212. https://doi.org/10.1080/00141841003764013

Jahnsen, S. Ø. (2014). Innestengt eller utestengt? Norsk prostitusjonspolitikk og kampen mot menneskehandel, $\mathrm{PhD}$ thesis, University of Bergen.

Jensen, R., Seferowicz, H., and Turkerud, K. (2014). Adam (9) får operasjon likevel. NrK [Online], 10 June. Available at: www.nrk.no/ostlandssendingen/adam-_9_-far-operasjonlikevel-1.11768120 [Accessed on 16.05.2015].

Johansen, N. B., Ugelvik, T., and Aas, K. F. (eds.) (2013). Krimmigrasjon? Den nye kontrollen av de fremmede. Oslo, Universitetsforlaget.

Jønsson, H. V., and Petersen, K. (2012). Denmark: A national welfare state meets the world. In Brochmann, G., and Hagelund, A. (eds.) Immigration Policy and the Scandinavian Welfare State 1945-2010. New York, Palgrave Macmillan, pp. 97-148.

Jørgensen, M. B., and Meret, S. (2012). Framing scandinavian conceptualizations of irregular migration. Nordic Journal of Migration Research, 2(4), 289-297. https://doi. org/10.2478/v10202-012-0005-9

Karlsen, M.-A. (2021). Waiting out the condition of illegality in Norway. In Jacobsen, C. M., Karlsen, M.-A., and Khosravi, S. (eds.) Waiting and the Temporalities of Irregular Migration. London and New York, Routledge.

Karlsen, R. (2015). Irregulære barns rett til helsehjelp i Norge. In Bendixsen, S. K., Jacobsen, C. M., and Søvig, K. H. (eds.) Eksepsjonell velferd? Irregulcere migranter $i$ det norske velferdssamfunnet. Oslo, Gyldendal Norsk Forlag, pp. 88-106.

Karl-Trummer, U., Metzler, B., and Novak-Zezula, S. (2009). Health Care for Undocumented Migrants in the EU: Concepts and Cases. Brussels, International Organization for Migration. Available at: http://tinyurl.com/32hffyf

Khosravi, S. (2006). Territorialiserad mänsklighet: irreguljära immigranter och det nakna livet. In de los Reyes, Paulina (ed.) Om välfärdens gränser och det villkorade medborgarskapet. Swedish Government Official Report SOU 2006: 37, pp. 283-310. 
Khosravi, S. (2010). An ethnography of migrant 'illegality' in Sweden: Included yet excepted? Journal of International Political Theory, 6(1), 95-116. https://doi.org/ 10.3366/E1755088210000479

Khosravi, S. (2014). Waiting. In Anderson, B., and Keith, M. (eds.) Migration: The COMPAS Anthology. Oxford, Centre on Migration, Policy and Society, pp. 74-74. Available at: https://compasanthology.co.uk/waiting/

Kilnes, C. (2013). Ingen skal fryse i hjel i Trondheim. Frelsesarmeen i Trondheim åpner opp dørene for romfolket på natterstid. Adressa, [Online] 06 January. Available at: http:// www.adressa.no/nyheter/trondheim/article6962941.ece [Accessed on 28.05.2015].

Kjærre, H. A. (2010). No direction home - The margins of a welfare state and the illegalized body. In Thomsen, T. L., Jørgensen, M. B., Meret, S., Hviid, K., and Stenum, H. (eds.) Irregular Migration in a Scandinavian Perspective. Maastricht, Shaker Publishing, pp. 231-257.

Kjærre, H. A. (2015). Kontrollvelferd i det norske mottakssystemet: Mottakstilværelsen og livet utenfor. In Bendixsen, S. K., Jacobsen, C. M., and Søvig, K. H. (eds.) Eksepsjonell velferd? Irregulcere migranter $i$ det norske velferdssamfunnet. Oslo, Gyldendal forlag.

Knapskog, S. (2013). Når er utlendingar 'ulovleg' i Noreg? Ein analyse av forholdet mellom helselovgivinga og utlendingsregelverket, Master thesis, University of Bergen.

Koser, K. (2010). Dimensions and dynamics of irregular migration. Population, Space and Place, 16(3), 181-193. https://doi.org/10.1002/psp.587

Kuhnle, S., and Kildal, N. (2005). Normative Foundations of the Welfare State: The Nordic Experience. Florence, KY, Routledge.

Lægreid, P. (2003). The Structural Anatomy of the Norwegian State 1947-2003. Bergen, Rokkansenteret.

Lægreid, P., Opedal, S., and Stigen, I. M. (2005). The Norwegian hospital reform: Balancing political control and enterprise autonomy. Journal of Health Politics Policy and Law, 30(6), 1027-1064. https://doi.org/10.1215/03616878-30-6-1027

Larchanché, S. (2012). Intangible obstacles: Health implications of stigmatization, structural violence, and fear among undocumented immigrants in France. Social Science \& Medicine, 74(6), 858-863. https://doi.org/10.1016/j.socscimed.2011.08.016

Larsen, C. A. (2008). The institutional logic of welfare attitudes: How welfare regimes influence public support. Comparative Political Studies, 41(2), 145-168. https://doi. org/10.1177/0010414006295234

Larsen, L. E., and Eie, L. G. (2011). - De kan ikke forvente gratis fødsler. NRK [Online], 10 November. Available at: www.nrk.no/sorlandet/_kan-ikke-forvente-gratis-fodsler1.7870202 [Accessed on 16.05.2015].

Laubenthal, B. (2011). The negotiation of irregular migrants' right to education in Germany: A challenge to the nation-state. Ethnic and Racial Studies, 34(8), 1357-1373. https://doi.org/10.1080/01419870.2010.538424

Lawler, P. (2013). The 'good state' debate in international relations. International Politics, 50(1), 18-37. https://doi.org/10.1057/ip.2012.26

Leerkes, A. (2016). Back to the poorhouse? Social protection and social control of unauthorised immigrants in the shadow of the welfare state. Journal of European Social Policy, 26(2), 140-154. https://doi.org/10.1177/0958928716637139

Lewis, P. G., and Ramakrishnan, S. K. (2007). Police practices in immigrant-destination cities political control or bureaucratic professionalism? Urban Affairs Review, 42(6), 874-900. https://doi.org/10.1177/1078087407300752

Liden, H., Stang, E. G., and Eide, K. (2017). The gap between legal protection, good intentions and political restrictions. Unaccompanied minors in Norway. Social Work \& Society, 15(1), 1-20. 
Lister, R. (2009). A Nordic nirvana? Gender, citizenship, and social justice in the Nordic welfare states. Social Politics: International Studies in Gender, State \& Society, 16(2), 242-278. https://doi.org/10.1093/sp/jxp007

Loga, J. (2002). Godhetens makt i den politiske offentlighet. Kvinneforskning, 4, 32-39.

Lønseth, P. K. (2011). Returnekternes ansvar. Aftenposten, kronikk. [Online] 24 October. Available at: http://www.aftenposten.no/meninger/Returnekternes-ansvar-6677873. html\#.UxzCl_1_vyA [Accessed on 16.05.2015].

Lupton, D. (2012). Medicine as Culture: Illness, Disease and the Body. London, Sage.

Magalhaes, L., Carrasco, C., and Gastaldo, D. (2010). Undocumented migrants in Canada: A scope literature review on health, access to services, and working conditions. Journal of Immigrant and Minority Health, 12(1), 132-151. https://doi.org/10.1007/ s10903-009-9280-5

Magnussen, A.-M., and Aasen, H. S. (2013). Prioritering av helsetjenester og retten til nødvendig helsehjelp: noen tanker om rett og politikk. In Ketscher, K., Lilleholt, K., Smith, E., and Syse, A. (eds.) Velferd og rettferd: Festskrift til Asbjørn Kjønstad 70 år. Olso, Gyldendal Juridisk, pp. 375-388.

Magnussen, A.-M., and Nilssen, E. (2013). Juridification and the construction of social citizenship. Journal of Law and Society, 40(2), 228-248. https://doi.org/10.1111/j.14676478.2013.00621.x

Marklund, C. (2017). The Nordic model on the global market of ideas: The welfare state as scandinavia's best brand. Geopolitics, 22(3), 623-639. https://doi.org/10.1080/1465 0045.2016 .1251906

Marrow, H. B. (2009). Immigrant bureaucratic incorporation: The dual roles of professional missions and government policies. American Sociological Review, 74(5), 756776. https://doi.org/10.1177/000312240907400504

Marrow, H. B. (2012). The power of local autonomy: Expanding health care to unauthorized immigrants in San Francisco. Ethnic and Racial Studies, 35(1), 72-87. https://doi. org/10.1080/01419870.2011.594168

Måseide, P. (1991). Possibly abusive, often benign, and always necessary. On power and domination in medical practice. Sociology of Health \& Illness, 13(4), 545-561. https:// doi.org/10.1111/1467-9566.ep10843655

Mathiesen, E. (2002). Medisin og vitenskap-Aktuelt problem-Helsetilbud til kirkeasylanter en utfordring for helsevesenet. Tidsskrift for den Norske Laegeforening, 122, 1678-1681.

Mburu, C. B., Middelthon, A.-L., and Hilden, P. K. (2015). Utvikling av psykiske og psykososiale helsetjenester ved helsesenteret for papirløse migranter. In Bendixsen, S. K., Jacobsen, C. M., and Søvig, K. H. (eds.) Eksepsjonell velferd? Irregulcere migranter $i$ det norske velferdssamfunnet. Oslo, Gyldendal Norsk Forlag, pp. 163-180.

McGoey, L. (2012). Strategic unknowns: Towards a sociology of ignorance. Economy and Society, 41(1), 1-16. https://doi.org/10.1080/03085147.2011.637330

McLoughlin, D. (2014). Giorgio Agamben on security, government and the crisis of law. Griffith Law Review, 21(3), 680-707. https://doi.org/10.1080/10383441.2012. 10854758

McNevin, A., and Missbach, A. (2018). Luxury limbo: Temporal techniques of border control and the humanitarianisation of waiting. International Journal of Migration and Border Studies, 4(1-2), 12-34. https://doi.org/10.1504/IJMBS.2018.091222

Melberg, A., Onarheim, K. H., Spjeldnaes, A. O., and Miljeteig, I. (2018). Towards universal health coverage for undocumented migrants? Tidsskriftet den Norske Laegeforening, 138(1), 1-6.

Mezzadra, S., and Neilson, B. (2013). Border as Method, or, the Multiplication of Labor. Durham, NC, Duke University Press. 


\section{References}

Midtbøen, A. H. (2017). Innvandringshistorie som faghistorie: Kontroverser i norsk migrasjonsforskning. Nytt Norsk Tidsskrift, 34(2), 130-149. https://doi.org/10.18261/ issn. 1504-3053-2017-02-03

Misje, T. (2020). Social work and welfare bordering: The case of homeless EU migrants in Norway. European Journal of Social Work, 23(3), 401-413. https://doi.org/10.1080/ 13691457.2019 .1682975

Mitchell, K. (2006). Geographies of identity: The new exceptionalism. Progress in Human Geography, 30(1), 95-106. https://doi.org/10.1191/0309132506ph594pr

Mohn, S. B., Ellingsen, D., Solheim, Ø. B., and Torgersen, K. (2014). Asylsøkere, ulovlig opphold og kriminalitet - et marginalt problem? Kristiansand, Oxford Research.

Näsholm, L. (2014). 'Helping Others and Helping Myself Too'. A Study of Irregular Migrants' Experiences of Doing Volunteer Work, Master Thesis of International Social Welfare and Health Policy, Oslo and Akershus University College, Faculty of Social Sciences.

Nielsen, A. (2016). Challenging rightlessness: On irregular migrants and the contestation of welfare state demarcation in Sweden, $\mathrm{PhD}$ thesis, Linnaeus University.

Nijhawan, M. (2005). Deportability, medicine, and the law. Anthropology \& Medicine, 12(3), 271-285. https://doi.org/10.1080/13648470500291436

Nilsen, A. T., and Eie, L. G. (2011). Trekker inkassokrav etter fødsel. NRK [Online], 2 December. Available at: www.nrk.no/sorlandet/trekker-inkassokrav-etter-fodsel-1.7900105 [Accessed on 16.05.2015].

Nilsen, A. T., Kolaas, S., and Solli, H. J. (2014). Louila får livsviktig operasjon likevel. $N R K$ [Online], 25 November. Available at: www.nrk.no/trondelag/rikshospitaletopererer-louila-likevel-1.12062261 [Accessed on 28.05.2015].

Nilssen, E., and Kildal, N. (2009). New contractualism in social policy and the Norwegian fight against poverty and social exclusion. Ethics and Social Welfare, 3(3), 303-321. https://doi.org/10.1080/17496530903209550

NOAS (2011). Retur til hva? Norsk praksis overfor statsløse palestinske asylsøkere. Rapport I - 2011. Oslo, Norsk Organisasjon for Asylsøkere (NOAS).

NOAS (2013). Asyldebatten og sentrale asylpolitiske hendelser. Notat. Available at: https:// www.noas.no/asyldebatten-og-sentrale-asylpolitiske-hendelser-1980-2013/

Noll, G. (2010). Why human rights fail to protect undocumented migrants. European Journal of Migration and Law, 12(2), 241-272. https://doi.org/10.1163/157181610X496894

Nordling, V. (2017). Destabilising Citizenship Practices?: Social Work and Undocumented Migrants in Sweden, $\mathrm{PhD}$ thesis, Lund University.

Norwegian Red Cross (2007). Arsrapport. Available at: www.rodekors.no/nyheter/ rapportsenter/rapporter/ [Accessed on 16.05.2015].

NTB (2014). Dødssyk niåring får ikke hjelp på grunn av asylsøkerstatus. NRK [Online], 10 June. Available at: www.nrk.no/norge/dodssyk-gutt-far-ikke-hjelp-1.11767035 [Accessed on 10.06.2014].

Nuland, B. R. (2007). Ansikt til ansikt med fattigdommen. Frivillige organisasjoners hjelpetiltak overfor fattige. Rapport 2007/18. Oslo, Fafo.

Nyers, P. (2011). No one is illegal between city and nation. Studies in Social Justice, 4(2), 127-143. https://doi.org/10.26522/ssj.v4i2.998

Olsen, E. D. H. (2018). Out but still in: Norway's approach to migration and asylum as a Non-EU state. GLOBUS Research Paper, 6. Oslo, Arena Centre for European Studies.

Olwig, K. F. (2011). 'Integration': Migrants and refugees between Scandinavian welfare societies and family relations. Journal of Ethnic and Migration Studies, 37(2), 179-196. https://doi.org/10.1080/1369183X.2010.521327 
Ong, A. (2003). Buddha is hiding refugees, citizenship, the new America. In California Series in Public Anthropology 5. Berkeley, University of California Press.

Ong, A. (2006). Neoliberalism as Exception Mutations in Citizenship and Sovereignty. Durham, NC, Duke University Press.

Ottesen, S. H., Eick, F., and Hilden, P. K. (2015). Erfaringer fra helsesenteret for papirløse migranter. In Bendixsen, S. K., Jacobsen, C. M., and Søvig, K. H. (eds.) Eksepsjonell velferd? Irregulcere migranter i det norske velferdssamfunnet. Oslo, Gyldendal forlag.

Øverbye, E. (2017). Likhet og ulikhet under Erna Solbergs regjering. Tidsskrift for Velferdsforskning, 20(2), 164-170. https://doi.org/10.18261/issn.0809-2052-2017-02-05

Parekh, S. (2004). A meaningful place in the world: Hannah Arendt on the nature of human rights. Journal of Human Rights, 3(1), 41-52. https://doi.org/10.1080/147548 3042000185215

Pedersen, A., and Kuhnle, S. (2017). The Nordic welfare state model. In Knutsen, O. (ed.) The Nordic Models in Political Science. Oslo, Fagbokforlaget, pp. 219-237.

Perna, R. (2019). Bound between care and control: Institutional contradictions and daily practices of healthcare for migrants in an irregular situation in Italy. Ethnic and Racial Studies, 42(2), 103-122. https://doi.org/10.1080/01419870.2018.1533645

Petersen, A., and Wilkinson, I. (2014). Editorial introduction: The sociology of hope in contexts of health, medicine, and healthcare. Health, 19(2), 113-118. https://doi.org/ $10.1177 / 1363459314555378$

Peutz, N. M. (2006). Embarking on an anthropology of removal. Current Anthropology, 47(2), 217-241. https://doi.org/10.1086/498949

Peutz, N. M., and De Genova, N. (2010). Introduction. In De Genova, N., and Peutz, N. M. (eds.) The Deportation Regime: Sovereignty, Space, and the Freedom of Movement. Durham, NC, Duke University Press, pp. 1-32.

Pinto Albuquerque, C. (2016). Time and public policy. Desynchronization of lifecycle and outlines of a contemporary 'biopolitics'. Time \& Society, 25(2), 253-271. https://doi. org/10.1177/0961463X15577258

Plambech, S. (2014). Between 'victims' and 'criminals': Rescue, deportation, and everyday violence among Nigerian migrants. Social Politics: International Studies in Gender, State \& Society, 21(3), 382-402. https://doi.org/10.1093/sp/jxu021

Povinelli, E. A. (2011). Economies of Abandonment: Social Belonging and Endurance in Late Liberalism. Durham, NC, Duke University Press.

Pratt, G. (2005). Abandoned women and spaces of the exception. Antipode, 37(5), 10521078. https://doi.org/10.1111/j.0066-4812.2005.00556.x

PU, Politiets Utlendingsenhet (2017). Forsvunnet. Asylsøkere som forsvinner fra kjente adresser. Available at: www.politiet.no/aktuelt-tall-og-fakta/aktuelt/nyheter/2017/07/24/ pu-de-fleste-forsvunne-asylsokere-forlater-landet/ [Accessed on 01.08.2019].

Puar, J. (ed.). (2012). Precarity talk: A virtual roundtable with Lauren Berlant, Judith Butler, Bojana Cvejic, Isabell Lorey, Jasbir Puar, and Ana Vujanovic. The Drama Review, 56(4), 163-177. https://doi.org/10.1162/DRAM_a_00221

Quesada, J. (2012). Special issue part II: Illegalization and embodied vulnerability in health. Social Science \& Medicine, 74(6), 894-896. https://doi.org/10.1016/j.socscimed. 2011.10.043

Rajaram, P. K., and Grundy-Warr, C. (2004). The irregular migrant as homo sacer: Migration and detention in Australia, Malaysia, and Thailand. International Migration, 42(1), 33-64. https://doi.org/10.1111/j.0020-7985.2004.00273.x

Ramsay, G. (2017). Impossible Refuge: The Control and Constraint of Refugee Futures. London, Routledge. 
Ramsay, G. (2019). Time and the other in crisis: How anthropology makes its displaced object. Anthropological Theory, 6(2), 139-152. https://doi.org/10.1177/1463499619840464

Redfield, P. (2005). Doctors, borders, and life in crisis. Cultural Anthropology, 20(3), 328361. https://doi.org/10.1525/can.2005.20.3.328

Rose, N., and Valverde, M. (1998), Governed by law? Social \& Legal Studies, 7(4), 541551. https://doi.org/10.1177/096466399800700405

Rugkåsa, M. (2010). Transformasjon og integrasjon: kvalifisering av minoritetsetniske kvinner til arbeid og deltakelse $i$ den norske velferdsstaten, $\mathrm{PhD}$ thesis, Universitetet i Oslo.

Ryste, T. H., Aarøy, T., and Valland, G. (2015). Når dere leser dette, har jeg forlatt dere. BT [Online], 22 January. Available at: www.bt.no/nyheter/lokalt/Nar-dere-leser-dette_-harjeg-forlatt-dere-3286426.html [Accessed on 16.05.2015].

Rytter, M. (2019). Writing against integration: Danish imaginaries of culture, race and belonging. Ethnos, 84(4), 678-697. https://doi.org/10.1080/00141844.2018.1458745

Salter, M. B. (2008). When the exception becomes the rule: Borders, sovereignty, and citizenship. Citizenship Studies, 12(4), 365-380. https://doi.org/10.1080/13621020802184234

Schultz, J. (2019). The Internal Protection Alternative in Refugee Law: Treaty Basis and Scope of Application Under the 1951 Convention on Refugees and Its 1967 Protocol. Leiden, Brill Nijhoff.

Schweitzer, R. (2019). Health care versus border care: Justification and hypocrisy in the multilevel negotiation of irregular migrants' access to fundamental rights and services. Journal of Immigrant \& Refugee Studies, 17(1), 61-76. https://doi.org/10.1080/155629 48.2018.1489088

Seeberg, M. L. (2017). Alt er relativt: Ytelser til barnefamilier i norske asylmottak, 1989-2017. Tidsskrift for Velferdsforskning, 20(4), 268-285. https://doi.org/10.18261/ issn.2464-3076-2017-04-02

Sharma, S. (2014). In the Meantime: Temporality and Cultural Politics. Durham, NC, Duke University Press.

Sigvardsdotter, E. (2012). Presenting the Absent: An Account of Undocumentedness in Sweden, PhD thesis, Uppsala University.

Sigvardsdotter, E. (2013). Presenting absent bodies: Undocumented persons coping and resisting in Sweden. Cultural Geographies, 20(4), 523-539. https://doi.org/10.1177/ 1474474012465845

Sivesind, K. H., Lorentzen, H., Selle, P., and Wollebæk, D. (2002). The voluntary sector in Norway. Composition, changes and causes. Report, 2. Oslo, Institutt for samfunnsforskning.

Slagstad, R. (2004). Shifting knowledge regimes: The metamorphoses of Norwegian reformism. Thesis Eleven, 77(1), 65-83. https://doi.org/10.1177/0725513604044236

Slagstad, R. (2009). Styringsvitenskap - ånden som går. Nytt Norsk Tidsskrift, 3(4), 411-429.

Søvig, K. H. (2013a). Straffansvar og straffeforfølgning av humanitære hjelpere ved ulovlig opphold. In Johansen, N. B., Ugelvik, T., and Franko Aas, K. (eds.) Krimmigasjon? Den nye kontrollen av de fremmede. Oslo, Universitetsforlaget, pp. 139-155.

Søvig, K. H. (2013b). Hvorfor nekte, eller gi, irregulære immigranter tilgang til velferdsytelser? In Rasmussen, Ø., Eskeland Schütz, S., og Søvig, K. H. (eds.) Undring og erkjennelse. Bergen, Fagbokforlaget, pp. 705-717.

Søvig, K. H. (2015). Tilgang til velferdstjenester for irregulære migranter etter det norske regelverket. In Bendixsen, S. K., Jacobsen, C. M., and Søvig, K. H. (eds.) Eksepsjonell velferd? Irregulcere migranter $i$ det norske velferdssamfunnet. Oslo, Gyldendal forlag. 
Spencer, S. (2018). Multi-level governance of an intractable policy problem: Migrants with irregular status in Europe. Journal of Ethnic and Migration Studies, 44(12), 2034-2052. https://doi.org/10.1080/1369183X.2017.1341708

Spencer, S., and Delvino, N. (2019). Municipal activism on irregular migrants: The framing of inclusive approaches at the local level. Journal of Immigrant \& Refugee Studies, 17(1), 27-43. https://doi.org/10.1080/15562948.2018.1519867

Staver, A. (2015). Hard work for love: The economic drift in Norwegian family immigration and integration policies. Journal of Family Issues, 36(11), 1453-1471. https://doi. org/10.1177/0192513X14557491

Stenum, H. (2012). Making migrants governable: Counting and defining the 'illegal migrant'. Nordic Journal of Migration Research, 2(4), 280-288. https://doi.org/10.2478/ v10202-012-0006-8

Stokke, O. (2016). Listhaug i Tyrkia: - Overbevist om at hjelp i nærområdene er det rette. Aftenposten [Online], 14 January. Available at: www.aftenposten.no/verden/i/qApo/ listhaug-i-tyrkia-overbevist-om-at-hjelp-i-naeromraadene-er-det-rette [Accessed on 30.12.2019].

Süssmann, A. (2015). Dronning i grenseland? Et menneskerettslig perspektiv på forskrift om rett til helse og omsorgstjenester til personer uten fast opphold i riket. In Bendixsen, S. K., Jacobsen, C. M., and Søvig, K. H. (eds.) Eksepsjonell velferd? Irregulcere migranter $i$ det norske velferdssamfunnet. Oslo, Gyldendal forlag, pp. 66-87.

Teig, I. L. (2012). Managing Patient Movement: Exploring Practices of Management, Responsibility and Trust in a Norwegian Psychiatric Hospital, $\mathrm{PhD}$ thesis, Universitetet i Bergen.

Thorbjørnsen, V. F. (2020). Health for all? Access to healthcare among precarious populations in Norway. Somatosphere. Available at: http://somatosphere.net/2020/healthcareaccess-norway.html/ [Accessed on 19.08.2020].

Thorshaug, K., and Valenta, M. (2012). Retursentre for utreisepliktige. Evaluering av konseptutvikling og etableringsarbeid $i$ Utlendingsdirektoratet. Trondheim, NTNU Samfunnsforskning AS.

Ticktin, M. (2011). Casualties of Care: Immigration and the Politics of Humanitarianism in France. Berkeley, University of California Press.

Ticktin, M. (2014). Transnational humanitarianism. Annual Review of Anthropology, 43, 273-289. https://doi.org/10.1146/annurev-anthro-102313-030403

Ticktin, M. (2016). Thinking beyond humanitarian borders. Social Research: An International Quarterly, 83(2), 255-271.

Trägårdh, L. (2018). Scaling up solidarity from the national to the global: Sweden as welfare state and moral superpower. In Witoszek, N., and Midttun, A. (eds.) Sustainable Modernity: The Nordic Model and Beyond. London, Routledge, pp. 79-101.

Tvedt, T. (2016). Derfor truer godhetstyranniet demokratiet selv. Aftenposten, 11 March. Available at: www.aftenposten.no/meninger/kronikk/i/715XB/derfor-truer-godhetstyrannietdemokratiet-selv-terje-tvedt [Accessed on 16.05.2015].

Tvedt, T. (2017). Det internasjonale gjennombruddet. Fra 'ettpartistat' til flerkulturell stat. Oslo, Dreyer Forlag.

Valenta, M., and Thorshaug, K. (2011). Asylsøkeres rett til å ta arbeid. Evaluering av konsekvenser av innstramminger i dokumentasjonskravet. Trondheim, NTNU Samfunnsforskning AS.

Valenta, M., Thorshaug, K., Molden, T. H., Berg, B., and Kjærre, H. A. (2010). Avviste asylsøkere og ventemottaksordningen. Mellom passiv tvang og aktiv returassistanse. Trondheim, NTNU Samfunnsforskning. 
Van der Leun, J. (2006). Excluding illegal migrants in the Netherlands: Between national policies and local implementation. West European Politics, 29(2), 310-326. https://doi. org/10.1080/01402380500512650

Van der Leun, J., and Bouter, H. (2015). Gimme shelter: Inclusion and exclusion of irregular immigrants in Dutch civil society. Journal of Immigrant \& Refugee Studies, 13(2), 135-155. https://doi.org/10.1080/15562948.2015.1033507

Van Der Waal, J., De Koster, W., and Van Oorschot, W. (2013). Three worlds of welfare chauvinism? How welfare regimes affect support for distributing welfare to immigrants in Europe. Journal of Comparative Policy Analysis: Research and Practice, 15(2), 164181. https://doi.org/10.1080/13876988.2013.785147

Van Houtum, H., et al. (2005). B/ordering Space. Aldershot, Ashgate.

Van Oorschot, W. (2007). Culture and social policy: A developing field of study. International Journal of Social Welfare, 16(2), 129-139. https://doi.org/10.1111/j.14682397.2006.00451.x

Vaughan-Williams, N. (2009). Border Politics: The Limits of Sovereign Power. Edinburgh, GBR, Edinburgh University Press.

Vedeler, M., Sætran, F., and Gimse, L. F. (2014). Loddtrekning avgjør hvem som får sove inne. Aftenposten [Online], 1 February. Available at: www.osloby.no/Loddtrekning-avgjorhvem-som-far-sove-inne-7454468.html\#.UuzRcPl_vyA [Accessed on 28.05.2015].

Vike, H. (2004). Velferd uten grenser: Den norske velferdsstaten ved veiskillet. Oslo, Akribe. Villegas, P. (2013). Negotiating the boundaries of membership: Health care providers, access to social goods, and immigration status. In Goldring, L., and Landolt, P. (eds.) Producing and Negotiating Non-citizenship: Precarious Legal Status in Canada. Toronto, University of Toronto Press, pp. 221-237.

Vitus, K., and Lidén, H. (2010). The status of the asylum-seeking child in Norway and Denmark: Comparing discourses, politics and practices. Journal of Refugee Studies, 23(1), 62-81. https://doi.org/10.1093/jrs/feq003

Waite, L. (2009). A place and space for a critical geography of precarity? Geography Compass, 3(1), 412-433. https://doi.org/10.1111/j.1749-8198.2008.00184.x

Waring, J., and Currie, G. (2009). Managing expert knowledge: Organizational challenges and managerial futures for the UK medical profession. Organization Studies, 30(7), 755-778. https://doi.org/10.1177/0170840609104819

Watters, C. (2007). Refugees at Europe's borders: The moral economy of care. Transcultural Psychiatry, 44(3), 394-417. https://doi.org/10.1177/1363461507081638

Weber, L. (2006). The shifting frontiers of migration control. In Pickering, S., and Weber, L. (eds.) Borders, Mobility and Technologies of Control. Springer, Dordrecht, pp. 21-43.

Weber, L. (2015). Deciphering deportation practices across the Global North. In Pickering, S., and Ham, J. (eds.) The Routledge Handbook on Crime and International Migration. London, Routledge, pp. 155-178.

Weheliye, A. G. (2014). Habeas Viscus: Racializing Assemblages, Biopolitics, and Black Feminist Theories of the Human. Durham, Duke University Press.

Wells, K. (2011). The politics of life: Governing childhood. Global Studies of Childhood, 1(1), 15-25. https://doi.org/10.2304/gsch.2011.1.1.15

Whitley, L. (2017). The disappearance of race: A critique of the use of Agamben in border and migration scholarship. Borderlands E-journal, 16(1), 1-23.

Whyte, J. (2013). Catastrophe and Redemption: The Political Thought of Giorgio Agamben. Albany, State University of New York Press.

Wijkström, F., and Zimmer, A. (2011). Introduction: Nordic civil societies beyond membership and movements. In Wijkström, F., and Zimmer, A. (eds.) Nordic Civil Society 
at a Cross-roads: Transforming the Popular Movement Tradition. Munich, Nomos, pp. 9-24.

Wikan, U. (2002). Generous Betrayal: Politics of Culture in the New Europe. Chicago, University of Chicago Press.

Willen, S. S. (2012a). How is health-related 'deservingness' reckoned? Perspectives from unauthorized im/migrants in Tel Aviv. Social Science \& Medicine, 74(6), 812-821. https://doi.org/10.1016/j.socscimed.2011.06.033

Willen, S. S. (2012b). Migration, 'illegality,' and health: Mapping embodied vulnerability and debating health-related deservingness. Social Science \& Medicine, 74(6), 805-811. https://doi.org/10.1016/j.socscimed.2011.10.041

Willis, E. (2006). Introduction: Taking stock of medical dominance. Health Sociology Review, 15(5), 421-431. https://doi.org/10.5172/hesr.2006.15.5.421

Wilson, T. M., and Donnan, H. (2012). Borders and border studies. In Wilson, T. M., and Donnan, H. (eds.) A Companion to Border Studies. Malden, MA, Blackwell Publishing Ltd., pp. 1-25.

Witoszek, N., and Midttun, A. (eds.) (2018). Sustainable Modernity: The Nordic Model and Beyond. London, Routledge.

Wollebæk, D., Enjolras, B., Steen-Johnsen, K., and Ødegård, G. (2012). After Utoya: How a high-trust society reacts to terror-trust and civic engagement in the aftermath of July 22. Ps-Political Science \& Politics, 45(1), 32-37. https://doi.org/10.1017/ S1049096511001806

Zhang, L.-C. (2008). Developing methods for determining the number of unauthorized foreigners in. Norway. Oslo - Kongsvinger, Statistics Norway/Division for Statistical Methods and Standards.

\section{Official publications}

\section{Laws}

Abortion Act (1975). Lov om svangerskapsavrbudd (abortloven) 13. juni 1975 nr. 50.

Child Welfare Act (1992). Lov om barneverntjenester (barnevernloven) 17. juli $1992 \mathrm{nr}$. 100.

Crisis Shelters Act (2009). Lov om kommunale krisesentertilbod (krisesenterlova) 19. juni 2009 nr. 44.

Education Act (1998). Lov om grunnskolen og den vidaregåande opplaeringa (opplaringslova). 17. juli 1998. $\mathrm{nr}$. 61.

Immigration Act (2008). Lov om utlendingers adgang til riket og deres opphold her (utlendingsloven) 15. mai $2008 \mathrm{nr} .35$.

Municipal Health Services Act (1982). Lov om helsetjenesten $i$ kommunene [Kommunehelsetjenesteloven - khl.] 19.november $n r$. 66. Annuled.

National Insurance Act (1997). Lov om folketrygd (folketrygdloven) 28. februar 1997 nr. 19.

Patient Right's Act (1999). Lov om pasient- og brukerrettigheter (pasient- og brukerrettighetsloven) 2. juli $1999 \mathrm{nr}$. 63.

Social Services Act (2010). Lov om sosiale tjenester i arbeids- og velferdsforvaltningen. 18. desember $n$ r. 131.

Specialised Health Services Act (1999). Lov om spesialisthelsetjenesten m.m. (spesialisthelsetjenesteloven) 2. juli $1999 \mathrm{nr} .61$. 


\section{Regulations}

Healthcare Regulation (2011). Forskrift om rett til helse- og omsorgstjenester til personer uten fast opphold i riket (IRM-helseforskriften) 16. desember $2011 \mathrm{nr} .1255$. ('Regulation concerning the right to health and care services to people without fixed abode in the country').

Priority Regulation (2000). Forskrift av om prioritering av helsetjenester, rett til nødvendig helsehjelp fra spesialisthelsetjenesten, rett til behandling i utlandet og om klagenemnd (prioriteringsforskriften) 12. januar $2000 \mathrm{nr} .1208$.

Regulation Amending the Social Services Regulation (2014). Forskrift om endring i forskrift 16. desember $2011 \mathrm{nr} .1251 \mathrm{om}$ rett til sosiale tjenester for personer uten fast bopel i Norge.

Social Services Regulation (2011). Forskrift om sosiale tjenester for personer uten fast bopel i Norge (IRM-sosialforskriften) 16. desember $2011 \mathrm{nr} .1251$. ('Regulation concerning the right to social services to people without fixed abode in the country').

\section{Circulars}

RS-2003-021. Anmodning om midlertidig arbeidstillatelse etter endelig avslag på søknad om asyl - utlending som kan returnere frivillig - uf $\$ 61$ tredje og fjerde ledd. Oslo, Utlendingsdirektoratet.

RS 2008-035V1. Personer i ordincere mottak med selvhushold. Rutiner og satser for økonomiske ytelser til beboere i statlig mottak, regulerte satser 2012. Oslo, Utlendingsdirektoratet.

RS-35V1/2008. Rutiner og satser for økonomiske ytelser til beboere i statlig mottak, regulerte satser 2015. Oslo, Utlendingsdirektoratet.

RS A-2/2011. Statlige veiledende retningslinjer for utmåling av økonomisk stønad til livsopphold 2012. Oslo, Arbeids- og sosialdepartementet.

RS A-2/2015. Statlige veiledende retningslinjer for økonomisk stønad 2016. Oslo, Arbeidsog sosialdepartementet.

RS G-72/00. Endringer $i$ utlendingsloven. Dette rundskrivet ble opphevet 29.08.2011. Oslo, Justis- og politidepartementet.

RS I-2/2008. Utgifter ved helsehjelp i norske helseinstitusjoner under den offentlige spesialisthelsetjenesten blant annet for personer som ikke er bosatt i Norge, Oslo, Helse- og omsorgsdepartementet.

RS I-5/2011. Om helsehjelp til personer uten fast opphold $i$ riket og personer uten lovlig opphold. Oslo, Helse- og omsorgsdepartementet.

RS I-34/2001. Veiledende retningslinjer for utmåling av stønad til livsopphold etter sosialtjenesteloven. Oslo, Sosial- og helsedepartementet.

\section{Consultation documents}

Juss-Buss (2011). Høringsuttalelser til endring av sosialforskriften - Utkast til forskrift til lov om sosiale tjenester $i$ arbeids- og velferdsforvaltningen.

Ministry of Health and Care Services (2010). Høringsnotat. Endring av prioriteringsforskriften - Helsehjelp til personer som oppholder seg ulovlig $i$ landet. Oslo, Helse- og omsorgsdepartementet.

Ministry of Labour and Social Affairs (2011). Høringsnotat. Utkast til forskrift til lov om sosiale tjenester $i$ arbeids- og velferdsforvaltningen. Oslo, Arbeids- og sosialdepartementet. 
Ministry of Labour and Social Affairs (2013). Høringsnotat. Utkast til endring i forskrift om sosiale tjenester til personer uten fast bopel $i$ Norge - kortvarig akutthjelp. Oslo, Arbeids- og sosialdepartementet.

NAV (2011). Høringsuttalelser til endring av sosialforskriften - Utkast til forskrift til lov om sosiale tjenester $i$ arbeids- og velferdsforvaltningen.

NAV (2013). Høringsuttalelser til endring av sosialforskriften - Utkast til endring i forskrift om sosiale tjenester til personer uten fast bopel i Norge - kortvarig akutthjelp kortvarig akutthjelp.

Norwegian Medical Association (Den norske legeforening) (2010). Høringsuttalelser til endring av prioriteringsforskriften - Helsehjelp til personer som oppholder seg ulovlig i landet.

Norwegian Nurses Organisation (Sykepleierforbundet) (2010). Høringsuttalelser til endring av prioriteringsforskriften - Helsehjelp til personer som oppholder seg ulovlig i landet.

Norwegian Red Cross (2013). Høringsuttalelser til endring av sosialforskriften - Utkast til endring i forskrift om sosiale tjenester til personer uten fast bopel i Norge-kortvarig akutthjelp - kortvarig akutthjelp.

\section{Other official documents}

Board of Health Supervision in Oslo and Akershus (2011). Avslutning av tilsynssak (201118307-9 FM-H). Oslo, Helsetilsynet i Oslo og Akershus.

Document No. 8:26 (2004-2005). Forslag fra stortingsrepresentantene Heikki Holmås, Geir-Ketil Hansen og Karin Andersen om tiltak for bedre behandling av ikke-returnerbare asylsøkere med endelig avslag og andre ikke-uttransporterbare utlendinger.

Document No. 15:286 (2011-2012). Skriftlig spørsmål fra Trine Skei Grande (V) til helseog omsorgsministeren. Besvart: 24.11.2011 av helse- og omsorgsminister Anne-Grete Strøm-Erichsen.

Document No. 15:502 (2014-2015). Skriftleg spørsmål fra André N. Skjelstad (V) til helseog omsorgsministeren. Svart på: 04.02.2015 av helse- og omsorgsminister Bent Høie.

Innst. 199 S (2011-2012). Innstilling fra kommunal- og forvaltningskomiteen om representantforslag fra stortingsrepresentantene Trine Skei Grande og Borghild Tenden om en regularisering av papirløse innvandrere i Norge. Vedlegg. Brev fra Justis- og politidepartementet $v /$ statsråden til kommunal- og forvaltningskomiteen, datert 28 . november 2011.

Innst. O. nr. 24 (1996-1997). Innstilling fra justiskomiteen om lov om endringer i lov av 24. juni $1988 \mathrm{nr} .64$ om utlendingers adgang til riket og deres opphold her (utlendingsloven) klagenemnd i utlendingssaker m.v. Andre forslag til endringar $i$ utlendingslova.

Innst. O. nr. 54 (1995-1996). Innstilling fra justiskomiteen om forslag fra stortingsrepresentantene Jorunn Ringstad, Lisbeth Holand, Anita Apelthun Scele, Lars Sponheim og Erling Folkvord om lov om endringer i lov av 24. juni 1988 nr. 64 om utlendingers adgang til riket og deres opphold her (utlendingsloven). Komiteens merknader.

Innst. O. nr. 66 (1999-2000). Innstilling fra justiskomiteen om lov om endringer $i$ utlendingsloven.

Meld. St. 27 (2011-2012). Barn på flukt.

Ministry of Health and Social Affairs, Sweden (2013). Hälso- och sjukvård till personer som vistas i Sverige utan tillstånd. Regeringens proposition 2012/13:109. Available at: http://www.riksdagen.se/sv/Dokument-Lagar/Forslag/Propositioner-och-skrivelser/ Halso--och-sjukvard-till-perso_H003109/ [Accessed on 24.05.2015]. 


\section{References}

Ministry of Labour and Social Affairs (2004). Nødhjelp til personer uten lovlig opp hold. Press release [Online], 4 October. Available at: www.regjeringen.no/nb/dokumenter/ nodhjelp-til-personer-uten-lovlig-opphol/id91176/ [Accessed on 24.05.2015].

Ministry of Labour and Social Affairs (2014). Ulovlig opphold skal ikke finansieres med sosialhjelp. Press release [Online], 15 March. Available at: www.regjeringen.no/nb/ aktuelt/Ulovlig-opphold-skal-ikke-finansieres-med-sosialhjelp/id753045/ [Accessed on 24.05.2015].

NOU 1997:7. Piller, prioritering og politikk: Hva slags refusjonsordning trenger pasienter og samfunn? Oslo, Helse- og omsorgsdepartementet.

NOU 2003:19. Makt og demokrati. Sluttrapport fra makt- og demokratiutredningen. Oslo, Arbeids- og administrasjonsdepartementet.

NOU 2011:10. I velferdsstatens venterom: Mottakstilbudet for asylsøkere. Oslo, Justis- og politidepartementet.

NOU 2011:17. Velferd og migrasjon: Den norske modellens framtid. Oslo, Barne-, likestillings- og inkluderingsdepartementet.

NOU 2017:2. Integrasjon og tillit: Langsiktige konsekvenser av høy innvandring. Oslo, Justis- og beredskapsdepartementet.

Ot.prp. nr. 31 (1999-2000). Om lov om endringer $i$ utlendingsloven. Oslo, Justis- og politidepartementet.

Ot.prp. nr. 75 (2006-2007). Om lov om utlendingers adgang til riket og deres opphold her (utlendingsloven). Tilråding fra Arbeids- og inkluderingsdepartementet 29. juni 2007, godkjent $i$ statsråd samme dag.

Ot.prp. nr. 112 (2004-2005). Om lov om endringer $i$ utlendingsloven (innkvartering ved søknad om asyl mv.). Oslo, Kommunal- og regionaldepartementet.

Prop. 141 L (2010-2011). Endringer i utlendingsloven m.m. (høring av barn mv.). Oslo, Justis- og politidepartementet.

UDI (2013). Court decisions. LG-2012-202569. Utlendingsloven av 1988 \& 47 annet ledd bokstav a), jf. straffeloven $\S 48 a$. Utlendingsloven av 2008 \$ 108 tredje ledd bokstav a), jf. straffeloven $\S$. Available at: www.udiregelverk.no/no/rettskilder/underrettsavgjorelser/ lg-2012-202569/ [Accessed on 16.05.2015].

UDI (2011-2017). Annual reports. Available at: www.udi.no/statistikk-og-analyse/ arsrapporter/ [Accessed on 16.05.2015].

UNE (2009). Tidsbegrensete oppholdstillatelser på humanitcert grunnlag. Praksisnotat av 09.10.2009. Available at: www.une.no/no/Praksis2/Notater/Oppholdstillatelser-pahumanitart-grunnlag-i-asylsaker-mm/ [Accessed on 16.05.2015].

UNE (2016). Medisinsk rådgiver i UNE [Online], 16 December. Available at: www.une.no/ aktuelt/arkiv/2016/medisinsk-radgiver-i-une/ [Accessed on 14.09.2020].

UNE (2020). FV 05. Faglig veileder. Helsemessige forhold som grunnlag for oppholdstillatelse $i$ medhold av utlendingsloven $\S 38$. Available at: www.une.no/kildesamling/ Faglege-rettleiingar/fv-04/ [Accessed on 16.05.2015]. 


\section{Index}

Note: Page numbers in italic indicate a figure, and page numbers in bold indicate a table on the corresponding page.

\section{Aarseth, Svein 83}

Abortion Act (1975) 97

abortion services 97

Act of Necessity, unwritten 34-35, 37, 40 administrative decrees $38-40,74-75,138$ administrative practices see borders in healthcare, materialising through administrative practices

Agamben, Giorgio 3, 5-6, 7, 39, 72, 137-138

Arendt, Hannah 3

Aster 27-28, 33, 36-37, 41, 54, 79

asylum reception centres: access to healthcare 77, 80; as exceptional care 25-26, 28, 30-32; as migration control 33

asylum seekers: discourses, 50; economic support 31; policies to limit arrivals 18 , 57; welfare rights 29 ; work permits, 33 ; see also rejected asylum seekers

Balibar, Etienne 9-10

ban on labour migration 17-18

bare life: biopolitics and sovereignty $7-8$; irregular migrants as example 3

Bergen: healthcare centre for undocumented migrants 106-108, 125; hunger strike in 52; as site of study 14

'biolegitimacy' 56

biopolitics 6-7, 9

birth, hospital billing 97-98

Blue Cross 44

bordering care $2-3$; legal bordering in healthcare 74-77; see also moral bordering borders 9-10; in context of healthcare 69; see also territory

borders in healthcare, materialising through administrative practices 90-110; ambiguities and contradictions 99-108; detection and deterrence 90-99; ignorance of providers 102-106; payment for healthcare 95-99; personal identification number 91-95; structural compensation 106-108; as thresholds 108-109

Bourdieu, Pierre 113

Brekke, J. P. 58-59

Brox, Ottar 61

'bureaucratic incorporation' 3, 86, 101

'bureaucratisation' 86

Butler, Judith 49

Casualties of Care (Ticktin) 129

categorisation of immigrants by healthcare providers $77-82$

children: long-staying 55, 80; and necessary healthcare 76 ; and regularisation of families 133-134; temporality of healthcare 120-121; unaccompanied minors 55

Child Welfare Act (1992) 140

Child Welfare Services 55

Christian Democratic Party (KrF) 61

Christian organisations, care offered by 41-45

Church City Mission 42, 44-45

compassion, Christian concept of 59

consultation paper on emergency provision 48, 63-64 
container-borders 9

Covid-19 pandemic, effect on healthcare centres 108

criminal liability of humanitarian assistance 41-42

Crisis Shelters Act (2009) 140

Dean, M. 73

decency (anstendighet) 60

deferred implementation (utsatt iverksetting) 118

De Genova, N. 13

delayed treatments 104-105

deportation: fear of, and asylum centres

32 ; temporality and healthcare 114 ,

$116-119,135$

deregularisation 138

deservingness 50-51, 63-65

'deservingness rank order' 49

detection, as internal border control 90-99

Diakonhjemmet Hospital 106, 110n4-5

dire need in Act of Necessity 37

D-number 109n2

drug rehabilitation 43-44, 73, 99

Dublin agreement 78

duty to leave 31-32

Dzortov, Adam 82-84, 88-89, 118, 130

Eba 25-27, 33, 54, 79, 80

Education Act (1998) 140

Ege, Arild 83

emergency, sense of, for socio-political regulation 39-40

emergency aid: consultation paper on 48, 63-64; defined 122; and unwritten Act of Necessity 34

emergency care centres 92, 94, 96, 98, 103-104

emergency shelters 44-45

Eriksson, Robert 48, 64-65

Eshe 32

ethics, medical 82, 83, 100, 104, 121, 132

Ethiopian deportations 32

European Economic Area, and migration and context of Norwegian welfare state $15-16,18$

'Euro refugees' 47n9

'everyday irregularity' 93

exception 11, 29, 39-40

exceptional care 25-47; care as unstable landscape 28-32; care offered by NGOs and Christian organisations 41-45; municipal emergency aid 36-38; significance of necessity
$38-41$; survivability of the body $32-35$; universalism 45-46

exceptional care, personal stories see Aster; Eba; Zeki

exceptionalism, sovereign 39-40, 108, 137-138, 141

expert decisions in intersection between law, politics, and medicine 82-85

Fassin, Didier, 8, 56, 129, 139

Faremo, Grete 52-53

Fattighuset, self-help house in Oslo 44

'final decision' 79, 118

'final rejection' 81

food insecurity 32

foreign aid 56-57, 61

Foucault, M. 6-7, 39, 138

France: Code du Travail 54; healthcare professionals in case assessments 88, 132; as homeland of human rights 56; medical permits 117-118, 129-130; State Medical Assistance (AME) 106, 142

Frankenberg, Ronald 116

'freeze, no one should' 34, 45, 63

funding: for general practitioners 96 ; for NGOs 44

general practitioners (GP) 92, 96

'generous betrayal' 61

Germany: Duldung ('toleration') 118; provision of medical care 101

'goodness, tyranny of' 60-63

governmentality 39,138

Gripsrud, Jostein 62

Hage, Ghassan 124

Hagelund, Anniken 60, 62

Haraldsplass Deaconess Hospital 107, 110n5

healthcare centres for undocumented migrants $42-43,106-108,125-128$

healthcare providers: categorisation of immigrants by 77-82; doctors' control of patients' time and space 116; general practitioners (GP) 92, 96; 'impossible situation' of $82,100,122$; reluctance on non-medical help 102, 131-132; see also borders in healthcare, materialising through administrative practices; territory, healthcare providers and sovereign decisions

Healthcare Regulation: and access to healthcare $75,78,140$; in conflict with 
ethics $82,84,100,121$; on payment for services 96-97; temporality of healthcare 119-120,122, 134, public health concerns (communicable diseases and mentally ill patients) $66 \mathrm{n} 3$

'healthcare that cannot wait' $76,97,98$, $100,119, \mathbf{1 2 0}, 123$

health migration (medical migration) $87-88,99,130$

here-and-now perspective 123-126, 128

Hind: medical story and sovereign decisions 70-71, 78-82, 84-85, 88; precarious inclusion of 101-102; temporal effects on asylum decision $113,117,118-119,130,134$

Høie, Bent 84, 98

homeless shelters 36

Homo Sacer project 5, 137

hopelessness 124-125

hospital bureaucracy 83,86

hospital compensation 97-98, 106-108

Huitfeldt, Anniken 48

humanitarian aid from NGOs 41-45

humanitarian care, characteristics of 59

humanitarian exceptions, and mismanaged life 53-56

humanitarianism 8 ; deservingness of irregular migrants 50-51, 139; and national identity 56-57

human trafficking 55

ignorance of providers 102-106

Immigration Act $(1988,2000,2008) 33$, $41,51,141$

Immigration Appeals Board (UNE) 79, 89, $118,132-133$

‘impossible situation' of providers 82,100 , 122

inclusion, problems with 3-4

indirect deterrence 57

internal protection alternative (IPA) 18

internationalism, Nordic commitment to 57

International Organisation for Migration (IOM) 65, 119

irregular migrants: defined 2, 3; entitlements to social services $2-3$; inclusion of 3-4; research on 13, 14-15; size of population 16; welfare rights in Sweden and Norway 45-46

irregular migrants, personal stories see Aster; Dzortov, Adam; Eba; Eshe; Hind; Reema (Hind's mother); Roland; Tuban, Louila; Zeki
Isaksen, Torbjørn Røe 48

Italy, services for irregular migrants 142

justice as reciprocity $66 \mathrm{n} 2$

kind-ism (snillisme) 61

Kosovo, asylum seekers from 46

Kristiansand hospital 97-98

labour market, EEA and context of Norwegian welfare state 15-16

labour migration ban 17-18

law-making by administrative decree 38-40, 74-75, 138

legal bordering in healthcare 74-77

legal residence 78, 79, 88

Liberal Party (Venstre) 61

life: and death matters 73; precarious life

139-140; role in power configurations 6-8

limbo 11

liminality 11

Listhaug, Sylvi 60-63

list patients 92

long-staying asylum children

(lengevorende asylbarn) 55, 80

Lønseth, Pål K. 53, 62

Lupton, Deborah 116, 133

management of populations 9

managerialisation of healthcare $85-88$

'managerialism' 86

Mburu, Christina Brux 127-128

medical conditions: as 'healthcare that cannot wait' 120; most common diagnoses $136 \mathrm{n} 1$

medical reports, and regularisation 129-133

migration: labour 17-18; medical 87-88, 99, 130

Ministry of Health and Care Services 74-76, 119-120

Ministry of Labour and Social Affairs 34-35, 37, 48, 63-64

mismanaged life, and humanitarian exceptions $53-56$

moral bordering 48-66; deservingness 50-51; deservingness, rights and justice 63-65; emergency aid 48; mismanaged life and humanitarian exceptions 53-56; national identity and internationalism 56-63; responsibility of and for irregular migrants 51-53; tyranny of goodness 60-63; welfare nationalism and humanitarianism 57-60 municipal emergency aid 36-38 
Municipal Health Services Act (1982) 46, 75

municipal responsibility for primary healthcare 91-92

national identity 56-63; and internationalism 56-57; and tyranny of goodness 60-63; welfare nationalism 57-60

National Insurance Act (1997) 75

National Insurance Scheme 29

national population register 92,93

NAV see Norwegian Labour and Welfare Administration

necessary care, in Act of Necessity 37

necessary healthcare 76,87

Necessity, Act of 34-35, 37, 40

necessity, significance of 38-41

'negatives' 79-81, 114

Netherlands, services for irregular migrants 142

New Public Management (NPM) 86

non-governmental organisations (NGOs): care offered by 41-45; services for women in prostitution 55-56

Nordby, Trygve 43

Nordic model: entitlements in 16; image of domestic welfare and foreign aid 56-57; social and economic equality in 16-17, 140, 141; welfare state context $15-18$

normative internationalism 57

Norwegian Directorate of Immigration (UDI): asylum seekers' benefits 29, 36; categorisation of irregular migrants 79; residence permits, work permits, and tax cards 26, 33; unaccompanied minors and humanitarian exceptions 55

Norwegian Labour and Welfare Administration (NAV): asylum seekers' benefits 29, 33, 37; emergency aid 48, 64-65

Norwegian Medical Association 82, 100, 107, 121

Norwegian Nurses Organisation 82, 100

Norwegian Red Cross 41-45, 107

Norwegian Tax Administration 26, 27

Norwegian welfare state $15-18,59-60$, 140-142

Oslo: asylum protests $21 \mathrm{n} 6,27,52$; healthcare centre for undocumented migrants 106-108, 125-127; as site of study 14

Oslo University Hospital (OUS) 83

Other, in moral borders 49 paperless (undocumented, papirløse) 13, 21n $4,52,77,79$

parental responsibility 53

Pascalian Meditations (Bourdieu) 113

Patients' Rights Act (1999) 38, 75, 76, 87

Pedersen, Siv Tove 73-74, 121

personal identification number (PIN,

fødselsnummer) 15, 91-95, 109n1

person without legal residence 52, 139

petty sovereigns 71

population state, as biopower 9-10

precarious inclusion 5-6, 75, 102, 138, 141-142

precarious life 139-140

precariousness, compared with precarity 29

primary emergency care see emergency care centres

Priority Regulation (2000) 89n1, 121-122

Progress Party (FrP) 60, 63

Pro Sentret 97

PROVIR 14, 15

Realm, everyone/all persons residing in the $38,75,133-134,140$

reception centres see asylum reception centres

Reema (Hind's mother) 119, 128-129, 130-131, 134

refugee crisis (2015) 39, 60

'regime of goodness' 61

regional health enterprises 95-96

regularisation through medical reports 129-134

'regulars,' at healthcare centres 126-127

rejected asylum seekers: economic support for 29-31; and irregular migrants 3, 50-51; legal/discursive distinction $v s$. legal residents $3,38,51,78-81,139$, 140; municipalities responsibility 34 , 36-37; staying in asylum reception centers $28-32,31$; work permits and tax cards 25-26, 32-33

'renewed consideration' (omgjøringsbegjaring) 79, 115, 119

residence permits $26,51,127$

responsibility of and for irregular migrants, moral borders of 51-53

're-stratification' 86

return refusers (returnektere) 52-53, 62

rights-bearing subjects 7 ; survivability and exceptional care 34

rights in welfare state $63-65$

Riise, Rolf 83 
Robin Hood-huset, self-help house in Bergen 44

Røise, Olav 83-84

Roland 113-116, 118-119, 128, 129, 135

'Roma-beggars' 45, 47n9

Salvation Army 44, 45

sectorial principle 141

'self-care' 128

sheltering irregular migrants $42,44-45$

social security number (personnummer) 109n1

Social Services Act (2010) 34, 38, 141

Social Services Regulation (2011) 36-37, 48

Solberg, Erna 64

sovereign decisions: in context of healthcare 138-139; and professional

discretion of healthcare providers 71-74, 88-89; temporality of 11

sovereign exceptionalism 39-40, 108, 137-138, 141

sovereignty: ethnographical approach 12-14; inclusion and exclusion 3, 5-6; retheorisation of 6, 10; as territorial state 9 Specialised Health Services Act (1999) 75,96

states' rights, and control of admission to territory 2

state violence, biopolitics and sovereignty 7-8

Strøm-Erichsen, Anne-Grete 97

structural compensation, dilemmas of 106-108

suffering 57-59

support number $109 \mathrm{n} 3$

survivability of the body $8,32-35,56$

Sweden: healthcare for irregular migrants

123 ; rights of irregular migrants $45-46$

tax cards $25-27$

temporal double bind 134

temporalities governing irregular migration $10-12,141$

temporality, effect on healthcare 113-136; deportation, effect on treatment 116-119; healthcare as urgent and temporary

119-123; here-and-now perspective 123-125; lack of residence and sociopolitical problems 125-129; migratory trajectories 134-135; regularisation through medical reports 129-134; Roland's personal story (see Roland) territory, healthcare providers and sovereign decisions 69-89; categorisation of immigrants 77-82; expert decisions between law, politics, and medicine 82-85; Hind's medical story (see Hind); legal bordering 74-77; managerialisation of healthcare 85-88; migration control implications 12-13, 87-88, 99; sovereign decisions and professional discretion 71-74, 88-89; state borders in context of healthcare 69

territory 9-10, 140

Ticktin, Miriam 8, 55, 129

Tuban, Louila 1, 6, 10, 74, 118, 121

Tvedt, Terje 61-62

'tyranny of goodness' 60-63

UDI see Norwegian Directorate of Immigration

unaccompanied minors 55

undocumented (papirløse) 52, 77, 79

UNE see Immigration Appeals Board (UNE)

United Nations Convention on the Rights of the Child (UNCRC) 76, 120

Universal Declaration of Human Rights (1948), right to standard of living 2

universalism 45-46

unreturnable (ureturnerbar) 51-52, 64

volunteer-run healthcare centres see healthcare centres for undocumented migrants

waiting centres 30,36

welfare, public responsibility for, in

Nordic model 16-17

welfare chauvinism $65 \mathrm{n} 1$

welfare nationalism and humanitarianism $57-60$

welfare state in Norwegian context 15-18, 59-60, 140-142

Wikan, Unni 61

Willen, Sarah 50, 63-64

withdrawal scheme $30,34,51,53,58,64$

women in prostitution: deservingness of

50,55 ; rehabilitation of 44

women's crisis shelters $47 \mathrm{n} 7$

workfare policies 17

work permits $25,27,33-34$

"Your Time or Mine" (Frankenberg) 116

Zeki 35-36, 43, 65, 99 